\title{
Echoes of the city : staging the urban soundscape in fiction film
}

Citation for published version (APA):

Aalbers, J. F. W. (2013). Echoes of the city : staging the urban soundscape in fiction film. [Doctoral Thesis, Maastricht University]. Maastricht University. https://doi.org/10.26481/dis.20131213ja

Document status and date:

Published: 01/01/2013

DOI:

10.26481/dis.20131213ja

Document Version:

Publisher's PDF, also known as Version of record

\section{Please check the document version of this publication:}

- A submitted manuscript is the version of the article upon submission and before peer-review. There can be important differences between the submitted version and the official published version of record.

People interested in the research are advised to contact the author for the final version of the publication, or visit the DOI to the publisher's website.

- The final author version and the galley proof are versions of the publication after peer review.

- The final published version features the final layout of the paper including the volume, issue and page numbers.

Link to publication

\footnotetext{
General rights rights.

- You may freely distribute the URL identifying the publication in the public portal. please follow below link for the End User Agreement:

www.umlib.nl/taverne-license

Take down policy

If you believe that this document breaches copyright please contact us at:

repository@maastrichtuniversity.nl

providing details and we will investigate your claim.
}

Copyright and moral rights for the publications made accessible in the public portal are retained by the authors and/or other copyright owners and it is a condition of accessing publications that users recognise and abide by the legal requirements associated with these

- Users may download and print one copy of any publication from the public portal for the purpose of private study or research.

- You may not further distribute the material or use it for any profit-making activity or commercial gain

If the publication is distributed under the terms of Article $25 \mathrm{fa}$ of the Dutch Copyright Act, indicated by the "Taverne" license above, 


\section{Echoes of the City}

Staging the Urban Soundscape in Fiction Film

\section{PROEFSCHRIFT}

Ter verkrijging van de graad van doctor aan de Universiteit Maastricht, op gezag van de

Rector Magnificus, Prof. dr. L.L.G. Soete, volgens besluit van het College van

Decanen, in het openbaar te verdedigen op vrijdag 13 december 2013 om 10.00 uur.

$$
\text { door }
$$

Jasper Frederik Willem Aalbers 
Dit werk maakt deel uit van het onderzoeksprogramma Soundscapes of the Urban Past: Staged Sound as Mediated Cultural Heritage dat (mede)gefinancierd is door de Nederlandse Organisatie voor Wetenschappelijk Onderzoek (NWO).

Promotor:

Prof. dr. K.T. Bijsterveld

Copromotores:

Prof. dr. A. Fickers (Université du Luxembourg)

Prof. dr. P.P.R.W. Pisters (Universiteit van Amsterdam)

Beoordelingscommisie:

Prof. dr. R. van de Vall (voorzitter)

Prof. dr. ir. W.E. Bijker

Prof. dr. G.L. Evans

Prof. dr. F.E. Kessler (Universiteit Utrecht)

Dr. J. Wachelder 

Reque minas firmat. Tantum haec in fine loquendi
ingeminat voces auditaque verba reportat.

(Echo still repeats the last words spoken, and gives back the sounds she has heard.)

Ovid, Metamorphoses III, 368-69

Translation by Mary M. Innes 


\section{Table of Contents}

$\begin{array}{ll}\text { Acknowledgements } & 6\end{array}$

1. Introduction: Echoes of the City $\quad 8$

1.1 The myth of the cinematic city 8

1.2 Soundscapes of the urban past in fiction film 11

$\begin{array}{ll}1.3 \text { Theoretical rationale } & 14\end{array}$

1.4 Corpus selection and method of analysis 17

1.5 Setting the stage 21

1.6 "Enhanced echoes" of the city 23

2. Practice in Theory, Theory in Practice: Developments in Film Sound

Technology and Film Culture, 1927-2010 26

2.1 Introduction 26

2.2 The introduction of film sound and debates between

formalists and realists $\quad 27$

2.3 "New Hollywood," new film sound and new theories 32

2.4 Theorizing the digitization of film sound 37

2.5 Conclusion 42

3. Big Village or Small City? The Soundscape of Amsterdam-in-film 44

3.1 Introduction 44

3.2 Traffic sounds, background sounds and the reality-effect 45

3.3 The soundmarks of Amsterdam-in-film 51

3.4 Amsterdam-in-film: a glocal village? $\quad 57$

$\begin{array}{ll}3.5 \text { Conclusion } & 60\end{array}$

4. Berlin Part I: City under Construction (1926-1945) 64

4.1 Introduction 64

4.2 Symphony and cacophony of a big city $\quad 67$

4.3 The soundscape of Fritz Lang's Berlin 75

4.4 The sounds of "class struggle" and "Kampfzeit" 77

4.5 Conclusion 83 
$\begin{array}{ll}\text { 5.2 Reconstructing the city-in-film } & 87\end{array}$

5.3 "New Cinema," new politics and new realism 94

5.4 All quiet in the border zone? 99

5.5 Unbordering Berlin and the city as a dance party 103

$\begin{array}{ll}5.6 \text { Conclusion } & 109\end{array}$

6. The Soundscape of the Lived City: Staging Sonic London 112

6.1 Introduction $\quad 112$

6.2 Arriving in London $\quad 115$

6.3 Traveling in London $\quad 122$

$\begin{array}{ll}\text { 6.4 Living in London } & 127\end{array}$

6.5 Leaving London and the end of the metropolis 133

$\begin{array}{ll}6.6 \text { Conclusion } & 135\end{array}$

$\begin{array}{ll}\text { 7. Conclusions } & 138\end{array}$

$\begin{array}{ll}7.1 \text { Representing the city: variations on a theme? } & 138\end{array}$

$\begin{array}{ll}7.2 \text { Representing cities in image and sound } & 140\end{array}$

$\begin{array}{ll}7.3 \text { The sound of silence } & 144\end{array}$

$\begin{array}{ll}7.4 \text { Echoes, resistance and play } & 145\end{array}$

$\begin{array}{ll}7.5 \text { Creative encounters: Sound Studies and Film Studies } & 147\end{array}$

$\begin{array}{ll}7.6 \mathrm{New} \text { (sound) perspectives } & 149\end{array}$

Annex A: Filmography (corpus) 152

Annex B: Films set in London, categorized by genre 168

$\begin{array}{lc}\text { Annex C: Other films discussed } & \mathbf{1 7 0}\end{array}$

$\begin{array}{lr}\text { Annex D: Tables } & 172\end{array}$

$\begin{array}{lr}\text { Bibliography } & 175\end{array}$

$\begin{array}{ll}\text { Samenvatting } & 187\end{array}$

$\begin{array}{ll}\text { Curriculum Vitae } & 194\end{array}$ 


\section{Acknowledgments}

Yes, indeed, this is my dissertation, but it could not have been written without the help of many people, whose input, assistance, support, friendship, trust and love must be acknowledged here.

First of all I want to thank Prof. Dr. Karin Bijsterveld and Prof. Dr. Andreas Fickers. Back in Utrecht, in 2007, Andreas thought of me when he was looking for someone to carry out PhD project 2 of the Soundscapes of the Urban Past project. And Karin accepted me in the project, even though at that point we had only met once. Without their trust, input, and guidance this dissertation would never have existed. I also want to thank my co-promotor, Prof. Dr. Patricia Pisters, for her advice, help and insights from a Film Studies perspective. And I am grateful to Annelies Jacobs, my fellow PhD colleague in the Soundscapes project. Her work has served as a constant inspiration for my own.

My colleagues in the Faculty of Arts and Social Sciences of Maastricht University turned a few historical buildings in the city center into an intellectual home. I am grateful to them, and to the supporting staff of both the faculty and the University Library. Without their work it would be impossible to carry out any research or, for that matter, to engage in teaching. I want to thank the students for the joy and inspiration I derived from tutoring them over the past five years.

Many people have read parts of this dissertation, or attended my presentations. For their feedback and input I want to thank all my colleagues and participants in our faculty's Graduate School, the research group for Science and Technology Studies, the WTMC workshops and summer schools, the NECS conferences and other (international) events. Specifically, I would like to mention Joeri Bruyninckx, Eefje Cleophas and Alexandra Supper, as well as Carolyn Birdsall, Nessa Johnston and Dana Mustata.

I want to thank the Netherlands Graduate Research School for Science, Technology and Modern Culture (WTMC) for their excellent graduate training program and their financial support in printing this dissertation.

Special thanks go out to Larry Sider, Georges Bossaers and Ben Zijlstra for sharing their professional knowledge and experience with me in interviews and correspondence. Kasper Peters, at Hollands Filmdoek, provided me with materials I could not have obtained otherwise. The staff at the former Filmmuseum in Amsterdam was most friendly and welcoming when allowing me to work in their library outside opening hours. 
Writing a dissertation can be a maddening process, but I was able to keep my sanity through acting. I am very grateful for all the dramatic experiences I had with the people from "Alles is Drama" and the $\mathrm{PhD}$ improvisation group. If I say that my friends, in Maastricht, Utrecht and elsewhere, provided the necessary distractions from my work I would not do them justice. Their friendship was an essential part of my life these last five years. I would list all of them here if that was only possible.

Which only leaves me five people to thank. Suzanne Zelissen was my partner for the better part of my PhD years. She reminded me that there was more to life than films. My sister Petra is everything a brother could ask for, and more: a sister, a friend and a confidant. Sofia Kaliarnta came into my life just over a year ago, but her love and care mean everything to me. Finally, my parents Wim and Joke Aalbers have raised me, guided me and supported me throughout all these years. There are no words or means by which I can express my gratitude to you. 


\section{Chapter 1}

\section{Introduction: Echoes of the City}

\subsection{The myth of the cinematic city}

Notting Hill, my favourite bit of London ... And so this is where I spent my days and years, in this small village in th middle of the city. (William Thacker, as played by Hugh Grant)

In NotTing Hill (Roger Michell, 1999), the Notting Hill area is introduced to us, the film audience, as a pleasant, sun-drenched village, with people walking across a market and a few bicyclists passing by. We do not see any cars, nor do we hear any distant car horns or sirens. Indeed, one would hardly believe that this neighborhood is located smack in the middle of London, one of the biggest cities of Europe. The film's plot is almost completely set in Notting Hill, and when it finally does venture into the "big world" of the metropolis, it is during a frantic, noisy car chase. BABYLON (Eddie Terstall, 1998) presents a similar soundscape of the Amsterdam Jordaan district. We see residents and tourists who quietly stroll through the neighborhood, and, apart from an incidental moped, we do not see see or hear any motorized traffic. When the French rock musician Flash seeks to enliven the place by giving a concert from atop the steeple of the Westerkerk, "normality" is soon restored by a passing tram that sounds its signature bell. This brief intrusion of a familiar urban traffic sound in fact signifies the return of a comforting calmness to the Jordaan. And in DER HIMMEL ÜBER BERLIN (Wim Wenders, 1987), we see a vast open space in the middle of Berlin, where Alexanderplatz used to be. We only hear the distant rumble of traffic, the wind's whisper in the grass and the drone of a helicopter passing over. A lonely old poet wanders across the deserted plain, trying to remember the sounds of Alexanderplatz before the war. In this scene, director Wim Wenders has made effective use of the city's scars after a century marked by unprecedented construction and destruction, as well as division.

As an academic subject, "film and the city" has been widely studied in Film Studies. Cinema emerged as an art form and as a mass medium at a time of rapid urbanization and industrialization, around the turn of the twentieth century, and these general cultural processes have also been linked to cinema from its beginning. As William Uricchio has argued: "There is a temporal coincidence, if not a generally shared causality, in the rise of urbanism and the development of cinema" (Uricchio 1982: 4). This concurrence of urbanization and the emergence of film as a mass medium has given birth to a "myth of the cinematic city." According to this myth, the flickering lights of the early 
cinematograph psychologically attuned the working class to the repetitive and noisy work in the factories, as well as to the danger and visual overflow of metropolises such as Berlin, Paris and New York (Charney \& Schwartz 1995: 10; Mennel 2008: 6).

A seminal text in which the ambiguities of modern urban life were addressed is Georg Simmel's "The Metropolis and Mental Life." In this essay from 1903, the German philosopher argues that individuals living in cities continuously have to adapt to changes in their environment that are beyond their control. Simmel describes the effects of the metropolis on these individuals' psychology and mental state in terms of sensory stimuli, sensory perception, imagery and motion, and delineates a new, "metropolitan type" of man (Simmel 2002 [1903]: 11-12). ${ }^{1}$ This metropolitan type is a two-faced character - just like the metropolis, in Simmel's view, is a highly ambivalent place. While Simmel is critical of the mental and psychological effects of the city on its residents, he also acknowledges its potentially liberating effect on the individual (Mennel 2008: 27).

The myth of the cinematic city has two dimensions. The first dimension involves the putative role of cinema, as a medium, in allowing the masses to attune to the experience of the modern metropolis. The second dimension pertains to the representation of big cities in film. Cities-in-film, according to the myth, are places of crowded streets, busy traffic and omnipresent advertising and consumerism - places, in short, of sensorial overstimulation. The two dimensions of the myth of the cinematic city also overlap. This overlap, between the metropolitan type of man's sensory perception and the cinematic representation of modern cities, is most evident in the specific genre of the "city-film" in the 1920s (Weihsmann 1997: 10; Mennel 2008: 21). Several well-known films - such as Alberto Cavalcanti's RIEN QUE LES HEURES (1925), Walter Ruttmannn's Berlin, DIE Sinfonie der Großstadt (1926) and Dziga Vertov's ChevoleK S KinOAPPARATUM (Man with a Movie Camera, 1929) - combined documentary footage of urban situations with rhythmic and experimental editing to create city symphonies as visual celebrations of modern life.

These classical films offer iconic representations of the modern city. In recent decades, however, cities such as Los Angeles and Tokyo have become exemplary of the postmodern incarnation of the myth of the cinematic city (Shiel 2001: 7; Mennel 2008: 201-03). In Sofia Coppola's LosT IN TRANSLATION (2003), Tokyo is seen through the eyes of two visitors: an American movie star and a photographer's wife. The two characters are completely out of touch and out of place in the Japanese capital. In this case, it is not so much fragmentation and sensorial overstimulation that characterizes the urban condition, but cultural and psychological estrangement, a typical postmodern

\footnotetext{
${ }^{1}$ Simmel is not specific about the nature of these stimuli, images and motions. As he writes: "To the extent that the metropolis creates these psychological conditions - with every crossing of the street, with the tempo and multiplicity of economic, occupational and social life - it creates in the sensory foundations of mental life ... a deep contrast with the slower, more habitual, more smoothly flowing rhythm of the sensory-mental phase of small town and rural existence" (Simmel 2002 [1903]: 11-12). Scholars working in Cultural Studies or Film Studies have referred to the (visual) perception of modern traffic, factory work and omnipresent advertising in relation to Simmel's argument (Singer 1995: 72-73).
} 
urban condition. In this renewed version of the city myth, cities have become homogeneous, anonymous "non-places" filled with solitary strangers (Augé 1995; Robertson 1995: 26; Mennel 2008: 196-201). Additionally, cinematic cities have become reduced to "any-spaces-whatever." Airports, hotel lobbies and shopping malls are places of transition; of "flow" rather than "place" (Shiel 2001: 11-12). They are, in other words, liminal spaces with fluid identities; limbos in which characters are "stuck," like in Steven Spielberg's THE TERMINAL (2004). In this film the protagonist, a traveler from a non-existent Central Asian country, is forced to live in a John F. Kennedy Airport terminal because his passport is no longer valid after a coup d'état in his home country. He is in New York, and at the same time he is not, while his own identity is also questioned.

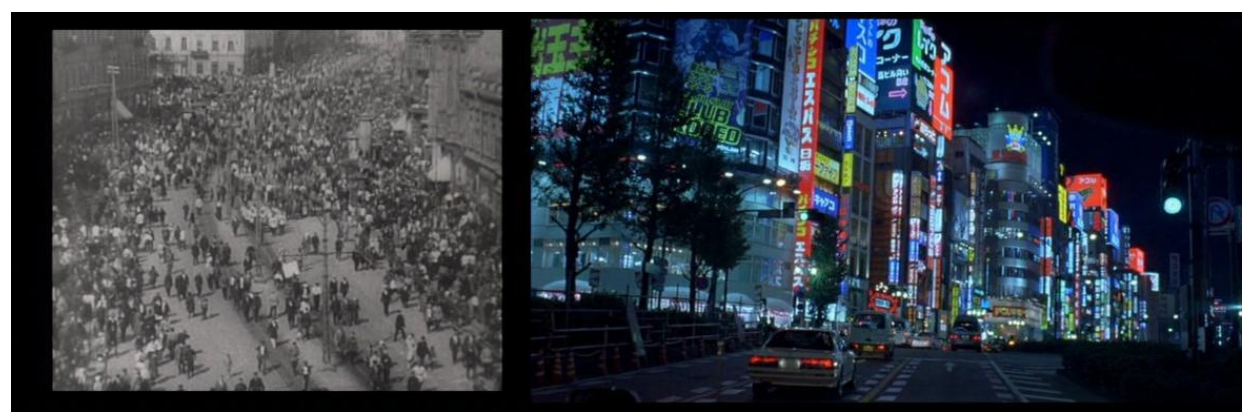

Illustration 1: The modern and postmodern myths of the cinematic city, as visualized in Chevolek s Kinoapparatom (Vertov, 1929) and Lost in Translation (Coppola 2003).Notice how the streets are filled with people in Vertov's film, whereas in Lost in Translation electronic billboards draw in all the attention. Written in Japanese, the film's two protagonists cannot read them, yet their colors and shapes are strangely familiar

How do these myths of modern and postmodern cinematic cities work? Following the French philosopher and linguist Roland Barthes, myths serve a purpose: to present as natural and true that which is but a discursive construction (Barthes 2000 [1957]: 142). The myths of cinematic urban modernity and postmodernity are thus part and parcel of the discourses about the modern city. Books and newspapers for instance, but also radio broadcasts, television and film, construct particular narratives of the urban experience and of city life. Peter Fritzsche describes how such narratives have co-constructed the identity of Weimar Berlin:

What heightens the fascination is the link between the city as a geographical place and the city as a narrated form. From the beginning, written records and urban existence have gone hand in hand. This correspondence created an imaginary symbolic order that was as important as the city itself. (Fritzsche 1996: 4) 
For this reason, the myths of cinematic urban modernity and postmodernity are an integral part of cities' identities. Urban identities emerge from the stories people tell each other about a city, and the mediated narratives they produce and consume. It is exactly in these processes that a geographical location, a space, is turned into a meaningful place (Hague 2005: 4-7; Thompson 1995: 209-13). Fiction films are part and parcel of these processes of urban identity construction.

Yet do the identities of cities-in-film outside the classical corpus support the myths of urban modernity and postmodernity in similar ways as the classical films mentioned above? The three examples of NotTING HILl, BABYLON and DER HIMMEL ÜBER BERLIN seem to question, if not contradict, the myths of the modern and the postmodern cinematic city. London and Amsterdam are not portrayed as dangerous and hectic urban environments, but rather as friendly, welcoming places. Amsterdam with its canals and narrow streets and Notting Hill with its street markets and colorful houses are depicted neither as dangerous places nor as anonymous ones. And Alexanderplatz in Wim Wender's Berlin is anything but crowded and busy. What's more, if we go beyond a purely visual analysis of the audio-visual medium of film, we may notice that the urban spaces in these three films are actually devoid of any loud sound: no traffic sounds, no sirens, no loud advertising or deafening construction work.

My dissertation starts out from the presupposition that film scholars working on the city-film relationship have been preoccupied with the visual representation of the city at the expense of its sonic representation. It is my contention that the soundscapes of cinematic cities play a crucial role in the staging of Amsterdam, Berlin and London in a way that challenges prevailing myths of the modern and postmodern cinematic city.

\subsection{Soundscapes of the urban past in fiction film}

In this dissertation I will examine the representation of urban soundscapes in fiction films situated in Berlin, London and Amsterdam, by identifying the conventions and repertoires employed by filmmakers to stage the urban environment through sound. ${ }^{2} \mathrm{My}$ research has centered on the question:

How have filmmakers staged the soundscapes of Amsterdam, Berlin and London in fiction film, and in which ways did this contribute to the changing identities of these cities?

\footnotetext{
${ }^{2}$ This dissertation is part of a wider research project, called Soundscapes of the Urban Past: Staged Sound as Mediated Cultural Heritage. This project was funded by NWO, the Netherlands Institution for Scientific Research in the context of its Cultural Dynamics program. Designed and carried out at Maastricht University by Prof. Dr. Karin Bijsterveld, Prof. Dr. Andreas Fickers, Annelies Jacobs and myself, the project's scholarly aim is to study dramatizations of sound in historical documents, radio plays and films - as mediated cultural heritage - in order to enhance our understanding of the continuity and change in representations of the city.
} 
To address this main question, I have formulated a set of more specific questions. For example, what repertoires and conventions in the use of city sounds in fiction film were developed between 1930 and 2000? How can we explain the emergence of these repertoires and conventions? What similarities and differences can be observed when examining the staged soundscapes of Amsterdam, Berlin and London in the 1930s, 1950s, 1970s and 1990s? And how have filmmakers employed these repertoires and conventions to stage changing urban identities and to stage the experience of urban sounds by city residents and visitors?

These various questions call for a clarification of the concepts used and methodological choices implied. First of all: why Amsterdam, Berlin and London? Second: why these particular decades? Third: which particular "city sounds" are involved? Fourth: who are the filmmakers and which films are considered? And finally: why fiction films?

At first sight, the selected set of cities - Amsterdam, Berlin and London - may seem a somewhat random one. Wouldn't Paris, Rome, or Vienna have been equally suitable cities to study? There are several theoretical and practical considerations that have led me to select these three cities. A major theoretical consideration was my decision to focus on a comparison of different types of modern metropolises. As a new metropolis in the early twentieth century, Berlin was the fast-growing capital of a relatively young nation and a key city in the public discourse on modernity and the city. Berlin is also a city with a spectacular, if tragic history; the shining center of the Weimar Republic, it was reduced to ruins, rebuilt, separated and reunited, all within a time span of seventy years. Having chosen Berlin, I needed a city with a more established identity and stable history by way of contrast. London has served as the capital of the British Empire for centuries, and although the city suffered heavily from bombing raids in the Second World War it was never occupied or completely destroyed. It thus would serve as a perfect contrast. To enrich my comparative argument, I added Amsterdam: if it is a not a metropolis like Berlin and London, it still undisputedly counts as a metropolitan city. At the same time, all three cities were, and still are, capital cities that have attracted institutions and businesses linked to their status of capital.

Berlin and London are also highly relevant choices from the perspective of Film Studies. Berlin was the home of the largest film industry in Europe before the Second World War, and throughout the twentieth century Germany hosted one of the most important film industries in Europe. Another major film industry in Europe was the United Kingdom, with London as the undisputed center and cultural capital throughout the twentieth century. Moreover, the British film industry has been closely interconnected with Hollywood. Many American studios shot and financed films in the United Kingdom, while there was, and still is, a strong migration of British talent and personnel to Hollywood and vice versa. In contrast, my decision to include Amsterdam is motivated by the fact that the Dutch film industry was not a major global or continental player. Despite the occasional flare of international ambition, most Dutch films have managed to attract Dutch audiences only. Given my particular angle, it is 
worth examining if this national focus is reflected in the representation of Amsterdam's soundscape.

Another consideration was a pragmatic one. In order for a comparative analysis to work, the analyst must be able to understand the film culture and language of the different cities and countries under study. This disqualified, for example, Paris and Rome as options for inclusion here.

That I identified the 1930s, 1950s, 1970s and 1990s as the most relevant and interesting decades for historical comparison resulted from the following considerations. First, the 1930s marked the introduction of synchronized and recorded film sound in Europe. The makers of the films from these years often experimented with new technology and broke with conventional production practices. In the $1950 \mathrm{~s}$, new production practices were introduced. A move from studios to outdoor locations was inspired by an international vogue for realism and facilitated by lighter, more mobile recording equipment. The 1970s, in the wake of the 1960s' upheaval, saw the arrival of a new generation of filmmakers, with a more explicit political agenda and drawn towards more experimental modes of representation. It was also a decade in which new film sound technologies and practices for both recording and montage, such as magnetic tape recording, portable microphones and multichannel editing, were widely introduced. Finally, the 1990s marked a strong increase in globalization and migration in all three cities, with consequences for demography, urban planning and popular culture. Digital technologies were introduced, and expected to bring about considerable changes in film production and sound design. Moreover, after years of division Berlin's unity was restored.

What do I consider as relevant "city sounds" in fiction film? In my analysis, I treat any diegetic film sound that is not understandable dialogue and that originates in urban public space, or that has its source in some private space but is nonetheless heard in urban public space, as an "Urban Sound Event." This includes, for instance, traffic sounds, church bells, street musicians and the "unspecific mush," as sound designer Larry Sider calls the hardly identifiable background sound of a city. ${ }^{4}$ In my analysis I do not merely focus on such Urban Sound Events (USEs), however; I also take into account silences when they have important narrative or representational functions. The same holds for non-diegetic music. Even though it is not part of the "world of the story," non-diegetic music can serve as a bridge between that world and the audience, as some examples from Berlin, in Chapter 4 and Chapter 5, will show.

\footnotetext{
${ }^{3}$ The notion of "diegetic" was derived from the ancient Greek word for narration, "diegesis," and refers to the world in which the story takes place. Dialogue, music played in the world of the story and most sound effects are diegetic sounds. But a voice-over or an accompanying musical score are non-diegetic sounds (Bordwell \& Thompson 2001 [1979]: 430).

${ }^{4}$ Larry Sider, personal correspondence, 20-02-2011.
} 
What do I mean when I refer to "filmmakers?" Usually this term refers to film directors only, but in this study I employ the notion to refer to anyone involved in the production of a film: the director as well as the producer(s), writer(s) and members of the sound crew. As film production is a collective effort, all these actors may have a decisive influence on a city's sonic representation.

Finally, why limit my corpus of films to fiction films? Fiction, as opposed to documentary, does not impose a standard of "veracity" on itself, even though films may be based on a "true story," or situated in a city that we know. Every element of a fiction film is part of a carefully constructed and staged world; every sound we hear has a function and meaning within the film. It is exactly this staged reality of the filmic city that this dissertation is interested in, as it tells us something about "the city as a narrated form," in the words of Peter Fritzsche (Fritzsche 1996: 4). Because I am interested in the mediated experience and perception of urban sounds, fiction films have proven to be an incomparably rich resource for this research.

\subsection{Theoretical rationale}

This study, like the wider research project of which it is part, is based on a number of theoretical assumptions about urban soundscapes, about their staging and about film sound. First, the concept of "soundscape" is center-stage. It was coined by the Canadian composer and ecologist Raymond M. Schafer in The Tuning of the World (1977, later published as The Soundscape). Schafer defines the soundscape broadly as:

The sonic environment. Technically any portion of the sonic environment regarded as an object of study. The term may refer to actual environments, or to abstract constructions such as musical compositions and tape montages, particularly when considered as an environment. (Schafer 1977: 274)

Given this broad definition, the word soundscape has been appropriated by a wide variety of scholars and has taken on varying meanings. "Soundscape" has been used to refer to a natural or urban environment, a musical composition and a sound art installation (Kelman 2010). Originally a noun, it has also become a verb: "soundscaping," or the shaping of sonic environments (Sterne 2013: 183). The sound historian Emily Thompson has defined "soundscape" as "both a world, and a culture constructed to make sense of that world" (Thompson 2002: 1). Because we do not pretend that the soundscapes in fiction films are direct reproductions of the soundscapes of actual cities, Thompson's definition is a productive one for this study. Filmic soundscapes may be understood as part of the culture that makes sense of the world.

As Jonathan Sterne pointed out, Raymond M. Schafer considered the soundscape of the world itself as a composition, composed, performed and listened to at the same time by each and every person: "Soundscape implies a way of listening to compositions - a rapt, total attention - and a sense of the world that is much like a compositional work" 
(Sterne 2013: 190-91). In this sense, the world itself is a staged soundscape. Moreover, if we do not consider the representation of a soundscape in fiction film as a "direct" reproduction of a "real" soundscape, it makes more sense to think of the soundscape of the world as a construct not entirely dissimilar from a film soundtrack.

My second assumption pertains to the staged character of represented city sounds. I start out from the observation that we do not have direct access to the soundscapes, or sonic environments, of the urban past. Unless anthropological or documentary recordings are available, we only have knowledge of these soundscapes through their staging or dramatization in historical texts, radio plays and films: our mediated cultural heritage of sound (Bijsterveld et al. 2007). Studying this cultural heritage, however, opens up a unique entrance into the changing meaning of city sounds to filmmakers and, indirectly, audiences.

Earlier works on the dramatization of urban sound - based on historical documents such as newspapers, diaries and pamphlets, but also in novels - have shown that the staging of sound as either positive or negative has contributed to the articulation of urban life as dynamic or, in contrast, sensory overwhelming (Bijsterveld 2001; Thompson 2002). In 1916, the British surgeon Dan McKenzie wrote about the agony produced by the sound of the motor-horn: "The motor-horn! The motor-horn! I often wonder why in all the world such an instrument of torture has ever been permitted to exist even for a single day!" (McKenzie 1916: 33-35, quoted in Bijsterveld 2008: 91). His outrage colorfully illustrates the debate on street sounds before the Second World War. All over Europe and North America, "anti-noise" societies were established and noise abatement campaigns initiated. Technicians began to measure aggravating sounds; anti-noise activists sought the attention of the press; and anti-noise societies aimed to raise the general public's awareness of noise. Furthermore, campaigners pushed for noise legislation, especially near schools and hospitals, because noise was considered to be detrimental to public health and efficiency (Thompson 2002: 120-30; Bijsterveld 2008: 104-33). But the sounds of the modern city were not only experienced and staged in negative terms. Futurist composers, in the early decades of the twentieth century, sought to imitate, evoke and celebrate the sounds of urban modernity in their music (Bijsterveld 2008: 139). These examples show how the different stagings of sound express differing perceptions and experiences - not just of sound but of modern city life in general. We claim that literary texts, fiction films and radio plays, in often different but sometimes similar ways, offer particular stagings of urban soundscapes, and through these stagings particular representations of the city (Bijsterveld, Jacobs, Aalbers \& Fickers 2013).

Finally, this study builds on the rich theoretical literature on film sound. This body of literature suggests that film sound does not offer a direct reproduction of original sounds that were recorded. Rather, it offers a representation of the pro-filmic event (the action that happened in front of the camera and the microphone). The recording process transforms sound materially. Furthermore the soundtrack of a fiction film is subject to a 
double intervention on the part of the filmmakers; it is designed in advance and edited in post-production.

The decisions taken by filmmakers during these interferences are informed by a number of factors, reflecting specific historical and material contexts. In this study four different contextual levels are acknowledged to explain particular representations of soundscapes, developments in representations over time or differences between cities. The first contextual level is the necessity for filmmakers to create a convincing realityeffect. This does not mean that a representation has to be a flawless reproduction of a particular urban soundscape, but that audiences need to believe that the represented city is the city they know, whether from personal experience or on the basis of other representations. This contextual level displays a constant tension between an imagined reality and a realized imagination. On the one end of this spectrum, we find the city as it is known or thought to exist, informing filmmakers' choices. On the other end there is the experience of a city pre-mediated by its representations in, for instance, fiction films.

This brings me to the second contextual level: film culture. Broadly speaking, film culture can be defined as the expression of dominant artistic paradigms shared by filmmakers, scholars, critics and audiences. For instance, the dominant Formalist theory of the pre-war years, which stressed the transformational nature of the medium (the idea that the camera is not a neutral mediator but that it changes the object of the representation), can help us to understand how and why filmmakers like Fritz Lang and Alfred Hitchcock experimented with sound as an artistic means of filmic expression. ${ }^{5}$ Film theory texts and secondary literature on the history of film theory informed my discussion of this contextual level, as well as film reviews in contemporary newspaper. ${ }^{6}$ In addition, I will also consider the conventions linked to specific genres as part of film culture. These genres, as will be clarified in my study of London-in-film, have significantly affected the use of sound for the representation of cities.

The third contextual level necessary for understanding changing representations of urban soundscapes is sound technology and film production practices. The technology of film sound has changed and developed considerably since the introduction of recorded and synchronized film sound in the late 1920s. The experimentation with these new technologies has resulted in new narrative and representational uses of film sound. For instance, when sound recording equipment became lighter and more mobile in the 1950 s, location shooting became easier and more popular, thereby challenging the conventional practices of studio recording.

The fourth and final contextual level pertains to politics. Politics can inform a filmmaker's choices, for instance when he or she wants to make a political point. But

\footnotetext{
${ }^{5}$ For a more elaborate and detailed discussion of Formalist film theory see Chapter 2.

${ }^{6}$ Occasionally, contemporary film reviews in magazines or newspapers offered interesting information about the corpus films, their production process and their reception. Sometimes these reviews were quoted from the secondary academic literature, but some of the reviews mentioned or quoted in Chapter 3 have been found in the digitalized online archives of newspapers that discussed the films under study.
} 
we can also think of censorship and propaganda. The kinds of films filmmakers are encouraged or forbidden to make have influenced the representations of urban spaces in fiction film. As Chapter 4 will show, for instance, the sights and sounds of filmic Berlin changed drastically after 1933, the year in which Adolf Hitler was appointed chancellor of the German Reich.

These contextual levels, as will become clear below, do not "work" independently from each other. On the contrary: they are often found to be connected or influencing each other. An example is the increase of films shot in a sober fashion on location after the Second World War. This can be explained by referring to film culture, that is: to the popularity of Italian Neorealism in the world of film-making at large, and to the dominance of the Realist theoretical paradigm. One of the explanations for the Italian filmmakers' aesthetic preferences at the time, however, is to be found in the situation that the Italians had no film studios left after the war, nor any state-of-the-art equipment. Here we see how film culture is inextricably linked to the availability of film technology and, indirectly, also to politics. After all, the Second World War was the result of political conflict. Many more of such connections will appear throughout this study.

\subsection{Corpus selection and method of analysis}

I selected and analyzed ninety-five films for my study (for the full list of films analyzed, see Annex A). These films vary greatly in terms of genre, tone and intended audience. They comprise crime thrillers, comedies, social dramas, propaganda films and literary adaptations. Some films were primarily produced for domestic markets, whereas others aimed at international audiences. I did not use "quality," a highly contested issue in Film Studies, as a criterion for selection. The theoretical rationale behind this research presupposes that ordinary, everyday genre films, made for broad audiences, can tell us as much about the staging of the urban soundscape as the classics of film history. Most of the films analyzed were produced in the countries in which they are situated, but my sample also includes the occasional American film, and films that are set in more than one of the three cities studied.

Selecting the films for my corpus involved a five-step process. First, I constructed a list of films with stories situated in Amsterdam, Berlin and London in the 1930s, 1950s, 1970s and 1990s. This list was based on database searches on websites such as the International Movie Database (www.imdb.com). References to films in film studies handbooks and other secondary literature also helped to establish this list. If many handbooks are based on the prevailing canon, they also led me to secondary literature with references to other, lesser-known films.

Second, I extended my selection of films somewhat beyond the four selected decades, by turning the 1930s, for example, into the "long" 1930s, in the same way as historians speak about the "long" nineteenth or "long" twentieth century. The reasons I had for such extensions varied. Alfred Hitchcock's first sound film, BLACKMAIL, is from 1929, the year in which the very first European sound films were produced. Would 
I have taken the 1930s strictly, BLACKMAIL would not have been part of my sample. Yet BLACKMAIL is a highly significant film in the history of film sound because Hitchcock experimented with the possibilities of this new technology, which in turn influenced other filmmakers. I therefore included it my corpus for the 1930s after all. In selecting films on Amsterdam I had another reason for slightly going beyond the decades proper. The production of Dutch fiction films in the 1930s and 1950s was so limited, that the corpus for Amsterdam in these decades would have been too small in comparison with London and Berlin, had I not included ForEIGN CORRESPONDENT (Alfred Hitchcock, 1940 ) in the 1930s and RIFIFI IN AMSTERDAM (Giovanni Korporaal, 1962) in the 1950s. My somewhat flexible approach also allowed me to create a wider representation of potential sites in a particular city. For instance I included the 1988 thriller AMSTERDAMNED in my corpus for the 1990s because of its elaborate staging of the Amsterdam canals, thereby answering a call from Mark M. Smith, who has argued that scholars studying urban soundscapes or their representations should not forget to take bodies of water in or near cities into account (Smith 2013).

The third step in the selection process pertained to the availability of films on Digital Versatile Disc (DVD). This may seem a too practical criterion subject to criticism from a scholarly point of view. However, as my method of analysis involved considerable rewinding and fast-forwarding of substantial stretches of film (our language hasn't caught up with technological development here), studying celluloid or even VHS copies of film would have posed quite a challenge. Also, if all films had to be analyzed on celluloid, possibly in archives or film museums, there would have been not enough time to analyze a corpus of the size I had in mind.

The original plan was to study ten films for each city and each decade. However, after the initial selection of films for my corpus fewer than ten films happened to be available for particular decades and cities. For Amsterdam in the long 1930s for instance, no more than seven films were relevant. The same holds for Amsterdam in the long 1950s. In other cities or decades, however, I ended up with a list of more than ten films. In that case, we reduced this first selection to ten films by bringing in two additional criteria: the role of the city as a character in the narrative (if the city itself was a character, it was selected) and the sample's diversity of genre.

I analyzed the city sounds in all these motion pictures using a combined quantitative and qualitative method. For the quantification of sound I needed to develop a new model, because, as the film sound scholar Michel Chion notes, "unlike the image, film sound lacks a frame" (Chion quoted in Connor 2000). The moving film image consists of a series of discrete photographs, but the soundtrack is continuous. The length of shots and the presence of an object in the image can be counted; but the different diegetic sounds in a film fade in and out, merge with dialogue and non-diegetic music and are not always discrete or clearly perceivable units. Yet for a quantitative analysis such clearly perceivable units of sound were required. Therefore I developed Urban Sound Event as a concept. The Urban Sound Event (from now on also referred to as USE) is a diegetic film sound that is not understandable dialogue and that has its source in public 
urban space, or in private space but is heard in public space or another private space. Two binary oppositions are important in this definition: diegetic and non-diegetic, and public and private.

The notion "diegetic" has been derived from the ancient Greek word for narration, "diegesis," and refers to the world in which the story takes place. Dialogue, music played in the world of the story and most sound effects are diegetic sounds. Yet a voiceover or an accompanying musical score are non-diegetic sounds (Bordwell \& Thompson 2001 [1979]: 430). The distinction between public and private spaces is made to acknowledge that the sounds that shape an urban identity are the ones that are, in principle, audible by multiple people. The spillover of sounds from private spaces into other private spaces or into public space is included in order to acknowledge the importance of sounds produced by neighbors.

The Urban Sound Events distinguished in my analysis are not necessarily individual or discrete sounds. One USE can encompass more than one sound. It can be a group of sounds originating in one source. For instance, I counted the sound of a car's engine and the sound of that same car's tires on the asphalt as one and the same USE. Similarly, sounds belonging to one and the same cultural event, like the various voices and instruments in a folk song, or the background sounds of a specific locale or location, make up a single USE.

In my quantitative analysis I counted all Urban Sound Events in the films of my corpus of 95 films, which amounted to a total of 9329 USEs. I coded them in terms of the source of the sound event, the city in which the film was situated, the moment in the film at which it occurred (to make it easier to revisit important sounds) and whether its source was on-screen or off-screen (or a combination of both). These USEs have been classified into specific categories, like traffic sounds or musical sounds, and have subsequently been translated into percentages. This was done for each film, but also for each city and each decade, and for London also per genre. In my arguments in the various chapters below I will frequently refer to these percentages, for it is only in comparison that we can see developments in the use of particular sounds in the filmic staging of urban soundscapes. In this way I was able to determine, for instance, that the share of traffic sounds in all USEs in films situated in Amsterdam, increased from $42.2 \%$ in the $1950 \mathrm{~s}$ to $46.7 \%$ in the $1970 \mathrm{~s}$. Occasionally my comparative approach includes percentages of on-screen or off-screen sounds, as it can be of importance whether or not the sources of sounds are visible on screen. An example of this involves the presence of cars in East Berlin in the 1970s (see Chapter 5).

A quantitative analysis of film sound? A litmus test

It is important to recognize that identifying and counting Urban Sound Events does not involve a strictly objective scientific method. To verify the validity of my analysis, a test study was carried out in which two other participants in the Soundscapes of the Urban Past research project viewed and listened to a sequence from Alfred Hitchcock's FOREIGN CORRESPONDENT (1940). In this sequence an 
American reporter arrives by train in London. He is welcomed by his host and they have a drink in a café. The next scene shows the reporter in his hotel room, playing around with an umbrella and a bowler hat, while the sound of Big Ben is heard on the soundtrack. The final part of the sequence shows him leaving his hotel and walking onto a busy street. The project participants were asked to identify all the USEs they could hear, and to note them down. When comparing their notes to the results of my analysis of this sequence, we mostly recognized and identified the same sounds. There were some differences though. For instance, the project participants recognized more discrete sounds than I had done. While I considered the sounds in the café as one long stretch of background sound, the participants heard many discrete sounds, like tinkling glasses and glasses being put down on tables and noted these sounds separately. Another difference was found in the recognition of specific sounds. While I identified an offline, squealing sound as the sound of a car horn, one of the other participants recognized it as the sound of the New York subway access gates. These differences teach us two things: that not all sounds audible are clasisfied in the same way by all listeners, as existing knowledge of or familiarity with specific sounds can influence the outcome of the analysis, and, second, that a certain amount of habituation may develop when analyzing a large number of films. Out of experience or habit, individual sounds are grouped together, because the analyst is familiar with that particular combination of sounds. These factors can affect the outcome of a quantitative analysis. I am aware of the challenge of "double reflexivity" that is inherent to the process of scientific research and that asks for a critical reflection upon the status of the observer (Giddens 1979: 47). The intersubjectivity created in the test situation, however, showed that the other two observers shared my classifications - even though they came up with a few more finegrained subclasses of discrete sounds. Moreover, my own observations remained consistent over time.

Building on the primary classification of Urban Sound Events in terms of source, space and it being on- or off-screen, particular narratological qualities were identified for each USE, depending on its function in a scene. These narratological qualities are drawn from Roland Barthes' essay "Introduction to the Structural Analysis of Narrative" (Barthes 1987/1966: 91-97). In this essay Barthes distinguishes four different types of elements of a narrative. The first two are the cardinal function and the catalyser, and both concepts are used for categorizing film actions. A cardinal function initiates an action or constitutes a response. An example is the sound of a car horn that warns a pedestrian to step aside. A catalyser on the other hand is a sound that is part of an ongoing action, such as a car horn that is sounded but that is not responded to by anyone. Next to these functions there are two indices, which Barthes calls informants and indices proper. Informants are sounds that inform an audience about the time or place in which an action takes place. One can think of many car horns sounded simultaneously, off-screen, informing us that the scene represents rush hour. Indices proper, on the other hand, are elements of a narrative that indicate the character or mood of a scene. An example would be car horns sounded in annoyance by a group of 
motorists stuck in a traffic jam. As these examples show, one and the same USE can have multiple functions depending on the narrative purpose. In such rare cases, USEs acquired more than one label.

It was quickly established that of these four narratological functions of film sounds, the catalyser and the informant are the most common, while cardinal functions and indices proper are rather exceptional. This is not surprising, considering that catalysers are sounds that just "happen to be there" and informants are sounds that establish and confirm a specific time or place. A sound that functions as a cardinal function or an indice proper - for instance, when initiating or concluding an action or setting the mood of a scene - is foregrounded and made important for the narrative.

The sounds that stand out invite further examination of course. For this reason, my qualitative analysis of city sounds in film was mainly directed towards such sounds that functioned as cardinal functions or indices proper. Relevant questions pursued in this respect included who or what produced the sound. At whom was it directed? Was it a common sound or a special one? How was it perceived or experienced by the protagonists? Was it characteristic of a particular place or time? And how did the sound interact with the image and with the non-diegetic music? By answering these questions I sought to determine what role specific sound events have played in telling stories and constructing urban identities.

In addition to the analysis of USEs based on the narratological criteria mentioned above, this study also makes use of Raymond M. Schafer's distinction between keynote sounds, soundmarks and sonic icons (Schafer 1994 [1977]: 9-10). Following Schafer, keynote sounds are the background sounds of a city; the sounds you would not notice until they are gone. In musical terms one could describe these keynote sounds as the basso ostinato (freely translated as "bass line"). Soundmarks are the sounds that stand out in a particular environment and are considered typical for a specific location. An example is the phrase "mind the gap," so often heard on the London Underground. Different from those soundmarks, sonic icons are particular sounds that, over time, have become iconic for a particular place, such as the sound of the Big Ben. There can be some overlap between sonic icons and soundmarks (for instance in case of the Big Ben, which is both soundmark and icon), but this is not necessarily the case.

\subsection{Setting the stage}

So far, I have discussed the subject of this study, its research questions, the theoretical rationale of the work and the corpus selection and method of analysis. These issues and concerns will be elaborated in the subsequent chapters. Specifically, Chapter 2 introducess two of the contextual levels that partially explain developments in the representation of urban soundscapes in fiction film: film sound technology and production practices on the one hand and film culture and theory on the other. I will sketch the development of these two contexts, because they have affected my three case 
studies substantially, and they are deeply interconnected. Film culture, for instance, coconstitutes what is considered to be a successful reality-effect. And what is seen to be a successful reality-effect of the city-in-film influences the way films are shot. In addition I will show how the theoretical rationale of this study relates to ongoing debates in film sound theory.

Chapter 3 discusses the representation of the soundscape of Amsterdam in fiction film. In this chapter I will show how the quantitative and the qualitative analyses can be combined, and how particular developments can be explained in relation to the four different contextual levels. With regard to the represented soundscape itself I will argue that the sonic representation of Amsterdam in fiction film has changed from that of a big village in the 1930 s to that of a "proper" city in the 1970 s and to that of a "glocal" village in the 1990s. The creative recycling of traditional sonic icons by filmmakers in the 1990s will shown to be of crucial importance in this changing representation.

Next, Chapter 4 is the first of two chapters about Berlin, and it is devoted to a discussion of the representation of Berlin's soundscape until 1945. I will argue that Berlin was represented as a city under continuous political and social construction. The Weimar period was a time of considerable political and social unrest in Germany, and Berlin, the fastest growing of all the European metropolises, was the focal point of fierce debates on urbanization and modernity. Filmmakers contributed to these debates by using the new technology of recorded and synchronized sound. New artistic paradigms and musical metaphors left their mark on representations of Berlin, which was often portrayed as a cacophony. However, after the rise to power of the Nazis, a new, harmonized representation of the city became dominant.

Chapter 5 presents the second part of my argument about Berlin. After the war, the city lay in ruins. In East-German "rubble" films of the postwar period, the city is rebuilt in ways that are analogous to the reconstruction of German society after the Stalinist ideal. The soundtracks of these films, filled with the sounds of reconstruction, echo both the shattered state of mind of the German people as well as the promise held by the future. This representation of Berlin as a city under material and political reconstruction continues throughout the second half of the twentieth century. A different city is audible on either side of the silent border; and also after the reunification of Berlin and Germany, the sounds of reconstruction keep "filling" the soundtrack. More recently, these sounds have been accompanied by the sounds of a new multicultural society: immigration brought new, often contested sounds to the filmic soundscape. Moreover, music, both diegetic and non-diegetic, tends to be very important in representations of Berlin. Not only do musical metaphors recur frequently in the discourse on this filmic city; Berlin-in-film is also a city filled with diegetic (popular) music, and in some key examples the non-diegetic score clearly echoes a character's experience of the city. Such scenes, most notably in BERLIN ALEXANDERPLATZ and LOLA RENNT, appear to challenge the distinction between diegetic and non-diegetic sound.

In Chapter 6, I discuss the representation in fiction film of the soundscape of London. I will show how several everyday activities in the city are differently staged in different genres. Thrillers and romantic comedies have different means of representing 
"arriving in London," for instance. Other activities discussed are "travel in London" and "living in London." My argument will concentrate on London-in-film as a fragmented city, experienced quite differently by different (types of) people. Not only can we distinguish differences in the representation of soundscapes from one city to another, or throughout history; at the same point in time one city can have different soundscapes, depending on the sort of story told and the characters on which that story focuses.

In the conclusion of this dissertation, Chapter 7, I will return to the myth of the cinematic city, and discuss how the study of urban soundscapes in fiction film deconstructs, or complicates, this myth. After elaborating the added value of sound for filmmakers and film scholars, and the important role of silence, I will discuss more indepth the theoretical and methodological contributions of this dissertation to the fields of Film Studies and Sound Studies.

\section{6 "Enhanced echoes" of the city}

One of these contributions deserving brief mention here already is my introduction of the concept of the enhanced echo as a metaphor for staged soundscapes. When writing about the representation of urban soundscapes one must be very careful not to mix up the "real" and the "represented." As suggested, I do not want to imply that the soundtracks of fiction films offer direct reproductions of historical urban soundscapes. In contrast, this study, as well as the research project Soundscapes of the Urban Past, examines the mediated staging of urban sound. The discourse on film sound similarly emphasizes the constructivist character of the film soundtrack (for more on this, see Chapter 2). Yet the examples film scholars usually discuss to explain this constructivist character all seem to come from the genre of science fiction. The sounds of the spaceship in ALIEN (Ridley Scott, 1979) and that of the laser swords in STAR WARS (George Lucas, 1977) are pure fantasy, created with very different sound sources. They do not signify any previously existing sound.

Yet the cars, the trains and the church bells we hear in films situated in Amsterdam, London or Berlin normally also have a life outside film. Studying films from less "fantastical" genres than science fiction or horror confronts us with the situation that the sounds and images in these films do refer to a material reality. "Real" sounds are recorded and used, films are shot on location and the sound of the city does find its place on the soundtrack, if only in the background. Therefore this dissertation must carefully walk a tightrope between constructivism on the one hand, and realism on the other. And I must carefully formulate what the objects of my analysis, the film soundtracks, actually are. For this reason I propose to use the metaphor of the enhanced echo to clarify that the soundtracks under study offer stagings and representations of historical sounds and soundscapes. Echo, in Greek mythology, is the name of the nymph who was stripped from her own voice and could only repeat the last sounds of words spoken by other persons (Ovid 1998: 61-66). The Oxford English Dictionary defines "echo" as follows: 
A repetition of sounds, which is produced by the reflexion of the sound-waves due to their incidence on something denser than the aerial medium in which they are propagated; hence concr. a secondary or imitative sound produced by reflected waves, as distinguished from the original sound caused by the direct waves. (OED)

This definition contains three important characteristics for us. First, the echo is a temporal and a historical phenomenon: it is a repetition of sounds. On film soundtracks, sounds are recorded so that they may be heard again, repeated, later. This "later" may be a week, a year, or even, as in the case of some of the films in my corpus, eighty years. Second, the echo has a material dimension. It is produced by the incidence of a sound wave on a material denser than air, and it is reflected from that material. Whether film sound is recorded optically (on photographic stock), on magnetic tape, or digitally, these materials return the sound to the world. The specifics of particular material circumstances - whether it is the film technology or the material reality of the city influence how the echo sounds. Which leads me to the final characteristic: an echo is notably different from the original sound while it is at the same time closely tied to it. This is the most important characteristic of the echo for my research: even though the film soundtrack is a construction, the sounds on it do signify a (once) existing reality, be it an original sound recorded on location, or a sound effect added later.

To be sure, this is not the first study that uses the metaphor of the echo to conceptualize the film soundtrack. In 1999, the French film scholar Véronique Campan already proposed to think of film sounds as echoes, in order to distinguish between the original sound and its recording. Campan states that the original sound leaves traces in the recording, and that these traces can never entirely correspond to the film image. Campan hereby recognizes that, because image and sound are often recorded separately and because a sound in film is not necessarily the sound it signifies, the traces left by a sound on the soundtrack do not necessarily correspond to anything in the image (Campan 1999: 23-5). Campan's argument is inspiring because it recognizes the importance of the original sound. However, she directs her attention to the perception of these echoes by the audience in the auditorium: to the experience of film sound. My interest is in a different aspect of film sound: what do these echoes - these transformed sounds - signify?

The metaphor of the echo can serve as a container concept for a number of additional topics and developments covered in this dissertation. First of all it is a useful concept for explaining the role of staged and mediated sound in cultural heritage. I mentioned above that the staging of urban soundscapes in fiction film contributes to the discourses about urban identity, and that mediated sound can also be considered part of our cultural heritage. But why do we need to listen to fictional sounds? The answer is that the conservation of historical sounds has been sparse; anthropological or documentary recordings of modern cities are rare, at least for the late nineteenth and first half of the twentieth century. And as with film sound it is with those rare recordings: the original 
sound has been transformed by the act of recording. "Live" sounds are transient; they start disappearing the very moment they are produced. Their only traces in history are their echoes; recorded, mediated, documented and described, or, in one word: staged.

Second, there is the intertextual and intermedial use of the echo metaphor. A number of the films in my corpus are adaptations from novels. They echo, as it were, the soundscapes described in these books. The best example is Alfred Döblin's Berlin Alexanderplatz, which will be described in more detail in Chapter $4 .^{7}$ Another case is Emil und die Detektive, for the first time adapted from Erich Kästner's book in 1931, and again in 1954 and 2001. To what degree can we understand these later films as echoes of the first one, especially considering the fact that the later films were set in the decades in which they were produced? Also interesting are the Dutch musicals DE JANTJES (1934) and BLEEKE BET (1934), both based on earlier versions as stage musical and silent film.

Finally, the metaphor of the echo can be helpful in explaining processes of iconization. As we shall see, over the years particular sounds have become iconic for Amsterdam-, Berlin- or London-in-film. Yet iconization is not merely a matter of repetition. Especially in Chapter 3, on Amsterdam-in-film, we shall see that the meanings and functions of sonic icons can change. As echoes they are inextricably connected to older stagings of sound, yet they are also different because of the historical, artistic and material circumstances in which they were created.

The metaphor of the echo also has its limitations, though, and must therefore not be taken too literally. First, the word echo can suggest to the reader a weaker or weakened sound, a "lesser" sound than the original - a faint or almost inaudable repetition. In contrast, I propose to think of the echo as a transformed sound, an intentional variation on an original. Moreover, in order to emphasize the creative work done by filmmakers, and to make clear that staged sounds are in no way "lesser" or less significant than their originals, I shall speak of enhanced echoes. A second objection might be that, like the mythological nymph, an echo has no agency. To think of film soundscapes as literal echoes of historical soundscapes would imply that there are no people involved in their creation and reception. It would ignore one of the central concepts in the research project: the staging of sounds in media. But if we propose that not only the historical sounds are echoed, but also filmmakers' and audiences' sensibilities for and attitudes towards sound and the city, the metaphor of the echo is a very suitable way of approaching the material relation between historical soundscapes, their recording, their staging and their mediation.

\footnotetext{
${ }^{7}$ For an extensive discussion of the staging and representation of sound in Berlin Alexanderplatz as novel, radio play, film and television series, see Andreas Fickers, Jasper Aalbers, Annelies Jacobs and Karin Bijsterveld (2013). Sounds Familiar: Intermediality and Remediation in the Written, Sonic and Audiovisual Narratives of Berlin Alexanderplatz, in Karin Bijsterveld (ed.), Soundscapes of the Urban Past: Staged Sound as Mediated Cultural Heritage (pp. 77-116). Bielefeld: Transcript Verlag.
} 


\section{Chapter 2}

\section{Practice in Theory, Theory in Practice: Developments in Film Sound Technology and Film Culture, 1927-2010}

\subsection{Introduction}

In the previous chapter I claimed that shifts in the representation of urban soundscapes in fiction film can be explained by unraveling four types of context. These contexts are: filmmakers' attempts to create reality-effects concerning cities-in-film, film sound technology and production practices, political issues and film culture, including film genres and the predominating intellectual discourse on film sound. Political views and ideas about "realistic" urban soundscapes, which differed for the three settings I studied (Amsterdam, London, Berlin), will be discussed in chapters 3, 4, 5 and 6. Changes in the use of film sound technology and in production practices, as well as in the intellectual discourse concerning film sound, had more generic effects, however, and they were also closely interrelated. For this reason, these contexts deserve a distinct chapter.

This chapter is historiographical in character and aims to show that developments in film sound theory, film sound technology and practices of film production evolved in tandem. I will focus on three key moments in the history of sound film to demonstrate these interconnections. First, I discuss the critical discourse concerning the introduction of film sound in the late 1920s and early 1930s, as this innovation sparked a debate between theorists whose views were either more formalist or more realist. Second, I will analyze the rise of mobile recording technologies in mainstream film-making in the 1950 s as well as the expansion of editing options in the 1970s. This, again, came with a renewed scholarly interest in the role of sound in film. And third, I will reflect on the introduction of digital technologies in film production, distribution and exhibition. Surprisingly, theorists of film sound have not yet widely responded to this recent technological development. I will show how the digitization of film sound invites us to reflect critically on the relationship between the "original" sound and its representation. Theories of the digitization of cinema have discussed the loss of what was known as "indexical referentiality": the direct, material relation between an object and its photographic representation. Theorists of the film image have responded to this loss by looking at other elements from Charles Sanders Peirce's semiotic system, aside from indexical ones, to understand the relation between an original and its representation. As I will argue, recent work on film sound theory, even though it is not explicitly 
concerned with digitization, moves into similar directions. The metaphor of the enhanced echo - which I use to characterize the relation between an "original" sound and its reproduction - builds on these new theories of film sound.

\subsection{The introduction of film sound and debates between formalists and realists}

The introduction of film sound at the end of the 1920s was quickly followed by a number of responses from film theorists and critics, most of them negative. These reactions can partially be explained by the technical quality of the first American sound films. Warner Brothers' earliest sound films, like THE JAZZ SINGER (Crosland, 1927) and THE Singing Fool (Bacon, 1928) were produced with the Vitaphone "sound-ondisc" technology. In this process, sound and image were recorded separately on, respectively, a gramophone disc and a photographic film stock. When showing a film to an audience, the film projector was manually "synchronized" to the gramophone player (Handzo 1985: 385-86). "Synchronization" refers to the process of ensuring that a film and its soundtrack are played in such way that sound and image coincide. If they do, the audience will hear what a character says the moment his or her lips are moving. Unfortunately, "synchronization" was not the strongest point of the Vitaphone technology. Moreover, the gramophone records were prone to wear and tear: repeated use could lead to scratches in the records, and thereby to glitches and repetitions in the playback (Handzo: 1985: 386).

The negative reception of early sound films by film critics was not only due to technical problems, however. It also expressed a critical response to the type of sound films produced by Hollywood: musicals and vaudeville films with skimpy plots to hold the songs together hardly impressed the critics. Nevertheless, early sound films offered a great attraction to the wider public. As so often in film history, negative critical reception did not prevent these films from becoming box office successes (Eyman 1997: $176,179,197-98,311-12)^{8}$

On a theoretical level, the negative tone of the critical responses can be explained by the dominant idea of what film, as an art form, ought to be. In the early, or "classical," period of film theory there were two main streams of thought: Formalism and Realism (Andrews 1976: 11, 104). Formalism was the dominant paradigm in film theory before the Second World War. It was inspired by "Gestalt psychology." Gestalt psychologists state that our perception of the world is pre-ordered by the knowledge that we already have of that world. The implication for art theory is that a piece of art can never be a direct imitation of reality, because an artist organizes and bestows order upon that reality, based on his or her own knowledge (Andrews 1976: 55-59). Film and photography challenge this assumption because their products appear to be direct, mechanical imitations of the reality in front of the camera. However, formalist critics

\footnotetext{
${ }^{8}$ A couple of years later, the discourse concerning the first Dutch-spoken sound films showed a similar development. The folk musicals DE JANTJES (Speyer, 1934) and BlEEKE BET (Oswald \& Benno, 1934) were popular successes despite a lukewarm critical reception (Van Gelder 1995: 11-13).
} 
argued that film actually can be art because photographic reproduction always produces a difference between reality and its depiction. For instance, it always turns a threedimensional environment into a two-dimensional plane (Andrews 1976: 12; Arnheim (1974 [1932]: 28-29). The addition of sound to films, and later color as well, was rejected by formalists because it undermined and even destroyed the organizational principles developed in silent film, and brought films closer to reality. Film sound thereby rendered film as artistic form impossible; film could only be art by being distinctly different from reality (Andrew 1976: 35; De Putter 1991: 186). Film, according to the formalists, was essentially a visual art form.

One of the most radical responses to film sound - and the best example of the above-mentioned presupposition - was voiced by the formalist German film critic Rudolf Arnheim. He stated that film, through the addition of sound, would come closer to realism and "naturalness." Therefore "sound film," so he stated, "did not lie on the path the best film artists were pursuing" (Arnheim 1974 [1932]: 27). This opinion is less surprising than his argument to support it: Arnheim claimed that the emotional effect of music was less strong than the effect of showing people move to unheard music. In other words, a sound implied in the image was more effective than letting audiences hear that same sound (Arnheim 1974 [1932]: 201-02). Later in his life, he reconsidered his opinion regarding the sound film, when stating that the privileged role of the image in his earlier theory was not in line with the principles of Gestalt Theory (Grundmann 2001).

What makes Arnheim's original argument so peculiar is that he formulated it in 1932, right after the introduction of recorded and synchronized film sound. Arnheim was an experienced film viewer, having worked as a film critic for Die Weltbühne during the 1920s (Grundmann 2001). In this period, the screening of films would be accompanied by an orchestra. There was no silence in which the experience of music could be suggested by the image. The case of Arnheim clearly shows how powerful the experience of the first sound films was: they made him forget or neglect the musical accompaniment of "silent" film. Or as the influential French film theorist Michel Chion put it more elegantly: "The symbolic date of 1927, the year of THE JAZZ SINGER, marks the moment when the entire previous cinema was retrospectively declared silent" (Chion 1999: 7).

Similar but less radical ideas about film and sound were developed by other formalist theorists. The Russian authors and filmmakers Sergei Eisenstein, Vsevolod Pudowkin and Grigori Alexandroff were convinced that sound should only be employed as a counterpoint to the image to prevent sound from undermining the principles and effects of montage (Eisenstein, Pudowkin \& Alexandroff 1998 [1928]: 84). ${ }^{9}$ If other theorists and critics, including the German art historian Erwin Panofsky and the Hungarian dramatist and film critic Béla Balász, were also critical about sound film, they saw opportunities nonetheless. Panofsky argued that sound did not change film substantially: "a moving picture, even when it has learned to talk remains a picture that

\footnotetext{
9 "Montage" was a theoretical concept developed by Sergei Eisenstein. It refers to the juxtaposition of images, in order to create meaning (Eisenstein 1974 [1949]: 75-87).
} 
moves and does not convert itself into a piece of writing that is enacted" (Panofsky 1974 [1934]: 156). Silent film, he recalled, was always accompanied by music. The potential problem was not sound, but speech, which should not be "poetic" (Panofsky 1974 [1934]: 156-57). He pointed at a failed adaptation of Shakespeare's A Midsummer Night's Dream to underline his argument (Panofsky 1974 [1934]). Rather than opposing sound film altogether, he acknowledged early sound film's shortcomings, and lamented the lost art of silent film acting (Panofsky 1974 [1934]: 164-65).

A similar sentiment was voiced by Béla Balász, who at the time viewed the introduction of film sound as a catastrophe, for it meant the destruction of the highly developed culture of silent cinema. He also predicted that "sound was not yet a gain for the film, but merely a task which would be an immense gain once it was fulfilled" (Balász 1952: 194-95). Looking back in 1952, however, Balász concluded that such task had not been fulfilled: "The art of the silent film is dead, but its place was taken by the mere technique of the sound film, which in twenty years has not risen and evolved into an art" (Balász 1952: 194-95). At the same time, Balász set an agenda for the further development of film sound. His formalist background shows from his view that sound should not make film more like nature, as well as from his call for a purposefully ordered "sound montage":

The demand is that the sound film should not merely contribute sound to the silent film and thus make it even more like nature, but that it should approach the reality of life from a totally different angle and open up a new treasurehouse of human experience ... It is the business of the sound film to reveal for us our acoustic environment, the acoustic landscape in which we live, the speech of things and the intimate whisperings of nature; all that has speech beyond human speech, and speaks to us with the vast conversational powers of life and incessantly influences and directs our thoughts and emotions, from the muttering of the sea to the din of a great city ... The sound film will teach us to analyse even chaotic noise with our ear and read the score of life's symphony ... Only when the sound film will have resolved noise into its elements, segregated individual, intimate voices, and made them speak to us separately in vocal, acoustic close-ups; when these isolated detail sounds will be collated again in purposeful order by sound montage, will the sound film have become a new art ... then the rattle and clatter of life will no longer overwhelm us, in a lifeless chaos of sound. (Balász 1952: 197-99)

Balász wrote this in 1952, but after the Second World War, Formalism was challenged by Realism as a new dominant theoretical perspective. Realism was based on the conviction that the essence of film is its capability of capturing and reproducing reality (Andrews 1976: 137-41; De Putter 1991: 194-98). Realist theorists therefore showed a greater appreciation of sound. André Bazin, the most influential realist, stated explicitly that "the primacy of the image is both historically and technically accidental" (Bazin 1974 [1958]: 88-89). This primacy of the image in film theory was challenged by the 
realist paradigm that thrived as a mode of film production as well. Italian "Neorealists" such as Roberto Rosselini and Vittorio De Sica actually turned the poor production circumstances of postwar Italy to their advantage when creating realistic, and very successful, social commentaries such as ROMA, CITTA APERTA (Rosselini, 1945) and LADRI DI BICICLETTE (De Sica, 1948) (Thompson \& Bordwell 2003 [1994]: 359-60).

It would be mistaken to presume that the relationship between film technology and production practices on the one hand and film culture on the other was one-directional. Not only did technological developments and artistic trends inform film theory and criticism; theory and criticism in turn inspired filmmakers as well. This becomes obvious when we look at the history of film studies as an academic discipline. Until the 1960s there was no such thing as an academic discipline of film studies. The discourse of film theory was constituted by journalists, literary scholars and art historians, many of whom were active in film production as well (De Putter 1991: 176-77). Sergei Eisenstein and his compatriots Pudovkin and Dziga Vertov were both director and film theorist. Béla Balász wrote about and for film; he co-wrote the scenario for G.W. Pabst's DreigroschenOPER (1931) and Leni Riefenstahl's DAS BLAUE Licht (1932). And in France, the Cahiers du Cinéma writers Jean-Luc Godard and François Truffaut later became the most important directors of the French realist film school Nouvelle Vague. $^{10}$

The active involvement of theorists and critics with film production can serve as an explanation for the judgmental, even normative, character of what is now known as "classical" film theory. The considerable attention to film sound, whether evaluated positively or negatively, was a logical effect of this active involvement.

The institutionalization of film studies at North-American universities in the 1960s, and the resulting differentiation between the academic discourse and the everyday practice of film production led, perhaps surprisingly, to a renewed emphasis on the image, at the expense of sound. The institutionalization of film studies was dependent on the recognition of film as a "true art form," and with that of the recognition of film directors as authors and artists (Thompson \& Bordwell 2003: 436). ${ }^{11}$ The theoretical toolset used for the intellectual legitimization of Film Studies as an academic discipline had already been developed by film critics of the French magazine Cahiers du Cinéma, like JeanLuc Godard, François Truffaut and Erich Rohmer. They formulated a "Politique des

\footnotetext{
${ }^{10}$ Cahiers du Cinéma is a very influential French film magazine. It was founded in 1951 by André Bazin and others to provide a platform for writers who were very critical of conventional French cinema, which they called "cinéma du papa" (Daddy's Cinema). Famous writers for Cahiers in that period were the later Nouvelle Vague filmmakers Frannçois Truffaut, Jean-Luc Godard, Claude Chabrolle and Jacques Rivette (Thompson \& Bordwell 2003: 374, 443-46).

${ }^{11}$ Greg Taylor writes about "groovy English professors, who had dared to pepper their curricula with liberal shakes of Fellini, Bergman and Welles" (Taylor 1999: 146).
} 
Auteurs": an approach to film that elevated to the level of artist those directors whose "signatures" could be recognized in their work (Van Putten 1991: 208-13). ${ }^{12}$

The discussion of the work of individual directors and their personal styles replaced the discourse on the essence of film. It also meant that film sound became of minor interest to critics. From the realistic perspective of the Cahiers writers sound was just one of the elements of film that a film director had at his disposal in the construction of his narrative. This can be illustrated with a quote from Truffaut about Alfred Hitchcock:

He is not merely an expert at some specific aspect of cinema, but an all-round specialist who excels at every image, each slot, and every scene. He masterminds the construction of the screenplay as well as the photography, the cutting, and the soundtrack. (Truffaut, 1984: 18)

If this quote may suggest that the "Politique des Auteurs" and realist film theory treated film sound as equal to the image, in practice this turned out differently. When Truffaut described the defining characteristics of Hitchcock as an "auteur," he restricted himself to thematic elements: the disturbing object, the empty object, the dominant mother and the wrong man (Pisters 2002: 40-43). And his colleagues Erich Rohmer and Claude Chabrol only mentioned certain visual stylistics: the point-of-view shots, the editing and the influence of German expressionism and Soviet montage theories (Pisters 2002: 38). Apparently, Hitchcock's use of sound was not what made him an auteur.

The "Politique des Auteurs" was instrumental in the institutionalization of Film Studies, but once this had been accomplished, academic film discourse started to focus on new theoretical concepts, such as the notion of "dispositif." After 1968, politically engaged (leftist) film theorists shifted their attention to the ontology of film. They proved less interested in the essence of film art than in the dispositif of film: the interrelation between projection technology, the place of exhibition, the illusion of film and the psychological state of the audience. As Jean-Louis Baudry claimed, the film dispositif reproduced the Renaissance perspective in painting and thereby created a perfect viewing position for the individual film viewer, the subject (Baudry 1986 [1970]: 286, 288-89). According to fellow theorist Colin MacCabe, this subject was petrified outside of action and production, and hence subjected to the dominant capitalist regime (MacCabe 1974: 52). Baudry compared the audience in a movie theater to the prisoners

${ }^{12}$ When Film Studies became institutionalized as an academic discipline in the 1950s and 1960s, the American critic Andrew Sarris translated the French concept of "Politique des Auteurs" (author politics) into "Author Theory." But this masks that the Politique des Auteurs was for a large part a rhetorical strategy, as François Truffaut claimed. He saw it as a polemical weapon, bound to a certain time and place, a weapon deployed in the effort to consider products of a mass entertainment industry as works of art (Sarris 1974 [1962]: 511). The Cahiers du Cinéma writers did not so much pursue the institutionalization of Film Studies. They were dissatisfied with the state of French cinema, which produced "respectable" films based on literary sources. Truffaut, Godard and the other writers opposed these films by searching for artistic merit in American studio productions. To that end they developed their Politique des Auteurs. By translating "politique" into "theory," Sarris robbed this "politics" of its cultural and historical specificity, and turned into a theory that covered all of cinema. 
in Plato's allegorical cave. These prisoners do not see real objects, but shadows, projected on a screen in front of them.

Baudry was well aware of an unintended consequence of using Plato's allegory of the cave as a metaphor for the functioning of the dispositif (or apparatus, in the English translation of Baudry's work) of cinema: film image and film sound had a different ontology. The images seen by the prisoners in Plato's cave are only the shadows of real things. But the sounds they hear are not only echoes bouncing back from the wall in front of them; they are also the original sounds produced behind their backs. In the words of Baudry: "it is true that in the cinema ... one does not hear an image of the sounds but the sounds themselves." (Baudry 1986 [1975]: 304-05) Baudry also had a solution for this "problem," however:

If a link is missing in the chain that connects us back to reality, the apparatus corrects this, by taking over the voice's echo, by integrating into itself these excessively real voices. (Baudry 1986 [1975]: 304)

The idea is then, apparently, that the dispositif itself, bridges the differences in ontological status between sound and image. In film theory, this came to be seen as a problematic solution, however. Baudry's "excessively real" sounds connect the audience to the real world, yet within a dispositif whose main task is, in Baudry's line of reasoning, not so much to show a real world, but only its image as sanctioned by the dominant capitalist culture. This contradiction could not be solved within a discourse that considered film as an essentially visual medium. A new perspective was required, one that considered image and sound as being each other's equals. This new perspective would emerge in the early 1980s.

\section{3 "New Hollywood," new film sound and new theories}

The breakthrough in film sound theory that would take place in the 1980s was not only a reaction to earlier theoretical work. The recognition of the problematic status of sound in the dispositif also required a new sensitivity to sound itself: a renewed sensitivity that cannot be seen in isolation from a series of developments in film production and technology in the American cinema of the 1970s. In Hollywood, the great directors considered "auteurs" by the critics of Cahiers du Cinéma were nearing the end of their creative years. The 1970s saw the retirement of such icons as Alfred Hitchcock, John Ford and Howard Hawks. Their places were taken by a new generation of young filmmakers, who made their first films in a period we now call "New Hollywood." The most famous of them were Steven Spielberg, Francis Ford Coppola, Martin Scorsese and George Lucas (Thompson \& Bordwell 2003 [1994]: 515-16). This new generation of film directors had grown up as film fans; for good reasons they were nicknamed the "Movie Brats" (Whittington 2007: 30). Some of them, Lucas and Coppola for instance, had received their education at the new film schools, or at the new film departments of North-American universities, where from the outset they were trained in all the basics of 
film-making: direction, writing, cinematography, editing and also sound. To William Whittington, this is one of the explanations for the special attention these directors showed for the relationship between image and sound (Whittington 2007: 33).

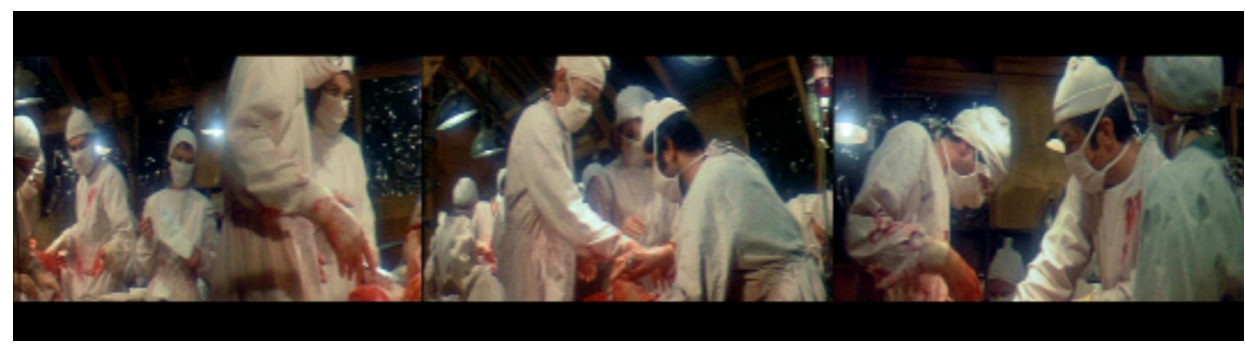

Illustration 2: Operation scenes in $M^{*} A * S^{*} H$ (Altman, 1970) sound hectic and "up close" because of Altman's innovative sound design.

Furthermore, these directors were able to capitalize on a range of developments in sound technology. For instance, the advantages of magnetic tape recording (better sound quality, more channels and therefore more options in mixing and post-production) were known since the 1940s already, but they were not used to their fullest potential until Robert Altman made M*A*S*H (1970) and NASHVILLE (1975) (Kellogg 1980 [1955]: 215-16; Altman 1980: 9-10). Altman combined the possibility of mixing various channels with the use of small, wireless microphones, which he pinned to his actors' clothes (Altman 1980: 9-10). As a result, the dialogues during operation scenes in $\mathrm{M}^{*} \mathrm{~A} * \mathrm{~S} * \mathrm{H}$ are overlapping and therefore sound realistic.

Another technological development was the introduction of the portable Nagra recorder. This device made it possible for filmmakers to record sounds on location, without having to bring in a truckload full of expensive and heavy equipment (Whittington 2007: 31). This Nagra recorder, a Swiss product, was used previously in French Nouvelle Vague films of the 1960s, like those of Jean-Luc Godard, but only found its way to Hollywood later, not in the least because of the Movie Brats' fascination with the Nouvelle Vague (Whittington 2007: 58-59).

Sound "designers" such as Walter Murch and Ben Burtt used these new technologies with success. Murch, for instance, used the possibilities of mixing sound in the postproduction of APOCALYPSE NOW (Coppola, 1979) in such a way that - in the mind of the protagonist - the sounds of the city of Saigon turned into those of the jungle, and the sound of a ceiling fan into that of a helicopter.

Ben Burtt used the same technology differently: he created the sounds of alien creatures in STAR WARS (Lucas, 1977) by mixing various animal sounds (Whittington 2007: 25). Burtt also used the Nagra recorder: he took it out on a "hunt" for sounds in the vicinity of Los Angeles, in order to find sounds that he could use in the creation of the sounds of space ships and other vehicles in the film (Whittington 2007: 32). 


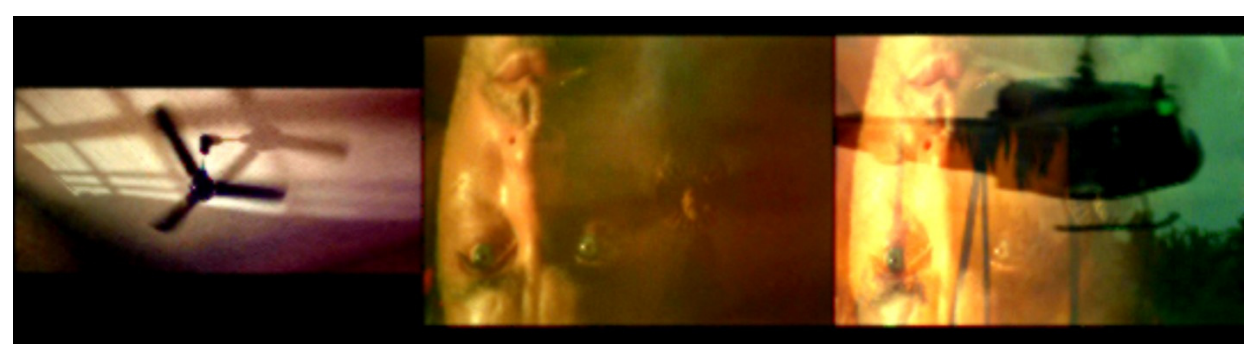

Illustration 3: In Apocalypse Now (Coppola, 1979) the sounds of a fan turn into those of a helicopter in the mind of Martin Sheen's protagonist, captain Willard

Movie theaters, meanwhile, had hardly invested in sound equipment since the 1950s, when the first stereo-systems proved not to be a lasting phenomenon. But in the second half of the 1970s, Dolby Laboratories developed technologies that offered noisereduction and "surround" sound. Movie theaters, especially the new multiplexes, installed these technologies in their auditoria, and, as a result, audiences could actually hear the innovations in soundtrack design of the popular films of these years (Handzo 1985: 418-425).

Unlike Eisenstein, Balász and many of their generation, the directors and sound designers who in the 1970s graduated from film schools were not film theorists. Nor was their attention to and treatment of film sound a reaction to the problematic role of sound in film theory. Both implicitly and explicitly, however, their work became the inspiration for a new group of theorists who engaged with film sound from the 1980s onwards. Implicitly, the innovations in the use of film sound - first in the French Nouvelle Vague and later in Hollywood - led to a new sensitivity for sound; a sensitivity that made it possible to recognize the inherent tension in Baudry's argument, and to develop new theoretical positions. The American film theorist Alan Williams did this when he revealed the falseness of Baudry's observation that "in the cinema one does not hear an image of the sounds, but the sounds themselves." Baudry's mistake, according to Williams, was that he considered film sound to be a reproduction of reality, rather than a representation, like the image. In the view of Williams, the material and spatial qualities of a sound recording render each one unique and different from the original (Williams 1980: 51-53). Two elements of Williams' argument are quite remarkable. First of all: whereas Arnheim used Gestalt theory to prove the visual essence of film, Williams refers to that very same theory to support his argument that film sound is - just like the image - a product of one's senses and the knowledge one already has (Williams 1980: 57-58). Second: in Williams' analysis of the role of sound in the dispositif - not rejecting Baudry's film theory entirely - he treats sounds as images. To establish this equality he uses the concept of attention: the microphone selects sounds for the audience just as the camera selects images (Williams 1980: 58$63)$. 
A similar argument has been developed by Rick Altman, who in the last decades has become the leading scholar on film sound. Altman emphasized what he called "the fundamental scandal" of the sound film, the fact that image and sound are presented in unity even though in reality they are different phenomena: "recorded by different methods, printed frames apart on the film, and reproduced by an illusionistic technology" (Altman 1980: 79). He compares film with a ventriloquist: the real origins of the sound are hidden in order to maintain the illusion (Altman 1980: 76-79).

The listening and viewing subject, the illusion and the dispositif continued to be the central concepts of film sound theory in the 1980s. Kaja Silverman, for instance, wrote extensively about the status of the female voice, from a psychoanalytic perspective. Mary Ann Doane and Michel Chion did the same, but for the voice in general. Their conclusions are similar: film sound is an integral part of the dispositif, and successfully cooperates in the co-construction of the filmic illusion by the viewer (Silverman 1988; Doane 1980; Chion 1982).

In the 1980s, the integration of film sound in classic Hollywood cinema was not only discussed by film theorists, but also by film historians, such as by Barry Salt, David Bordwell, Janet Staiger and Kristin Thompson. Although these film historians did not subscribe to the explicitly ideological conceptualizations of film, their conclusions did support the theoretical claim that sound was an integral part of the filmic illusion. They pointed out that after a short period of experimentation, sound was successfully integrated in the existing Hollywood style. To support this claim, they established that the average shot length of American silent films was equal to that of the sound films from the 1930s (Salt 1985: 37-43; Bordwell, Staiger \& Thompson 1984: 298-308). From a historical point of view, then, the introduction of sound had not radically altered the classical style of Hollywood cinema.

I already mentioned above that the films of the new directors of the 1970s (and the technological developments that made these films possible) were both implicitly and explicitly an inspiration for new film sound theorists of the 1980s. Implicitly they helped create a new sensitivity for sound that enabled the authors discussed above to develop new theoretical work. But the influence was also explicit. Rick Altman refers extensively to the work of Robert Altman, while Coppola's THE CONVERSATION (1974) is discussed by a number of authors, most notably Michel Chion (2009: 289). Sound designer Walter Murch was interviewed about his work on APOCALYPSE NOw, and in turn wrote the foreword to Chion's study Audio-Vision: Sound on Screen (1994). Finally Stephen Handzo has attributed the success of Dolby "surround sound" to the popular success of STAR WARS (Handzo 1985: 423). It would be wrong to suggest, however, that only the work of New Hollywood directors found an academic interest. Old masters such as Hitchcock, Lang and Luc Bresson, and avant-garde favorite Godard received their share of the attention as well (Weis \& Belton 1985: v-viii).

This second phase in film sound theory was concluded with the publication of the edited volume Sound Theory, Sound Practice (Altman [ed.], 1992). In his introduction to this volume Rick Altman states that the work done in the 1980s was strongly text-oriented, 
and that it is necessary to develop a broader perspective on film sound. Such a perspective, one that would approach film in the context of its material existence in a three-dimensional world, would benefit from a conceptualization of film as event. "Film as event" ties together the textual and contextual tradition of Film Studies, paying equal attention to the texts and the contexts of production and reception (Altman 1992a: 1-2):

Floating in a gravity-free world like doughnut-shaped spaceships, cinema events offer no clean-cut or stable separation between inside and outside or top and bottom ... In this three-dimensional Moebius strip world, the textual center is no longer the focal point of a series of concentric rings. Instead, like the pinhole at the center of an hourglass, it serves as a point of interchange between ... the work of production ... [and] the process of reception. (Altman 1992a: 3)

Sound Theory, Sound Practice, with "film as event" as its central theoretical concept, inaugurated a performative turn in Film Sound Studies. This performative turn led to a stronger contextualization and historicization of film production conditions and film exhibition circumstances. Essential to the concept of the performative turn is a refinement of Williams' observation that every recording of a sound is materially and spatially unique. In one of his chapters in Sound Theory, Sound Practice Altman states that the recording of a sound has two "spatial signatures": one of the space of recording and one of the space of playback (Altman 1992b: 23-28). This insight has had a number of significant consequences for theoretical work. Sound scholars began to recognize that the represented sonic space of film did not necessarily correspond to the represented visual space. The spatial relation between the camera and the represented object often differed from the spatial relation between the microphone and a sound source. Basing his argument on discussions among sound technicians, published in trade journals in the 1930s, Altman shows how, after the introduction of the sound film, there were two models for representing the human voice in Hollywood. The first model positioned the microphone near the camera, thereby creating an artificial, anthropomorphic spectator with whom the audience could identify. In this model the sound perspective respected the spatial characteristics of the perspective of the image. This came at the cost of dialogue intelligibility, though. Therefore a second model was developed, in which the microphone was positioned closely to the actor, and thus did not use the perspective of the image for the sound (Altman 1992c).

Interestingly, Altman, in 1992, still attempted to integrate this sound perspective in the model of the dispositif, arguing that sound, because it was always in close-up, anchored the spectator in a fixed position, thereby releasing the camera to move about freely (Altman 1992c: 62). The construction of the subject therefore takes place through the use of sound, and despite the mobility of the image. This is a curious reversal of Baudry's argument. After all, Baudry argued that it was the recreation of Renaissance perspective in cinema, a visual strategy, which created an ideal viewing position and a passive subject. 
The recognition of the second "spatial signature" of film sound, the one of the playback space, enabled theorists to direct their attention towards the context of exhibition. The perception of the sound perspective chosen by filmmakers is always influenced by the place of exhibition: a luxurious picture palace with early stereo sound offers a different acoustic environment for the reproduction of film sound than an outdated neighborhood movie theater, a modern multiplex with surround sound, a living room television set (with or without surround sound) or, for that matter, a laptop with headphones.

The performative turn is characterized by a number of related developments in the theoretical and historical study of film sound. The attention for the second spatial signature of film sound offered a new analytical perspective on those film events that did not have a first spatial signature: the silent films from before 1927. This perspective is well-documented in The Sounds of Early Cinema (ed. Richard Abel \& Rick Altman, 2001) and Silent Film Sound (Altman, 2004). These studies reveal that the acoustic environment of "silent film" was anything but silent. Orchestras and individual musicians (who improvised or used specially composed film music), traveling lecturers, actors reading dialogues behind the screen and audiences singing along with songs make early cinema a fascinating object of study for film scholars. The performative turn led to a new understanding of the term "silent film": the fact that early cinema was declared silent after the introduction of film sound (Chion 1999:7) was rather the result of a suddenly appearing, selective deafness in film theory than of a shortcoming in a primitive medium. Until the conceptualization of the second spatial signature of film sound, the actual auditorium was a no-go area for film scholars.

But the recognition of the second spatial signature in film sound studies did not only lead to an interest in silent film sound. It also drew attention to other technological developments in film sound, for instance the introduction of Dolby (stereo) surround sound technology in the 1960s and 1970s. Gianluca Sergi has extensively documented the history of this company and the technologies it produced for the film industry (Sergi 2004). Also, John Belton has written in detail about earlier, unsuccessful, attempts at adding stereo sound to the new format of widescreen cinema in the 1950s (Belton 1992). Finally, Mark Kerins, in a recently published study on film sound in the age of digital surround sound, pays attention to the way sounds are "placed" in the auditorium by filmmakers in order to create new spatial relationships between image and sound (Kerins 2010).

\subsection{Theorizing the digitization of film sound}

Looking back, the performative turn in film theory was inspired more by a contextualization and historicization of film than by critical reflection on new film sound technologies or production practices. This confronts us with an interesting phenomenon, as earlier debates on film sound apparently did have a relationship with the introduction of new technologies and practices. The "big change" to which film 
sound theory in the 1990s would be expected to relate is the digitization of film production, distribution and exhibition.

Back in 1985, Stephen Handzo referred to the use of several digital technologies (each of which has meanwhile grown out-dated) as a development to materialize in the (near) future (Handzo 1985: 424). Nowadays it is impossible to think of film production, distribution and exhibition without digital technologies. This development also forces us to think of film beyond the movie theater: DVDs and the internet are now often used to see films at home. And also: to listen to them, considering the central role of the sound system in home cinema (Nowell-Smith \& Thomas 2003: 6). However, theoretical reflection on the effects of the digitization in contemporary film culture mainly concerns the image. ${ }^{13}$ This is true to such degree that a widely used handbook in New Media studies discusses digitization only in relation to visual culture (Lister et al. 2003: 97-163). A central theme in this debate is the loss of indexical referentiality. ${ }^{14}$ This term refers to the physical connection that used to exist between a photographic image and the object photographed: the imprint left by light on a chemically treated piece of nitrate or celluloid (Bazin 2004 [1946-57]: 13). The word "indexical" is derived from the "index," one of the three types of signs identified by the American semiotician Charles Sanders Peirce. An index is a sign that represents its signified by virtue of a "real connection" to it (Peirce 1998 [1909[: 460-61). The possibilities offered by digital technologies to create images out of nothing (CGI or Computer Generated Imagery), pioneered in for instance JURASSIC PARK (Spielberg, 1993), exemplify this loss of indexical referentiality.

What goes unmentioned in most discussions about digital cinema is that this loss occurs on the soundtrack, be it optically photographed or magnetically recorded, as much as in the image. The sounds made by dinosaurs in JURASSIC PARK, for instance, were created in almost the same way as those of the aliens in STAR WARS; as a combination of existing animal sounds. However, the dinosaur sounds of JURASSIC PARK were not only mixed in the computer, but also materially transformed to the extent that the indexical referentiality, the physical link with the original sounds, was lost. ${ }^{15}$

But how should we theorize film sound and digitization? What does the loss of indexical referentiality mean for recorded sound? And, with respect to my own research, does it influence the way we can think about the relationship between a pro-filmic sound and its representation? In my view, there are two approaches to this subject. The first one denies the importance of indexical referentiality for understanding film at all, even before the introduction of digital technologies. This is a position taken by media

\footnotetext{
${ }^{13}$ Perhaps this relative lack of interest in digitalization, amongst scholars of film sound, is the result of the already existing realization, since the 1980 s, that the recorded sound is not an exact reproduction of an original sound, regardless of the existence of indexical referentiality. Bordwell \& Thompson (2001 [1979]) emphasize the importance of fidelity; the question of whether or not a sound "matches" its suggested source in the image: "If the viewer takes the sound to be coming from its source in the diegetic world of the film, then it is faithful, regardless of its actual source in production. Fidelity is thus purely a matter of expectaction" (Bordwell \& Thompson 2001 [1979]: 304).

${ }^{14}$ See for instance Minnis (1998), Rodowick( 2007) and McNeill (2010).

${ }^{15}$ See THE MAKING OF “JuRASSIC PARK” (Schultz, 1995).
} 
scholar Lev Manovich and film historian Tom Gunning. The second approach starts from the argument that referentiality does not necessarily have to be indexical. I will relate both of these approaches to recent theoretical work on film sound, by James Lastra and Steve J. Wurtzler, despite the fact that both these authors focus on the introduction of film sound in the late 1920s and early 1930s.

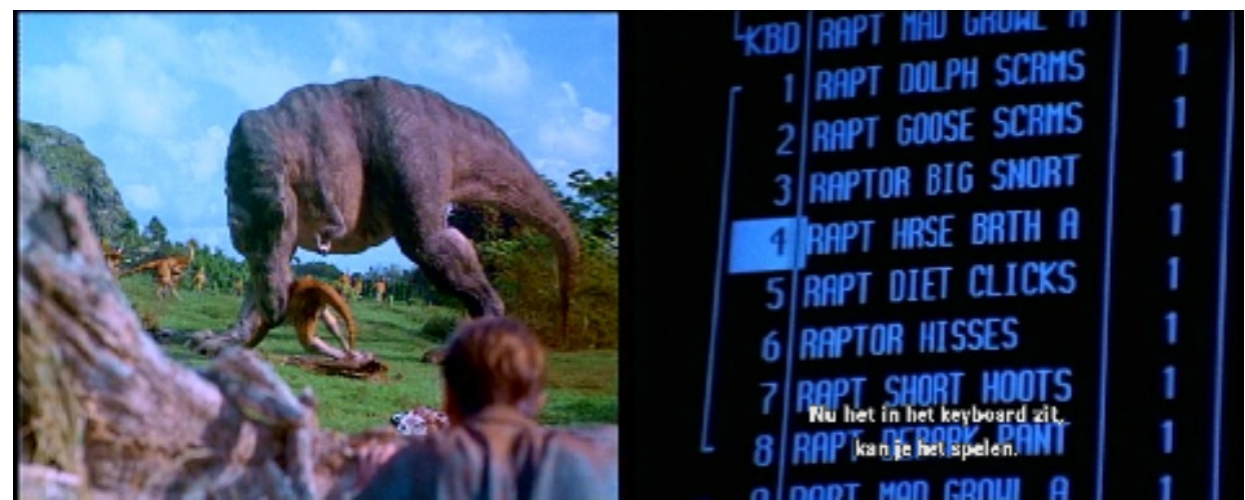

Illustration 4: The "dinosaur sounds" of Jurassic Park (Spielberg, 1993) were stored and edited digitally

New Media scholar Lev Manovich has argued that film is the successor of painting, not of photography. Following the introduction of Computer Generated Images in Hollywood action films, Manovich claims that live action film is but one component of digital film-making. Other elements are computer animation, painting, compositing and image processing, all of which do not rely on indexical referentiality (Manovich 2010 [2001]: 245-54). Film historian Tom Gunning takes the argument one step further by suggesting that the concept of indexical referentiality offers a very limited understanding of Charles Sanders Peirce's semiotic system. According to Gunning, it is not very useful for understanding film as a realist art form (Gunning 2010 [2007]: 25658). In a conscious and deliberate reference to pre-1960s essentialism, he proposes that the defining characteristic of film is motion. This is more a phenomenological than an ontological claim, as he emphasizes the importance of the experience of motion. And rather than arguing for a realist aesthetic, as Bazin would have done, he offers a "theory of the impression of reality" (Gunning 2010 [2007]: 265).

The question is now how these arguments relate to film sound. I would suggest it is instructive to link up the work of James Lastra with these positions regarding the digitization of film, even though Lastra discusses the early history of sound recording technology. On the subject of film sound as a representation of an original, rather than a reproduction, James Lastra mostly agrees with Alan Williams and Rick Altman (Lastra 2000: 124-28). He labels these scholars as "non-identity theorists" because they view the original sound and the recorded sound as not identical. However, he criticizes them for suggesting that there is such a thing as the original sound in the first place (Lastra 2000: 150). Lastra argues that even in the presence of an original sound event, for 
instance a classical concert, the position taken in by the listener is already one position out of many possible ones, and that another listener at another place in the same concert hall hears a different concert, in a strictly material sense (Lastra 2000: 151). This is an argument already inherent in Altman's discussion of the construction of sound space in film, but Lastra makes it explicit and theorizes its implications. Lastra suggests that we should not think of film sound in terms of the tension between the original (which in his opinion has never existed) and the copy, but regard it as a process similar to that of writing. By thinking about sound as writing we can focus on "effects" of authenticity and immediacy as produced by film technique and technology (Lastra: 152-53).

In my opinion Lastra's theory can be understood to correspond to Gunning's argument. Both move away from the original/copy issue to focus on the production of realistic experiences. ${ }^{16}$ The digitization of film does not force us to account for the loss of indexical referentiality in image and sound but allows us to think of all film, analogue and digital, as processes that aim to produce reality-effects. Most importantly, Gunning emphasizes the experience of motion by the audience as the defining characteristic of cinema, rather than the representation of motion. He stresses the importance of the audience's participation in the filmic experience, and thus acknowledges the significance of the space of the exhibition of film: its second spatial narrative (Gunning: 2010 [2007]: 265-67). The one comprehensive work on film sound in the digital era, Mark Kerins' Beyond Dolby (Stereo) (2010) also focuses on this space. Kerins shows how the new technology of digital surround sound enables filmmakers to "place" sounds in the auditorium, around the audience, thereby creating new spatial relations between image and sound. These new relations sometimes break with the conventional "continuity system" of popular cinema, but nevertheless confirm the unity of the represented space (Kerins 2010: 109-11). ${ }^{17}$

This approach to film sound in the digital age, emphasizing reality-effects and the participatory experience of film, is interesting, yet not sufficient in my opinion. A realistic experience and the reality-effect still rely on a correspondence to the "real" world, at least as it is imagined by the makers and the audience. This is especially important for films which are set in existing locations, such as modern cities. It might well be misleading to think of original sounds and copies, or to rely too heavily on the concept of indexical referentiality, but there is a relation between urban soundscapes and their representations in fiction film. This relation is absent from Lastra's theory. A more productive way to think of film sound, for this study at least, is suggested by an

\footnotetext{
${ }^{16}$ One would expect to see a reference to or discussion of Walter Benjamin's "The Work of Art in the Age of Mechanical Reproduction" in Lastra's chapter on sound theory. Curiously, there is none. Nor is Benjamin's work mentioned or referred to in Alan Williams' article (1980) or any of Rick Altman's articles and chapters referred to in this chapter.

${ }^{17}$ The continuity system is a concept that is used to refer to the organization of cinematic pace in classical Hollywood Cinema. Bordwell \& Thompson state that: "the basic purpose of the continuity system is to create a smooth flow from shot to shot" (Bordwell \& Thompson 2001 [1979]: 262). By presenting the cinematic space, through camera positioning, as unified and continuous, the filmmakers make it possible for the audience to follow the narrative without being disturbed by changes in the camera position between shots.
} 
observation by Gunning. If to me it seems a crucial insight, he does not pursue it any further. He argues that in Film Studies the index has been largely abstracted from Peirce's semiotic system, and is simplified. There are other types of signs, argues Gunning, and furthermore: "Peirce ... by no means restricts the index to the impression or trace" (Gunning 2010 [2007]: 256).

Charles Sanders Peirce distinguished between three types of signs in his system of semiotics: index, icon and symbol. As mentioned above, an index refers to its signified because it has a real connection to it. For instance: smoke signifies fire. An icon is a sign that references its signified because of a formal resemblance between the sign and the signified, like recognizing that it is a woman that has been painted from her resemblance with women. The relation between a symbol and its signified, finally, rests entirely upon cultural convention (Peirce 1998 [1909]: 460-61). An example would be a red traffic light, which signals "Stop!" When film scholars, following Bazin, mentioned the "indexical referentiality" of film and photography, they always referred to the material trace left on the celluloid by the combination of chemicals and exposure to light. However, Gunning offers a wider interpretation of Peirce's semiotic system. According to Gunning, the index can be anything that focuses attention (Peirce quoted in Gunning 2010 [2007]: 255-56). We can imagine that a person in the street, pointing up at a flying Superman functions as an index, even though there is no "real" connection between the two. The lesson that we can learn from Gunning's wider interpretation of Peirce's semiotics, is that films and film sounds can directly signify the "real" world without there being a physical relationship between the representation and the represented object; the pro-filmic event.

A similar argument can be read in Steve J. Wurtzler's book Electric Sounds: Technological Change and the Rise of Corporate Mass Media (2007). He grasps the two opposing models of constructing sound space in fiction film, which were previously discussed by Rick Altman, as models of transcription and signification. The former model presupposes the reproducibility of the sound event, and the latter model suggests the creation of a new sound perspective which "signifies" the diegetic world. Wurtzler lifts the debate out of the discourse of film sound phenomenology or ontology, and suggests that the transcription and signification paradigms are epistemological rather than phenomenological or ontological: they operate on the level of perceived relationships between technology and a phenomenal world, appearing in the realms of rhetoric, faith and discourse. So instead of studying film sound (or electric sound in general), Wurtzler zooms in on the discourse surrounding innovations in sound technology (Wurtzler 2007: 229-31). Because of his wider focus he is able to discredit the suggestion of Altman and Lastra that the realism/transcription model of film sound was inspired by the phonograph industry and that the intelligibility/signification model was based on practices of transmission in the telephone industry. Looking at multiple sound technologies throughout the twentieth century, Wurtzler argues that all sound media have been marked by tensions between these two models, and equally important, that the, eventually, conventional model for creating sound space in fiction film was not 
a victory of one model over another, but a fusion of the two models into a new one that simulated the perception of a sound event (Wurtzler 2007: 268-78). This fusion model, Wurtzler calls signifying fidelity:

This model for acoustic representation sought to use the creative potential of electrical sound technology to signify a mimetic relationship to an (often nonexistent) original sound event. (Wurtzler 2007: 18)

Like Lastra's study, Wurtzler's argument is not about digital technologies. But in the absence of satisfying models for understanding digital film sound's relationship to its "originals" there is much to learn from these theories of early film sound. In today's multimedia landscape of emerging media technologies, Wurtzler actually identifies a modern-day relevance for his study of a similar period in the early twentieth century (Wurtzler 2007: 11).

Wurtzler's model of film sound is one that acknowledges the constructivist character and the creative potential of film sound as well as its mimetic relationship to a (possibly but not necessarily non-existent) original sound event. It is in this model that the material reality of a city and its "original" soundscape can be an important factor in the successful creation of a reality-effect. The metaphor of the enhanced echo, which I use to conceptualize represented soundscapes, similarly relies on a mimetic relationship between a representation and the thing it represents.

\subsection{Conclusion}

The metaphor of the enhanced echo covers more than the relationship between an original sound event, its recording and its playback. As I have suggested in Chapter 1, and as I will demonstrate in the following chapters, film soundtracks also echo people's sensibilities to and opinions about sound. The enhanced echo also flags the role of staged and mediated sounds in conserving cultural heritage and constructing urban identities. And it can help us to understand intertextual and intermedial connections in the staging of sound - for instance in the adaptation of novels into sound films or radio plays.

The first part of this chapter revealed yet another use for the concept of the echo. Before I discussed the theorizing of film sound in the digital era, I outlined the histories - be it briefly - of film sound technology and production practices and of film sound theory; and I pointed out how these two contextual levels were oftentimes connected. We can understand these moments of connection as echoes. The use of film sound technology by filmmakers has echoed ideas about the essence of film and about film as art, as well as ideas about the relationship between image and sound. As will be pointed out in Chapter 4, for instance, Fritz Lang's use of sound in his first sound films echoed formalist ideas about film and sound.

Similarly, theorists of film sound have responded to and been inspired by new artistic and stylistic choices that were enabled by developments in technology and 
production practices. When sound equipment became lighter and more mobile, and filmmakers shot more and more on location, Realism became the dominant theoretical perspective in film theory. The use of new recording and mixing technologies in popular American cinema in the 1970s rekindled an interest in film sound among film theorists, who were by now part of academia.

After the institutionalization of Film Studies, clear connections between film sound theory and production practices have become harder to distinguish. Film scholars do not make films, and filmmakers are not involved in academic debates. ${ }^{18}$ Likewise, filmmakers are unlikely to design the soundtrack to their new blockbusters with a copy of Rick Altman's Sound Theory, Sound Practice in their hands. More surprisingly, perhaps, is the relative lack of attention paid by film sound scholars to the processes of digitization that have transformed film in the last two decades. But connections are still there, even if they are more often implicit than explicit. For this reason, the versatile and flexible concept of the echo is so useful in understanding these connections. Echoes can be made intentionally, but they can also happen accidentally, inevitably even. Beginning students of sound at the Dutch Academy for Film and Television are provided with a reader in which the role of sound in film is explained to them, with references to texts by Rick Altman, James Lastra and Michel Chion (Zijlstra 2010: 97). Their interest in film sound is probably not academic. But when they have finished their studies and move out into the world as film sound designers, they have read that the "original" sound does not exist. And in future Dutch films we may therefore hear an echo of Lastra.

This leads me to conclude the following: production practices can echo film culture, and vice versa. But the point where the echo comes into being, the material surface from which a sound wave reflects (so to speak, in this case), is still the film itself. Films must therefore be the primary object of our analysis and investigation, if at least we are to understand the staging and mediation of urban sounds in fiction film. Film culture and technology and production practices, but also politics and the intention to create effective reality-effects, can help us understand and explain changes, continuities and developments in these stagings and mediations. But in the following four chapters, which investigate the representation of the soundscapes of Amsterdam, Berlin and London in fiction film, the films themselves will each time serve as point of departure.

\footnotetext{
${ }^{18}$ Apart from an incidental exception, like sound designer Walter Murch, who wrote the foreword to one of Michel Chion's books.
} 


\title{
Chapter 3
}

\section{Big Village or Small City? The Soundscape of Amsterdam-in-film}

\begin{abstract}
Amsterdam - to me it means lots of gazing along the canals, familiar small cafés and of course hearing barrel organs everywhere. (Doolaard 1963: 4) ${ }^{19}$
\end{abstract}

\subsection{Introduction}

In this chapter I present the results of my case study on the staging and representation of Amsterdam's soundscapes in fiction films produced between the 1930s and the 1990s. Unlike what one might expect when focusing on urban sounds, Amsterdam has not been staged as an increasingly noisy metropolis. In contrast, its representation has shifted intriguingly from "big village" in the 1930s, to a "city proper" in the 1970s and to a "big village" once again in the 1990s, albeit a village displayed with a remarkable twist. I will substantiate my argument with help of both a quantitative and qualitative analysis of the use of different types of sounds in the staging of Amsterdam-in-film. Moreover, this chapter will foreground the quantitative analysis of sources of sound. Doing so allows me to elaborate on the ins and outs of this approach, while later chapters will build on this by combining it with a quantitave and qualitative analysis of narrative functions. My quantitative film analysis resulted in unexpected findings. One of these findings was a decline in the employment of traffic sounds - after an initial increase - in the 1990s, and a rise of the use of "typical" Amsterdam soundmarks, after many years of decline, in that same era. This counterintuitive finding prompted me to ask additional questions that could only be answered through a qualitative analysis of the narratives in which these sounds of Amsterdam-in-film prefigured.

In the sections below, I will discuss various types of sounds and their roles in articulating the changing identity of Amsterdam. First I examine the use of traffic sounds and background sounds, and explain their function in relation to filmmakers' attempts to create reality-effects. Constituting the first contextual level of my analysis, a focus on reality-effects also means taking into account the technological resources available to filmmakers, and the dominant production practices in the industry, which constitutes the second contextual level in this study. I will show how changes in these production practices affected the options for creating reality-effects, and thus the representation of Amsterdam soundscapes in fiction film.

\footnotetext{
19 "Amsterdam - dat wil zeggen, veel kijken langs de grachten, het bekende kroegje en het eeuwige draaiorgel niet te vergeten."
} 
Subsequently, I will discuss the soundmarks of Amsterdam-in-film. These are sounds that, in the words of the Canadian composer and acoustic ecologist Raymond Murray Schafer, are typical, or in some cases even unique for a particular place and meaningful to the people living there (Schafer 1994 [1977]: 264). Examples relevant for Amsterdam are the church bells of the Westerkerk, barrel organ sounds, folk musicians performing in the streets, the ringing of bicycle bells and tram bells. As it turns out, the appearance of these soundmarks in Amsterdam-in-film decreases between the 1930s and the 1970s, but they make a modest comeback in the 1990s. Over time, then, these soundmarks can be said to have evolved into sonic icons of Amsterdam-in-film. The quantitative variations in soundmarks (and sonic icons) are linked to different interpretations of these sounds over the years. I argue that these interpretations signify representations of Amsterdam that are at odds with the myth of the cinematic city as discussed in the first chapter.

In a final section I will discuss the representation of Amsterdam in fiction film in relation to international cinema, and in relation to processes of globalization after the Second World War. This international perspective allows us to see that the identity of Amsterdam-in-film does not simply change from that of a big village into that of a small city and vice versa, but that the tensions between the local and the global are appropriated in such a way that Amsterdam is represented as a glocal village. While the concepts of the "modern," the "global" and the "city" reflect one end of the representational spectrum of the filmic city, and the "traditional," the "local" and the "village" refer to the other end, these rather straightforward oppositions are themselves part of the myth of the cinematic city - a myth that, as I will propose, is actually in need of revision.

\subsection{Traffic sounds, background sounds and the reality-effect}

In the twentieth century, as we know from the historiography of sound, traffic sounds were the most extensively debated city sounds in the public arena. Already in the century's early years, intellectuals such as James Sully, Theodor Lessing and Dan McKenzie raised concerns about the "increase of nervousness as a consequence of the new urban sensory experiences enabled by motorized traffic" (Bijsterveld 2001: 47). In the 1930s this particular dramatization of traffic sound resulted in a wide array of antinoise activities campaigns all over Europe and the United States, in which traffic was considered the worst of all sources of noise (Bijsterveld 2001: 38; Thompson 2002: 117-18).

It is against this background that I have focused my quantitative analysis on Urban Sound Events (USEs), among which traffic sounds were one relevant category. How did the staging of such sounds in films set in Amsterdam develop over time? Given the public concerns about traffic sound in modern cities, it comes as no surprise, perhaps, that these sounds constitute a large category in the USEs registered for the films on 
Amsterdam. Cars, trains, trams, motorcycles and airplanes are dominant in the filmic representation of this city's public space. In the 1930s, traffic sounds make up $41.5 \%$ of all counted USEs. In the 1950s, this percentage is still fairly similar to the $1930 \mathrm{~s}$ (42.2\%), yet slightly rises to $46.7 \%$ in the 1970 s. Interestingly, the 1990 s display a decrease of traffic sounds to $37.6 \%$ (Annex D, Table 1).

It is important to note that when speaking about traffic sounds, I only refer to discrete sounds that can be attributed to identifiable sources in the diegetic film world, such as an airplane flying over or a car horn in the distance. When watching and listening to films, however, it is not possible to identify all traffic sounds as such discrete sounds. In addition to discrete sounds, filmmakers also use non-discrete ones. Frequently, these background sounds (called "ambience" by film sound technicians) are a mix of various sounds that are not clearly identifiable individually. The blur of traffic may figure as a major source of such background sounds.

In the films in my sample, the percentage of Urban Sound Events categorized as background sounds increases substantially from the 1930s (8.8\%) to the 1950s (25.3\%), while in the 1970s and 1990s this percentage roughly remains at the same level. In my sample, Amsterdam is thus not portrayed as an increasingly noisy metropolis, but as a location in which the relative presence of traffic sounds and indiscriminate background sound first increases after which, in the 1990s, it decreases again. How to understand this somewhat unexpected outcome, that is: unexpected in relation to the modern and postmodern myths of the cinematic city? How to understand the large increase in background sounds in the 1950s, and the subsequent stability in their presence until the 1990s? And what can clarify the diminishing dominance of traffic sounds when we compare the 1990s to the 1970s? If Amsterdam was staged in a way that contrasts with preconceived notions of city life, why did this happen? Answers to these questions can be found in filmmakers' desire to achieve a reality-effect, technological developments in film sound recording and changes in film-making practices.

Let me first return to the distinction between discrete traffic sounds on the one hand, and background sounds on the other. For composer and environmentalist Raymond Murray Schafer, author of The Soundscape (originally published in 1977), background sounds form the "keynote sounds" of a particular soundscape, its basso ostinato. The opposite of keynote sounds are "foregrounded sounds": sounds that "are listened to consciously" (Schafer 1994 [1977]: 10). In addition to this musical perspective, Schafer also uses an acoustic ecologist approach. In this perspective, he discerns hi-fi and lo-fi societies. In pre-industrial hi-fi societies the signal-to-noise ratio is more favorable than in industrial, lo-fi societies. Whereas in the past, many sounds were clearly discernible from each other, today's soundscapes acoustically mask many former signals (Schafer 1994 [1977]: 43). When looking at (and listening to) Amsterdam-in-film, a similar development can be seen: we detect a clear increase in the background sounds from the 1930s to the 1950s (Annex D, Table 1). In other words, filmmakers increasingly staged Amsterdam-in-film as a lo-fi environment. The relative stability of presence of these background sounds in the following decades suggests they can be interpreted as keynote sounds in the filmic staging of Amsterdam. Background sounds de facto obscure signals 
and make the city-in-film noisier. This noisiness, it seems, has become a keynote sound of the urban environment, both in real life and in film. We have become so familiar to these background sounds, that their absence would immediately be noticed. This is what the German filmmaker Fritz Lang had in mind when he avoided the use of any unmotivated background sounds in his first sound film M - EINE STADT SUCHT EINEN MÖRDER (1931). As a result Berlin sounds eerily and unnaturally quiet in this film (Vogt 2001: 241).

Despite Lang's objections, it has gradually become standard practice in film production to situate a scene at a particular location through the use of proper "ambient sound," also defined as "the sonic background of a scene" (Sonnenschein 2001: 38). This does not mean that background sounds are recorded together with the other sounds. In this respect, Stephen Handzo has pointed out that "in making dialogue recordings ... ambient sound is never wanted" (Handzo 1985: 395). Moreover, even when separately recorded, ambient sounds do not need to be recorded at the place and time to which they refer. What became important in film-making was that ambient sounds needed to speak to the idea audiences were supposed to have of the place and time in which the film was situated (Sonnenschein 2001: 38; Watters quoted in Sonnenschein 2001: 207). The use of ambient sound is meant to create a reality-effect, which Roland Barthes defined as the significance of the insignificant elements of a narrative. In discussing the concept, he asks:

Is everything in the narrative significant, and if not, if insignificant stretches subsist in the narrative syntagm, what is ultimately, so to speak, the significance of this insignificance? (Barthes 1986: 143)

The answer to Barthes' rather abstract question lies in his understanding of a sign. According to Barthes, a sign consists of a signifier (a word on a page, for instance) and a signified (the meaning of that word in a language) (Barthes 2000 [1957]: 112-13). "Insignificant stretches of a syntagm" (a structuralist synonym for "sentence") are signs from which the signified is "expelled." Barthes attributes to the signified the function of integrating the sign into a system of signs, of bestowing meaning and structure onto it. The signified, in other words, shows the constructed status of the text. The absence of the signified in "insignificant stretches of syntagm" is the very signifier of realism. Insignificant stretches of syntagm are insignificant because they do not need meaning. They do not represent a reality; they are presented as real (Barthes 1986 [1968]: 14648).

What are the implications here? Based on Barthes' differentiation, background sounds, which can be interpreted as insignificant for the execution of the plot or the telling of the story, help to create a reality-effect. Those sounds, exactly because they are there even though they do not necessarily have to be there, add a sense of realism to the fiction. This is, ultimately, their "significance." Fritz Lang only wanted background sounds when they contributed something to the action, but when they do, it seems, they stop being background sounds proper, and they no longer produce a reality-effect. 
If we now link the actual presence of traffic in Amsterdam in the twentieth century to the wish to create reality-effects by filmmakers, the initially counterintuitive staging of urban sound in films set in Amsterdam becomes more understandable. Between 1930 and 1950, the number of cars and trucks registered in Amsterdam increased slightly from approximately 15,000 to 20,000 . During the 1950s and 1960s, however, these numbers skyrocketed, going from 75,000 in 1960 to 160,000 in 1970 (Nelissen and Schmal 1980: 225). The increase of discrete traffic sounds in films from the 1950s to the 1970s can thus be explained from the link between the sonic ecology of Amsterdam and the reality-effect sought after by filmmakers. Similarly, the decrease in traffic sounds in film witnessed for the 1990s in comparison to the 1970s can be related to the effectiveness of measures to make the inner city of Amsterdam "car-unfriendly" (Gemeente Amsterdam 2009: 5-6, 12).

This explanation does not yet account for why background sounds increased so sharply in the 1950s. Had Amsterdam suddenly become a noisier place in the perception of filmmakers and audiences? It is hard to say without having interviewed filmmakers active in the 1950s. But a look at the developments in film sound technology and film-making practices may offer an alternative explanation for the aforementioned increase. Because these technologies and recording practices have been subject to considerable changes, it is safe to assume that, over time, the dispositif of film has produced different reality-effects. As I argue below, this is one possible explanation for the considerable increase in background sounds from the 1930s to the 1950s.

When the first Dutch sound films were made, in the 1930s, the sound recording equipment was large and heavy and had to be stored in a truck (Whittington 2007: 31). This made filming on location expensive, and less attractive than filming in a studio. Moreover, various parties had invested considerable sums of money in building studios with sound stages in the early 1930s (De Groene Amsterdammer 29-07-1933: 13; Dibbets 1993: 218-19). For the film BLEEKE BET, for instance, an entire Jordaan neighborhood street had been reconstructed in the Cinetone Studios in Duivendrecht (Amersfoortsch Dagblad/De Eemlander 26-05-1934: 14). In case of such studio productions, every single sound had to be recreated, or added during post-production. Reasons of economy thus prompted filmmakers only to use those individual sounds that were considered crucial for the film's atmosphere or plot.

In the 1950s, the recording equipment had become less heavy and more mobile, making location shooting more attractive. This is noticeable in the first Dutch color film, JENNY (Van Hemert, 1958). The use of typical locations did not go unnoticed to film critics: "The director goes out of his way to open up a picture book of Amsterdam" (Leeuwarder Courant 19-04-1958). ${ }^{20}$ And also: "Now and then it seems as if Van Hemert is in love with the beautiful "pictures" that he saw" (in Dagblad voor Amersfoort, 21-02-1958: 6). ${ }^{21}$ These reviewers seem to have ignored, however, that the move to location shooting also had audible consequences. It was the rise of location

20 "De regie gebruikt die omwegen om een prentenboek van Amsterdam voor ons open te slaan."

21 "Zo nu en dan lijkt het of Van Hemert verliefd was op de mooie "plaatjes" die hij zag..." 
shooting that explains the increase in background sounds in the films of the 1950s: as soon as shooting on location became easier, sound recorders picked up the background sounds of the city, which could not be prevented by, for instance, closing a street (which would keep unwanted traffic out of the film image). Moreover, the options for mixing the soundtrack in post-production had increased significantly by the $1950 \mathrm{~s}$, making it possible for sound editors to include background sounds without ruining the comprehensibility of dialogue. Stephen Handzo describes how in the United States the maximum number of tracks that could be mixed increased from four in the 1930s to twelve in the 1940s (Handzo 1985: 414). The situation differed in the Netherlands, however. In the 1930s, American and German film manufacturers divided the world's film market between them. This implied that filmmakers in the Netherlands (in the 1930s) had no choice but to work with the German Tobis-Klangfilm equipment. As Douglas Gomery has suggested, this "established an important technological constraint for European Film-making” (Gomery 1976: 61). If technologically Dutch cinema was probably not ahead of Hollywood, possibilities for mixing dialogue, music and ambient sounds would increase in the Netherlands as well. ${ }^{22}$

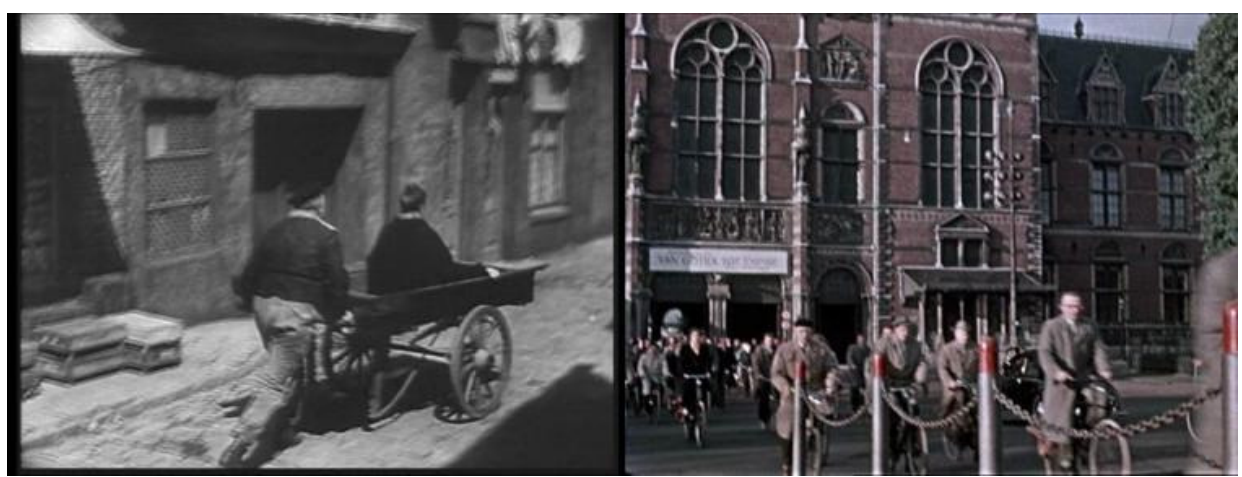

Illustration 5: A studio-built Jordaan street in Bleeke Bet (Oswald \& Benno, 1934), and location filming in front of the Rijksmuseum in Jenny (Van Hemert, 1958)

My quantitative analysis, through the identification of USEs, revealed which sounds can be heard in the soundscape of Amsterdam-in-film. However, if we then want to understand what these sounds meant - what roles specific, discrete sounds played in the narratives of fiction films - we also need a qualitative analysis. We can ask: how do characters in films experience traffic sounds? Or: how did filmmakers stage these sounds? Did this staging change and, if so, what does that tell us? Let me present the example of car sounds: In the 1930s, sounds associated with cars still seem to have a positive connotation. For example, in BLEEKE BET (Oswald \& Benno, 1934) an offscreen car horn signifies the arrival of a taxi, which causes excitement; traveling by car is a privilege linked to such special occasion as a wedding. And in PYGMALION (Berger,

${ }^{22}$ Personal interview with Georges Bossaers, 2011. 
1937) the arrival of a car in a poor neighborhood is accompanied by children's enthusiastic cheers, as it signifies the protagonist's upward social mobility. By contrast, in GEEN PANIEK (Koedijk, 1973) car drivers collectively sound their horns, displeased as they are about a traffic jam in which they have ended up.

A similarly striking example concerns the sounds produced by airplanes. The nuisance caused by airplanes from nearby Schiphol Airport has long been hotly contested in Amsterdam and its vicinity (Beekhuis 1966; Van Praag et al. 1997; De Zeeuw 1998). In the films under study, however, we do not find any representation of or reflection on these debates. As argued above, changes in the appreciation of car sounds were explicitly expressed in film. Cars were luxury items in the 1930s, and on screen their arrival was met with positive reactions, but by the 1970s traffic congestion led car drivers to sound their horns in disapproval. The representation of airplane sound in fact follows a similar pattern between the 1930s and 1970s: air travel was reserved for a rich uncle who arrived from the Dutch Indies, as in OP STAP (Winar, 1935), and in JENNY the sound of an aircraft signaled the arrival of a beloved boyfriend. However, in BLUE MOVIE (Verstappen, 1971), a film set in the Bijlmer - at the time, a newly built suburb of Amsterdam filled with large concrete apartment buildings - the sound of airplanes flying over mildly disturbs the main character. Next, airplane sounds disappear from Amsterdam-in-film, until they briefly but significantly reappear in JEZUS IS EEN PALESTIJN (Crijns, 1999). In this film, again situated in the Bijlmer, an airplane nearly crashes into an apartment block, only seven years after a real accident took place there (on October 4, 1992, when an El-Al Boeing 747 crashed, killing 43 people). If JEZUS IS EEN PALESTIJN offers the most explicit representation of airplanes and their sounds in Amsterdam-in-film after the 1950s, this film refers to the 1992 disaster and does not stage the nuisance caused by airplane sounds.

Strikingly, the sound of airplanes hardly features in Amsterdam-in-film, especially after the $1950 \mathrm{~s}$ (their share in traffic sounds decreases from $7.3 \%$ in the $1950 \mathrm{~s}$ to $0.8 \%$ in the 1990s), while in my sample their noise nuisance is not represented as an issue. This perhaps surprising absence - given the prevalence of airplane noise in public debates in the 1970s and the 1990s - may once again be linked to film-making practices: the sound of an airplane passing can ruin a recording and force the filmmakers to rerecord a scene (sound recordist Kees Linthorst, quoted in Linthorst 1988: 169). Background sounds and the sounds of other modes of transportation do find their place on the soundtrack, and because of the desired reality-effect they are even consciously placed there. But airplane sounds tend to be too loud and too disruptive. The Dutch actor Sylvain Poons recalled the following event from the set of DE JANTJES (Speyer, 1934):

They had closed off the entire Brouwersgracht, tying ropes to the trees ... and several thousands of people stood there watching. They had never seen anything like it. At that point Mr. Benno [the film's writer and producer] began to talk through his megaphone: "Ladies and Gentlemen, we are making the first Dutch sound film here, De Jantjes, and we ask you for your complete silence, 
as every meter [of film] lost will cost thousands and thousands of guilders. If a bit exaggerated, everyone was dead silent right away. Next, we rehearsed a scene eight, ten, twelve times, in beautiful weather, and just as we started the recording, a plane flew over our heads, at 2000 meters, and they weren't as quiet then as the ones today. Benno nervously threw his hands up in the air shouting: GO, GO, GO. Suddenly we had an uproar (Poons quoted in Van Gelder 1995: 11-12) ${ }^{23}$

Poons' testimony may be "a bit exaggerated" as well. His claim that "several thousands of people" watched eight to twelve rehearsals of a scene in dead silence seems unlikely. More important are the things disclosed by this anecdote about film-making practice in the 1930s: it was costly, and airplanes flying over could ruin a sound recording. Although today's airplanes either fly at higher altitudes ore are less noisy, sound recordists will still ask for a pause when hearing them flying over (Linthorst quoted in Linthorst 1988: 169; De Zeeuw 1997).

\subsection{The soundmarks of Amsterdam-in-film}

Traffic sounds, like those of cars, motor bikes, trains and airplanes can be heard in every major Western capital. But some sounds are tied to particular locations, such as the sound of the Big Ben, which is highly specific for London. Such sounds are "soundmarks" in the vocabulary of Raymond Murray Schafer (1994 [1977]: 9-10). It is important to make a clear distinction between soundmarks and sonic icons. The soundmark is a geographical concept: a sound that belongs to a specific place and signifies that place. Its location can be fixed, like church bells, or slightly more mobile, like the "horns or whistles" that Schafer mentions (Schafer 1994 [1977]: 239). The sonic icon is a historical concept. A sound may become iconic over time. Although its significance for a particular place or situation may not be obvious from the beginning, in the course of time it has come to signify more than just its immediate meaning. Once a sound has evolved into a sonic icon of a place it also signifies that place, and all qualities people associate with it. Soundmarks and sonic icons are different concepts, but a specific sound can be a soundmark of a city-in-film and become iconic for that city-in-film as well.

In my analyses of films set in Amsterdam I have identified five sounds of Amsterdam that can be considered soundmarks, which characterize Amsterdam as a

\footnotetext{
23 "De Brouwersgracht was helemaal afgezet, met touwen tussen de bomen ... en er stonden enige duizenden mensen te kijken, dat hadden ze nog nooit gezien. Toen ging meneer Benno een toespraak houden door zijn megafoon: mijne dames en heren, we maken hier de eerste Nederlandstalige film met geluid, De Jantjes, en wij verzoeken u doodse stilte te bewaren, aangezien iedere meter die verloren gaat, duizenden en duizenden guldens kost. Tikkie overdreven, maar het was meteen doodstil. Dan wordt zo'n scène acht, tien, twaalf keer gerepeteerd, doodstil, prachtig weer, en we zijn net met de opnamen begonnen, komt er op 2000 meter hoogte een vliegtuig over, en ja, ze waren niet zo geluidloos als nu, waarop Benno in zijn zenuwen met zijn handen in de lucht WEG, WEG, WEG, begint te roepen. Het was een tumult ineens."
} 
unique place. These soundmarks are: the sounds of tram bells, bicycle bells, the bells of the Westerkerk, barrel organs and local folk artists singing songs about Amsterdam, or performing in an unmistaken Amsterdam accent. Apart from the local singers, these sounds need some extra explanation. The Westerkerk is a church in the Jordaan neighborhood. This neighborhood, as well as the church and its sound, have featured significantly in Dutch films, especially in the 1930s. Although trams and bicycles are not unique to Amsterdam, the absence of an extensive subway system emphasizes the presence and sounds of trams and bicycles in the city (Honig 1996). Barrel organs are common in both Amsterdam-in-film and Berlin-in-film, but the appearance and sound of these instruments differ markedly in the two cities (De Waard 1971; Röhmer 1983) (Illustration 6).

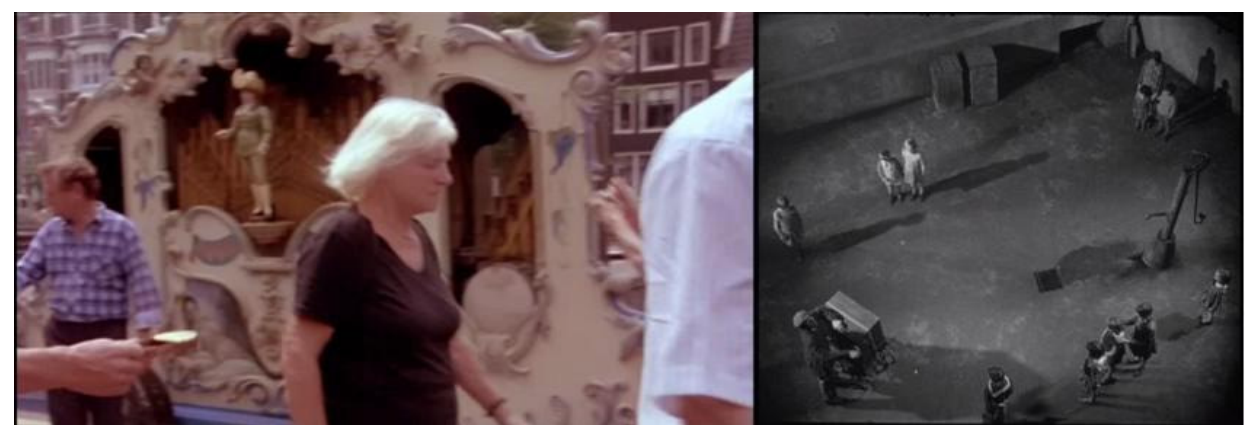

Illustration 6: A barrel organ in Amsterdam in AMSTERDAMNED (Maas, 1988) and a different one in Berlin in M-EINE STADT SUCHT EINEN MÖRDER (Lang, 1931)

As percentages of all Urban Sound Events, these five sounds were never omnipresent, but between the 1930s and the 1970s their presence even dwindled, showing a minor "comeback" in the 1990s (Annex D, Table 2). The stagings of these soundmarks in the 1990s (and incidentally already in the 1970s) emphasize the iconic character of these sounds, however. If we put these findings next to those indicating the increases in traffic sound and background sounds up until the 1970s, one could argue that, in the 1970s, the sounds typical for Amsterdam were drowned out by the emerging, globally homogeneous "city sounds." This is a convincing interpretation of the findings, but the context in which the remaining local sounds are presented in the 1970s and especially in the 1990s offers an extra level of meaning. But let me first elaborate on several of the local sounds as such.

Given the fact that the bicycle is a relatively silent and cheap mode of transportation, its gradual disappearance from the filmic soundtrack in an era of increasing wealth and car ownership is barely surprising. In JENNY (Van Hemert, 1957), the bicycle is presented as a women's mode of transportation, against the motorcycle and the car for men. And in MAKKERS STAAKT UW WILD GERAAS (Rademakers, 1960), the bicycle is 
staged as a poor man's vehicle. ${ }^{24}$ The bicycle strikes back in TURKS FRUIT (Verhoeven, 1973), in which it is represented as a rebellious and youthful alternative to the car. However, we do not hear the sound of its bells. But, in a number of 1990s films, such as ZusJe (Westdijk, 1995), BABYLon (Terstall, 1998) and Jezus Is Een PALESTijn (Crijns, 1999), the bicycle returns as a useful and trendy mode of transportation, and the sound of its bells is audible in the city center again.

Tram bells suffer a similar "fate" as bicycle bells. The exception, in the 1970s, seems to be NAAKT OVER DE SCHUTTING (Weisz, 1973), in which the tram is used in a chase scene. It is clear, though, that the characters "are genuinely surprised by the spectacular situation they find themselves in" (Kooijman 2008: 193). They seem to realize that the idea of a chase scene does not fit the old-fashioned tram, since "proper" chase scenes in the 1970s involve cars and motorcycles, as in GRIJPSTRA EN DE GIER (Verstappen, 1979).

To understand the presence (albeit modest presence), decline and relative "return" of local Amsterdam sounds in films between the 1930s and the 1990s, we need to know more about Dutch film culture. Film publicist Hans Schoots claims that Dutch filmmakers up until the 1970s, and in contrast to international, notably American trends, kept offering escapism from the hard realities of everyday life. When set in cities, Dutch films tended to take place in "old fashioned social contexts with a hint of folk romanticism." Schoots argues that the 1980 film SPETTERS (Verhoeven, 1980) marked the beginning of a new trend towards a more realistic and cynical worldview in Dutch cinema (Schoots 179-80).

City sounds that seem out of place in the mythical cinematic city, such as the sounds of bicycles, church bells, barrel organs and folk music, are the soundmarks of these cities-with-a-hint-of-folk-romanticism. The disappearance of these soundmarks in the 1970s and the related staging of Amsterdam as a modern city, which my analysis has revealed, can be said to anticipate Schoots' new "cynical worldview." Their vanishing suggests a move away from small-time gezelligheid associated with the big village and towards the hustle and bustle of a global city. That these atypical urban soundmarks returned in the 1990s seems to be in contrast with Schoots' argument. To account for this it is relevant to note that the context in which the soundmarks were staged in the 1990s was radically different from the context in which they were presented earlier. Filmmakers started "playing" with soundmarks, thereby imbuing them with new meanings, and constituting a double identity of Amsterdam-in-film: it became both a big village and a small city. These new meanings of Amsterdam-in-film's soundmarks also emphasize their iconic character. Only over time, as I will argue, these sounds came to signify specific interpretations of Amsterdam-in-film.

Let me give the example of folk music. Diegetic folk music, preferably performed by famous working-class artists who sang in an unmistakable Amsterdam accent, was a

${ }^{24}$ In KUHLE WAMPE ODER WEM GEHÖRT DIE Welt (Dudow, 1933) the bicycle is presented in a similar way. See Chapter 4, section 4. 
relatively important element of films set in Amsterdam in the 1930s and 1950s. In the 1930s three popular "Jordaan-musicals" were made: DE JANTJES (Speyer, 1934), BLEeKE Bet (Oswald \& Benno, 1934) and OrAnJE HeIn (Nosseck, 1936). The film OP STAP (Winar, 1935) is not set in the Jordaan, but does feature similar musical interludes. These films displayed a typical imagination of Amsterdam, or at least of the Jordaan neighborhood: a representation of Amsterdam as a small town where residents knew their neighbors well. ${ }^{25}$ This imagination also relied heavily on the staging of gezelligheid, ${ }^{26}$ as created by barrel organs and folk musicians such as Heintje and Louis Davids. Contemporary critics pointed out that this imagination of Amsterdam did not necessarily correspond to reality anymore, but that it did correspond to the audience's putative knowledge about Amsterdam:

The characters are drawn after the stereotypical views we hold of Jordaan residents, which certainly do not correspond to reality anymore but which are nonetheless accepted by many Amsterdam residents familiar with the Jordaan. (Amersfoortsch Dagblad/De Eemlander 31-08-1934: 7) ${ }^{27}$

Proper Jordaan musicals were not made in the 1950s anymore, but many films drew for their popular appeal on the presence and music of famous stars like Heintje Davids and Willy Alberti. Apart from Heintje Davids in EEN KONINKRIJK VOOR EEN HUIS (Speyer, 1949), characters would not spontaneously erupt in song anymore, but many plots were situated around musical or variety performances. In such cases, the fame of the artists was no obstruction to the narrative of the film, but an asset to be exploited to the maximum. This holds, for instance, for the performers Snip and Snap in STERREN Stralen Overal (Rutten, 1953) and for comedian Wim Sonneveld in Het WONDERLIJKE LEVEN VAN WILLEM PAREL (Rutten, 1955).

The sounds of folk tunes, like other local Amsterdam sounds, became less present in the 1970s, and when they did appear, they did so in a different form. Like the tram in NAAKT OVER DE SCHUTTING, folk music was presented as old-fashioned, a relic from earlier decades. Moreover, familiar moments for inserting folk music or a brief tune, such as in the restaurant scenes in GEEN PANIEK (KOEDIJK, 1973) and GRIJPSTRA EN DE GIER (Verstappen, 1979), were now used to insert bits of "Oriental" music, which indicates that migration and multiculturalism (and exotic dining in particular) had entered the popular imagination in film.

In the 1990s, however, folk music re-emerged in the soundscape of Amsterdam-infilm. In LEK (2000), director Jean van de Velde presents a folk song in Amsterdam

\footnotetext{
${ }^{25}$ The Jordaan is a neighborhood in Amsterdam, just West of the city center. Traditionally, it was a working class neighborhood with a reputation for treasuring its particular sense of community. In recent decades, the Jordaan has become gentrified.

${ }^{26}$ The extent to which something is "gezellig." This adjective's meaning can best be "situated" in between "pleasant" and "cozy." It may refer to the atmosphere during a social activity or to that of a particular place.

27 "De figuren zijn geteekend naar de traditioneele voorstelling die zich men gaarne van de Jordaners maakt, die weliswaar niet meer geheel met de werkelijkheid klopt, doch niettemin door vele met de Jordaan bekend zijnde Amsterdammers wordt geslikt."
} 
dialect in a new context. It is no longer a spontaneous outburst of likeable Amsterdamishness, or framed as a valuable cultural heritage in a performance. Instead, the film opens with a scene in which gangster boss Haveman sings a karaoke version of André Hazes' song Kleine Jongen (“Little Boy”), while torturing a traitor with a blowtorch.

Barrel organs would receive a similar treatment. In the $1930 \mathrm{~s}$ films DE JANTJES, OP STAP and KOMEDIE OM GELD (Ophüls, 1936) organs are, together with performances by folk musicians, at the center of social get-togethers and celebrations. But by the 1950s they have already become to represent a contested sound. For example, in HET WONDERLIJKE LEVEN VAN WILLEM PAREL the barrel organ's sound is not just presented as a soundmark of Amsterdam; the organ players also voice their protest about their being expelled from the inner city in a parade to the mayor's house. This scene echoes a similar protest march in 1937 and predates a protest in 1972. In both cases the huge and loud barrel organs and their owners paraded through the city. Interestingly, in view of the "zeitgeist," the 1937 protest was restricted to the areas were barrel organs were still permitted, whereas the 1972 parade ventured into the "forbidden" Leidsestraat, and subsequently came into conflict with a passing tram (De Tijd, 18-06-1937; POLYGOONJOURNAAL 72:05). Fiction films did not have a place for barrel organs left either: the only appearance of a barrel organ in a film from the 1970s is in the film HET JAAR VAN DE KREEFT (Curiel, 1975). Crucially, this barrel organ is but a miniature version.

In AMSTERDAMNED (Maas, 1988), the barrel organ is back, but, like the folk song in LEK, it is presented in a new context. First, its uplifting music is audible at the beginning of one of the film's murder scenes, during which a woman is stabbed while sunbathing on an air mattress on a canal. This is ominous for what happens with the same organ later on in the film, during a speedboat chase: a police-car in full pursuit of the film's serial killer crashes into the organ and, to the abhorrence of its owner, destroys it completely. The sound of the racing police car's engine is abruptly drowned out by breaking wood and crashing metal. After the crash it is quite silent, apart from the thud of the last piece of wood falling on the car's windshield and the organ's owner's angry punches against that same windshield.

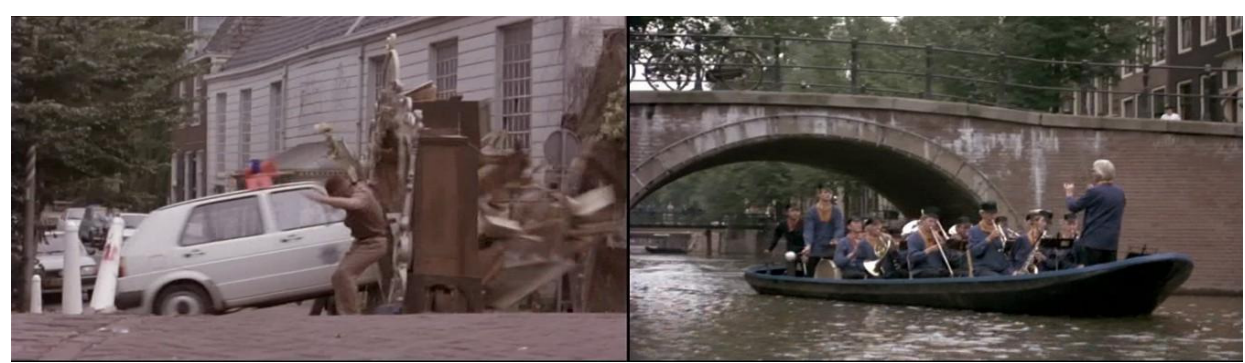

Illustration 7: In Amsterdamned (Maas, 1988) a barrel organ is destroyed in a chase sequence, but a little boat carrying a band playing the theme of Fanfare (Haanstra, 1957) is preserved 
Director and screenwriter Dick Maas makes a very explicit cultural statement here, both in relation to the imagination of Amsterdam's soundscape and to the old tradition of Dutch musicals. Remarkably, only a few minutes after the organ crash, two speedboats go to great lengths in order not to crash into a barge on which an orchestra plays the theme music of Bert Haanstra's FANFARE (1958), with Haanstra himself - his master's voice of Dutch film - conducting the brass band playing. Maas thus leaves no doubts about which soundmark he considers worthy of preservation and which one he thinks Amsterdam can do without.

The new stagings of soundmarks of Amsterdam-in-film in the 1990s did not just pertain to violence and destruction, though. In BABYLON (1998), filmmaker Eddy Terstall celebrates the new "progressive" Amsterdam; a city of free love, multiculturalism and legislated cannabis use in the summer of 1998. This film presents only distant car sounds, while the sound of bird song is as persistent as background as the sound of traffic. Characters walk and ride their bicycle through the Jordaan neighborhood, and the film's five independent love stories are connected by the sound of the bells of the Westerkerk, which already served as object of an admiring folk song in the Jordaan musical BLEEKE BET (1934). And when at the end of BABYLON, in an attempt at musical iconoclasm, the French shock-rocker Flash climbs the church's bell tower to play a concert from atop of it, his music is drowned out by the reassuring sound of the bells and the noise of a passing tram down in the street.

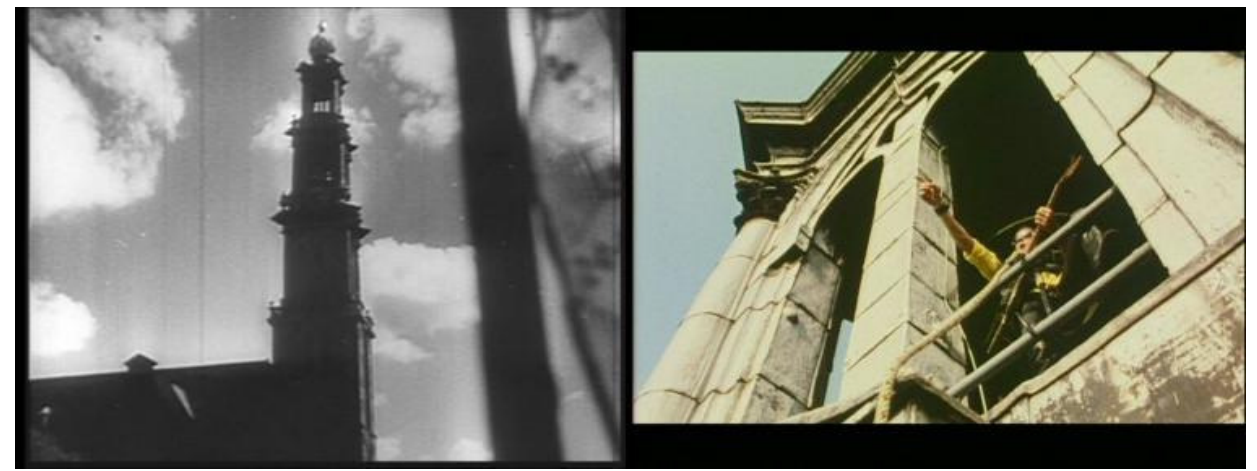

Illustration 8: De Westertoren as an object of affection in Bleeke Bet (Oswald \& Benno, 1934) and scaled by the French rocker "Flash" in Babylon (Terstall, 1998)

The films that creatively recycle Amsterdam-in-film's soundmarks also display important differences, however. BABYLON, on the one hand, is a romantic comedy. AMSTERDAMNED and LEK, on the other hand, are thrillers. All these films are set in Amsterdam, but the Amsterdam of BABYLON is not the same city as the Amsterdam of the two thrillers. Genre, as elucidated in Chapter 6, can be an important factor in the design of a film's soundtrack. These examples of Amsterdam-in-film from the 1990s reveal that depending on the genre we may listen to a different place. The Amsterdam of 
LEK and AMSTERDAMNED is a small city: modern and dangerous, but on a small scale the barrel organ we hear before a murder is the same one we see destroyed later on. The Amsterdam of BABYLON rather seems one big village, even if its size is hardly that of a friendly country town. Amsterdam-in-film grew from a village in the 1930s to a proper city in the 1970s. But in the 1990s, not in the least because of the creative recycling of its soundmarks, it is both: village and city.

\subsection{Amsterdam-in-film: a glocal village?}

There is one early example of this creative recycling of Amsterdam's soundmarks, in the 1970s. The tram-chase scene in NAAKT OVER DE SchUTTING (WEISZ, 1973), in which the characters and the extras involved clearly realize how ridiculous the situation is, has been interpreted as an example of karaoke Americanism. Jaap Kooijman borrows this term from Thomas Elsaesser, and uses it to

recognize "Hollywood" in Amsterdam in all of its different manifestations, not merely as an imitation of the American generic example, but also as a form of active cultural appropriation. (Kooijman 2008: 189)

Kooijman continues by recognizing other moments of karaoke Americanism, among others in TURKS FRUIT and AMSTERDAMNED (Kooijman 2008: 191-92). Why do I bring this up? Because the concept of karaoke Americanism clearly suggests Dutch filmmakers did not operate in isolation. The relatively small Dutch film industry always operated in a cinematic culture dominated by foreign, especially American and German, films (Verdaasdonk 1985: 82; Dittrich 1986: 107-08). The Dutch audience's knowledge, tastes and expectations were shaped by these foreign films, and so were the practices of Dutch filmmakers. However, karaoke Americanism does not mean that Dutch filmmakers slavishly copied or reproduced the conventional plots and representational strategies of American cinema, but that they refashioned them, to suit their needs. ${ }^{28}$ The cynical, ironic or even iconoclastic recycling of soundmarks - sounds that make Amsterdam unique - is an important element of this process of appropriation.

\footnotetext{
${ }^{28}$ My description of the appropriation of (mainly) American generic conventions and representational strategies by Dutch filmmakers, is informed by a number of other accounts of "appropriation," concerned with such subjects as popular culture, modern technology and television game shows. With regard to popular culture, John Fiske has argued that "a homogeneous, externally produced culture cannot be sold ready-made to the masses: culture simply does not work like that" (Fiske 1990 [1989]: 23). One can imagine that cultural artifacts produced in another country, under different cultural and social circumstances, will be even more difficult to "sell to the masses." Mikael Hård and Andrew Jamison make this clear with regard to technological development, in their international comparative account of the intellectual appropriation of technology (Hård \& Jamison 1998: 10-15). The international appropriation of cultural artifacts, finally, can take place in several ways. Eggo Müller has described how television producers adapted internationally traded concepts for entertainment and game shows for specific national audiences. Regarding elements from these shows, he distinguishes between strategies of accommodation and of assimilation. In case of accommodation, producers adapt some details of the foreign format to local or national specificities, while assimilation implies
} 
The process of the international circulation of standards and their national or local appropriation led not only to homogenization and standardization, but also to cultural diversification and hybridization (Burke 2009: 2). In the early 1930s, the language barrier erected by "talkies" (films with recorded dialogue) between films from different countries catalyzed a debate on the need for a national, Dutch cinema (Dibbets 1993: 263). It was claimed that there should be a national cinema, producing films for the Dutch market, based on a Dutch screenplay and with Dutch actors (Dittrich 1986: 110). This desire for a national cinema was also fuelled by a fear of a supposed Americanization or Germanization of Dutch culture (Dibbets 1993: 264-67; Dittrich 1986: 108). Thus, when the first Amsterdam-set Dutch sound film, DE JANTJES, premiered in 1934, critics hailed it as a sign of a Dutch film industry in the making (Van Gelder 1995: 12). In fact, Dutch films were anything but solely national affairs: the makers of "Dutch" sound films in the 1930s were often German and Austrian emigrants; the boom of the Dutch film industry in the 1930s would simply not have been possible without them (Dittrich 1986: 125). Furthermore, the international character of Dutch cinema did not only show from the variety of the nationalities involved in film production. It was also expressed by the international literary examples filmmakers used as sources of inspiration (van Gelder 1995: 42).

Dutch filmmakers, then, have always cooperated with and were influenced by their international colleagues. In addition, many films have staged Amsterdam as an internationally connected place. Even in the 1930s, when the soundscape of Amsterdam-in-film rather reminded one of a village instead of a large city, the Dutch capital was in fact the capital of a colonial empire. In DE JANTJES a group of men leave on a steamship to become soldiers in the Dutch Indies. And in OP STAP a rich uncle arrives by airplane from those same colonial territories. Alfred Hitchcock used Amsterdam and the Netherlands, still neutral at the time, as a place for international diplomacy in times of a looming war in FOREIGN CORRESPONDENT (1940). Soon after the war, the Netherlands ceased to be a colonial power, but Amsterdam did not become isolated from the rest of the world. At the end of STERREN STRALEN OVERAL, the protagonist, an Amsterdam taxi driver, migrates to Australia with his family. And, as we can hear in GeEN PANIEK, GRIJPSTRA EN DE GIER and JEZUS IS EEN PALESTIJN, the Netherlands are staged as a country that receives migrants as well. Migration, together with tourism, is an important characteristic of what has come to be called "globalization" (Bianchi 2002: 280-96; Szeman 2003: 194). Amsterdam-in-film, as well as its real-life counterpart, is a major tourist destination. The tour boats that populate the canals can be heard in DIAMONDS ARE ForeVER (Hamilton, 1971), AMSTERDAMNED and BABYLON, the latter film also having tourists as major characters.

Evidently, the process of globalization has left its traces in Amsterdam and, because of filmmakers' attempts to create reality-effects, in Amsterdam-in-film. But this does not yet mean that the city-in-film has turned into some sort of non-place, disconnected

a full reconstruction of a foreign program in terms of the receiving culture. Müller argues that the recognition of the interplay between both strategies underscores that the international circulation of cultural artifacts does not lead to homogenization (Müller 2002: 469-70). 
from any sense of identity or history (Auge 1995: 77-78). In its filmic representation Amsterdam is not an interchangeable metropolis filled with the same sounds and images as any other capital of a Western country. ${ }^{29}$ Nor is it "theme park Amsterdam," as Jan Nijman called the city in the 1990s (Nijman 1999: 156). ${ }^{30}$ Auditory traces of globalization are there, as reflected in particular in the re-appropriation of soundmarks of Amsterdam in the 1990s. The chases in NAAKT OVER DE SCHUTTING, GRIJPSTRA EN DE GIER and AMSTERDAMNED and the karaoke version of the folk song in LEK rely for their new meanings on a familiarity with American - or at times Asian-thrillers and action movies. The tension between the local and the global is always present in Amsterdam-in-film, playing an important part in the negotiations on the identity of the city. As film critic Alwin de Kluyver wrote about LEK:

This mixture of melodrama and brutal action seemed for a long time to be the terrain of action specialist John Woo, but director Jean van der Velde is able, without all-too-conspicuous thieving, to add a Dutch twist to it. This is made clear immediately, in the incredibly tense opening scene, when André Hazes' emotional sense is linked up with medieval torture practices (De Kluyver 2000: no page). ${ }^{31}$

We can understand this example, the opening scene of LEK, as a moment of the assimilation of American and Chinese action-genre conventions. Director Jean van de Velde does not merely insert a "foreign" element - the torturing of one criminal by another - into a Dutch film; he turns torture into a Dutch film element as well, by playing André Hazes' song Kleine Jongen at the same time. And perhaps most remarkably, he emphasizes and foregrounds this assimilation by not playing an original recording of the song, but by having the criminals sing a karaoke version of it.

"Globalization" suggests that on a worldwide scale places and cultures look, smell, taste or sound more similar. With respect to our topic here, as the above discussion of Dutch cinema shows, this does not seem to be the case. If Dutch filmmakers adapted and appropriated international forms, they did not slavishly copy them. The problem with the globalization discourse, as Roland Robertson argues, is its presumption that the globalization process overrides locality. This interpretation of globalization neglects the fact that largely the local is "constructed on a trans- or super-local basis" and diametrically opposes universalism to particularism (Robertson 1995: 26). In order to account for the international circulation of people, products and cultural forms on the one hand and specific local appropriations on the other, Robertson has introduced the concept of glocalization into social theory. Glocalization shifts the attention towards

\footnotetext{
${ }^{29}$ The exception to that rule being the representation of the business district in DE PIJNBANK (Van Gogh, 1998).

${ }^{30}$ The exception to this may be BABYLON.

31 "Die mengeling van melodrama en keiharde actie leek lange tijd voorbehouden aan actiefilmer John Woo, maar regisseur Jean van der Velde weet er, zonder al te opzichtig te jatten, een mooie Hollandse draai aan te geven. Iets wat meteen in de ijzingwekkend spannende openingsscène duidelijk wordt wanneer het sentiment van André Hazes gekoppeld wordt aan middeleeuwse martelpraktijken."
} 
"the ways in which homogenizing and heterogenizing tendencies are mutually implicative" (Robertson 1995: 27). Local, or urban, identities are thus constructed in relation to global trends or developments and therefore globalization is not only a process of homogenization, but also of heterogenization. The examples given above, of the recycling of Amsterdam soundmarks, demonstrate that globalization, in the domain of fiction film, hardly involves a one-way process of cultural and social homogenization. Dutch filmmakers are influenced by, and relate to, American cinema, but they use local elements that are "typically Dutch" or "typically Amsterdam" in order to stage Amsterdam-in-film as a unique place. ${ }^{32}$ For this reason, the Amsterdam-in-film of the 1990s is perhaps best described as a glocal village, to vary on a well-known phrase by Marshall McLuhan.

This discussion on the international dimensions of Dutch cinema culture, and Amsterdam-in-film in particular, helps us to understand better the double identity of Amsterdam-in-film in the 1990s: its staging, through sound, as both city and village. As my argument in this section reveals, the representation of Amsterdam and its soundscape in fiction films has always been informed by local and national as well as international developments. In the 1930s the perceived threat of foreign cultures was central to the appeal of the first Jordaan musicals, with their emphasis on traditional music and local culture. But in the Amsterdam-in-film of the 1970s and especially of the 1990s, more foreign influences, themselves an expression of increasing globalization, have seeped into the soundscape. This is as much a result of filmmakers' attempts to create reality-effects (after all: the effects of globalization were visible and audible in Amsterdam) as it is a result of the local appropriation of international cinematic styles. The appropriation of the conventions of American and Asian action movies was at the basis of the creative recycling of soundmarks of Amsterdam-in-film a process that is central to the staging of Amsterdam's "double identity" in the 1990s. National and international film culture, as well as filmmakers' attempts to create realityeffects explain this double identity of the soundscape of the Amsterdam-in-film of the 1990s.

\subsection{Conclusion}

In this examination of the soundscape of Amsterdam-in-film I have looked at and listened to different categories of city sounds: traffic sounds, background sounds and soundmarks. Having observed changes in the presence of these sounds, and of their specific stagings, I concluded that Amsterdam-in-film changed from a big village in the

\footnotetext{
${ }^{32}$ Arjun Appadurai has amply demonstrated how the experience of modernity for him, as a young boy in India, was inextricably linked to the consumption of American cultural artifacts, such as Harold Robbins novels, Humphrey Bogart films and jeans (Appadurai 1996: 1-2, 6-7). Clearly, notions of globalization and cultural homogenization are equated with Americanization, while at the same time the specifically local character of the appropriation of these and other cultural artifacts guarantees heterogenization, diversification and cultural hybridity (Burke 2009: 2).
} 
1930s into a proper city in the 1970s, and that Amsterdam was staged as both city and village in the 1990s. I argue that these developments can be explained by referring to three different contextual levels: filmmakers' efforts at creating specific reality-effects, new developments in film technology and production practices, and conventions of national and international film culture.

The 1930s saw the construction of a unique identity for Amsterdam-in-film, in which folk music and local traditions were highlighted. Films portrayed a village-like city, in which motorized traffic was staged as an attraction. This filmic imagination of Amsterdam did not necessarily correspond to historical realities, as the construction of this identity was also influenced by debates in film culture: the first Dutch sound films were seen as important weapons against a feared Americanization and Germanization of Dutch culture.

From the 1950s onwards, the representation of Amsterdam-in-film gradually changed from a big village into a small city. We can understand this change by looking at the changing technologies and practices of film sound recording. In the 1950s, filmmakers worked with lighter and more mobile sound recording equipment; shooting on location became much more convenient and conventional. Furthermore, the possibilities for mixing and editing film sound had improved. As a result of these developments, filmmakers more often placed ambient sounds on their soundtracks, enabling the construction of reality-effects that emphasized the setting of a story in a larger urban environment.

Not just the technologies of film sound recording changed. The city, and with it the audience's knowledge and perception of the city, changed as well. Inner city traffic expanded up until the 1970s, and somewhat declined in the last decades of the twentieth century. Immigrants from other cultures brought their food, languages and music with them. Amsterdam increasingly became a tourist destination. Audiences familiar with Amsterdam expected this to be represented in film, and filmmakers delivered on that expectation. For instance, characters in films set in Amsterdam went to have dinner in oriental restaurants, where they listened to music that was quite different from the corny folk songs of the Jordaan musicals. Among the audience, these new filmic representations of Amsterdam in turn contributed to changing expectations of Amsterdam-in-film and of Amsterdam itself. The example of the tram-chase IN NAAKT OVER DE SCHUTTING exemplifies these changing expectations. The responses of the protagonists and extras in this film clearly express that it is a joke to film a chase scene, normally staged with cars, using trams. In addition, this example clarifies that the identity of a city cannot be separated from its fictional stagings.

A second shift in the representation of Amsterdam-in-film took place in the 1990s. As the scenes in Chinese or Turkish restaurants show, the increasing international circulation of people, products and cultural forms after the Second World War - also known as globalization - became audible in Amsterdam-in-film in the 1970s, and especially in the 1990s. Not only because tourists, immigrants, different languages and new types of music appeared in Amsterdam-in-film, but also because Dutch filmmakers 
appropriated narrative conventions from American and other movie traditions by using typically Dutch or Amsterdam-like elements in foreign formats. This appropriation, which is sometimes referred to as karaoke Americanism, prompted a creative recycling of soundmarks of filmic Amsterdam, and thereby the staging of the double identity of city in the 1990s. Amsterdam-in-film was both a small city and a big village or, concisely, a glocal village.

As these shifting stagings of Amsterdam-in-film show, filmmakers have used sound as a means of showing the tensions between the modern and the traditional and as a narrative resource to negotiate between these extremes. They have done so by creating oppositions between what is seen and what is heard or by allowing the sound to confirm, nuance, mock or undermine the image of the city-in-film. NAAKT OVER DE SCHUTTING, AMSTERDAMNED and LEK show us a modern image of the city of Amsterdam, yet in their soundtracks we hear the enhanced and distorted echoes of the Jordaan musicals. And in these Jordaan musicals, and other films from the 1930s, Amsterdam is presented as a big, traditional village while off-screen car horns and incidental airplane engines sound in a modern era. These examples underscore the simultaneity and co-presence of the modern and the traditional - of village and city characteristics within a single entity. We can only recognize this simultaneity and copresence, when we carefully watch and listen to films.

In the introduction to this chapter I suggested that the myth of the cinematic city is in dire need of revision, and that this case-study of Amsterdam-in-film provides a good starting-point for re-examining it. The function of a myth is to present as natural that which is only a discursive construction (Barthes 2000 [1957]: 142). That modern cinematic cities are crowded, overwhelming places and that postmodern cinematic cities are homogeneous non-places is hardly a natural or obvious state of affairs. This chapter, by means of an audiovisual analysis of Amsterdam-in-film, reveals these myths to be discursive constructions with a visual bias. Exactly because of the audiovisual copresence of the modern and the traditional we may argue that Amsterdam-in-film is different from the mythical cinematic city. It was actually Berlin-in-film, the topic of our next chapter that inspired the rise of this myth among film critics and theorists. 


\section{Chapter 4}

\section{Berlin Part I: City under Construction (1926-1945)}

\subsection{Introduction}

The myth of the cinematic city found its fullest expression in the city symphony films of the 1920s: RIEN QUE LES HEREUS (Cavalcanti, 1925), CHEVOLEK S KINOAPPARATUM (Vertov, 1929) and BERLIN, DIE SINFONIE DER GROßSTADT (Ruttmannn, 1927). In fact, the latter has become so iconic, for Berlin and for the city film that we may posit Weimar Berlin as the stereotypical example of the cinematic city. It was the myth incarnate.

In this chapter, the first of two on Berlin in this dissertation, I will examine the representation and staging of the soundscape of late Weimar Berlin in fiction film, and the transformations this soundscape underwent during the Nazi period. I will show how the soundtracks of films situated in Berlin between 1927 and 1945 represented the city as a metropolis under continuous political, social and material construction. Berlin-infilm during the 1930s and 1940s was the site for the celebration of modernity and the expression of modern anxieties. Film sound, as I will argue, played an important role in these processes.

The origins of the representation of Berlin's dynamic identity can be traced back to the city's rapid growth during the Wilhelmine period and to its ambivalent status in the Weimar Republic. Weimar Berlin was a city strongly shaped by the forces of industrialization and urbanization. When it became the imperial capital in 1871, Berlin counted less than one million inhabitants. But by 1925 this number had risen to over four million (Grywatz 1988: 203; Matzerath 1984: 293). Berlin also became the leading industrial and commercial city on the European continent (Hughes 1983: 175-77). This enormous growth of Berlin was translated into the architecture, infrastructure and soundscape of the city. The German philosopher Ernst Bloch wrote in 1935 that "Berlin ... is a constantly new city, on which not even the lime becomes or is even set" (Bloch 1991 [1935]: 195). This continuous construction of Berlin also had a particular political dimension. As Martin Gaughan states:

More visibly marked since the beginning of the twentieth century than London or Paris by the process of an accelerated modernization and rapid urbanization, Berlin's transitory character was the occasion for concerned commentary from both the left and right of the political spectrum. (Gaughan 2001: 41) ${ }^{33}$

${ }^{33}$ Especially in the aftermath of World War I public debate in Germany was characterized by what the historian Georg Steinhausen called "an atmosphere of decline in imperial Germany," and what his colleague Karl Lamprecht referred to as "orgies of ...pessimism" (Stoffers 2007: 264). Part of this widespread 
This political commentary coincided with the identification of Weimar Berlin as a vibrant artistic community and cultural avant-garde:

One should not be so awestruck today by the cultural brilliance of the avantgarde, for whom the cosmopolitan atmosphere of Berlin represented the best impulses of Weimar Germany, to forget that for a broad spectrum of antimodernist and folkish Germans, Berlin and all that it stood for was the devil incarnate. Berlin became a crystallization point of resentment against industrialization, capitalism, democracy and the cultural influence of the West following Germany's defeat in World War I. (Natter 1994: 214)

In this description Weimar Berlin is presented as the archetypal metropolis; a modern, industrialized city that offers attractions and dangers, and that is forcefully positioned against pre-modern rural life and nature, both by the city's admirers and by modernity's discontents. Weimar Berlin was not "only" a city; it was also the subject of a broad cultural discourse on modernity and modern life. Peter Fritzsche argues that this discourse must be seen as a fundamental element of Berlin's identity:

What heightens the fascination is the link between the city as a geographical place and the city as a narrated form. From the beginning, written records and urban existence have gone hand in hand. This correspondence created an imaginary symbolic order that was as important as the city itself. (Fritzsche 1996: 4)

Fritsche's argument concerns written records of Berlin, but I argue that film - as it was considered to be the most appropriate medium to represent the modern city - also expressed the city's "narrated form." When film sound was introduced in the late 1920s, it played its part in this expression. The premise of the two chapters on Berlin in this dissertation is that the staging of city sounds in films set in Berlin - from the Weimar years, through the period of the Third Reich and the Cold War into the 1990s represents Berlin as a city that is continuously "under construction." This premise is based on the historical development of the city - the destruction in the Second World War, the ideological and material division after the war and the material and political reconstruction after the unification - and the theoretical presumption that the staging of the urban soundscape offers us an insightful account of the experience of the city by contemporary filmmakers. How city sounds contribute to this staging of Berlin as "under construction" will be explained by referring to four contextual levels:

pessimism was that modern city life inspired a desire for nature and country life (Stoffers 2007: 265). Contemporary commentators recognized a change in the human condition, and in particular the human senses and nerves, in the modern era caused by the acceleration of information and traffic so typical of industrialization and urbanization (Stoffers: 247-58). Georg Simmel, for instance, discussed the emergence of a "metropolitan type" (see Chapter 1, section 1). 
filmmakers' attempts to produce reality-effects, film sound technologies and production practices, film culture, and politics. ${ }^{34}$

Berlin's tumultuous political history in the twentieth century makes it an interesting case study for this research, as can be understood from the paragraph above. However, Berlin is an obvious choice for a case study from the perspective of Film Studies as well: in the 1920s, the German film industry, headed by the UFA company ${ }^{35}$ was the largest film industry in Europe and the only serious international competitor for Hollywood (Hake 2008: 32). Weimar Germany boasted film-making talent unmatched anywhere in the world, with internationally successful directors such as Fritz Lang, Wilhelm Friedrich Murnau and Georg Wilhelm Pabst. Films like MADAME DUBARRY (Lubitsch, 1919), Das Cabinet DES DR. CAligari (Wiene, 1920), DR. MABuSE, DER SPIELER (Lang, 1922) and DeR LETZTE MANN (Murnau, 1924) were internationally successful. Weimar Cinema is therefore one of the most extensively documented and studied subjects in Film Studies, especially with respect to the connection between cinema and the city: ${ }^{36}$

Weimar Germany was a paradigmatic moment in the history of the cinema-city relationship, not only in the films which it produced, but in terms of the theoretical discourse and cultural analysis to which they gave rise. (Shiel \& Fitzmaurice 2001: 3)

This chapter and the following one will contribute to this theoretical discourse and cultural analysis by examining the cinema-city relationship in a long-term perspective, supported by a quantitative analysis of film sound. The analysis on which these chapters are based follows the same methodology as the one used for Amsterdam in the previous chapter, implying the identification and classification of Urban Sound Events (USEs). Although my analysis of Berlin-in-film has focused on the same classes of sounds and soundscape concepts as I have used for the cases of Amsterdam and London, the information on background sounds, traffic sounds and sounds originating from musical performances has proven to be most revealing in terms of the city's representation. In addition, this chapter--the first of the two Berlin chapters-will pay particular attention to the way particular sounds operate as cardinal functions, catalysers, informants or indices proper. These concepts, which were coined and described by the French literary

\footnotetext{
${ }^{34}$ For a detailed explanation of the theoretical rationale behind this research, see Chapter 1, section 3.

${ }^{35}$ Universum Film-AG (UFA) started during World War I as a cooperation between the Ministry of War, financial institutions and the film industry. After the war it continued to be the major German film studio (Hake 2008: 26).

${ }^{36}$ Libraries can be filled with the literature on Weimar cinema. I mention a few titles here: two of the most influential histories of Weimar cinema are Siegfried Kracauer's From Caligari to Hitler (1947) and Lotte Eisner's L"Écran Démoniaque: Influence de Max Reinhardt et de l"expressionisme (1952). More modern accounts of the period include Tom Gunning's The Films of Fritz Lang: Allegories of Vision and Modernity (2000) and Thomas Elsaesser's Weimar Cinema and After: Germany's Historical Imaginary (2000).
} 
theorist Roland Barthes, will help me understand the narrative qualities and functions of city sounds in fiction films (Barthes 1987 [1966]). ${ }^{37}$

In the following sections I will first discuss the staging of Berlin's soundscape in fiction film as a symphony and a cacophony of the big city. These two different stagings rely on two audiovisual strategies: the musicalization of noises and the noisification of music. A second section will examine the use of city sounds by Weimar Germany's most prominent filmmaker: Fritz Lang. Lang made the transition from silent to sound film successfully, had strong opinions on the subject and a remarkable and unique style (Vogt 2001: 241; Gunning 2000). During the last years of the Weimar Republic and the first years of the National Socialist period representations of the city were explicitly political. In the third and final section I will therefore discuss the political construction of the city and of urban life in propaganda films from both the left and the right. In addition, I will discuss how National Socialist cinema presented a "harmonized" image and soundscape of the modern city.

In the previous chapter I discussed the representation of Amsterdam's soundscape in fiction film in relation to different categories of sound, and different levels of analysis and interpretation. The chapters on Berlin offer another perspective: they will discuss the representations of Berlin in fiction film in a chronological order. This chronological perspective will allow me to highlight the changes and continuities in the representation of Berlin's soundscape in film and to show the changing relevance of the different contextual levels of interpretation - the reality-effect, technology, politics and film culture - for the explanation of Berlin's changing identity in film - an identity that was constantly "under construction."

\subsection{Symphony and cacophony of a big city}

The idea was originally Carl Mayer's. The famous screenwriter, who had written the screenplays for the expressionist classics DAS CABINET DES DR. CALIGARI (Wiene, 1920) and DER LETZTE MANN (Murnau, 1924), imagined a film about Berlin. But not just a film, a symphony: "It seemed as if I suddenly heard the thousand voices of the melody of this city" (Mayer quoted in Vogt 2001: 171). ${ }^{38}$ Mayer approached Karl Freund, at the time head of production at Fox Europe, and Walter Ruttmannn, a director of abstract short films who did have the ambition to work with "living material" for "a long time" (Prox quoted in Vogt 2001: 171). Together, they started the production of the film that would become BERLIN, DIE SINFONIE DER GROßSTADT (Ruttmannn, 1927). I will argue that BERLIN, DIE SINFONIE DER GROßSTADT relies on a strategy that we could call the musicalization of city sounds in its presentation of city life as exciting. After that I will show how Piel Jutzi's BERLIN ALEXANDERPLATZ and other sound films

\footnotetext{
${ }^{37}$ For a precise description of the concepts see Chapter 1, section 4, and also the next section in this chapter.

38 "Es war mir, als hörte ich urplötzlich die tausendstimmige Melodie dieser Stadt."
} 
offered a very different representation of the soundscape of Berlin-in-film. In Jutzi's film we hear a noisification of music and he turns the soundscape of Berlin-in-film into a cacophony of a big city. This cacophony does not stem from the mere presence of city sounds, but from their particular staging at key moments in some of the films analyzed in this chapter.

BERLIN, DIE SINFONIE DER GROßSTADT has become iconic for the representation of Weimar Berlin. The famous historian of Weimar cinema, Lotte Eisner, states that it influenced all the "social" films of the period (Eisner 1952: 330). Contemporary critic and theorist Siegfried Kracauer named it the most important of the "cross-section" films that were characteristic of what he called the "stabilized period" of the Weimar Republic (Kracauer 1984 [1947]: 196). ${ }^{39}$ Its "pure patterns of movement" symbolized the "tempo" of Berlin (Kracauer 1984 [1947]: 197). This last quote hints at the importance of musical metaphors that surrounded the genre of the city films.

It was 1926 when Meyer and Ruttman started working on BERLIN, DIE SINFONIE DER GROBSTADT. $^{40}$ In America the first short, experimental sound films were made by Warner Brothers, but the new technology had yet to make its way into movie theaters, notably in Europe. The "thousand voices of the melody of the city" that Mayer heard could not be recorded for film. So Edmund Meisel, who had become famous with his score for Sergei Eisenstein's film BRONENOSETS POTYEMKIN (BATTLESHIP POTEMKIN, 1925), was asked to compose the music for "BERLIN." He describes his score for the film as follows:

Labor march - machine rhythm - march of school children - office rhythm traffic rhythm - counterpoint of Potsdamer Platz - Afternoon choir of the big city - traffic fugue - counterpoint of babble - sports rhythm - signaling music of neon advertisements - dance rhythm - the increase of all the noises of the big city into the counterpoint execution of the major themes towards the concluding fermata Berlin. (Meisel quoted in Vogt 2001: 173) ${ }^{41}$

Meisel aimed to translate the noises of the city into music. The city dwellers were his intended audience (Meisel quoted in Vogt 2001: 173). He listened to the sounds of the city, and his score for the film was written for a full orchestra combined with sound effect machines. It is not likely that this ideal performance, based on Meisel's score and instructions, was ever presented to audiences. Contemporary reviews all emphasize the

\footnotetext{
${ }^{39}$ In the middle of the 1920 s the political, economic and social climate in Weimar Germany stabilized slightly, and according to Kracauer this stabilization was reflected in the films of the period (Kracauer 1984 [1947]: 141-47).

40 "Berlin" was released in 1927, but according to Guntram Vogt the production lasted for approximately one year (Vogt 2001: 171)

${ }_{41}$ “Arbeitsmarsch - Maschinenrythmus - Schulkindermarsch - Bürorythmus - Verkehrsrythmus Kontrapunkt des Potsdamer Platz - Mittagschoral der Großstadt - Verkehrsfuge - kontrapunktisches Stimmengewirr - Sportrythmus - Signalmusik der Lichtreklamen - Tanzrythmus - Steigerung aller Großstadtgeräusche in kontrapunktischer durchführung der Hauptthemen zur Schlußfermate Berlin.”
} 
musical metaphors in the film image, but the music itself is not mentioned. Neither are sound effects. During the opening night the film was accompanied by a 75-member orchestra, a jazz combo and an organ (Anymous 2007). And although the luxurious Berlin picture palaces could employ full orchestras, smaller movie theaters - especially in smaller towns - often had to manage with small ensembles or even with a single pianist. A recent eightieth anniversary recording of Meisel's score features the full orchestra and the organ, but no sound effects. ${ }^{42}$

I want to argue, at this point, that we can understand the score of BERLIN, DIE SINFONIE DER GROBSTADT on two levels. First of all, there is the level of Meisel's intention with the music: he wanted to recreate the soundscape of Berlin in the cinema; to surround the audience with the sounds of the city and make them audible to the city dwellers as elements of a symphony. For this intention to be realized, musical instruments were combined with sound effect machines. Sound historian Carolyn Birdsall has argued that the integration of sound effects in the musical score played by an orchestra implied "a process of aestheticisation and narrative organisation whereby musical sound (and sense) is created out of noise" (Birdsall 2012: 150). This formulation reflects an argument made by composer Pierre Schaeffer in relation to his objet sonore: "a sound extracted at random from its causal context cannot be so easily incorporated into a musical pattern whose principles have been evolved over centuries" (Schaeffer quoted in Dyson 2009: 56). Frances Dyson brands the groundbreaking work done by Schaeffer's musique concrete as noisification of music or a musicalization of sound (Dyson 2009: 56).

I find these concepts intriguing, but will use them in a slightly different way. To do so we I will look at Meisel's score for BERLIN, DIE SINFONIE DER GROBSTADT on the second level. This is the level of its actual rather than its intended performance. As mentioned above, Meisel's intended performance of his score was never carried out. Instead, on the opening night of the film there was an organ and a jazz combo, but there were no sound effects. In other movie theaters the score had to be played by considerably less equipped orchestras, ensembles or even single pianists. This meant that city sounds were simply translated into a conventional musical score. Without sound effect machines the score of BERLIN, DIE SINFONIE DER GROßSTADT offered a musicalization of city sounds. We can understand such musicalization of city sounds as a strategy employed by filmmakers to stage a city's soundscape in a harmonic and exciting way: as a symphony.

To say that in 1926 the sound film had not yet made its way to Europe is not entirely correct. By that time, the leading German film studio UFA already possessed the patent for a sound film technology, named Tri-Ergon, developed by Hans Vogt, Joseph Engl and Joseph Masolle. But a 1925 short experimental film, DAS MÄDCHEN MIT DEN SCHWEFELHÖLZERN (Bagier), was so disappointing that one year later the company

${ }^{42}$ The recording is a coproduction of ARTE, ZDF, the Bundearchiv/Filmarchiv in Berlin, the RundfunkSinfonieorchester Berlin and Deutschlandradio Kultur. It is featured on a 2009 DVD release of Ruttmannn's work by the Munich Filmmuseum, the Bundesarchiv Berlin, ZDF and ARTE. 
decided to sell the patents to a Swiss conglomerate (Hake 2008: 55). It was only after the American success of THE JAZZ SINGER (Crosland), in 1927, that the sound film seemed a commercially and artistically realizable product. In 1928 two German companies started working on a technology that might rival that of the American combination ERPI / Warner Brothers. The first, Tobis (Tonbild Syndicate A.G.) acquired the Tri-Ergon patents and several hundreds more, while the second, Klangfilm, was a collaborative project between the electrical manufacturers Siemens and Halske A.G. and AEG (Allgemeine Elektrizitäts Gesellschaft). Rather than competing between themselves, the two companies decided to merge to be more competitive with ERPI / Warner Brothers. In March 1929 the merger was finalized (Gomery 1976: 51-54). Soon the first German sound film was released: Walter Ruttmannn's MELODIE DER WELT (1929). MELODIE DER WELT is a musical journey around the world, and does not visit Berlin. Neither would Ruttmannn do this in his later sound films. ${ }^{43}$ The first visits to Berlin in the history of sound film were made in 1931. These visits took place in the following films: M - EINE STADT SUCHT EINEN MÖRDER (Lang), EMIL UND DIE DETEKTIVE (Lamprecht) and BERLIN ALEXANDERPLATZ (Jutzi).

BERLIN ALEXANDERPLATZ is the first film adaptation of Alfred Döblin's famous novel with the same title. It tells the story of Franz Biberbopf, a man who is just released from prison and has difficulty adjusting to life in the big city. He tries, but fails, to stay on the right side of the law.

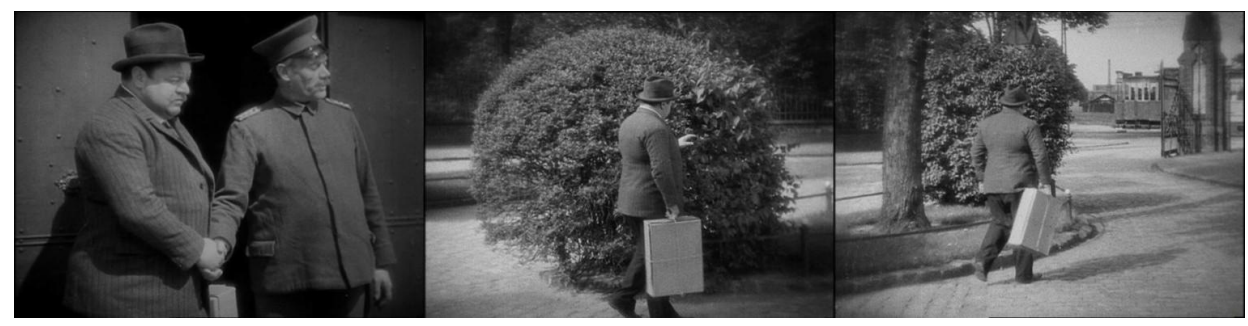

Illustrations $9 a, 11 \mathrm{~b}$ and $11 \mathrm{c}$ : Franz Biberkopf leaves prison and heads for a tram

The film starts with a journey into the city of Berlin. The first image in the film is one of the walls of the Tegel prison. A door opens and Franz Biberkopf, the protagonist of BERLIN ALEXANDERPLATZ, is released from prison. He shakes the hand of the prison guard, who closes the door behind him (Illustration 9a). Softly, non-diegetic music fades in. Biberkopf seems unhappy with his release: the music punctuates Franz' initial move back towards the door, back to prison, and this punctuation ends abruptly as Franz realizes that the door is closed and he cannot go back. Wind instruments join the strings as Franz turns around and looks at the trees. A violin section gives the music a pastoral quality as Franz walks past the trees and the bushes and feels their leaves (Illustration $9 b)$. The passing of a tram, some twenty meters ahead, is underscored by a drum ruffle

${ }^{43}$ Although he did make other city films about Stuttgart (1935) and Düsseldorf (1936). 
and the high pitch of a flute, followed by the sound of a tram bell - the first diegetic sound effect in the film - placed carefully alongside the musical composition. The tram passes, followed by a bicycle and a number of pedestrians ((Illustration 9c). Franz looks worried. A cello imitates the rhythm of machines and steam trains. The cello tune is punctuated by the bell of yet another passing tram. The tram stops for Franz, the sound of its brakes simulated by a high pitched flute. Franz steps on board the tram (Illustration 9d).

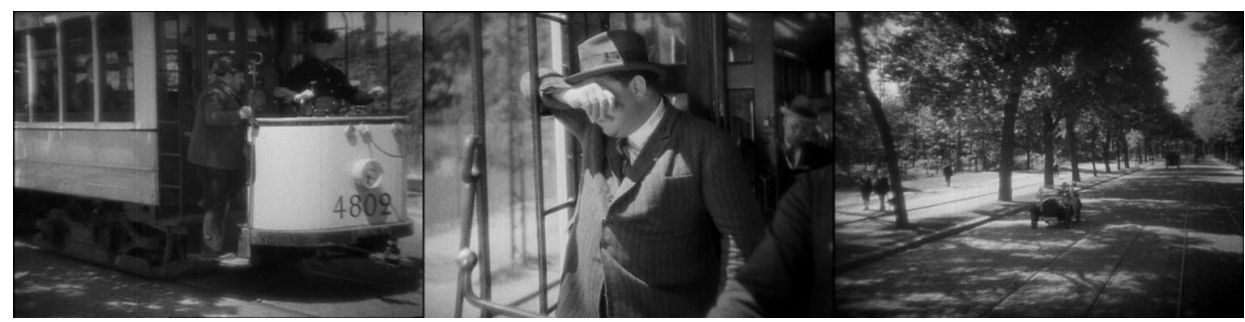

Illustrations 9d, 11e and 11f: Franz Biberkopf gets on a tram and heads for Berlin

A tram bell starts a new section in the music: low strings, with a steady rhythm and still rather soft. But quickly the music speeds up and gains in pitch and turns again in the cello theme we heard just earlier, punctuated ever more often by the tram bell. Franz is not feeling well; he wipes his sweaty face with the sleeve of his jacket (Illustration 9e). A clarinet is added to the music, reducing its sinister quality and adding some sense of excitement and energy. The rails pass under the tram, the tram bell rings. A car passes, sounding its horn (Illustration 9f). More wind instruments join the music, increasing the pitch and the volume. A truck passes and sounds it horn. The tram increases its speed and the rails pass ever faster under it. Franz looks worried at a group of mounted police the tram is passing.

The streets are suddenly full of cars, pedestrians and cyclists; the tram has to sound its bell almost constantly now (Illustration 9g). Other trams pass as well, at a very close distance to Franz. The tram passes road constructions. The sound of the workers hitting on the stones blends in with the music, but it has no discernible rhythm, so the overall sound becomes more chaotic (Illustration 9h). Franz looks scared now. Drums accentuate his playing with his hat. The music now increases its pace even further, almost losing track of its own rhythm. Strange angles in images of a passing tram increase the sense of unease and displacement (Illustration 9i). One shot looks like an abstract painting or drawing before we realize that it is a cart filled with planks. The road is ever more crowded with cars, trams, motorcycles and buses. It becomes too much for Franz. He jumps of the tram, but ends up almost in front of another, in the middle of traffic (Illustration 9j). Franz is now encircled by fastly moving traffic. The music increases its pitch even further, the passing cars become blurred. Franz flees into a courtyard, closes the door behind him and suddenly there is silence, apart from a faint rumbling far away (Illustration 9k). Franz sits down on a bench. Outside the city 
continues as if nothing happened. The music is now replaced by proper traffic sounds, of car engines and trams passing (Illustration 91).

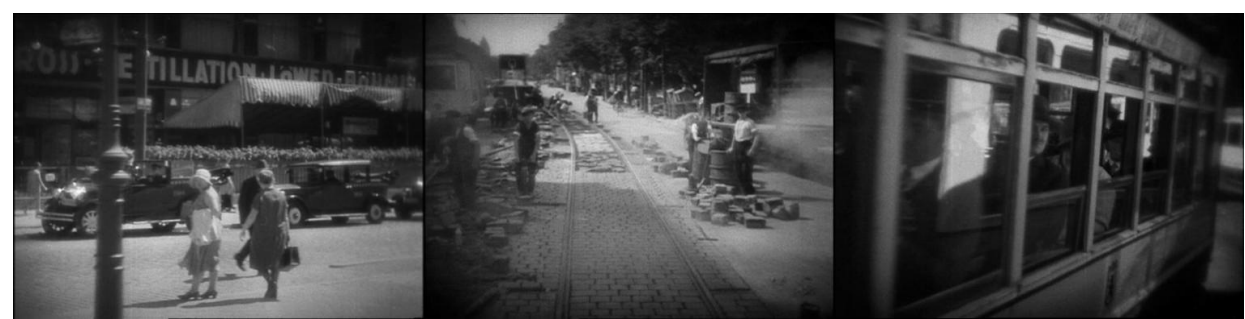

Illustrations 9g, 11h and 11i: Views of Berlin from Biberkopf's tram

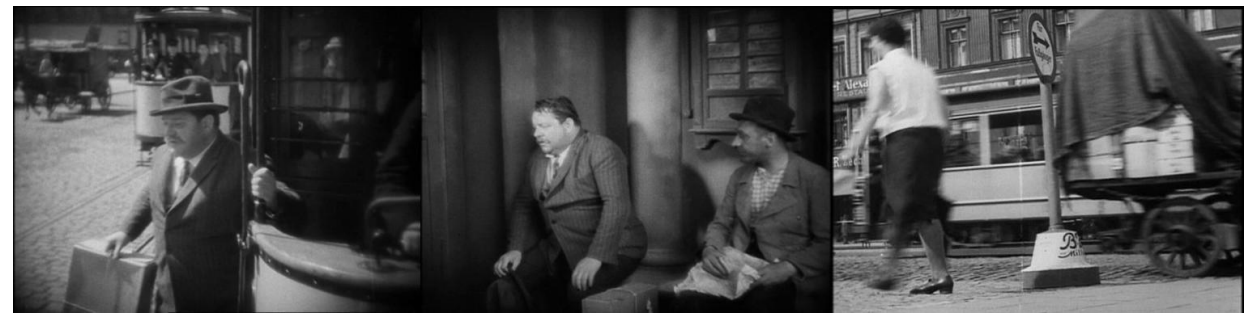

Illustrations $9 j, 11 \mathrm{k}$ and 11l: Biberkopf gets off the tram and finds rest in courtyard

What happens in this sequence is that, in the mind of Franz Biberkopf, the sounds (and the sights) of the city turn into a chaotic and threatening cacophony. The tram ride initially is underscored by music with a steady rhythm and a low pitch, but as the traffic becomes more crowded, and the tram enters the city of Berlin, the pitch rises, the rhythm increases and the music becomes ever more chaotic. The film audience does not hear the actual traffic sounds, but Biberkopf's musical interpretation of them. Only diegetic sounds with a "musical" quality are mixed with the music: the tram bell, car horns and the sound of the road construction. It is only when Franz has sought refuge in a courtyard that we hear the distant low rumbling of city traffic. When the camera leaves Biberkopf alone for a moment and shows us the city without his interpretation of it, far less intrusive and sinister traffic sounds are heard.

In a remarkable contrast to the score of BERLIN, DIE SINFONIE DER GROßSTADT, the soundtrack of BERLIN ALEXANDERPLATZ offers, during this opening sequence, a noisification of music: the filmmakers do not aim to translate the experience of the city's soundscape into music, as Ruttmannn and Meisel did for BERLIN, DIE SINFONIE DER GROBSTADT. In contrast, the music is increasingly staged as noise, in order to communicate Biberkopf's experience of Berlin's soundscape to the audience. The music 
communicates to us far better the effect of the sounds on Biberkopf - his experience of them - than the actual traffic sounds could do. ${ }^{44}$

This change from music to noise is adhered to consistently in BERLIN ALEXANDERPLATZ. While plenty of diegetic music is used in scenes taking place in cafes and night clubs and during a wedding, it is not part of the big outdoor scenes in the film. During the scenes at Alexanderplatz, when Franz is working as a street vendor, the film presents us with the soundscape of a modern city. Trains and trams arrive at and depart from the big train station; buses and cars drive by and sound their horns. Around Franz construction work takes place, filling the square with its sounds. Only from far away the soothing sound of church bells is heard to announce lunchtime. Biberkopf has to raise his voice to be heard by the crowd surrounding him, and he urges people to come closer, so that he may still have a voice left the next day.

In terms of narrative function, traffic sounds in BERLIN ALEXANDERPLATZ are more than just background sounds. In Roland Barthes' terms: they are not only informants; elements that locate a scene in a particular time and space. They are also cardinal functions and indices proper. Cardinal functions are elements of a narrative that, in the words of Barthes, inaugurate or conclude an uncertainty. They necessitate a response or an action, or they are themselves responses to or actions in relation to a previous element that is also a cardinal function (Barthes 1987 [1966]: 93-94). With this definition in mind, the traffic sounds, both during the tram ride and at Alexanderplatz, operate as cardinal functions. Those sounds heard during the tram ride make Biberkopf nervous and prompt him to jump off the tram and search for silence in a courtyard. The city sounds of the Alexanderplatz work more subtly - they demand from Biberkopf that he raises his voice and urges bystanders to come closer.

Indices proper refer to the character of a narrative agent (any character in a narrative), or to an atmosphere or mood. Barthes uses the example of stormy weather during a summer night in one of Ian Fleming's James Bond stories: the weather refers to the "heavy, anguish-laden climate of an action as of yet unknown to the reader" (Barthes 1987 [1966]: 97). Berlin, the city, is in Jutzi's film a narrative agent. Perhaps not as much as contemporary reviewers might have wanted, comparing the film to the novel by Alfred Döblin (see also footnote 10). But the sounds both express the character of the city as busy, frantic, accelerated and threatening-a "secular inferno" as Norbert Grob has it (Grob 2003: 62) - and the character of Franz Biberkopf. As Guntram Vogt argues: "The transition from the hectic traffic to the seclusion of a courtyard ... can, with the atmosphere of the big city, successfully express the psyche of the character" (Vogt 2001: 29). ${ }^{45}$

\footnotetext{
${ }^{44}$ While the cacophony of the big city may overwhelm Franz Biberkopf, the experience of this cacophony can be quite different to characters in other films: the young detectives in EMIL UND DIE DETEKTIVE feel comfortable in the noisy and busy city, and it is through the sound of the boy Gustav's horn that they rally and finally capture the criminal they pursue.

45 “der Übergang vom hektischen Verkehr zur Abgeschlossenheit eines Innenhofs ... kan mit der Atmosphäre der Großstadts die Psyche der Figur schlagend zum Ausdruck bringen."
} 
That this representation of the soundscape of Berlin as an active agent of narrative is not just a modern-day interpretation becomes clear if we look at the conscious construction of the soundscape in BERLIN ALEXANDERPLATZ: the scenes at Alexanderplatz were extremely difficult to record for the production crew. Because the sound technology was very sensitive it was not possible to film the scene and record the dialogue on location. Therefore the vicinity of Alexanderplatz, including the Wiensmeisterstraße and the Grenadierstraße, had to be rebuilt in the Babelsberg studios (Rehhahn 1996: 222; Vogt 2001: 252; Braunger 2008: 28). Nonetheless, the background sound for these scenes was constructed from original recordings: "In Jutzi's film the soundscape of the city was constructed with original recordings from the $1930 \mathrm{~s}$ of driving cars or tram bells" (Braunger 2008: 40). ${ }^{46}$ Stockpiled sounds from studio catalogues were apparently not deemed adequate to fulfill the narrative function of the soundscape in this film. All in all, the noisification of music in the opening sequence, the conscious construction of the soundscape of Berlin, its narrative functions as cardinal function and indice proper and its effects on the protagonist of the film lead me to suggest that, in direct contrast to Walter Ruttmannnn's city symphony, Phil Jutzi's BERLIN ALEXANDERPLATZ presents a cacophony of the big city: an experience of the sensations of the city as overwhelming, fragmentary, disjointed and atonal.

This specific representation of Berlin's soundscape as a cacophony is present in other films of the Weimar period as well (for instance EMIL UND DIE DETEKTIVE and DAS TESTAMENT DES DR. MABUSE). ${ }^{47}$ Ironically, it is exactly the opening sequence of BERLIN ALEXANDERPLATZ, the tram ride into the city, that Norbert Grob refers to as a "grand city symphony" (Grob 2003: 60). Musical metaphors are omnipresent in the discourses surrounding the city films and the introduction of the sound film in the 1920s and early 1930s, but the use of the word symphony is at best inconsistent. Grob, in 2003, may have referred to the opening tram ride as a "grand city symphony," but a contemporary reviewer of the film - for the trade journal Der Film - complained that the sound film in general had to be "symphonic," and that BERLIN ALEXANDERPLATZ was not that:

The sound film must show everything, have wide horizons ... But the film, which is at best a chamber piece, lacks breath and span for such drama ...

\footnotetext{
46 “In Jutzi’s Film wird die Geraüschkulisse der Stadt durch Originalaufnahmen aus den 30er Jahren von fahrenden Autos oder klingelnden Strassenbahnen konstruiert."

${ }^{47}$ Not every film set in Berlin stages the soundscape city as a cacophony though. Two films set in particular locations in the city sound very differently. VIKTOR UND VIKTORIA (Schülze, 1933) is a "different-type-ofnoisy" film. Long sequences in the film take place in a variety theatre. The dominant sounds in this film are those of variety musical performances and of the audience applauding the performers. Another film, GRAND Hotel (Goulding, 1932), is set in a fancy hotel and apart from some cars arriving and departing in front of the building, it features no traffic sounds. Rather, the characteristic sound on the soundtrack is that of the quiet bustling of the hotel lobby, and the soothing music played there. Music that to the audience seemed to be nondiegetic, but appears to have been diegetic all the time when Greta Garbo's character notices that the music has stopped and that it is quiet in the hotel, after the murder of John Barrymore. When Lionel Barrymore and Joan Crawford, as the last guests, have left the hotel, the music comes back in and Lewis Stone's doctor remarks that "nothing ever happens."
} 
Where was time? Where was Alexanderplatz, where was Berlin, where was that boiling contemporaneity and the misery, the dullness and the dreariness, the background? (quoted in Vogt 2001: 254) ${ }^{48}$

According to this review, BERLIN ALEXANDERPLATZ should have been symphonic, but here, symphonic has nothing to do with music: it is a reference to theme and content. And this brings us back to Ruttmannn's city symphony BERLIN, DIE SINFONIE DER GROßSTADT, which was in name and in construction a symphony, but which was criticized by many reviewers for staying on the surface, and not offering an in-depth analysis of life in Berlin.

\subsection{The soundscape of Fritz Lang's Berlin}

A film that does not stage the soundscape of Berlin as a cacophony in the same way as Berlin AleXANDERPlatz is M - EINE STADT SUCHT EINEN MÖRDER. Fritz Lang, who directed such silent masterpieces as METROPOLIS (1927) and DIE NiBELUNGEN (1924), was quite careful with his first sound film, believing that sounds should not be added to films without purpose. ${ }^{49}$ He made a specific point about this issue in relation to city sounds:

Only bring in noises from outside when they have a relation to the narrative. So, only slam a door when it is important for the action: now he is outside, without showing it in the image. Use footsteps only when someone else is waiting for the one who comes and the moment of arrival is absolutely necessary for advancing the action (Lang quoted in Vogt: 241$)^{50}$

Consequently, "M" is a rather silent film. Its street scenes are not filled with the bustle of traffic as are the scenes in BERLIN ALEXANDERPLATZ: Lang did not stage the city in terms of cacophonic noises or diffuse background sounds (Vogt 2001: 244-45). Instead, there is only the occasional sound of a car horn, far away, off-screen, to remind us that

\footnotetext{
48 “der Tonfilm ... muß alles zeigen, große Horizonten haben... Aber dem Film, der bestenfalls ein Kammerspiel ist, fehlte der Atem, die Weite zu einem solchen Drama. ... wo war die Zeit, wo war der Alexanderplatz, wo war Berlin, wo diese kochende Gegenwart und das Elend und die Stumpfheit und Versumpftheit, der Hintergrund?"

${ }^{49}$ Lang's opinion here is in line with those of Formalist theorists who dismissed the artistic potential of the sound film (see Chapter 2, section 2). Interestingly enough, Alexander Döblin, the author of Berlin Alexanderplatz (the novel) was very enthusiastic about the sound film (Rehhahn 1996: 211, 217). The sounds of the city are also a central theme in his novel (Braunger 2008: 40). This suggests that both a film's source material and the artistic sensibilities of those directly involved may serve as a relevant level on which to understand the construction of represented soundscapes.

50 “Außengeraüsche nur dann zu bringen, wenn sie Beziehung zur Handlung haben, also ein Türklappen nur, wenn es für die Handlung von Wichtigkeit is: jetzt ist er draußen, ohne das Bild zu zeigen; Schritte nur, wenn etwa ein anderer auf den Kommenden wartet und der Augenblick des Kommens für den Fortgang der Handlung von unbedingter Notwendigkeit ist."
} 
we are still in a city. This is also a result of the fact that almost the entire film was shot in the studio (Voigt 2001: 239-40). Sounds had to be added in post-production, and whereas the conscious decision for BERLIN ALEXANDERPLATZ was to include original recordings, Lang only included those city sounds that he thought were absolutely necessary to the story.

If Lang may have been careful about adding city sounds to his film, he did make diegetic sound, and especially diegetic music, a crucial element in the narrative of $\mathrm{M}$. The film starts with a little group of children playing a game and singing a song about the big black man who is going to chop them to pieces with an axe. They are then told not to sing that song by an anxious adult, and it becomes apparent that there is a child murderer loose on the streets of Berlin. This child murderer, played by Peter Lorre, compulsively whistles "In the Hall of the Mountain King" from Edvard Grieg's Peer Gynt Suite when stalking potential victims on the streets. It is this trademark, this leitmotiv that adds suspense to the "chase" scenes. It also leads to the capture of the murderer by the city's criminals in the end, as a blind beggar recognizes him from his whistling.

In his second sound film, DAS TESTAMENT DES DR. MABUSE, Fritz Lang actively employed city and traffic sounds in the narrative. The film opens with a scene in which a detective has entered a factory as part of an investigation. The soundtrack is dominated by a loud industrial thumping that shakes the furniture, drowns out all other sounds and makes the dialogue between two criminals unintelligible. Outside the factory a truck departs loaded with barrels. It is silent when the detective sneaks out (there are no background sounds and his footsteps are not heard), but suddenly there is a loud bang as a block of wood is thrown from the roof - the detective jumps aside just in time. He runs away evading a barrel rolled towards him. The barrel explodes. The explosion and the rolling barrel are heard. The footsteps of the running detective, again, are not.

Lang adheres in this opening scene to the principles he outlined for M. But instead of imbuing "innocent" sounds with sinister meanings, the dangerous sounds in "Mabuse" are straightforward: the thumping of the machines, the falling block of wood, the exploding barrel. This is in line with the story and theme of the film: whereas $M$ was a film about a normal looking man failing to repress the dark side of his personality, and the massive hunt at someone who blends in with the crowd, "Mabuse" is the story of a master criminal who from his jail cell still rules an army of crooks in an attempt to destabilize society. The bad guys are recognizable, they are powerful and omnipresent, the danger is obvious and the sounds that come with that danger are loud, threatening and intrusive.

A second significant scene in DAS TESTAMENT DES DR. MABUSE takes place after approximately 30 minutes into the film. The character Dr. Hauser is on the verge of unmasking his colleague, Prof. Dr. Baum, as an accomplice of criminal mastermind Mabuse. But while waiting for a red light on a crossroads, he is shot by an assassin sitting in a car next to him. The assassin masks the gunshot by sounding his horn and getting other drivers waiting at the crossroads to sound their horns too. This includes 
Dr. Hauser, whose car horn produces a high and squeaking sound - in stark contrast to the lower, more threatening horns of the other cars. Only after Dr. Hauser has been shot, the traffic light turns green again, and the drivers stop sounding their horns and drive away. Dr. Hauser's not moving car prompts the cars behind him to sound their horns and this alerts the police agent who is directing traffic. It is only then that the police agent finds out that a crime has taken place, one masked by the sound of car horns. Fritz Lang produces a real cacophony here that is also actively employed in the narrative. The idea of a cacophonous city, or the notion that this amount of noise is part of city life, is in line with Lang's strictly functional use of film sound.

Lang's particular use of city sounds in $M$ and in DAS TESTAMENT DES DR. MABUSE can not only be understood as adhering to formalist principles; his deployment also had consequences for the reality-effects that these background sounds usually produce. Background sounds, as argued in Chapter 3, produce reality-effects exactly because they are in the background, exactly because they are not directly related to the action or the plot. Lang's exclusive use of sounds which contribute to or are necessary for the action implies that these sounds cannot be background sounds, and that therefore they no longer produce a reality-effect or at least they do so considerably less. Perhaps this is why to our modern ears Lang's Berlin sounds particularly empty if not unreal or even uncanny. There is an overlap here with the narrative functions of film sounds. We may posit that cardinal functions and indices proper - those sounds that actively contribute to the action and the plot - do not produce reality-effects. This important task is relegated to the sounds that function as catalysers or informants.

\subsection{The sounds of "class struggle" and "Kampfzeit"}

The Weimar period was a time of great political and social unrest in Germany. The extreme right and far left clashed not only in parliament and on the streets, but also in film. Modernity, modern life and the city were contested subjects in heated debates. And Berlin was, as Wolfgang Natter calls it, the crystalization point of these debates (Natter 1994: 214). Guntram Vogt has observed that Berlin, being the central metropolis of the pre-Nazi years, was also the dominant city to be filmed, not only because of the city's architecture and infrastructure, but also because of the "ever faster increasing political and social antagonisms in the city" (Vogt 2001: 31). ${ }^{51}$ In this section I will examine the articulation of this specific identity of Berlin in the representation of the city's soundscape in several films that are explicitly political or ideological.

Historical distance makes it risky to read political subtexts into films. This is especially tricky for the Weimar period. Actually, this issue has already provoked academic controversy and stirred prolonged debate. ${ }^{52}$ Therefore I will limit myself in

\footnotetext{
51 “....andererseits aufgrund der sich immer schneller verschärfenden sozialen und politischen Konflikte in der Stadt."

${ }^{52}$ In a by now classical book on the period, Siegfried Kracauer stated that Weimar cinema had psychologically prepared the German people to accept the new regime of the Nazis (Kracauer 1984 [1947]: 11-18). Initially
} 
this section to films that are explicitly political or ideological. This to avoid the mistake of reading into films a political subtext that one can only identify with the knowledge of hindsight - while acknowledging that in the last years of the Weimar Republic and during the Third Reich film was used as a means of propaganda.

Bruce Murray has described the emergence of a leftist cinema in the late Weimar years, next to the established film industry that was increasingly under conservative control (Murray 1990: 233-37). One of the films produced in this marginal leftist film industry was Slatan Dudow's Kuhle WAMPE OdER: WeM GEHÖRT DIE Welt? (1932). "KuHLE WAMPE" tells the story of a young woman from a poor family. After her unemployed brother commits suicide the family is evicted from their house and forced to live in a slum of tents outside the city. The older people lose faith and spend their time drinking and partying, but the young people, in-between romantic adventures, join the communist party to build a better future.

The production and release of KUHLE WAMPE ODER: WEM GEHÖRT DIE WELT? encountered some serious problems exactly because of its socialist message. The company from which the makers rented the sound equipment for the production wanted to cancel the agreement halfway the production because they were afraid to lose other clients. And when the film was released, it was at first banned by the censor under pressure of right wing protests (Brecht 1932: 44-45, Kracauer 1932: 51). Perhaps even more important for the filmmakers: there were doubts about the potential of the sound film to be a truly revolutionary art form. Walter Benjamin for instance felt that the introduction of sound film was a push by the industry to defuse the revolutionary potential of the silent film (Benjamin quoted in Segeberg 2003: 85). Sound film led to further standardization and industrial centralization. Furthermore, and here Benjamin's opinion echoes that of the formalist film theorists discussed in Chapter 2, synchronized sound and dialogue destroyed the audience's imagination (Benjamin quoted in Segeberg 2003: 85). On the other hand, the prominent Soviet filmmaker and theorist Sergei Eisenstein did see a role for sound in film: it had to offer "counterpoints" to the image. A counterpoint is an aesthetic situation in which one element of a work of art expresses a different meaning than another element that is placed next to it (spatially or temporally). The difference between these meanings then produces a third meaning that can serve as a commentary. ${ }^{53}$

Four diegetic sound events in KUHLE WAMPE ODER: WEM GEHÖRT DIE WELT? can be discussed in terms of the political and ideological construction of the modern city of Weimar Berlin. The first one concerns modes of transportation. A young man's search for a job is carried out by bicycle during a lengthy scene in the beginning of the film.

this was an indirect result of the difficulties in which the Weimar Republic found itself after World War I and in the 1920s, but later, according to Kracauer, it was a direct result of the ownership of the UFA studio by the conservative businessman Alfred Hugenberg, who supported Hitler (Kracauer 1984 [1947]: 144, 284). It should be noted, though, that ever since its publication Kracauer's thesis has been criticized for being teleological. His arguments were discredited by scholars of film culture, film reception and gender studies who underlined the richness and heterogeneity of Weimar cinema (Hake 2008: 29).

${ }^{53}$ For more on Eisenstein's theory of film and sound, see Chapter 2, section 2. 
Together with other unemployed men he races from factory to factory to seek employment. Yet the sound of bicycles is not heard over the non-diegetic music. The bicycle, the poor man's mode of transportation, is silenced, but cars, which do not have an important role in the narrative, are dominantly present: car related sounds make up $33 \%$ of all Urban Sound Events in KUHLE WAMPE. This opening scene of KUHLE WAMPE ODER: WEM GEHÖRT DIE WELT? offers a clear example of a counterpoint use of sound. Moreover, the same sequence shows the depressing living conditions of the Berlin working class, but is underscored by what composer Hanns Eisler called "quick and sharp" music, suggesting that the image of Berlin as the bright capital of the European avant-garde detracts attention from the horrid living conditions of the working class (Scheunemann 2003: 426-27).

The second noteworthy sound event can be discerned in the scene following the bicycle ride, in which the young man comes home. His mother complains that it is the same struggle, each and every day. Two musicians perform in the courtyard near the house. They play a small organ and a singing saw. After the frantic traffic scenes, the calm of the courtyard and the melancholic music evoke the hopelessness of the working class' situation (Vogt 2001: 284). Apparently, singing saws were very specific to Berlin. Actress Hertha Thiele, who played Anni, the young man's sister, said she did not know the singing saw from Leipzig, where she came from (Thiele quoted in Vogt 2001: $278){ }^{54}$ I will return to the organ, and specifically the organ in the courtyard, in the next chapter, as it is an important element of the political construction of the city.

The third sound event to be mentioned here is a theatrical song sung during a sports event for communist youth. It comments on the practice of house evictions, a subject treated in the film's first part:

See the landlord throw out an old tenant / He immediately brings in the movers / "Go ahead, and load up the junk" / "Oh no, you are making a mistake / We have lost our benefits mister landlord" / "You owe me a half year's rent / God knows I've been patient enough."55

The text and staging of the song, embedded in a longer performance of Hans Eissler's "Go ahead and don't forget," implies that inhumane evictions will not take place under communism. This is an example of how diegetic music can play a role in the political construction of (the experience of) city life.

A film from the opposite end of the political spectrum bears some striking similarities to "KUHLE WAMPE." HitlerJUNGE QUEX (Steinhoff, 1933) was made and released shortly after the Nazi party came to power, but before Joseph Goebbels reorganized the film industry. It was produced by UFA, still a commercial company, in response to a film from competitor Bavaria Film: S.A.-MANN BRAND (Seitz, 1933).

\footnotetext{
54 “... die "Singende Säge” auf den Hinterhöfen - das kannte ich aus Leipzig nicht."

55 "Da schmeißt der Wirt "nen alten Mieter raus! Die Möbelträger bringt er sich gleich mit / So, laden Sie mal immer auf den Kitt / Ach nee, Sie ha"m sich wohl bei uns jeirrt / Wir sind doch ausgesteuert word'n, Herr Wirt! / Sie sind eind halbes Jahr die Miete schuldig / Ich war, weiß Gott, jetzt lang genug geduldig!"
} 
These two films mark a curious moment in German film industry, when the production of Nazi propaganda was not centralized and controlled by the government, but rather a promising business opportunity.

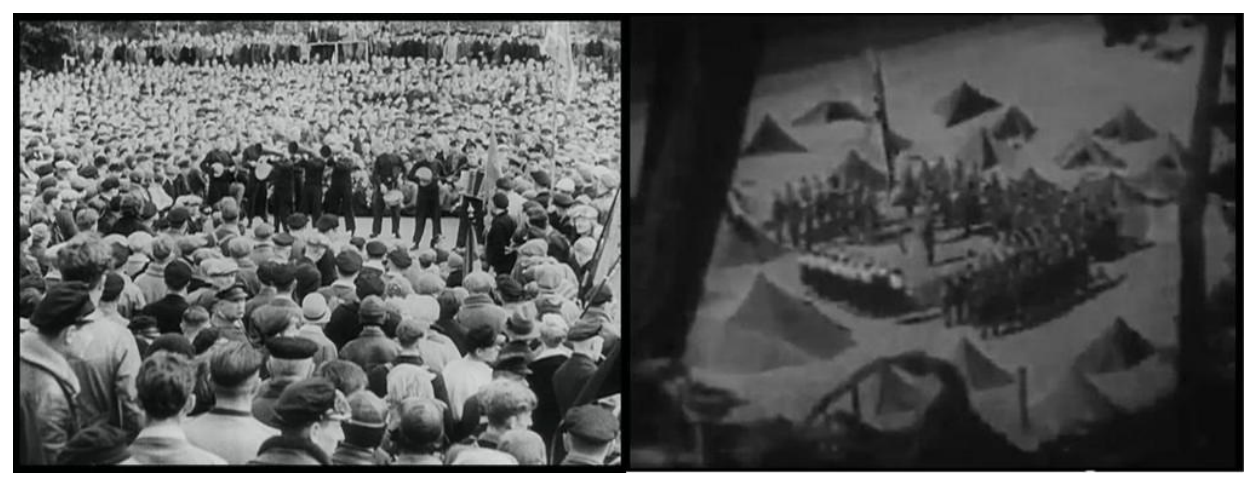

Illustrations 10: Similar audiovisual strategies in Kuhle Wampe oder: Wem Gehört die Welt? (Dudow, 1932) and Hitlerjunge Quex (Steinhoff, 1933)

HITLERJUNGE QUEX, which takes place during the last years of the Weimar Republic, tells the story of the young Heini, who is forced by his father to join a communist youth camp. There he sneaks away and finds a Hitler Youth camp, which he likes better. Against his father's will he joins the Nazis, who give him the nickname Quex ("Mercury"). At the end of the film Heini is killed by grown up communists when he distributes Nazi pamphlets.

What is interesting here is that Heini does not seem to join the Nazis because of their ideology or politics. Nor is there any discussion of communist politics. Instead, Heini is attracted by the uniforms the Hitler Youths wear, by their rhythmic marching, and because they sing together while raising the Swastika flag. Apart from the symbol on the flag and the actual lines of the song, the Hitler Youth camp looks and sounds similar to the sports event for communist youth shown in "KUHLE WAMPE" Also, as in "KUHLE WAMPE," the older generation is blamed for their passivity and their having allowed the country to deteriorate.

A difference between HitlerJunge QUEX and "KUHLE WAMPE" is that the communist film does not feature any Nazis, whereas HITLERJUNGE QUEX spends quite some time on representing the communists. They are portrayed as disorderly, illmannered and even promiscuous. Their travel to and stay at their youth camp is characterized by such activities as yelling, screaming, drinking and mocking the passing Hitler Youth. Back in the city the young communists meet at the fairground, which is continuously announced and underscored by the sound of a loud barrel organ, and the adult communists spend their time in a café. The Hitler Youth on the other hand live in a clean group house, and spend their leisure time distributing political pamphlets. 
Significant is the role of the city in HITLERJUNGE QUEX. In a contemporary textbook on youth and film a plot summary of the film hints at the bad influence the city can have on youth:

... Heini's heart belongs to the Nazis, particularly since he went on a weekend camp and had the opportunity to see the contrasting conduct of two youth groups: the clean, disciplined, happy comradeship of the Hitler Youth, compared with the atmosphere of the Communist's camp - oppressed and poisoned by big city life. (A.U. Sander quoted in Welch 1983: 61)

Indeed, during the "Kampfzeit" (the Nazi term for their supposed "period of struggle" at the end of the Weimar Republic), the Nazis considered the city as a corrupt place; a breeding ground for communists. In the opening sequence of HITLERJUNGE QUEX, a street riot is staged in response to the theft of a single apple by a hungry child. The riot is scored with the chaotic sounds of an agitated crowd, galloping police horses and whistles.

However, after 1933 and especially after the start of the war, cities in films increasingly become harmonized spaces (Birdsall 2012: 161-62). Films situated in cities continue to demonstrate a fascination with modernity and progress. In these films we still encounter crowds, traffic and machines, but no longer in terms of a cacophony of a big city. Quite the contrary:

The portrayal of the urban, moreover, is not only crucial in terms of the status of sound in Nazi cinema, but also underlines the attempts to tame the supposedly chaotic space of the modern metropolis, symbolized by its noisy sounds and unpredictable rhythms. (Birdsall 2012: 148-49)

In HITLERJUNGE QUEX there is already an idea of what an urban soundscape under National Socialist cinema might sound like. It is in the marching of the Hitler Youths that an early form of affirmative resonance is found. Following Cornelia Epping-Jäger, Carolyn Birdsall defines affirmative resonance as "a practice or event when a group of people communally create sounds that resonate in a space, thus reinforcing the legitimacy of their group and its identity patterns" (Birdsall 2012: 34).

The first time we hear the Hitler Youths marching in HITLERJUNGE QUEX is when they pass the communist youths who are also on their way to a camp site. Heini, still with the communists, is impressed by the marching, but the other communist children ridicule the Hitler Youths. The second time is when Heini walks along with a Hitler Youth boy to inquire about their organization and join them. Their footsteps synchronize in a way that suggests that the rhythm of the marching is found intuitively; as if it already, naturally, resides in Heini's body and between the two young German boys. Later on in the film however another Hitler Youth boy is seduced by a communist girl: as he walks her to the fairground their footsteps are slightly asynchronous. The 
affirmative resonance produced by the act of marching is disturbed by communist plotting.

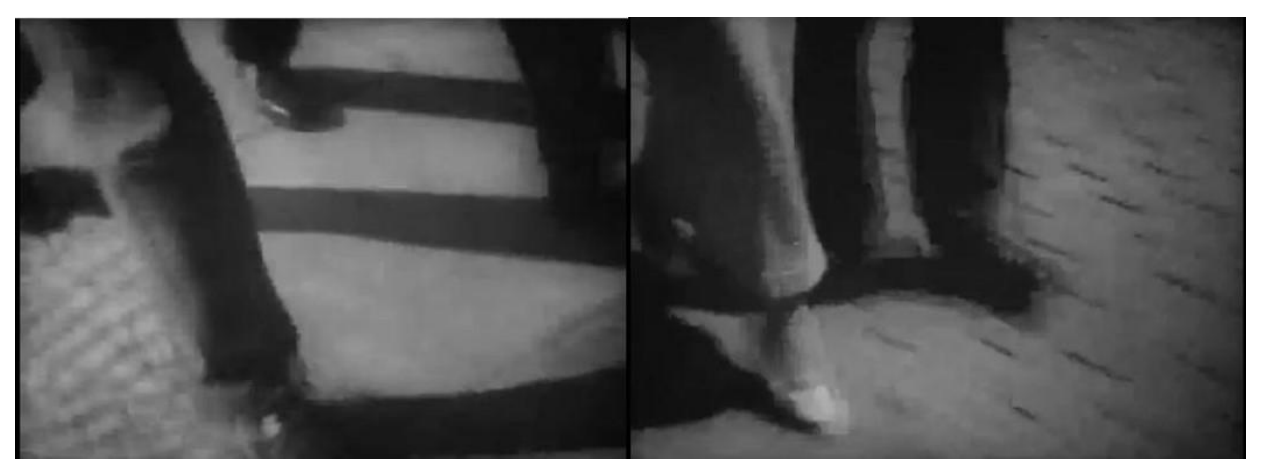

Illustrations 11: On the left, Heini's and the Hitlerjugend boy's legs march synchronously. On the right, however, the communist girl's legs move in a different rhythm than the other Hitlerjugend boy's legs, in HITLERJUNGE QUEX (Steinhoff, 1933)

Part of the harmonization of the city was a return to the musical metaphors of melody and symphony that surrounded the discourse about BERLIN, DIE SINFONIE DER GROßSTADT (Rentschler 1996: 177, 188).$^{56}$ Affirmative resonance became an element of this new musicalization of city sounds. In the propaganda film WUNSCHKONZERT (Eduard von Borsody, 1940), which borrowed its title from the radio show with the same name, several instances occur wherein Urban Sound Events are musicalized and/or produce affirmative resonance.

The film opens with a scene taking place during the 1936 Olympics in Berlin. Stock documentary footage is used to show the crowds in the stadium and the arrival of Hitler. Blending in with the non-diegetic music from the opening credits, large bells in the stadium tower are tolled to signify the start of the film and the start of the opening ceremony. Like church bells in pre-modern towns they urge people to come together in a celebration or ritual (both the people in the film, and the people in the cinema). ${ }^{57} \mathrm{In}$ response to this call the crowds cheer and applaud as a well instructed choir when Hitler arrives, and later as the national teams parade into the stadium. There is a significant rise in the pitch as the German team enters. The use of sound (music, chants, bells) in this scene can be understood as another example of the musicalization of sound. This coincidence of affirmative resonance and the musicalization of sound emphasizes that

\footnotetext{
${ }^{56}$ Despite Ruttmannn's later work for the National Socialist regime we must not make the mistake of understanding his earlier city symphony in the context of Nazi aesthetics. Nazi propaganda adapted the musical discourse surrounding "Berlin," but gave it an entirely different meaning.

${ }^{57}$ In 1940, church bells were also an important part of victory celebrations. All the more ironic it seems that in Germany, during the war, some ninety thousand bells were destroyed by bombing or melted down to be turned into guns and bullets (Birdsall 2010: 144). On the historical importance of church bells in communities, see also Corbin (1998 [1994] and 2004).
} 
the latter is not only a strategy for filmmakers, but that it also refers to the experience of sound by the audience.

Later on, the radio show from which the film borrows its title is staged: an early form of interactive media, in which soldiers at the front and families at home can request certain pieces of music to be played by a resident orchestra. In the radio studio in Berlin the orchestra plays for an audience and its performance is broadcasted across the Reich. This is not affirmative resonance in Birdsall's definition - a resonance in a material public space - but a variation in which the resonance is immaterial: the radio show, by responding to letters and broadcasting requested music, creates a connection between Berlin, the front and the families in the rest of the country, thereby reinforcing the legitimacy of the group, the German nation and the status of Berlin as the central capital (Birdsall 2012: 113).

In contrast to leftist film-making, which sought to highlight the inequality and poverty in the city through the use of counterpoints between image and sound, National Socialist cinema harmonized the city and the urban experience, both before and during World War II: "In the closed political system of the Third Reich a productive, protesting criticism was replaced by a smoothing out - in film - of the accumulated contradictions of the city" (Vogt 2001: 39). To control the city environments in such a way that they conformed to this ideal, outdoor or location shooting was minimized (Rentschler 1996: 216). This is an interesting development: whereas the recording of early sound films was restricted to the studio because of practical reasons - and economy and technology thus determined to a great extent the sound of the represented city - in later years the politically required aesthetic of the represented city led filmmakers to film indoors, although location shoots were (at times) possible.

With what now seems a grim irony, the harmonized representation of Berlin continued throughout World War II, even though the reality of the city was that of daily bombings and destruction. Berlin even became the subject of another city symphony in 1942, Leo de Laforgue's SYMPHONIE EINER WeLTSTADT (released in 1950), which showed the last images of the city before the allied bombing raids began. ${ }^{58}$ After the war, the reconstruction of the (cinematic) city would have to be material and political at the same time.

\subsection{Conclusion}

This chapter has been informed by a number of oppositions. First, there is the contrast between the staging of the city as a symphony and as a cacophony. This contrast concerns the representation of the city, but more importantly, the representation of the experience of the city by characters in a film. The representation of the city as a symphony offers an experience of the city as harmonious and grandiose. The cacophony of a big city, on the other hand, offers an experience of the city that is also overwhelming, like the symphony, but next to that fragmented, disjointed and atonal.

${ }^{58}$ Unfortunately I was not able to include this film in my analysis, as I could not obtain a copy. 
These two possible stagings of the urban soundscape relied on two opposed audiovisual strategies that filmmakers could employ. The city symphony made use of the musicalization of city sounds; the translation of sounds into music, and the experience of sounds as music by film characters. Cacophonous stagings of the soundscape, on the other hand, relied, among other things, on the noisification of music; the merger of music with city sounds, and the subsequent experience of music as noise by the audience. This experience could then signify a psychological state of mind of a character and his or her experience of the soundscape of the modern city.

When the city is staged as a symphony or a cacophony, it is not a neutral background to the action. It is imbued with character, or agency. We can understand the extent to which a city is an active element in the plot through another opposition: the opposition between sounds that function as cardinal functions and indices proper on the one hand, and sounds that are "merely" informants or catalysers on the other. We may propose a "cardinal function-to-catalyser" ratio and an "indice proper-to-informant" ratio to "measure" the active character of the city in film as expressed through film sounds. I will use these ratios in the next chapter to examine the development through time of the active character of the city in fiction film.

A final opposition that we can discern in this chapter is the opposition between counterpoint uses of sound and the use of sound for the creation of affirmative resonance. Following theorists such as Sergei Eisenstein and Bertolt Brecht, leftist filmmakers created counterpoints between image and sound to signify and comment on the social reality of Weimar Germany, for instance in the film KUHLE WAMPE ODER: WEM GEHÖRT DIE WELT? On the other end of the political spectrum right wing and Nazi propaganda films, such as HITLERJUNGE QUEX and WUNSCHKONZERT, presented a harmonious staging of the city. Affirmative resonances - communally created sound events that reinforce the legitimacy and identity of a group - contributed to this harmonious staging of Nazi Berlin.

These tensions and oppositions that we recognize in the representation of Berlin's soundscape in the (long) 1930s are the result of the instability of the city's identity and the instability of Weimar society. Filmmakers did not merely try to achieve a realityeffect when staging the city. They participated in the political and cultural construction of Berlin's identity, a city that was paradigmatic for the broader concepts of modernity, industrialization and urban life in the first third of the twentieth century. This chapter has pointed out that the distinction between the city and the city-in-film that I still used in the previous chapter cannot easily be maintained. The identity of the city is discursively constructed, and fiction films are part of that discourse.

This process of discursive identity construction coincided, in the late 1920s and early 1930s, with the introduction of recorded and synchronized sound in cinema. The theoretical debate surrounding this innovation overlapped with the debates on politics, art and modernity, as we can see in the writings of for instance Walter Benjamin and Sergei Eisenstein (Eisenstein 1928; Segeberg 2003: 85). Furthermore, the addition of sound offered filmmakers new possibilities to articulate the oppositions and tensions at the heart of these debates. The soundtracks of these films do not simply echo the 
soundscape of Berlin in the late Weimar and Nazi periods, but also the various opinions about modernity, politics and sound itself.

Weimar Berlin, because of the iconic status of BERLIN, DIE SINFONIE DER GROBSTADT, has become the blueprint of the cinematic city. However, the addition of sound to film complicates the myth of the cinematic city, as it forced filmmakers to reconsider how to stage and represent Großstadt Berlin: as a symphony or a cacophony, harmonious or filled with social dissonances? These two, musically phrased, oppositions resemble the opposition between the attraction and the danger of the city one of the bedrocks of the myth of the cinematic city. However, whereas the latter opposition signifies particular qualities or properties of the city to outsiders, the former two capture the experience of city life by the inhabitants of the city-in-film. A sonic perspective on Berlin-in-film makes it clear that this experience was staged by filmmakers in strongly diverging ways. 


\section{Chapter 5}

\section{Berlin Part II: City under Reconstruction (1946- 2001)}

\subsection{Introduction}

That the novel [Berlin Alexanderplatz] was adapted for film so shortly after its publication was especially an advantage regarding the city's portrayal. Ten years later Germany found itself at the climax of World War II, after which the city of Berlin was no longer recognizable. (Braunger 2008: 28) (99 $^{59}$

What Amely Braunger implies in this quotation is that Berlin Alexanderplatz could not have been made into a film after the Second World War. Practically and materially, the city that Alfred Döblin described did not exist anymore. After the war, Berlin was a transformed city. Allied forces from four different countries occupied it, while much of its architecture and infrastructure was destroyed and many of its surviving residents were traumatized. A political system that had been in place for over a decade was suddenly gone, and the city's identity - as vibrant center of Weimar Germany and shining capital of the Third Reich - had to be reinvented all over again. ${ }^{60}$ Accordingly, "city under reconstruction," as a metaphorical label for Berlin-in-film in the second half of the twentieth century, should be understood in a literal sense as well.

In this chapter I will discuss the representation of the ongoing (re)construction of Berlin and its identity in fiction film, and specifically the role of sound in this representation. I will make use of the quantitative analysis of Urban Sound Events (USEs) to compare the staged urban soundscape of the 1950s with that of the 1930s, 1970s and 1990s, and also compare the soundscape of the two Berlins in the 1950s and 1970s. For Berlin was no longer a single city after the war. It was first divided into four occupation zones, and by 1949, after the establishment of the Federal Republic of Germany (FRG) ${ }^{61}$ and the German Democratic Republic (GDR), ${ }^{62}$ into two cities: West Berlin and East Berlin.

\footnotetext{
59 "Das der Roman zo kurz nach Erscheinen verfilmt wurde, konnte vor allem für die Stadtansichten nur von Vorteil sein. Zehn jahre später sollte sich Deutschland auf dem Höhepunkt des Zweiten Weltkrieges befinden, nach dessen Ende die Stadt Berlin nicht wieder zu erkennen war."

${ }^{60}$ It is possible to understand the "reinvention" of Germany's and Berlin's identity after the Second World War as similar to the "invention of tradition" as described by Eric Hobsbawm and Terence Ranger (Hobsbawn \& Ranger 1983: 1). The invention of tradition is an important part of building nations and nation states, an argument also reflected in Benedict Anderson's concept of "imagined communities" (Anderson 1991: 1-8).

${ }^{61}$ Bundesrepublik Deutschland (BRD).

${ }^{62}$ Deutsche Demokratische Republik (DDR)
} 
Comparing East and West Berlin is not simply comparing two cities, but two divided parts of what used to be one city. The similarities between them are not incidental, and neither are the differences. Post-war Berlin-in-film, as much as the real city it signifies, is a contested place where ideologies and political systems clash. The previous two chapters have shown how the representation of the urban soundscape in film is informed by a number of conceptual or theoretical contrasts or oppositions. It is tempting to take these and other ones, and to project them onto a divided Berlin-in-film. If occasionally this will lead to interesting and fruitful insights, it would also be a limiting perspective that ignores the similarities between, and the shared history and culture of, East Berlin and West Berlin. The artificial nature of the division between the two is addressed in a special section, in this chapter, on the border zone between East Berlin-in-film and West Berlin-in-film. This zone that cut through the middle of what used to be one of the busiest places of the metropolis proved an unnaturally silent place; a deserted place even and one that was quite dangerous to cross.

After the reunification of the two Germanies in the early 1990s, the slow and sometimes painful reconstruction of the city and of its identity was also represented in film. I will show that this "new" Berlin-in-film's soundscape is partly a blend of that of East Berlin and West Berlin, and partly a continuation of that of West Berlin-in-film only. As the old tensions disappeared, a new "other" emerged: the migrant. Below I will argue that migration and the integration of foreign elements in Berlin's soundscape serve as important issues in Berlin-in-film of the 1990s.

To be sure, urban identities are always under construction in cities everywhere. This is as valid for Amsterdam or London as it is for Berlin. But nowhere has this construction been so explicitly staged, and heard, as in Berlin-in-film. And the more explicit the (re)construction of the city and its identity are staged in fiction film, the clearer we can see and hear how the myth of the cinematic city is a construct - a rather limited perspective on what a city-in-film can look or sound like.

\subsection{Reconstructing the city-in-film}

After the World War II, Berlin lay completely in ruins. American and British bombing raids and the Soviet army's siege had taken a devastating toll on the city's infrastructure (Evans 2010: 11). It is safe to argue, then, that "under construction" - the metaphor I use to characterize the representation of the identity of Weimar and Nazi Berlin - does no longer apply to the long $1950 \mathrm{~s},{ }^{63}$ for in that period Berlin was under re-construction in a quite literal sense. This reconstruction of the city after the war was an important theme in East German film of the immediate postwar period. In these Trümmerfilme ("rubble films") the psychological recovery of the war is thematically connected to the political and material reconstruction of the city.

${ }^{63}$ The "long 1950s" here refers to the period 1945-1962. This framing of the 1950s does not only offer me the possibility to discuss the "rubble films" (Trümmerfilme) of the immediate postwar years; it also conforms to the conventional periodization of (West) German cinema in other historical works (Hake 2008: 92-93). 
In May 1945 the Soviet army conquered Berlin and established a military administration, the Sowjetische Militäradministration in Deutschland (SMAD), to govern what would later, in 1949, become the German Democratic Republic (GDR). West Germany, and the Western part of Berlin, were divided in an American, British and French zone. In the East, in 1946, the SMAD supported the foundation of Deutsche Film A.G. (DEFA), which would organize film production in East Germany according to the Soviet model of centralization and state control. The task of DEFA was to produce films that countered sentiments of nationalism and militarism and promoted the principles of international cooperation. Its goal was to move away from the filmic traditions of the former big German studio UFA and the political legacies of the Third Reich, and to contribute to the creation of a socialist society in East Germany (Hake 2008: 95).

By contrast, film production companies in West Germany, from 1949 onwards the Federal Republic of Germany (FRG), were private, profit-oriented companies that catered to a wide audience. Here too, "rubble films" and anti-war films were produced, but they were not popular with war-weary audiences. Films on social issues were popular, however (Bergfelder 2005: 24-9; Hake 2008: 112). ${ }^{64}$ After the box office failures of the rubble-films, postwar West German cinema was characterized by depoliticization, which was in stark contrast to East German cinema. This period of depoliticization would end with the 1962 "Oberhausen Manifesto," in which young filmmakers denounced "daddy's cinema," and in which there was a new place for politics. These filmmakers established the "Young German Cinema" (Hake 2008: 15356; Rentschler 1984: 35-39). Before discussing this movement, I present an analysis of films set in Berlin in the late 1940s and the 1950s, beginning with the so-called "rubblefilms."

The first film produced by DEFA was DIE MÖRDER SIND UNTER UNS (Staudte, 1946). It tells the story of a doctor who is traumatized by the war, and the young woman with whom he shares an apartment. The film was shot on the streets of Berlin and in the old UFA studio in Babelsberg. Production circumstances were difficult: lights and cameras would often break down, as was true of the microphones (Vogt 2001: 419). The street scenes showing the city in ruins were filmed on Andreasstraße, but the ruins remain in the background; they are merely the backdrop for the action, which is concerned with psychological recovery and justice. At the very same time the city in ruins is also a metaphor for the protagonist's state of mind, which is also expressed in sound, such as by a cold wind howling through a broken window and a wall collapsing. But there are also sounds that imply a new future: As the protagonist, a doctor, walks

\footnotetext{
${ }^{64}$ The rubble films discussed in this chapter are all East German DEFA productions. One reason for this is that many West German films were set in other cities than Berlin. ZWISCHEN GESTERN UND MORGEN (Braun, 1947), for instance, was set in Munich. Another reason is the limited availability of these films on DVD. The West German BERLiner BALLADE (Stemmle, 1948) was not available to me at the time of this study. There were also foreign rubble films, most famously Roberto Rosselini's GERMANIA ANNO ZERO (1947), but I have chosen to focus on films by German filmmakers. For more detailed studies of rubble-films, see Stettner (1992) and Shandley (2001).
} 
through the streets with his former army commander, with whom he discusses the future, women are clearing the rubble, and the sound of brick on brick and brick on metal is heard. As if the war had been just a minor event, the former commander kicks away an army helmet left in the ruins.

Director Wolfgang Staudte uses diegetic music to stage this moment of transition in Berlin. The first scenes of the film show the city in ruins, while seemingly inappropriate, joyful piano music is played. However, this music turns out to be diegetic: It comes from a small cabaret venue where the doctor hangs out and gets drunk. In an echo of the beginning of KUHLE WAMPE ODER: WEM GEHÖRT DIE WELT?, the counterpoint between music and image suggests a bitter commentary on the state of affairs in Berlin. The sound of (variety) music and performances, innocent and happy as it was in such 1930s films as VIKTOR UND VIKTORIA (Schünzel, 1933) and GRAND HOTEL (Goulding, 1932), now refers to passivity and aimlessness. Much later in the film however, the equally joyful sound of a street organ is used positively: the organ is shown and heard the moment the doctor decides to help a sick child, rather than kill his former commander in revenge over a war crime he was forced to commit. Here the happy music punctuates a positive development and turning point in the story.

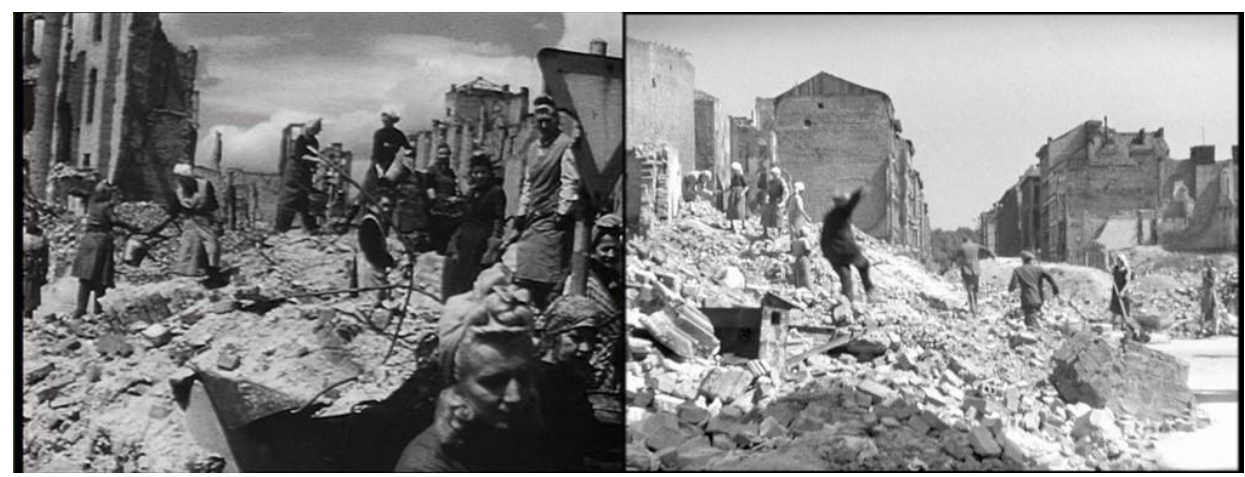

Illustrations 12: Sights of a Berlin in ruins in Die Mörder Sind Unter Uns (Staudte, 1946) and Irgendwo in Berlin (Lamprecht, 1946). Significantly, in both films women clear the rubble

In that very year, 1946, another rubble-film was released by DEFA: IRGENDWO IN BERLIN (Gerhardt Lamprecht). This film, about a group of young boys living their lives in the ruins of Berlin, without fathers or father figures left, represents postwar Berlin as a very silent place. If in DIE MÖRDER SIND UNTER UNS this silence is compensated for by non-diegetic music, there is but little music in IRGENDWO IN BERLIN. And traffic sounds and background sounds are so rare, that when the children play "war" in the rubble every footstep is audible. The sound of clearing the rubble - which is again work done by women - is present in the foreground. One hears trams and tram horns, but at a considerable distance. They are far away from this part of city, "somewhere" (irgendwo) in Berlin. When the children, playing with fireworks, launch a rocket, a faint reply comes from a faraway car horn. But in this part of Berlin there are no modern 
modes of transportation. There is only a horse-drawn cart, and the characteristic sound of an old water pump, not exactly an icon of modern times. In IRGENDWO IN BERLIN, the war not only destroyed the city's infrastructure, but an entire mode of modern, urban life. And with that life, the soundscape that results from it.

A third rubble film from 1949 is more explicitly concerned with reconstruction than the previous two: UNSER TÄGLICH BROT (Slatan Dudow) tells the story of a family torn apart by different expectations about Germany's future. ${ }^{65}$ The passive father has resorted to drinking, respecting only the son who earns money, however shady his job may be. The father meanwhile argues bitterly with his other son, who oversees the reconstruction of a socialist factory, without having earned any money so far. Machine and industrial sounds function as the signifiers of progress and reconstruction, especially in the finale, which celebrates the production of a first line of tractors and the wholehearted involvement of a reunited family in the production process.

Through the use of a street organ in a courtyard, UNSER TÄGLICH BROT explicitly refers to pre-war cinema, especially KUHLE WAMPE ODER WEM GEHÖRT DIE WELT:

The reflection of city images from pre-war cinema is indicated in a scene in which street organ music penetrates the house of the Weber family. After the ideological modernization of the city in Nazi-film, in which horse drawn carts and courtyard music were consciously employed as nostalgic reminiscences, and after the forced representation of an unharmed city during the war ... the performance of a street organ artist in Dudow's film is a casually emphasized reference to the poverty and simplicity of the immediate postwar years" (Vogt 2001: 451). ${ }^{66}$

In this light it is most striking that it is the capitalist father who gets annoyed and shuts the window through which the music enters the house. The street organ, in films situated in Berlin in the 1930s and long 1950s, has come to signify a variety of moods, atmospheres and even political contexts. For Fritz Lang, in "M" (1931), it was a cultural artifact to toy with, especially appropriate for the sound film. In "KUHLE WAMPE" (Slatan Dudow, 1933) it signified despair and poverty. In HITLERJUNGE QUEX (Hans Steinhoff, 1933), in the scenes that are set on the fairground, the organ symbolizes the disorderly and immoral behavior of communists. After the war, the street organ is not only a reference to poverty, but it also underlines a positive, productive decision by the protagonist of DiE MÖRDER Sind UNTER UnS. Finally, in DiE HALBSTARKEN (Georg

\footnotetext{
${ }^{65}$ The title words, so closely associated with a Christian prayer, emphasize these different expectations. The young socialists want to provide Germany with its daily bread through their own labor, whereas members of the older generation put their faith in God and wait for a miracle to happen.

66 "Der Rückbezug auf Stadtbilder der Filmischen Vorkriegszeit wird angedeutet durch eine Szene, in der in die Hinterhofwohnung der Webers Leierkastenmusik dringt. Nach der ideologischen Modernisierung der Stadt im Nazi-Film, der darin bewußt Pferdedroschken und Hinterhofmusik als nostalgische Reminiszenzen eingesetzt hatte, und nach der um eine heile Stadt bemühten Darstellung während des Krieges ... bedeutet der Auftritt eines Leierkasten-Musikers in Dudows Film eher einen beiläufig-nachdrücklichen Hinweis auf die Armut und Einfachkeit der unmittelbaren Nachkriegsjahre."
} 
Tressler, 1956), a film discussed in more detail below, the organ sounds anchor the safe courtyard home of the one teenager who does not want to take part in a robbery and is subsequently abducted and beaten by the others. These examples show how the street organ, depending on the filmic context can have a variety of functions and meanings. Tellingly, its sound is never the sound of progress, modernization or construction, but it does play a role in the political (re)construction of Berlin in film. It usually signifies simplicity and poverty, but these concepts are differently appreciated in the films mentioned above.

The barrel organ is also one of the soundmarks of Berlin-in-film - a sound that is closely tied to specific locations and that is important to people living there. And over time, it has become a sonic icon of Berlin. ${ }^{67}$ The meanings associated with sonic icons can change however, as pointed out in Chapter 3, where I showed how the soundmarks of Amsterdam-in-film were given new meanings and interpretations by filmmakers in the 1980s and 1990s.Crucially, soundmarks did not lose their old meanings, but to these old understandings were added new ones.

After this discussion of the East German rubble films and their soundscape of Berlin-infilm in the long 1950s, let us turn to West Berlin. The representation of Berlin through film sound encompasses more than the sounds of destruction, reconstruction, production and street organs. At this point we can take a look at the quantitative analysis of Urban Sound Events in the films studied, and draw comparisons between East and West Berlin, as well as with the Berlin of the 1930s. In the representation of the full soundscape of Berlin, analyzed in terms of the quantitative presence of Urban Sound Events, three developments can be discerned: an increase in the share of traffic sounds, a decrease in the share of sounds of musical events and a decrease in the active employment of city sounds in the narrative.

A first significant development is the rise of the share of traffic sounds in the total number of USEs: from $34.6 \%$ in the Weimar period to $45.1 \%$ in East Berlin and $54.8 \%$ in West Berlin in the 1950s (see Annex D, Table 3). As with the total number of USEs, the rise is stronger in the West than in the East. A similar picture applies to background sounds, which are closely related to traffic sounds, because the sounds produced by unseen or unspecified traffic tend to blend into the background sound of an urban environment. The share of background sounds rises from $5.9 \%$ in Weimar Berlin to 9.4\% in East Berlin and $13.3 \%$ in West Berlin in the 1950 s.

Such figures, if anything, suggest that the quick reconstruction of both the urban infrastructure and the German economy was recognized and responded to by filmmakers. Another explanation is the increase in filming on location. As in the Netherlands, the technological restrictions of the 1930s had kept film production mainly in studios, where the new sound technology had also prompted big investments in

${ }^{67}$ For an explanation of the difference between a soundmark and a sonic icon, see Chapter 3, section 3. 
production equipment. ${ }^{68}$ In the 1950 s, sound recording technology became smaller and lighter - facilitating a move to locations - and the success of Italian Neorealism gave rise to an international trend that favored location shooting. The increase in the average number of USEs per film and in the share of traffic sounds and background sounds can thus be understood in the context of changes in film production technology and film culture.

So far, the results of my analysis suggest a strong difference between the 1930s and 1950s. However, if examined in more detail, especially the traffic sounds show a marked difference between East and West Berlin. Cars are the source of $78.8 \%$ of all traffic sounds in West Berlin in the 1950s. With their engines running, tires screeching, doors slammed or simply passing by they are omnipresent. Other modes of transportation are marginalized: trams account for $11.5 \%$ of all traffic sounds. Trucks, airplanes and trains do not represent more than 3\% each. In East Berlin, the sound is rather different: here, cars are dominant as well, accounting for $48.8 \%$ of all traffic sounds, but trams produce $26.2 \%$ of all traffic sounds. The sound of cars does not drown out other sounds. Trucks account for $7.5 \%$, trains for $5.9 \%$, whereas $9.3 \%$ of the traffic sounds constitutes a hotchpotch of sounds impossible to specify beyond "traffic." The representation of other modes of transportation besides cars, in East Berlin-in-film, reflects the city's actual traffic - with less cars and more public transportation - but also the GDR's film-making policies: DEFA's goal after all was contributing to the creation of a socialist society, and in film this may lead to an emphasis on public spaces and public transportation.

Second, next to traffic sounds, we can look at what in this chapter I call "musical" sounds: sounds produced by musical performances, or related to places where such performances take place. Whereas traffic sounds increased from the 1930s to the $1950 \mathrm{~s}$, musical sounds decreased, relatively at least. If in the Weimar period musical sounds accounted for $12.3 \%$ of all USEs, in the 1950s in East Berlin-in-film this dropped to $6.0 \%$ and in West Berlin-in-film to $6.6 \%$. This decline must mainly be understood as a result of a shift in genre. The corpus for the 1930s contains the musical VIKTOR UND VIKTORIA, which dominantly featured variety and orchestra performances. Furthermore, a film like BERLIN ALEXANDERPLATZ had quite a few scenes set in cafés during which folk songs were sung. Musicals, when made in the 1950s, were no longer situated in Berlin.

As regards musical sounds, the two Berlins show a distinct difference: in West Berlin-in-film $30.4 \%$ of all musical sounds is recorded music, while in East Berlin-infilm this is only $8.7 \%$. On the other hand, public performances of live music account for $47.8 \%$ of all cultural USEs there, while the figure for West Berlin-in-film is $34.7 \%$. This difference can be explained by a similar logic as the difference in car and tram

\footnotetext{
${ }^{68}$ In the large Babelsberg studio outside Berlin the first sound stage, the "Tonkreuz" sound stage (the largest of its kind in Europe), was opened in 1929. In the Netherlands the introduction of sound films prompted the building of studios in Duivendrecht and Eindhoven (see Chapter 3, section 2).
} 
sounds: First, the difference in the USEs can reflect a difference in the soundscape of the cities: there were simply more radios, gramophones and tape recorders in West Berlin than in East Berlin - a difference made up for through live music. A second explanation is that film-making policies in the GDR promoted the representation of "public" music over that of private property and luxurious artifacts.

A third development concerns a decrease in the active employment of city sounds in film narratives. Two indicators of the degree to which sounds are actively employed in the narrative are the cardinal function to catalyser ratio and the indice proper to informant ratio. These ratios show the proportional relationship between the active narrative functions (cardinal functions for "doing" and indices propers for "being") and passive narrative functions (catalysers and informants) that can be attributed to USEs. ${ }^{69}$

In the films analyzed for the late Weimar period, the cardinal function to catalyser ratio is 0.38 . For both East and West Berlin in the 1950s this is 0.21 . The indice proper to informant ratio in the late Weimar period was 0.22 . In the 1950s this decreased to 0.15 for West Berlin and even to 0.10 for East Berlin. These decreasing ratios show that filmmakers used city sounds less as active elements in the narrative. The principle of Fritz Lang - that sounds must only be used if they are necessary in propelling the narrative - was not adhered to by his postwar colleagues. This development fits into the (international) shift from Formalist to Realist aesthetics in both film production and film theory that took place after the Second World War (see Chapter 2). There was no space for Formalist experiments with sound such as in Lang's "M," or sound "mistakes," like the missing sound of footsteps under the image of a running man. This development is in line with the increase of background sounds in the 1950s: People have gotten used to traffic sounds; they have become more normal.

Finally I want to discuss two films from the 1950s that highlight the emergence of a youth culture, and pay attention to the sounds associated with it. These are the East and West-German answers to the famous American film ReBEL Without a CAUSE (Nicholas Ray, 1955). Die HALBSTARKEN (Georg Tressler, 1956) is a West German film about two brothers, the oldest of whom drags his younger brother into his gang of teenage criminals. Two sequences in this film stand out in terms of their sound: The first one is a scene in a newly opened café, where the gang members hang out and have a party during which they play rock'n'roll music on a gramophone. At the end of the party they play a Prussian march and ridicule it, before they leave the café without paying their bill. A group within the urban population - the young and morally depraved - is connected to the new modern music of rock'n'roll and to the availability of luxury goods. And if it is not already bad enough that the teenagers play American music, they also ridicule German cultural heritage. Rock'n'roll music was not considered to be appropriate, in the 1950s, and was hardly played on the radio, both in East and West Berlin. German teenagers could hear this music on AFN (American

${ }^{69}$ These functions of narrative were described by the French semiotician Roland Barthes. For their definition, see Chapter 1 , section 4 or chapter 4 , section 2 . 
Forces Network), foreign commercial broadcasters such as RTL, or on records. Rock'n'roll was not only "inappropriate" because it was a prominent part of a supposed Americanization of German youths; it was also considered to be connected to juvenile delinquency (Siewert 2009: 80-81; Stahl 2010: 59-60). This is a sentiment that was clearly present in DIE HALBSTARKEN.

The second sequence from that film is one in which the young criminals discuss their plan for a robbery. In this scene their actual dialogue is drowned out by the sounds of airplanes passing over off-screen. The scene stands in sharp contrast to the rest of the film, in which background sounds are present but seem dimmed. The filmmakers employ sound in this scene to hide the criminals' plans from the audience, but the choice for airplane sounds is significant. Criminals flee after committing a crime, and airplanes fly. Because the German word for fleeing (fliehen) sounds very similar to the word for flying (fliegen), there is a close association between the sound that, for now, hides the crime from the audience and the act of committing that crime.

In the East-German film BERLIN - ECKE SCHÖNHAUSER (Gerhard Klein, 1957) a group of youths, including the three protagonists, hang out at a corner under the elevated tramrails. One of the guys is on his way to become a criminal, but crucially, he is drawn into crime by a Western smuggler. The kids are interested in Western culture and music, and because of that they are regarded as no-goods by adults. In this film rock'n'roll music is again staged as a bad agent, negatively affecting young people, yet this time it is also framed as part of a seductive capitalist culture. Thus, a political dimension or message is added to the theme of youth cultures and generation gaps. This political dimension is absent in DIE HALBSTARKEN, a film that does not even mention the existence of East Berlin.

In sum, we can say that the reconstruction of Berlin after the Second World War was explicitly audible in only a select number of East German films, which were made with the intent of re-educating the public. However, even if we do not hear the sounds of reconstruction, Berlin-in-film is a new city: we can hear a clear difference between Berlin-in-film before the war and after. In addition, there is also a difference between the soundscapes of East Berlin-in-film and West Berlin-in-film. In the communist East there seems to be more emphasis on public transportation and live musical performances, whereas in the capitalist West we hear more cars, radios and gramophones. Crucially, West and East German filmmakers shared a dislike of American rock'n'roll music, which was equated with the Americanization of culture and moral corruption of young people.

\section{3 "New Cinema," new politics and new realism}

In the conventional historiography of West-German cinema, the end of the first postwar period is set in February 1962 (Hake 2008: 153). At the Oberhausen Film Festival, twenty-six young German filmmakers signed the "Oberhausen Manifesto" in which the 
old film - "daddy's film" - was declared dead. ${ }^{70}$ These filmmakers, among them directors Haro Senft, Alexander Kluge and the (later very successful) Dutch film producer Rob Houwer, criticized the escapism of popular West-German cinema, but also films in the genre of "social drama" that fail to situate social problems in a wider political context. They promised to "breathe new life" into German cinema and make it internationally renowned again. The signatories of the Oberhausen Manifesto wanted an Autorenkino (author's cinema), like Italian Neorealism and, especially, the French Nouvelle Vague (Thompson \& Bordwell 2003: 456; Hake 2008: 153; Rentschler 1984: 35-39). Changes in film subsidy policies, artistic clashes and the unpopularity of films made by the Young German Cinema with mass audiences led the group to fall apart. It was succeeded by the New German Cinema; an even more heterogeneous group of filmmakers who were only united by their own film distribution company, the Filmverlag der Autoren. (Thompson \& Bordwell 2003: 457, 572; Rentschler 1984: 3946).

Sound occasionally played a role in the re-politicization of West-German cinema. For example, Rainer Werner Fassbinder's film DIE DRITTE GENERATION (1979) has a remarkable soundtrack, which mixes background sounds, dialogue and sounds produced by televisions and radios in equal measures. The film follows a group of young, middleclass left-wing radicals preparing and carrying out a bank robbery and the abduction of a businessman. Fassbinder uses the blur of sounds to underline the ideological corruption of the third generation of left-wing terrorists (Hake 2008: 167).

Wolfgang Petersen's EINER VON UNS BEIDEN (1974) tells the story of a student's attempt to blackmail a plagiarizing professor. In this film unspecified background sounds are almost always present, even in indoor scenes, albeit at a very low volume. This is most notable during the scenes at the university. The presence of off-screen sounds - the presence of the outside world - serves as a quiet reminder that this private drama must be understood in a wider, post-1968 context; as part of a conflict between generations and between authority figures and people who question authority. The background sounds play another role as well: they differ distinctly as regards the inner city area in which the student has his shabby lodgings and the idyllic suburb where the professor lives in his luxurious villa. In the inner city, we hear the constant drone of traffic, whereas quietness and birdsong are the keynote sounds of the suburb. Here, the soundtrack serves to develop the contrast between the film's two main characters.

Background sounds in general become more important in films situated in West Berlin in the 1970s. The increase in the percentage of USEs that constitute unspecified background sounds is hardly noticeable - from $13.3 \%$ in the 1950 s to $14.2 \%$ in the 1970 s - but they are becoming more important in the staging of the city as more than a mere background to the action. The examples from DIE DRITTE GENERATION and EINER VON UNS BEIDEN mentioned above show how background sounds become politicized. However, background sounds are also foregrounded in a less politically but more

\footnotetext{
${ }^{70}$ The Oberhausen film festival, at which the manifesto was drafted and signed, was a festival for short films, and during the 1950s and 1960s one of the few venues in West Germany where films from Eastern Europe were shown.
} 
socially engaged film: CHRISTIANE F. - WiR KINDER VOM BAHNHOF ZOO (Uli Edel, 1981). ${ }^{71}$ In this film city sounds are distorted and exaggerated to gain access to the perception of the protagonist, the troubled teenage drugs addict Christiane, when she is under the influence of heroin.

Like the rise in background sounds from the Weimar period to the 1950s, the change in use of these sounds should also be understood as a result of technological developments and film production practices: the increased possibilities in mixing multiple tracks and the popularization of this technique by both French Nouvelle Vague filmmakers and Hollywood pioneers such as Robert Altman. ${ }^{72}$ However, decisions of filmmakers to use these techniques in order to stage the city as a political environment, or through the ears of a drug addict, seem motivated by the changing film culture - the re-politicization of West-German cinema.

Background sounds become more important and more present in films set in East Berlin as well. Yet here the changes are significant in quantitative as well as qualitative terms. Background sounds made up $9.4 \%$ of all USEs in the 1950 s, and $27.4 \%$ in the 1970 s. At the same time traffic sounds decreased from $45 \%$ in the 1950 s to $34.1 \%$ in the 1970s. Considering that background sounds consist partly of non-distinct traffic sounds, it is possible to conclude that in the staging of East Berlin's soundscape the emphasis somewhat shifted: from distinct traffic sounds to non-distinct background sounds. But why did this happen?

Remarkably, the changes do not correspond at all to developments in traffic and transport in East Germany. The use of public transportation increased slightly between 1953 and 1973, with public transportation companies transporting 1.74 billion passengers in 1953 and 1.81 billion passengers in 1973 (DDR 1955: 230; DDR 1974: 246). Far more spectacular is the increase of the number of cars in East Germany. In 1950 there were 75,710, a number that rose to 298,575 in 1960 and 1,159,778 in 1970 (DDR 1974: 245). This increase is not reflected in the representation of the soundscape of East Berlin in film, in which discrete traffic sounds - of which cars make up the largest part - decreased. ${ }^{73}$

It is in the political context, and not in the actual presence of traffic in East Germany, that an explanation for the abovementioned developments can be found. Until 1972, official art policies in East Germany forced filmmakers to make contemporary films that

\footnotetext{
${ }^{71}$ The protagonist in this film is not presented as a criminal or "lazy" junk, but as a vulnerable young person growing up in a depressing environment, without much parental supervision and without a father figure. The representation of addiction in this film is a world apart from that in the British film TRAINSPOTTING (Boyle 1996, see Annex A), which will be discussed in chapter 6.

${ }^{72}$ See Chapter 2, section 3.

${ }^{73}$ It should be noted that, when viewed as a share of all traffic sounds, car sounds did increase from the $1950 \mathrm{~s}$ to the 1970s in East Berlin-in-film. So although car sounds decreased as a percentage of all USEs, they did so less than other traffic sounds. But this minor increase, from $48 \%$ to $55 \%$ of all traffic sounds, hardly reflects the much steeper increase of the number of cars in East Germany.
} 
described social realities in the light of revolutionary optimism and according to a pre-scribed, emblematic-allegorical model of representation that had found its dogmatic form in the Stalinist model of Socialist Realism. (Blunk 1984: $235)^{74}$

However, after Erich Honecker succeeded Walter Ulbricht as leader of the East-German Communist Party in 1973, art policies grew slightly more liberal. Alongside films that glorified the system, there was space for films that discussed the discrepancy between people's expectations and actual realities, in relation to the important questions of life in the GDR. This implied a new conceptualization of realism: the image of reality is no longer already a given; it has to be developed or constructed (Blunk 1984: 234-35). This new realism was essentially thematic, in that themes and subjects could be discussed that up until 1973 were taboo: the flight to West Germany for instance in DIE FLUCHT (Graf, 1977), poverty and suicide in SOLO SUNNY (Wolf, 1980), or marital infidelity and single-parent families in Die Legende von PaUl UND PAUla (Carow, 1973). As these films were situated in "everyday life," hypothetically they would not only show another East Germany or East Berlin but also make it audible.

With this new knowledge of the changes in art and film policies, an explanation can be formulated for the discrepancies between the developments in actual traffic and transportation in East Germany (an increase), in traffic sounds in East Berlin-in-film (a decrease) and in background sounds in East Berlin-in-film (an increase). This is the explanation: In the new, more critical representation of East Berlin, car sounds are present in the distance, but not prominent in the lives of the characters-revealing that common people cannot afford cars. Sunny, in SOLO SUNNY, travels by public transport through the city, and only shares a van with her band when they go to the countryside. Paul and Paula, the two lovers in DIE LEGENDE VON PAUL UND PAULA, both carpool to work, but the cars that pick them up are the only ones that drive through their otherwise empty street.

This particular staging of traffic is also evident in the presentation of traffic sounds as either on-screen or off-screen. In West-Berlin-in-film in the 1970s, distinct car sounds are on-screen in $78 \%$ of the cases, but in East Berlin this is $89 \%$. As there were fewer cars in the filmic representation of East Berlin in the 1970s than in the 1950s, those present are thus more often visible than in the past. The higher share of car sounds having their source on-screen, as a percentage of all car sounds, thus only emphasizes that the presence of car sounds is not taken for granted. At the same time, background sounds in East-Berlin-in-film in the 1970s are less often on-screen than such sounds in West-Berlin ( $20 \%$ versus $38 \%$ ), emphasizing that car-ownership is quite a remote possibility for the protagonists in East Berlin.

\footnotetext{
74 “... die gesellschaftliche Wirklichkeit im Lichte eines der emblematisch-allegorischen Darstellungsweise verschriebenen revolutionären Optimismus zu beschreiben, der im stalinistischen Modell des sozialistischen Realismus seine dogmatische Verfestigung erfahren hatte."
} 
Some city sounds do not occur in film as often as background sounds or car sounds, but are nevertheless very distinct for Berlin-in-film. Over time, these soundmarks - sounds that are closely tied to a place and that are important to the inhabitants of that place may acquire an iconic status and become sonic icons. Sonic icons signify, apart from their obvious meaning, all the associations filmmakers and audiences have with a place. $^{75}$

Three prominent sounds that have acquired this iconic status in Berlin-in-film are those of barrel organs, the elevated tram (Straßenbahn) passing overhead (including its bells) and construction work.76 Let us have a closer listen to these three iconic sounds of Berlin-in-film. The barrel organ, to begin with has various narrative functions: branding the communists as chaotic and unruly in HITLERJUNGE QUEX, emphasizing the poverty and simplicity of the crisis and postwar years in KUHLE WAMPE ODER: WEM GEHÖRT DIE WELT? and UNSER TÄGLICH BROT, and, finally, establishing the safe domesticity of the parental house in DIE HALBSTARKEN. But in the 1970s, like in Amsterdam, the street organ seems to have disappeared from the Berlin soundscape. Music was now produced by other sources: a classical orchestra in DIE LEGENDE VON PAUL UND PAULA, local pop bands in that same film and in SOLO SUNNY and a David Bowie performance in CHRISTIANE F. - WIR KINDER VOM BAHNHOF ZOO. In addition, recorded music becomes more important as a source of "cultural" sounds in films set in West Berlin: from $30 \%$ in the 1950 s to $56 \%$ in the 1970 s. In the re-united Berlin of the 1990s the street organ pops up once more, in IN WEITER FERNE, SO NAH (Wenders, 1993), but not in such a significant way as in AMSTERDAMNED (Maas, 1988; cf. Chapter 3). The street organ, in other words, largely ceases to function as a Berlin soundmark of poverty and simplicity.

The passing of a tram does not produce a sound that is very iconic to Berlin. Many cities have trams and they more or less sound the same. However, the sound of the tram bell is different for different cities. The East Berlin tram bells audible in DIE FLUCHT for instance are slightly lower and more muffled than the ones in Amsterdam in NAAKT OVER DE SCHUTTING. Like the sound of trams themselves, the sound of tram bells is more often audible in films situated in East Berlin than in West Berlin, but in both cases there were fewer in the 1950s and 1970s than in the Weimar period. In the 1990s, the recognizable sound of the tram bells disappears almost entirely from the staged Berlin soundscape. This is surprising, considering that other tram sounds do persist in the 1990s, such as the sound of trams passing overhead. Such a sound of a tram passing overhead is a very distinct rumble, much different from the sound of a tram passing by on the street, and it has been a recurring feature of the staged soundscape in Berlin, accounting for $1.5 \%$ to $4 \%$ of all USEs. This finding is hard to interpret, although a

\footnotetext{
${ }^{75}$ Soundmarks are sounds that are unique to a particular location, and important to the local population. For a more detailed discussion of soundmarks, see Chapter 3, section 3.

${ }^{76}$ In Chapter 3, I mentioned "folk music performances in an unmistaken Amsterdam accent" as soundmarks of Amsterdam. Indeed, the accent of specific urban or regional populations can be an important factor in the construction of group or place identities. With regard to Berlin, Andreas Fickers et al. have pointed out the importance of the Berlin accent in the radio adaptation of Berlin Alexanderplatz (Fickers, Aalbers, Jacobs \& Bijsterveld 2013). Further research into this area would certainly be welcome.
} 
rumble overhead seems to announce itself less friendly and good-natured than a single chiming tram bell.

The story of DIE LEgEnde VON PAUL UND PAUla is embedded in large urban renewal projects in East Berlin, where dilapidated apartment buildings were replaced with modern ones. Therefore the soundtrack of the film features the sounds of regular construction work, but also on several occasions the demolition of old buildings with explosives.

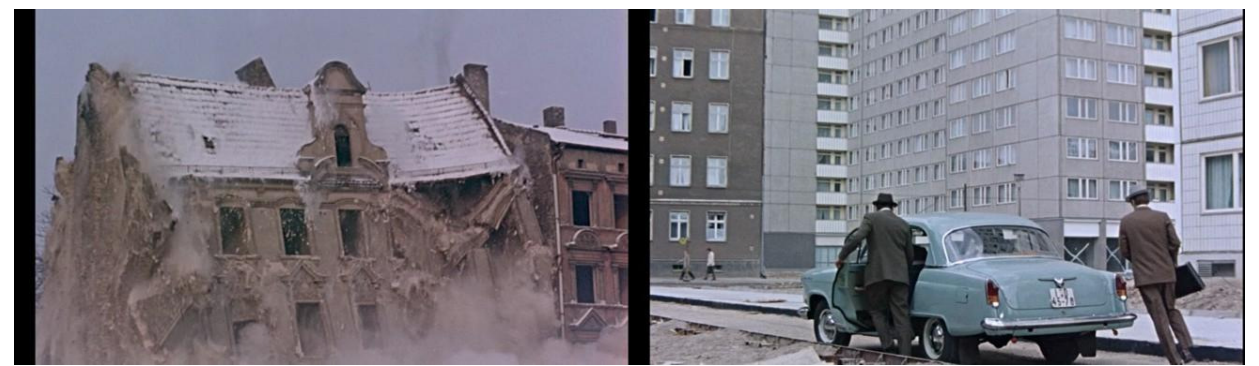

Illustrations 13: Construction work and carpooling in Die Legende von Paul und Paula (Carow, 1973)

These sounds recall earlier films in which construction work and the corresponding sounds are audible: BERLIN ALEXANDERPLATZ and the rubble films of the immediate postwar years. The presence of construction sounds and the subjects of construction and reconstruction in the rubble films, in DIE LEGENDE VAN PAUL UND PAULA and later in DAS LEBEN IST EINE BAUSTELLE (Becker, 1997) highlights that Berlin-in-film is constantly under construction. The continuous political, social and psychological reconstruction of the identity of Berlin is fully embodied in the sounds of the material reconstruction of the city-in-film.

Changing circumstances in politics and film culture can explain the new stagings of Berlin-in-film in the 1970s, in films from both East and West Germany. In both West Berlin-in-film and East Berlin-in-film background sounds become more important. In the former that change is qualitative, in the latter it is quantitative. But in both cases the change echoes a new conceptualization, by filmmakers, of both Berlin and film. The city's identity remains "under construction": some soundmarks gradually disappear from the soundscape, whereas others remain important signifiers of Berlin. It is remarkable, yet perhaps not surprising, that construction sounds - the sounds of change and renewal - function as a sonic icon of Berlin-in-film.

\subsection{All quiet in the border zone?}

In Wim Wenders' 1993 film IN WEITER FERNE SO NAH, the protagonist Peter Falk asks a taxi driver to drive him to Rummelsburg. The taxi driver declines, saying he does not go to East Berlin. Falk replies: "You know, there was an incident, a couple of years ago, 
they tore down a wall. I don't know if you recall, but for me it was a big thing." One can hardly think of a better opening scene for this section on the border zone between East Berlin and West Berlin. In this scene, the taxi driver does not want to drive to East Berlin, even though he can do so freely. With the collapse of the Wall, the entire border zone has disappeared as well, and Berlin is one city again. But when this border zone was still there, what did it sound like? How did filmmakers represent the crossing of the border between the two Berlins through sound? I would like zoom in on two moments in the film to which IN WeIter FERNE So NAH was a sequel, the famous DeR HIMMEL ÜBER BERLIN, the 1987 film set on both sides of the Wall.

The first moment is the scene in which Cassiel, an angel, accompanies an old poet during his walk across a barren field on the Western side of the wall, where Potsdamer Platz used to be. The soundtrack to this scene is dominated by dramatic violin music, and the inner monologue of the poet, who recalls how Potsdamer Platz changed in the 1920s and 1930s, with the arrival of the Nazi regime. However, under the music and dialogue other sounds are present. These sounds are relatively low in volume. There is the sound of wind in the grass, and a low rumble at a distance, caused by traffic sounds on the streets, hundreds of meters away. An occasional bird song can be heard as well. A few sounds of the past are invoked in an inner monologue: The old poet remembers Potsdamer Platz as a busy square, with trams, horse-drawn streetcars and two cars. The old man scratches his right ear, before the scene ends with the drone of a helicopter passing over the border zone. The old man's monologue concludes with a reference to Homer:

Muse, mention to me the immortal singer who, left alone by his mortal audience, lost his voice; he who turned from an angel of poetry into an ignored or ridiculed street organ player - outside, on the doorstep of No Man's Land. ${ }^{77}$

The second scene worth highlighting here is that in which Damiel, another angel played by Bruno Ganz, transforms into a mortal man. When Damiel turns into a human being, bird song is replaced by the cawing of crows. Cassiel carries Damiel and passes right through the Wall from East to West. Damiel wakes up on the Western side, hearing the sound of a helicopter flying over. The soundscape has not really changed, although the traffic sounds are slightly louder on this side of the divide. When Damiel walks into the city, the siren of a passing ambulance is audible.

Another wailing siren in the border zone is depicted in a British espionage thriller, A DANDY IN ASPIC (Mann, 1968). It is a military alarm, and it sounds when the protagonist tries to cross the border, into East Berlin, illegally. The scene starts with the arrival of the protagonist in East Berlin's Friedrischstraße. He does not cross the border at the famous Checkpoint Charlie, but at the train station, where his passport must be

\footnotetext{
77 "Nenne mir, Muse, den armen unsterblichen Sänger, der, von seinen sterblichen Hörer verlassen, die Stimme verlor; wie er, vom Engel der Erzählung zum unbeachteten oder verlachten Leiermann draußen an der Schwelle zum Niemandsland wurde."
} 
checked. The waiting room for this checkpoint is a silent place. There are people travelers and soldiers - but they do not speak, except for the protagonist and his girlfriend. An occasional passing train produces a sound characteristic for Berlin: the rumble of the elevated Straßenbahn. When the protagonist is rejected entry to East Berlin he refuses to go back, and instead runs through the door onto the empty streets near the border. The alarm sounds, guns are fired and he stops running. He has a short discussion with an East German officer, but has to return to the West. Significantly, even though the scene takes place in the middle of the city, near the busy Friedrichstraße, one can hear only very faint background sounds. The sound of the train does not reappear.

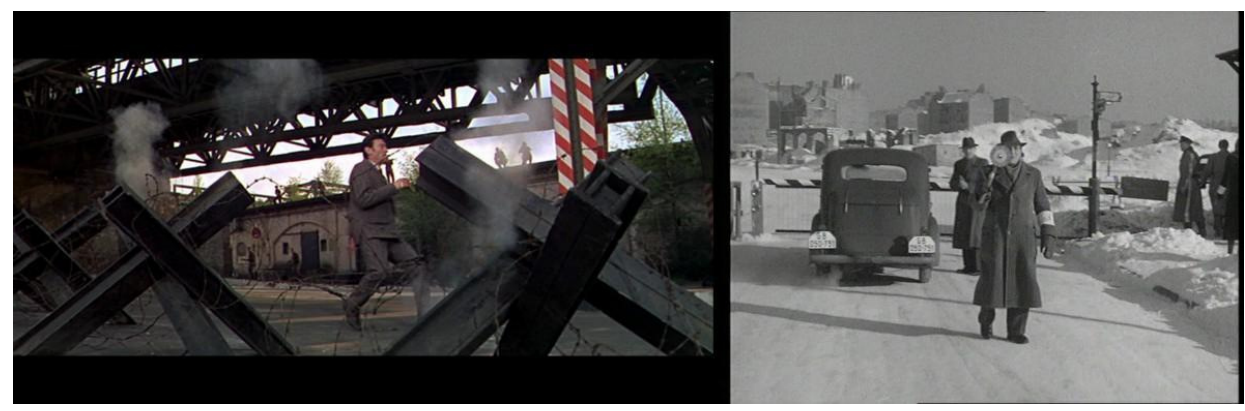

Illustrations 14: Dangerous border crossings in A Dandy in Aspic (Mann, 1968) and The Man Between (Reed, 1953)

That crossing the border illegally is a dangerous enterprise is the message in another British thriller as well. In THE MAN BETWEEN (Reed, 1953), the sounds of a busy West Berlin boulevard is muted as the female protagonist nears Brandenburger Tor. Her German sister-in-law tells her that East Berlin is at the other side, while threatening, non-diegetic music is played. At a first, legal, crossing of the border, the checkpoint is a busy place, with cars on the West side and horse-drawn carts on the East side, but we do not hear their sounds. Instead, the ominous theme music of the film is played. As the visitors return to the West, there is only the sound of the horse-drawn cart under the music. The sister-in-law tells the protagonist that they'd better not speak English, as that would make them suspect.

The film ends with two attempts to return to West Berlin. During both attempts, the border is a busy, but completely silent space, with only the sound of the protagonists' car. The first attempt fails, and ends with gunshots fired at the car. During the second attempt the protagonist hides in a truck. Now the border area is not just a silent place, it is also a place where you keep silent, in order not to be detected. Instead of not speaking English, the characters do not speak at all. The silence is only disrupted by the truck's engine and the dialogue between the driver and the guards. When another refugee runs away to distract attention from the protagonist, the soundtrack consists of screaming guards and non-diegetic music. The scene ends with the running refugee being shot, and a guard dog barking. 
So, what kind of place is this border zone in the heart of one city, or two? It may be useful to return to the function of the city of Berlin in Weimar cinema for a moment. As Wolfgang Natter has claimed, Berlin stood for the brilliance of avant-garde culture, but also represented, at least for a broad spectrum of anti-modernist and folkish Germans, a crystallization point of resentment against industrialization, capitalism, democracy and the cultural influence of the West (Natter 1994: 214-15). Understood in the specific context of Weimar Germany, Berlin was a stereotypical filmic city; the metropolis that forcefully contrasted with the rural environment, the countryside and the small town. Before World War II, this opposition between the city of Berlin and the countryside is expressed in the small trips to the country made by Berlin residents in films such as Robert Siodmak's MENSCHEN AM SONNTAG (1930), or Walter Ruttmannn's sound collage WEEKEND (1930). But after the war there is suddenly - in the middle of Berlin a place of silence, a place secluded from the city din. In the empty barren field that used to be busy Potsdamer Platz, the sound of wind and bird song form the sonic background to the musings of the romantic poet in DIE HIMMEL ÜBER BERLIN. This interpretation of the empty, silent border zone as a site of nature, in stark contrast to the stereotype of the big modern city, exists outside of film as well. Jens Lachmund has pointed out how a new ecology emerged in the empty spaces that existed in Berlin - and in other WestGerman cities - after the bombing raids of World War II, and how these spaces in turn became sites of particular interest for a new field of science called "urban ecology" (Lachmund 2003: 234-37).

But one more thing should be said about this silence, and of the sounds that stand out from it: the silence of the border zone is not the same silence as that of the countryside. It is not a comforting silence. It is one that implies the absence of a city that used to be there. The silence of the border zone is a threatening silence. When crossing the border, one should not be audible, or noticeable, and definitely not be recognized as a foreigner. In case of detection the silence is ended immediately by alarms, gunshots, screaming guards and barking dogs. The border zone can only be traversed, not inhabited, and is closely related to the passage between life and death. Not paying attention to sound, or not being silent can kill you in the spy movies of the 1950s, 1960s and 1970s. And that what used to be in the border zone has disappeared, and is sought for in vain: a quest that, in DER HIMMEL ÜBER BERLIN, turns an immortal singer into a mute and ridiculed street organ player.

These negative connotations of silence are not restricted to film scenes situated in the border zone between East and West Berlin. As we shall see in Chapter 6, the absence of sounds creates a sinister, uncanny experience of London-in-film. In this respect, Raymond M. Schafer has observed that in literary texts silence is hardly ever evaluated positively (Schafer quoted in Flückiger 2001: 231-32). Similarly, John Cage's experimental composition 4'33," in which a pianist sits inactive behind his instrument for four minutes and thirty-three seconds to confront the audience with the natural sounds of the auditorium and the human bodies inside it, signifies absence and shortage (Flückiger 2001: 232). The experiences of the silence in Berlin-in-film are part of a wider cultural discourse on silence as a negative element of the soundscape. 
Accordingly, film sound scholar Barbara Flückiger has indicated that silence can only exist in contrast and relation to sound, and is part of the design of a film's sound. She argues that silence is only made possible by the presence of sound (Flückiger 2001: 232-3). If this sounds strange, we can think of Michel Chion's remarks about the introduction of the sound film: "The symbolic date of 1927, the year of THE JAZZ SINGER, marks the moment when the entire previous cinema was retrospectively declared silent" (Chion 1999: 7). Silent cinema only became silent (which became a negative adjective when it was equated with "dumbness") after the introduction of the sound film, which was new and modern. Within films, silent scenes only become silent in contrast to noisy scenes. Therefore, in our experience of silence in film, or in our identification with characters who experience silence, we also anticipate sound; we are waiting for it. These sounds may be the sounds of danger (sirens, gunshots or barking dogs); but they also signify presence and life.

In this respect we can hear how the last filmic border crossing in DER HIMMEL ÜBER BERLIN brings new life to the angel-turned-human, Damiel. As he walks out of the silent border zone and into West Berlin in 1987, two years before the Wall comes down, a siren is sounded. But it is not a siren of danger, not an alarm that prompts soldiers to shoot him. Rather, it is the sound of an ambulance on its mission to save lives. And when this sound has disappeared, it is quiet in the border zone again.

\subsection{Unbordering Berlin and the city as a dance party}

On November 9, 1989, the Berlin Wall came down. Less than a year later, on October 30 1990, West Germany and East Germany were formally reunited. Berlin, also reunited, became the capital of Germany. These developments, apart from being of immense historical significance, highlight the difference between the architectural and infrastructural reality of the city and its political construction. Officially, the Wall came down on November 9, but its complete demolition took two years. Berlin became the capital of Germany in 1991, but it was only after the remodeling of the Reichstag, in 1999, that the German government moved from Bonn to Berlin.

Echoes of the Wall's demise resounded in several films. Recently, German filmmakers have returned to the period of the division of Berlin, both nostalgically (Goodbye Lenin) and critically (DAs Leben Der ANDERen, Der BaAder MeinhofF KOMPLEX). But German films set in Berlin and made in the 1990s rather dealt with the present and immediate future of a reunited Berlin. These films stage the soundscape of a Berlin that was once again under construction: politically, socially and also materially, with large construction projects taking place on and near Potsdamer Platz and the Reichstag. Both the practice and the idea of (re)construction were interwoven with the reality of building a new life in a capitalist city (for the Easterners), a link that is even expressed in a single film title: DAS LEBEN IST EINE BAUSTELLE. ${ }^{78}$

\footnotetext{
78 "Life is a Construction Site." As Sabine Hake has suggested, this title is "a telling reference to Berlin as a construction site of new national and post-national identities" (Hake 2008: 220).
} 
With the new political reality of a democratic unified Germany came the freedom to protest, and sounds of protest are audible during several scenes of films situated in Berlin in the 1990s. In DAS LEBEN IST EINE BAUSTELLE for instance, a protest escalates into a violent encounter between the protesters and the police. Yelling voices, running people, police sirens and passing cars constitute a brief cacophony in which protagonist Jan loses control of himself, accidentally hits a police officer and thereby sets in motion the story of the film.

Protest also plays an important role in WAS TUN WENN'S BRENNT? (Schnitzler, 2001). Two middle-aged anarchists and squatters have not given up on their ideals from the 1980s and still engage in protests against big companies, although their former friends have moved on and settled in bourgeois middle-class lives. In 2000 the explosion of a forgotten bomb in an abandoned building - previously used by American authorities - brings the group together again in new acts of protests. Ironically, the bomb goes off just after a real estate agent speaks of the building's "historical silence" and the growing housing market in "the new Berlin." The "historical silence," and the fact that so many of the old protesters have moved on, point at a paradox in these films: while the reunification of Germany and Berlin for the Easterners meant that their voices could be heard, for many Western leftist radicals it signaled a defeat of their ideals and a silencing of their political voices.

The "new Berlin" was also a Berlin that was not only inhabited by Germans. West Berlin had already witnessed the arrival of many migrants from Turkey in the 1960s and 1970 s, but their presence is hardly audible in the films in my corpus. Only in Christiane F. - WIR KINDER VOM BAHNHOF ZOO we can hear a distant Muslim call to prayer. But many films from the 1990s stage Berlin as a multicultural city, with people from many different countries and origins living and working together. This can be heard as well. For instance in EMIL UND DIE DETEKTIVE (Buch, 2001): when the young detectives pursue a thief in a taxi, the taxi driver is an Italian migrant, playing uplifting Italian pop music on his car radio. But migration is not always unproblematic, notably illegal immigration being a cause for struggle in films such as OBSESSION (Sehr, 1997), ICH CHEF, DU TURNSCHUH (Kutlacan, 1998) and NACHTGESTALTEN (Dresen, 1998). In ICH CHEF, DU TURNSCHUH "exotic" music is used: in the Turkish restaurant where protagonist Dudi - a migrant from Afghanistan - works, and also on the construction site where he has a second job. A labor dispute that involves illegal workers who want more pay culminates in a strike, during which African workers host a party on the site, playing their music loudly and thereby infuriating the foreman. Music is used in this scene to assert authority, to claim a location. Importantly, this action is taken by people who are not supposed to have any authority. Following Gilles Deleuze and Felix Guattari, Patricia Pisters has argued that an important aspect of music is to create territories:

According to Deleuze and Guattari, the refrain is territorial and has the function of creating "safe havens" in the chaos of the world: a child comforts itself in the dark by softly singing a nursery rhyme; every household is an 
aurally marked territory. Homes are created by sound walls: a radio that is playing, singing, and speaking voices; the sound of the washing machine. Countries are created by national anthems. Sound has much stronger capacities to territorialize than sight. (Pisters 2013: 122)

The Wunschkonzert radio broadcasts and the movie of the same name used music to stake out the territory of Nazi Germany (see Chapter 4). But in ICH CHEF, DU TURNSCHUH this claiming of territory through the use of music is a subversive activity. The emotions it provokes in the character of the foreman highlight his inability to rationally respond to this subversive and transgressive activity, and, on a higher level, to his inability to come to terms with a new, multicultural society.

In fact, historians of sound have shown that the sounds of ethnic minorities have often been dismissed as subversive noises. Nineteenth-century African-American slaves, for instance, were supposed to keep quiet, and their music was often considered to be-subversive - noise. As long as they were singing during work, plantation owners appreciated the singing, as the musical tempo was thought to increase productivity. Yet outside the labor context, their drums signified a threat to societal order (Smith 2001: 36, 66-68 ). White observers of African-American religious services, for instance, reported to be appalled by the "yelling, screeching and groaning" of the participants in these services (White \& White 2004: 248). ${ }^{1}$ Historian of sound Mark M. Smith even claims that almost every sound produced by African-Americans as well as native Americans was considered to be noise by the colonial elites (Smith 2001: 10).

Let us return to the representation of a multicultural society in the films studied. Sonically, migration or immigration is not only signified through the use of foreign music; language is a factor as well. The inability to understand another person plays a role in the plot of both ICH CHEF, DU TURNSCHUH and NACHTGESTALTEN. In the former film, Dudi's meager knowledge of German complicates his life even more, and in NACHTGESTALTEN, a business man's attempt to bring a young, stranded African boy from the airport to his uncle's flat is also hampered by their not sharing the same language.

Finally, the construction of the identity of Berlin as a multicultural place is linked up with the material construction of Berlin. The (illegal) immigrants are doing the construction work and producing the construction sounds, in ICH CHEF, DU TURNSHUH and in OBSESSION. In the latter film the connection is political as well, as illegal immigrant John (Daniel Craig) works on the construction site near the Reichstag, the future seat of the government of the new Germany.

If many films emphasize reunited Berlin as a "new" Berlin, the question to me is: does it sound very different from the older Berlins? Interestingly, public spaces are important in films set in Berlin. Several films situated in Berlin in the 1990s and 1970s mostly take place on the streets: CHRISTIANE F. - WIR KINDER VOM BAHNHOF ZOO, DER HimMEl ÜBER Berlin, NACHTGESTALTEN and LOlA RENNT (Tykwer, 1998), for instance. These films refer back to an older, at the time very successful, genre in 
German cinema in which the city street featured as main setting; the silent "street films" of the 1920s, such as Die STRAßE (Grune, 1923) and DiE Freudlose Gasse (Pabst, 1925). "Street films" constituted a subgenre of the melodrama, the films of which

projected psychological conflicts onto spatial configurations and presented their protagonists with highly codified spaces: ... the street as the ultimate symbol of the city's dangers and attractions. (Hake 2008: 42)

NACHTGESTALTEN tells the stories of a young farmer's exploration of the underworld of Berlin and his meeting with a drug abusing child prostitute, who reminds one of Christiane F.: that of a homeless couple in search for a place to stay the night and that of the aforementioned businessman and the African boy. The street setting of the film is the high proportion of traffic-related USEs ( $50 \%$ of all USEs in the film). The city's attractions and dangers are audibly reflected in an underground rock music party, a police siren in the distance, and a scene in which the young prostitute is beaten up by her pimp. Or, for that matter, in the pouring rain in which businessman Peschke is left with young boy Feliz after his luxurious car has been stolen by young punks.

Another film that can be understood as an echo of the 1920s street films is Tom Tykwer's LOLA RENNT. Quite unexpectedly, in 1998, LOLA RENNT was an international art house success. Its story is that protagonist Lola has twenty minutes to collect 100,000 Deutschmarks and run to the other side of the city to deliver them to her boyfriend, so that he can pay off a debt he has with a criminal. This simple story is played out three times with minor variations having enormous consequences for Lola and her boyfriend Manni. On the soundtrack the non-diegetic techno-music stands out, accompanying Lola on her run through the city, but there are some instances in which diegetic sound is important for the narrative. The sounds of car brakes and car horns come just in time, or just too late to avoid a crash. And the siren of a fire engine sounds much louder from Lola's perspective than Manni's. This signifies perhaps that her experience of the situation is much more intense than his.

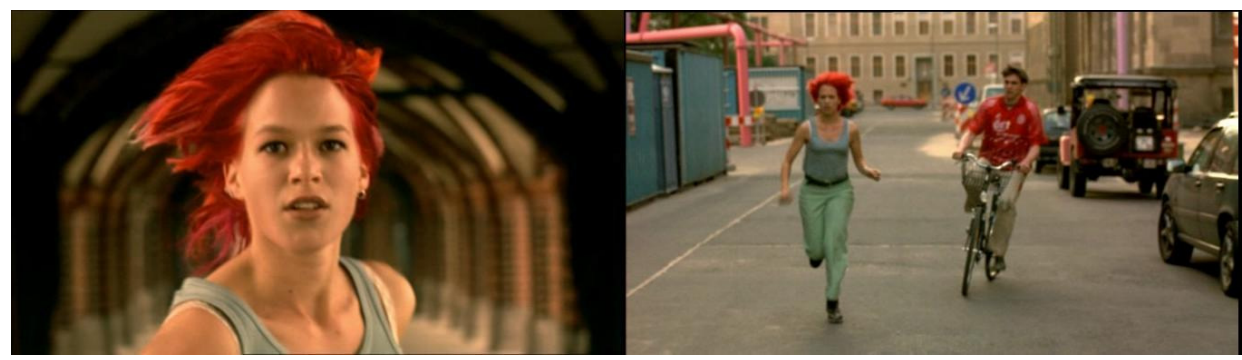

Illustrations 15: Lola running through Berlin. While she runs, we hear the beat of the nondiegetic techno-music in Lola Rennt (Tykwer, 1998)

In this film, the music is important in the experience of the city as well. Technically, the musical score is non-diegetic: It exists outside of the world of the narrative. However, Senta Siewert has argued that LOLA RENNT is one example of many European films 
from the 1990s in which the use of pre-existing pop music "unborders" the diegetic and the non-diegetic levels of narration (Siewert 2009: 298-301). The use of techno-music in the film creates a greater identification with the character of Lola, stimulating a shared pulse between film and audience, and thereby "unbordering" the two (Siewert 2009: 231-35, 291). ${ }^{79}$

Thus there is a crucial difference between the use of diegetic music in ICH CHEF, DU TURNSCHUH - as described above - and the use of non-diegetic or pseudo-diegetic music in LOLA RENNT. In the former the music is used to stake out and claim a territory. It spreads out from the striking laborers over the entire construction site. But in the latter the music stresses the subjectivity of the experience of the city. The film positions the audience inside one character, instead of giving an "objective" account of the actions that make up the story.

We could argue that the process of unbordering, in which the audience comes to share the characters' experience of the city through recourse to what, at first impression, seems to be non-diegetic music, echoes the musicalization of city sounds and the noisification of music I discussed in relation to BERLIN, DIE SINFONIE DER GROBSTADT (Ruttmannn, 1927) and Berlin AleXANDERPLATZ (Jutzi, 1931, see Chapter 4). On the one hand the score is a "translation" of the urban soundscape into techno-music, staging the city not as a symphony, but as a dance-party. On the other hand we can understand this music as sharing with us Lola's heightened sensorial experience of the city, echoing how the music at the beginning of BERLIN ALEXANDERPLATZ allowed the audience to share the experience of the city by Franz Biberkopf. If we agree to non-diegetic music becoming part of the story in this way, we must perchance do away with the strict division between the diegetic and the non-diegetic, which is what Senta Siewert argued in relation to LOLA RENNT (Siewert 2009: 231-235).

Non-diegetic music operates on the level of what literary scholar Gérard Genette has called "the extra-diegetic." This is the level of the narrating instance. Aside from the extra-diegetic level, Genette identified the intra-diegetic or, simply, diegetic level, which is the story being told, and the metadiegetic level: a story within a story (Genette 1980 [1972]: 227-34). A plot or narration can make transitions from one level to another, such as Odysseus who starts telling his adventures to the Phaeacians in book IX of the Odyssey, and Genette calls such transitions "metalepses." He claims that a metalepsis can only be achieved by an act of narration, for instance when Homer allows Odysseus to start his tale:

What shall I tell you first? Where do I stop? For the heavenly gods have given me so much distress. Well, I will make a start by telling you my name (Homer 2006 [700 B.C.]: IX, 17-20)

Genette states that any other form of metalepsis - any instance in which the narrative moves from one level of narration to another - is transgressive, and that it produces an effect of strangeness that is either comical or fantastic. He calls such transitions, in

${ }^{79}$ I admit that the term "unbordering" is a flawed translation of the German word Siewert uses: Entgrenzung. 
which the narrating agent intrudes into the diegetic world, pseudo-diegetic (Genette 1980 [1972]: 234-37). However, Genette's work is occupied with literature, and not with other art forms. He himself acknowledges that filmmakers have stylistic devices at their disposal that are less transgressive, such as the blur, slow-motion and the voiceover (Genette 1980 [1972]: 237). Considering that the "pseudo-diegetic" dance music in LOLA RENNT does not alienate the viewers from the film, but rather draws them in and strengthens their identification with Lola, we may add it to Genette's list.

Film music scholar Robynn J. Stilwell proposes to think of the crossing of the border between the diegetic and the non-diegetic as a process, rather than a moment. She recognizes a space between the diegetic and the non-diegetic, a space that she calls the "fantastical gap." Stilwell does not refer to Genette, but her use of the word "fantastic" similarly hints at the transgressive nature of transitions between levels of narration that are not proper metalepses. Stilwell thinks of the fantastical gap as a liminal space, characterized by magic, danger and a sense of unreality (Stilwell 2007: 184-7). It is certainly interesting to think of the music in BERLIN ALEXANDERPLATZ and LOLA RENNT as occupying this liminal space, this "fantastical gap." The word "fantastic" also emphasizes that Biberkopf's and Lola's experiences of the city, even though they are shared with the audience, are deeply subjective and may not be shared by other characters in the narrative. Similarly, "magic," not a theme usually found in film situated in contemporary modern cities, brings these films closer to the realm of fairy tales and morality plays. This allows us to understand these films in new terms altogether, as well as in relation to other fictional and scholarly texts. We might be tempted to think of BERLIN ALEXANDERPLATZ as a medieval morality play for the modern age, or of LOLA RENNT as a postmodern version of Joseph Campbell's stereotypical "journey of the hero" (Campbell, 1949).

The soundscape of the "new" Berlin-in-film of the 1990s again presents Berlin as a city under construction. A new city with a new identity has to be constructed from the elements left over from East and West Berlin-in-film. The new filmic soundscape echoes the soundscapes of both cities, even though it more resembles West Berlin-infilm.

The "unbordering" between East and West Berlin-in-film is not an easy, painless process. The former citizens of East Berlin-in-film see their entire lives transformed and reconstructed - as indicated by the film title DAS LEBEN IST EINE BAUSTELLE. Some of their former neighbors from the West, on the other hand, no longer have the possibility, or feel the need to let their voices be heard in dissent with the dominant ideology. New borders and new "others" emerge in this difficult process of reunification. Immigration, and especially illegal immigration, becomes a contested subject. New citizens bring their own culture and sound to the soundscape of Berlin-in-film, which leads to emotional confrontations.

We do not only hear echoes of West Berlin-in-film and East-Berlin-in-film, however. In LOLA RENNT, one of the most influential and successful German films of the 1990s music is used to represent the experience in a way that resembles both the 
noisification of music and the musicalization of noise that we recognized in iconic films from the Weimar era. This film furthermore challenges us to rethink the distinction between diegetic and non-diegetic music. The divide between the two is not as strict as it appears on first sight.

\subsection{Conclusion}

In the previous chapters I have pointed out how sets of theoretical and conceptual oppositions inform the representations and stagings of urban soundscapes in fiction film. If anywhere, so I expected, such oppositions will be most explicit and articulated in the chapter that deals with the division and subsequent reunification of Berlin. However, it proves difficult, if not mistaken, to project oppositions onto the divided city. One cannot simply group East Berlin, communism, public transport and live music at one end of the representational spectrum and West Berlin, capitalism and luxury commodities like cars and radios at the other end. There is too much that these two cities share in culture and history, and their historical separation was so forced and unnatural - as my section on the sound of the border zone pointed out - that it would be more justified to underline Berlin's continuities as a single city.

My double approach to the understanding of Berlin-in-film's soundtrack in the 1950 s and 1970s may be the result of an overemphasis on or simplification of the political contrast between capitalist democracy and communism. By emphasizing the differences between the two Berlins-in-film, it is easy to draw attention away from their similarities. But these similarities were there. For instance, in the 1950s the perceived Americanization or Westernization of German youths - symbolized by the popularity of rock'n'roll music - was an issue of concern in East as well as West Germany, and this concern was expressed in films such as DIE HALBSTARKEN and BERLIN - ECKE SCHÖNHAUSER. Furthermore, it would be wrong to assume that the differences revealed by my analyses can all be explained by referring to politics, and can only be explained by referring to politics. The higher number of USEs produced by trams in East Berlinin-film (compared to West Berlin-in-film) may well reflect a politically motivated emphasis on public transport. But it could also (and at the same time) be part of filmmakers' efforts of creating reality-effects, given that there was actually more tram use in East Berlin. Finally, we should not make the mistake of simplifying the political dimension: the political situation and its relation to film culture constantly shifted throughout the period under study in both East Germany and West Germany. The political changes in East Germany in the early 1970s, for instance, led to different art policies that gave filmmakers slightly more freedom, not just thematically, but also stylistically. Similarly, the emergence of a new generation of politically motivated filmmakers in the West, around the same time, had ramifications for the representation of the urban soundscape of West Berlin as well.

Throughout the twentieth century, Berlin-in-film has been a city under construction. Its outlook, soundscape and identity were never fixed. Political antagonisms, artistic 
experiments with new technologies, division and reunification, and destruction and reconstruction have resulted in an ever changing urban identity. If there is anything that is "typically" or "essentially" Berlin, it is this dynamism. Invariably, changing circumstances have caused filmmakers to rethink and renegotiate what we now recognize as the conceptual and theoretical oppositions underlying the representations of the soundscape.

This rethinking and renegotiation has led to surprising continuities and similarities, as well as to unexpected new uses of the same sounds or the same technologies. The reunification of Berlin and the subsequent "unbordering" work in films set in Berlin in the 1990s revealed that previously accepted divisions and contrasts may not have been logical and natural, and that new rivalries and borders are quickly found. The role of sound is important in this regard. The addition of sound to film in the late 1920s offered filmmakers new possibilities to articulate the tensions and conflicts underlying modern city life, but we also understand better how sound is used to bridge differences. A wall may be built to split the city in two, so that its residents can no longer see the other side, but sound - territorial by nature - will flow across that wall. To build a wall of silence is nearly impossible. It is never completely silent in the border zone, and a partial silence is merely an enforced silence; transgression is responded to with the sudden sounds of violent oppression. When borders disappear and differences are settled new representations of the city, and of the urban soundscape, emerge. Such representations will again challenge the myth of the cinematic city. The city as a dance-party? Why not? 


\section{Chapter 6}

\section{The Soundscape of the Lived City: Staging Sonic London}

\subsection{Introduction}

At the beginning of Danny Boyle's 28 DAYS LATER (2002) a man wakes up from a coma, in a deserted hospital. As he wanders onto the streets we see that he is in London, as suggested by images of famous landmarks such as the Houses of Parliament and the London Eye. At the same time, something seems terribly wrong. The city is empty. We see cars left behind in the middle of the street, a bus lying on its side, while the streets are littered with garbage. And there is the silence. Apart from the man's footsteps and the sound of a lonely bird flapping its wings, we hear nothing at all. It feels uncanny; the silence, even more so than the image of a deserted London, underlines that something is not quite right.

This eerie effect partly stems from the fact that London-in-film is very much a "biographical city": "a city understood from the point of view of a life lived in it" (Brunsdon 2007: 13). ${ }^{80}$ Its identity is constructed through the staged activities and experiences of its residents and visitors. Because sound connotes movement and activity, a silent city feels like an empty, postcard-like place with no discernible urban identity. In this chapter on the soundscape of London-in-film I will take a closer look at how the experience of the city is staged in fiction film. I will analyze the sonic representations of three everyday, common activities or modes of being in London: arriving in the city, traveling through the city and living in the city. Finally, I also touch upon the act of leaving London.

My argument will explore how particular sonic representations of these everyday activities articulate the narrative conventions of specific genres. In previous chapters I addressed several times that the genre to which a film belongs may influence the design of its soundtrack. ${ }^{81}$ That genre is an important consideration for sound designers working on a film is underscored by sound designer David Sonnenschein:

Depending on the film genre and style, the degree of realism can vary ... Regardless of whether the genre is a realistic drama, terror or comedy, the path

\footnotetext{
${ }^{80}$ Although this is not only true for London, Charlotte Brunsdon coined her concept of "biographical city" in relation to London.

${ }^{81}$ See for instance my discussion of AMSTERDAMned (Maas, 1988), BABYlon (Terstall, 1998) and LeK (Van de Velde, 2001) in Chapter 3, as well as my analysis of "musical" sounds in Berlin in the 1930s and 1950s in Chapter 5 .
} 
to finding the best ambience needs a keen observation of the visual elements on the screen, an understanding of the emotional moment and the ability to access your own inner ear to create the best sonic landscape for the scene. (Sonnenschein 2001: 27, 38)

But what is genre, and how does it work? Rick Altman gives the following definition of film genres: "in order to be recognized as a genre, films must have both a common topic ... and a common structure, a common way of configuring that topic" (Altman 1999: 23). This definition is particularly useful to this chapter, as it acknowledges that the type of representation - the common structure - is closely connected to and intertwined with the subject - the common topic - in genre films. In a genre film, the sound strategies that filmmakers use and the repertoires of sounds they employ to represent the city are closely connected to, and intertwined with, the subjects discussed in a film (romance, crime, poverty). Over time, the repetition and evolution of these connections establish the conventions of a filmic genre, which I consider to be part of film culture (see Chapter 1).

Recent studies have examined the connections between sound and genre, notably regarding developments since the $1970 \mathrm{~s}$, but these studies concern genres that leave ample room for "fantasy" when it comes to sound design: horror, science fiction and animation films (Spadoni 2007; Whittington 2007; Whittington 2012). Because the use of sound in "realist" genres, such as films situated in contemporary cities, has hardly been studied yet, this chapter aims to explore this concern, albeit in a preliminary fashion.

Of course, it would be misguided to attribute all idiosyncrasies and developments found in the representation of urban soundscapes to genre alone. Genre should not be understood as an all-determining factor, not only because of the wide variety of types of films and historical developments within genres, but also because films are not produced in a vacuum. As argued in the previous chapters, the architecture and infrastructure of the city, politics and developments in film technology and production practices also influence and contribute to the staging of urban soundscapes.

Why do I explicitly discuss the role of genre in relation to London-in-film, rather than Amsterdam-in-film or Berlin-in-film? This is mainly related to the nature of the available material on London. Having selected the corpus of films for this study, I recognized that many of the films for my analysis of London-in-film were genre films, such as thrillers or (romantic) comedies. ${ }^{82}$ The share of films that clearly belong to one genre was considerably greater for London than it was for Berlin and Amsterdam. A possible explanation for this is that British cinema, much more than Dutch or German cinema, is built on a studio system that resembles that of Hollywood. Because this studio system sustained the production of successful genre films (Street 2009: 36-37),

\footnotetext{
${ }^{82}$ See Annex B for a division by genre of the films, analyzed for this study, that are set in London.
} 
the available materials for my research contained a comparatively high number of genre films. $^{83}$

Having analyzed these materials, I grouped the films by genre, in the same way I grouped films by decade for Amsterdam and Berlin, after which I compared the various groups. My quantitative analysis of Urban Sound Events in this corpus, as well as some more qualitative observations, revealed considerable differences in the staging of everyday activities between genres. Thrillers (comprising also crime and police films), (romantic) comedies and social dramas, for example, rely on different conventions of representing the experiences of arriving, traveling and living in London. This led me to recognize that a comparative perspective on representations of urban soundscapes may highlight not only differences between cities or between cities in different periods of time, but also between various conventional, generic representations of one and the same city. In this chapter I demonstrate that the various experiences of London presented in genre films - or to be more precise: the various sonic stagings of everyday activities in that city - contribute to a construction of multiple Londons-in-film.

The notion of multiple Londons is not a new one. As early as in 1905, the British novelist Ford Madox Ford wrote that London was a "ragout of tit-bits, so appealing and so innumerable" (Ford 1905: 8). London, in other words, should not be understood in its totality, but as a mosaic of these bits (Brooker 2002: 31). This notion of multiple Londons is echoed in the academic discourse on London-in-film. Thinking of Londonin-film as a variety of different cities, tropes or places is a recurring motif in the discourse on British cinema. Charlotte Brunsdon's study of cinematic London after 1945 examines the biographical city, in which narratives "take place" (Brunsdon 2007: 5), through various tropes such as Landmark London, Going Up West and Thames Tales. She investigates "how the spaces that are, in the cinema, created through miseen-scène, cinematography and editing, invoke and stage this city" (Brunsdon 2007: 5). This particular phrasing emphasizes how the city-in-film is a staging, a construction and, at best, an interpretation of the actual city. Brunsdon's approach to London-in-film is particularly interesting here because it recognizes that there are various Londons to be found in film history. She offers an extensive analytical approach that relates to a number of remarks and arguments on the subject made by other authors as well.

The French film historian Pierre Sorlin, for example, has argued that the representation of the city in postwar (neorealist) European cinema was based on the opposition between the periphery and the centre (Sorlin 1991: 116-17). He explicitly refers to the British film IT ALWAYS RAINS ON SUNDAYS (Hamer, 1947), which opposes the suburban Coronet Grove and the urban Petticoat Lane in order to demonstrate the discrepancy between the perceived attraction of the big city - as a place of glamour and excitement - and the everyday reality of urban life (Sorlin 1991: 112-13). Emphasizing the fragmented character of modern London, Sorlin connects specific experiences of the

\footnotetext{
${ }^{83}$ Possibly, genre films, because of their popularity and success, are more likely to have been preserved and re-issued on Digital Versatile Disc, which was one of the criteria by which I selected films for this study.
} 
city to particular locations in that city, showing how there are even different Londons in one film.

In their discussion of cinematic London in the 1990s, film scholars Ewa Mazierska and Laura Rascaroli detect different Londons as well (Mazierska \& Rascaroli 2003: 171). They recognize a posh London in SLIDING Doors (Howitt, 1998) and NOTTING HILL (Michell, 1999), in which the "social map" of the city is either concealed or contradicted. In contrast to this polished version of the city, they see a fragmented and chaotic, essentially postmodern London in Beautiful People (Dizdar, 1999) and WONDERLAND (Winterbottom, 1999). Mazierska and Rascaroli, in their introduction, state that cinema has also offered different Londons over time (Mazierska \& Rascaroli 2003: 166-67). In this respect, British film scholar Colin MacArthur has argued that there have been several "London discourses" in cinema: for instance the wartime propaganda documentaries about London in the Blitz, or the 1960s films that produced the "Swinging London" discourse. He also refers to films from the 1980s that show London as an urban wasteland, in opposition to Thatcherite policies (MacArthur 1997: 35-36).

In the four sections below I will discuss the various stagings and representations of the following activities in and experiences of London. In the first section, on arriving in London, I show how there are three ways of arriving in London-in-film, and how each of these sound. I also discuss how different genres make different use of these three ways of arriving. The second section concentrates on traveling in London, and it addresses such questions as: which means of transportation do we hear in London-infilm? How does traveling through the city sound? And what do these represented journeys tell us about the identity of London and its inhabitants? In the third section I will pay attention to the sound of "living in London" by considering the keynote sounds of the London-in-film soundscape and how characters in films react very differently to those everyday sounds. Finally, in the fourth section I will show how difficult it is, if not impossible, to leave London-in-film. Apparently, it is so difficult that no sonic conventions of "leaving London" have yet been developed by filmmakers. Residents and visitors alike, it seems, are forced to stay in London-in-film, as if having to await the end of times in this metropolis.

\subsection{Arriving in London}

London Films was a film production company that, between 1932 and 1956, produced nearly one hundred films. Some of them achieved fame and great success, such as the historical epic The PRIVATE LIFE OF HeNRY VIII (Korda, 1933) and the Cold-War thriller THE THIRD MAN (Reed, 1949). And all of them shared the same signature trait: the logo of London Films, which was a shot of the Clock Tower of Westminster Palace. A landmark of London, the tower also became a landmark of London-in-film (Brunsdon 2007: 12, 28). 
A shot of the Clock Tower, the Tower Bridge or - nowadays - the London Eye will send a clear message: London is the location of this film, or of this scene in the film. Perhaps more famous than the Clock Tower is the bell it houses, the Big Ben, and as much as an image of the Clock Tower tells us we are in London, the four-toned chime of the Big Ben is an auditory landmark, a soundmark of London and London-in-film. ${ }^{84}$ To hear its sound tells us as much as would an image of the Clock Tower or the Tower Bridge: we are in London.

In the Alfred Hitchcock thriller ForeIGN CORRESPONDENT (1940), an American journalist travels to London to cover a peace conference. Just before he arrives in the city by a train, which is puffing out smoke and steam as it enters the station, an image of the Clock Tower is shown to establish the location of the train station. But the Big Ben is not heard. Only two minutes later, when the image shows us the journalist in his hotel room, we actually hear the bells. While they sound, the journalist practices a little dance-routine involving an umbrella and a bowler hat: he is not just in London - he is in England. If we had already forgotten, the Big Ben reminds us that we have arrived in London.

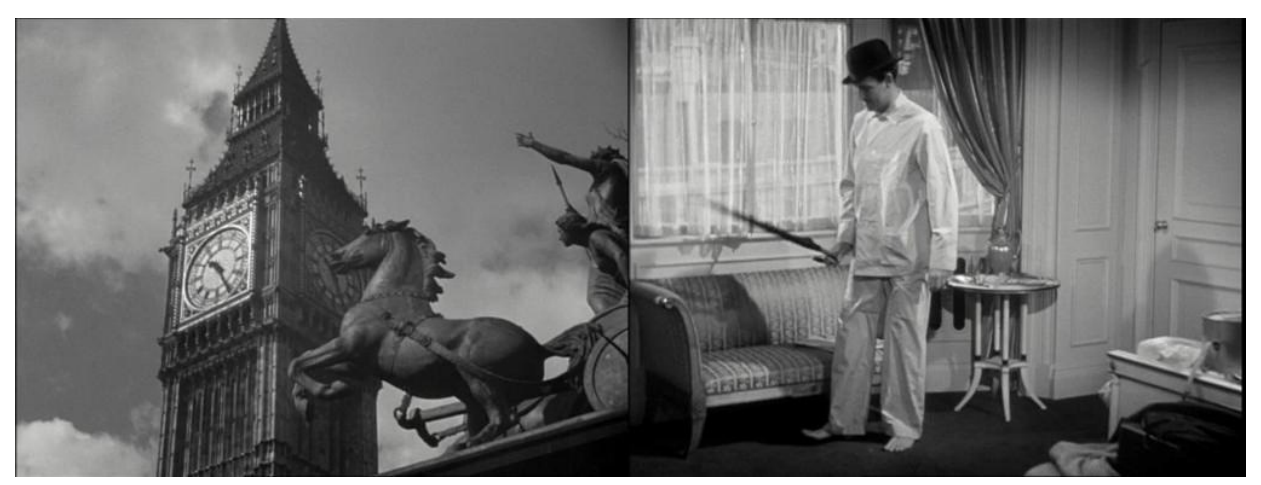

Illustrations 16: Big Ben, a bowler hat and an umbrella inform us that we have arrived in London, in FOREIGN CORRESPONDENT (Hitchcock, 1940)

There are more ways of arriving in London, however. I detected three. The abovementioned sequence from FOREIGN CORRESPONDENT is an example of the first way: the film arrives in London together with its protagonist. London, in such films or sequences, is a location to be visited, professionally or for pleasure, but only temporarily. And as the protagonists are visitors or tourists, the city is introduced through the landmarks for which it is known throughout the world, and through the sounds widely associated with the city.

Another arrival scene that fits in this category is found in TRAINSPOTTING (Boyle, 1996). Its protagonist Renton, a Scottish former drug addict, seeks to make a new start in the capital. The city is introduced through shots of tourist landmarks of London, including - again - the Clock Tower, but the city is not heard. Instead, the images are

${ }^{84}$ For a definition and extensive discussion of soundmarks, see the third section of Chapter 3. 
accompanied by the exciting pop music of Ice MC's Think About The Way. Although the music is non-diegetic, and not heard by Renton, it succeeds in letting the audience share his experience of arriving in London, as a city where you go to in order to start with a brand new slate.

Big Ben is not the only soundmark of London, and not everyone arriving in London is new to the city. One of the two main characters in LoNDON (Keiller, 1994) is a photographer returning home. When the cruise ship on which he works passes under the Tower Bridge it sounds its horn. The sounds of ship horns are a soundmark in particular of London's East End, where the docks used to be. The sound in this scene has a nostalgic and melancholic quality, in line with the overall mood of the film and its two protagonists, as it refers to a part of the city that no longer exists.

In earlier films, made when the docks were still there, ship horns regularly figured as soundmarks of London. In BULLDOG DRUMMOND COMES BACK (King, 1937), for example, they establish the East End Limehouse district as the location of a sequence, even though we are not shown the River Thames, a bridge or a ship. This use of the ship horn presumes familiarity with the East End area, for the audience as well as for the main character in the film, the detective Hugh Drummond. At some point in the film, in his country mansion, Drummond receives a message from the film's villain, stating that a next clue can be found in Limehouse. The next scene - which takes place in an otherwise generic street - is underscored by a multitude of ship horn sounds, and the audience is supposed to understand that the action has moved to Limehouse.

But what if an audience or the characters in a film are not familiar with the geography and soundmarks of London? Clues such as the ship horn might be lost on them, or need additional explanation. This happens in OUT OF THE CLOUDS (Dearden, 1950), a romantic comedy about two travelers - one from Germany and one from the United States - who are stuck in London for a night because the bad weather makes leaving by airplane impossible. They spend the night in a stereotypical London pub, and standing on a balcony they hear the sounds of ship horns and church bells. Their English hostess, however, needs to explain the significance of the sounds:

Just you stand and listen to it though [ship horns are heard in the distance]. I often come out here and listen. Like a concert it is sometimes, the sounds of the ol" River [a church bell rings]. That's St. Mary's Rotherhite, she's always the first. You'll hear all the others in a minute. Southwick and Bow and St. Pauls, and the City churches [several church bells rings, one of them the Big Ben, then a ship sounds its horn]. There's a big'un coming up. That'll be the Dutchman I expect, always in on Fridays [a big rumble startles the tourists]. That's just the barges banging together at their moorings; the wash of a big ship always sets them off.

There is a remarkable difference in the experience of these sounds by the various characters in this scene. The English hostess enjoys the sounds of the city and the river much like a concert. For her, they are also regular, recognizable sounds that structure 
the flow of time. But to the German and the American tourists, who have just arrived in the city, all these sounds are new, even startling. The sounds only become meaningful because of the explanation given by the hostess; the bells are given a name. And the atmosphere that these iconic London sounds create is so romantic that as soon as the hostess leaves to prepare dinner, the tourists share their first passionate kiss of the film.

This first type of arrival scene, involving arrival in London together with one or more of the characters and joining them in their (first) experiences, is counterbalanced by a second type: being plunged into an already ongoing action in situ. Films or sequences that start like this often have protagonists who already live in London and they seem to rely on music, rather than sound effects, to accompany the action.

BLACKMAIL (1929), Alfred Hitchcock's and Britain's first sound film, is a case in point. It starts with a police raid on a suspect's house. A police car drives along a street, the police officers invade the building where children are playing in the courtyard and a window is broken, but none of these events is heard: instead the sequence is accompanied by non-diegetic music. The choice of music over sound effects here might not be prompted by a wish to create a mood as by technical limitations. BLACKMAIL was made in a sound version and in a silent version, but the sound version contained parts of the silent film as well. The opening sequence was one of them (Barr 1999: 81-83). The sound scenes of the film were shot at the newly built (temporary) sound studio of British International Pictures, but location shots could not yet be made with sound, because of the same technological limitations that influenced early German and Dutch sound films (Ryall 1993: 22).

Following the pattern set by BLACKMAIL, "arriving in London" in public spaces and on streets is underscored by non-diegetic music, sometimes while the opening credits of the film are superimposed over the images of the city. Examples of this type of introduction are found in STAGEFRIGHT (Hitchcock, 1950) and THE LADYKILLERS (Mackendrick, 1955) in the 1950s, STEPTOE AND SON (Owen, 1973) and A TOUCH OF CLASS (Frank, 1973) in the 1970s and the aforementioned TRAINSPOTTING in the 1990s.

But two films present an alternative version of this second type of arrival scene: Basil Dearden's THE BLUE LAMP (1950) opens brusquely with a police chase in the streets of London underscored by roaring car engines and wailing sirens. This opening scene pulls the audience into the film as much as it alienates them by not "smoothing" the transition from "real life" to watching a film. Many years earlier, an alternative version of THE 39 STEPS (Hitchcock, 1935), a version that now no longer exists, also started with images and sounds of the bustle of the big city:

The opening sequence of THE 39 STEPS is a brilliant evocation of what a loud and busy city can be to a friendless outsider. We see a quick tumble of images from the city ... with a barrage of city noises. (Film critic Maurice Yacowar, quoted in Barr 1999: 20) ${ }^{85}$

\footnotetext{
85 Throughout history, films have often been in circulation in various versions, for instance because of nationally varying censorship regulations. Also, films were not always preserved with the same care and dedication as today. Therefore it is not uncommon for us to see a version of a film that is different from the
} 
In its currently known version, THE 39 STEPS starts with an image of the word "Music Hall" lighting up, before moving into that entertainment venue. This start of a film in a place of entertainment is an example the third type of "arriving in London." As with the second one, the protagonists of films that start in entertainment venues are mainly people who are already living and working in London. But instead of showing the streets or the landscape of the city, these films start in a pub, a theater or a music hall. The sounds of these places contribute to the image of London as a city of attractions.

THE 39 STEPS' opening scene, in a music hall, starts with a stage performance, but soon descends into chaos, as people in the crowd begin to fight. The German film VIKTOR UND VIKTORIA (Schunzel, 1933) relocates halfway through from Berlin to London, but London itself is never seen or heard, apart from the scenes in the theatre where Viktor and Viktoria perform. The first public space in Guy Ritchie"s SNATCH (2000) is an empty and quiet pub, quite unlike the crowded club of NIL BY MOUTH (Oldman, 1997) and the busy pub where protagonist Nadia has a depressing blind date in WONDERLAND.

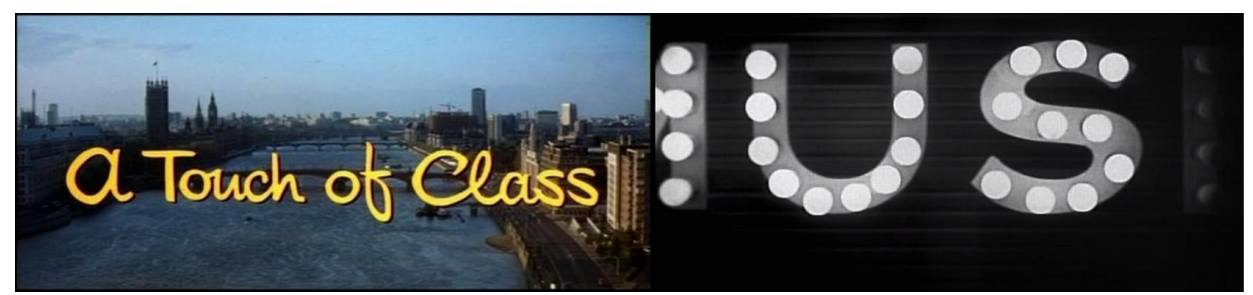

Illustrations 17: Alternative ways of arriving in London-in-film, in A TOUCH OF CLASS (Frank, 1973) and THE 39 STEPS (Hitchcock, 1935)

If we take a look at the spread of different genres over the various ways of "arriving in London" we see that the arrival in the city with the protagonist (often with the use of landmarks and soundmarks to confirm the location) is mostly used for thrillers and action movies. Four thrillers in my corpus use this first way of arriving in London, and only one romantic comedy and one social drama. ${ }^{86}$ What can we learn from this? That the city's presentation as a place to visit is closely tied to its dangers: crime, murder and espionage. Innocent tourists or strangers to the city may arrive there only to be sucked up in a maelstrom of action and violence.

What is the role of sound in this stereotypical introduction of the city? It can simply confirm the location through the use of soundmarks, as happens in FOREIGN CORRESPONDENT and in the American film BRANNIGAN (Hickox, 1975). But sound can

versions shown in cinemas at the time of the film's original release. The most famous example of this is probably Fritz Lang's METROPOLIS (1927). Long stretches of this film were believed to be lost, until they were found in Buenos Aires in 2008 (Anonymous 2008).

${ }^{86}$ The thrillers are Bulldog DRUMMOND COMES BACK, FOREIGN CORRESPONDENT, SEVEN DAYS TO NOON and BRANNIGAN. The other two films are OUT OF THE ClOUDS and NAKED. 
also be used to emphasize the mythical identity of the city as a place of attraction and danger. Bulldog DRummond COMES BACK cuts to Limehouse when we find the protagonists standing on a street, just outside a bar. From inside the bar we hear music being played: the attraction. Yet from further away we hear ship horns. These do not only indicate that we are near the river, in a dockside district, but they also have a warning, foreboding quality.

A twist on the foreboding quality of city sounds is the opening scene of SEVEN DAYS TO NOON (Boulting \& Boulting, 1950): after an introductory shot of the Clock Tower underscored by the sound of the Big Ben we are shown a quiet Downing Street, where the only sound is that of the mailman's footsteps as he delivers a letter to no. 10. The silence here predates and predicts the silence in the city later on in the film, after the city has been evacuated.

The second way of arriving in London - being plunged into an ongoing action - is used as often in thrillers as in (romantic) comedies ${ }^{87}$ Films using this introduction have protagonists who already live in London, and they introduce us to their everyday activities. This is the case for the gangsters in PERFormance (Cammell \& Roeg, 1970) and LOCK, STOCK AND TwO SMOKING BARRELS (Ritchie, 1998), but also for the yuppies in Four Weddings and a Funeral (Newell, 1994) and Notting HiLl. This introduction emphasizes regularity and rhythm, or that (petty) crime is part of everyday life in London as well. ${ }^{88}$

The soundtrack of these films contributes to this introduction by using quite unremarkable yet pleasant non-diegetic music, or recognizable pop songs. Often this music is played over the opening credits of the film. For thrillers the music is more exciting and fast-paced, emphasizing the glamorous or spectacular nature of crime and police work. Good examples are the classical score accompanying BLACKMAIL's police raid and LOCK, STOCK...'s use of Hundred Mile High City by the band Ocean Colour Scene. When the music stops or is faded out, background sounds, the keynote sounds of the city, are faded in. Traffic in the distance or close by, footsteps on the pavement or a car door closing indicate that the credit sequence is over, that the stage is set and the real story begins. If during the credits sequence some actions have already been shown, they tend to be used to introduce characters rather than set the plot in motion. This happens for instance in FOUR WEDDINGS AND A FUNERAL, where the opening sequence establishes the motif that Charles (Hugh Grant) almost always misses weddings because he can't get out of bed.

Seven films from my corpus, equally divided between thrillers and comedies, combine the first and the second type of arrival scene. ${ }^{89}$ These films open with a credit

\footnotetext{
${ }^{87}$ The second way of arriving in London is used in the comedies Four WEDDINGS AND A FUNERAL, STEPTOE \& Son, The Ladykillers, Fever Pitch, Notting Hill and Bridget JoneS" Diary; in the thrillers Stage Fright, Blackmail, Lock Stock and Two Smoking Barrels, The Blue Lamp, Performance and A DANDY IN ASPIC; and in the social drama WATERLOO BRIDGE.

${ }^{88}$ An exception is Hitchcock's STAGE FRIGHT, which starts when two people in a car flee from the scene of a murder - hardly an everyday situation for them.

${ }^{89}$ These films are The Lavender Hill Mob, Melody, A Touch of Class, Bulldog Drummond’s Bride, NIGHT AND THE CITY and FRENZY.
} 
sequence laid over images of famous landmarks or recognizable sights of London, underscored by non-diegetic music. It is only when the credits are over that the music ends and the film focuses on the main characters, who subsequently go about their daily business in London.

The third type of arriving in London - setting an opening scene in an entertainment venue (café, concert hall etc.) - is found in four films of my sample. ${ }^{90}$ Two of these films are social drama, a genre of British film that depicts the everyday life of the working classes and addresses social issues such as crime, juvenile delinquency, capital punishment and homosexuality (Street 2009: 91). This genre has its origins in the "kitchen-sink dramas" of the late 1940s, which were a reaction against the prevalent tradition in British cinema to depict only the middle and higher classes, or the lower classes only from the perspective of the middle classes (Hutchins 2009: 304). Social drama is sometimes also called "social realism" because filmmakers working in this genre make extensive use of such realist strategies as location shooting and filming in color to enhance the reality-effect (Street 2009: 91-92). ${ }^{91}$ Three of the films in my corpus belong to this category: NIL BY MOUTH, NAKED (Leigh, 1993) and WONDERLAND. Two of them, NIL BY MOUTH and WONDERLAND, start in a café or pub and these opening scenes are underscored by the chatter of patrons, the sound of glasses tinkling and either diegetic recorded music or live musical performances. These uplifting surroundings stand in stark contrast with the dark mood of the films and its characters. In NIL BY MOUTH, Ray's attempts to order drinks hint at his alcoholism as well as his unhappiness and his lack of patience and self-control. In WONDERLAND, Nadia is on a miserable blind date in a café, and she decides to ditch her date and leave.

What these two examples show is a counterpoint use of sound: the soundtrack presents an uplifting environment, whereas the characters are miserable. These scenes thereby set up the characters and the theme of the films through a contrast between the setting (of which the sounds are an essential element) and the action.

The three ways of introducing London in film, of arriving in the city, emphasize different experiences of the city. In the first one the audience arrives in the city together with the characters in the film, and shares their experience of a (re)new(ed) meeting with a city they do not yet, or no longer, recognize. The soundtrack, the sounds and the soundmarks of the city contribute to making this either a positive experience (of new chances in life and romance) or a negative one (of dreary nostalgia, disappointment or danger).

In the second and third type of arrival scene in London, the characters already live in the city. The films intrude into their lives. In the second type, the otherwise rather brusque introduction is eased by replacing city sounds with appropriate non-diegetic music. In the third type, the characters are presented in a specific environment associated with leisure and spare time, places where they may go to take a break. That these places do not necessarily provide relaxation can be heard in the oppressing

${ }^{90}$ ViKTOR Und ViKTORIA, THE 39 STEPS, Nil By MOUTH and Wonderland.

${ }^{91}$ Color was still a novelty in British cinema of the 1950 s. 
crowdedness of the pub in WONDERLAND, or the potentially dangerous chaos of the working class music hall in THE 39 STEPS. The main characters would do better to get out of there and go somewhere else, possibly by taking the tube...

\subsection{Traveling in London}

You hear the train nearing the station. The rumble coming from the dark tunnel gets louder and louder until the brakes kick in, and the wheels of the train screech against the metal of the rails. The vehicle comes to a halt at the platform and with a pneumatic "pssh" the doors open. A robotic male voice speaks to you from the public address system: "Mind the Gap."

"Mind the Gap" says "London" as much as the sound of Big Ben does. In tourist shops all over London trinkets are sold with the logo of the Underground and the words "mind the gap" on them. Remarkably though, the Underground is not often represented in London-on-film. In my corpus it only features extensively in two films: in BLACKMAIL, when the protagonists briefly ride a metro, and in THE LAVENDER HILL MOB (Crichton, 1951), when Alec Guiness' character uses a tube station to escape from the police. Despite its characteristic look and sound, and despite its importance to residents and visitors alike, the Underground, as a neutral backdrop to everyday activities, is remarkably absent from cinematic London and its soundscape. ${ }^{92}$ We can quantitatively compare Urban Sound Events (USEs) related to the London's underground to USEs signifying trams in Amsterdam, or the Straßenbahnen in Berlin. Only $0.1 \%$ of all USEs in London are connected to the Underground. In comparison, $0.7 \%$ of USEs in Amsterdam are produced by trams, and even $7 \%$ of all sounds in Berlin come from the Straßenbahn.

An obvious explanation for this striking difference is that the Underground is located under the ground. Unless characters actually travel by metro, it is not audible in films. Unlike the Amsterdam trams or the Berlin Straßenbahn, the sound of the London Underground rather belongs to a different realm of the city. A director may choose to show a character descending the long escalator only, as happens in one scene in WONDERLAND.

Another explanation for the fairly low presence of the Underground in filmic London, one that connects to the literature on London-in-film, is that while the Underground, more than anything else, connects the different parts of the city, London is often portrayed as a variety of separate communities within the larger community of the United Kingdom, if not as a collection of different and unrelated places (Brunsdon:

\footnotetext{
${ }^{92}$ Exactly because it operates invisibly, in a realm separated from the city above it, the Underground proved to be a useful setting for one genre: horror films. The Underground is used as a backdrop in DEATH LINE (Sherman, 1973), AN AMERICAN WEREWOLF IN LONDON (Landis, 1981) and CREEP (Smith, 2004), films not included in my corpus. Its historical dimension was of importance to CREEP director Christopher Smith: "everything that has happened in London since the days of Jack the Ripper is kind of embodied in the Underground" (Smith quoted in Brunsdon 133).
} 
12-13; Gibson: 363; MacArthur: 35; Mazierska \& Rascaroli: 166; Sorlin: 112-17). Brunsdon describes the relation that London characters have with various areas in the city specifically "through journeys which they do and don't, can and can't aspire to make" (Brunsdon 2007, 90). Because places in the same city differ so much, filmmakers have chosen to show these important journeys between them, as journeys above the ground, making the audience aware of the changes in location. The "immediate" connectivity that the Underground offers is therefore of little use to filmmakers who represent London. ${ }^{93}$

This is not to say that no travel takes place in London-in-film. Quite the contrary, but most traveling occurs aboveground. As is true for Amsterdam and Berlin, traffic sounds make up the largest part of USEs. Together with background sounds, which mainly consist of non-discrete and unspecific traffic sounds, they account for more than $50 \%$ of all USEs. ${ }^{94}$ If not the Underground, which means of transportation do people in London-in-film use? What are the sounds of travel through the city?

As in other cities, cars are the major mode of transportation in London-in-film. Sounds produced by cars make up between $57.6 \%$ (in the 1930s) and $79.9 \%$ (in the 1970s) of all traffic-related USEs. More striking is the low number of sounds produced by buses, even though the red, double-decked Routemaster bus is a visual icon of London. No more than $4.8 \%$ of all traffic-related USEs originate from buses in the $1930 \mathrm{~s}$, and in later decades its share even drops. Individual buses are still heard passing in the background in BLACKMAIL (1929), but in BRANNIGAN (1975) these potentially iconic bus sounds are part of the mix of non-discrete traffic and background sounds: the buses can be seen in the busy traffic, but their sounds do not stand out.

When taking a closer look at developments in the presence of specific, discrete traffic sounds, we notice two anomalies in the 1950s: in this decade there are relatively high numbers of train sounds and airplane sounds (Annex D, Table 4). Train sounds constitute $14.3 \%$ of all traffic sounds in this decade, and airplane sounds make up $5.3 \%$. These relatively high numbers can be explained by referring to just two films, however. THE LADYKILLERS is situated in an old lady's house, the back garden of which borders on the train tracks near King's Cross Station. Trains are heard passing by and sounding their horns throughout the film, and in the end they are essential in the disposing of bodies, when the titular criminals start killing each other. Of the 80 USEs related to trains in London in the 1950s, 54 come from THE LADYKILLERS.

This use of a location characterized by nearby transportation infrastructure is also seen in the above-discussed OUT OF THE CLOUDS. The time the two travelers spend in London's East End is but a brief interlude. In fact, all other scenes take place at Heathrow Airport, where airplanes land and take off on a regular basis. Of the 30

\footnotetext{
${ }^{93}$ Charles Dickens, reflecting on the building of the first underground tracks in London, already noticed their destructive impact on the cityscape, and on urban communities (Williams 1990: 65).

${ }^{94} 58.3 \%$ in the $1930 \mathrm{~s}, 52.2 \%$ in the $1950 \mathrm{~s}, 50,8 \%$ in the $1970 \mathrm{~s}$ and $15,8 \%$ in the $1990 \mathrm{~s}$. See also Chapter 3 , section 2 , for more on the relation between traffic sounds and background noises.
} 
sounds produced by airplanes in London in the 1950s, 28 come from OUT OF THE Clouds.

When looking at the modes of transportation in relation to genres (Annex D, Table 5), we notice the following: there are no sounds of airplanes and ships in the category social drama, and only few sounds of trains (3\% of all travel-related USEs). This absence suggests that social dramas depict a stratum of the urban population that is bound to its place of residence, with little prospect of (social) mobility. People in these films have little means to leave the city or their local environment and to travel the world. Again the connection between spatial and social mobility seems obvious. Relevant in this regard are Ray's childhood memories of holidays spent outside of London in NIL BY MOUTH. These holidays are now a thing of the past for Ray, who lives a dead end existence in a South London estate.

Cars are the dominant mode of transportation in London-in-film in all genres, but mostly so in thrillers. In comedies, car sounds make up $68 \%$ of all USEs related to traffic. In thrillers this amounts even to $75.1 \%$. This higher percentage for thrillers may be explained by the number of car chases, in films such as THE BLUE LAMP and BRANNIGAN. Higher percentages for airplanes (5.9\%) and trains $(12.4 \%)$ in comedies can be attributed to single films (OUT OF THE CLOUDS and THE LADYKILLERS) in the same way that the high percentage of motorcycles $(6.0 \%)$ in social dramas can be explained with reference to WONDERLAND, in which one character drives around on a motorcycle for a long time.

Travel sounds in general are most common in thrillers, in which they make up $43.8 \%$ of all USEs. Romantic comedies have a similar percentage: 41.1 , but in social drama only $33.3 \%$ of USEs are related to travel. Background sounds, which are tightly interwoven with traffic sounds, are more common in social drama $(14.7 \%$ against $11.6 \%$ in comedies and $9.6 \%$ in thrillers). However, because these differences are smaller than those in traffic sounds, we may conclude that travel is less present in social drama. This conclusion would suggest that what is said about London-in-film in the academic discourse pertains to the specific genre of social drama rather than to other genres: London is a collection of separate communities, where travel from one place to another - also in terms of social mobility - is rare or difficult. This suggests that when it does happen, it is also highly significant.

As argued in chapters 3 and 5, background sounds consist to a considerable extent of non-discrete and unspecific traffic sounds. In London the relation between the two is remarkable: traffic sounds show a steady decrease in their presence in the soundscape from the 1930s until the 1990s, whereas background sounds show a steady increase. ${ }^{95}$ Similar developments were explained in part by an increase in location shooting, caused by new artistic trends and improvements in recording technology, and partly by the increase in actual traffic in cities. But other explanations seem relevant as well.

\footnotetext{
${ }^{95}$ As percentages of all USEs in respective decades.
} 
The difference between Amsterdam and Berlin on the one hand and London on the other is that, cumulatively, background sounds and traffic sounds increased in the first two cities until the 1970s, after which they declined, whereas in London they declined steadily throughout the twentieth century. My quantitative analysis of city sound appears to suggest that London-in-film has become less and less a city through which characters travel. But does a more detailed, qualitative analysis of scenes of traveling through London-in-film support this conclusion? Given my definition of Urban Sound Events as solely diegetic sounds, a decrease in or absence of such events indicates silence, or the ceasing of the activity that produced them. But as I showed in my discussion of TRAINSPOTTING, non-diegetic music - which falls outside the definition of the USE - can also be important in representing the experience of the city by a character.

A close look at a number of scenes set in London reveals that the experience of traveling through the city does not necessarily involve hearing the sounds that modes of transportations and their users in the diegetic world "ought to" produce. Again, the opening scene of BLACKMAIL serves as a good example: the film opens with the image of a police car driving through London, but the sound of this car is not heard. Instead, the soundtrack consists entirely of non-diegetic music. Another good example is found in WONDERLAND. The character Nadia sneaks away from a disappointing blind date, and subsequently wanders through the streets of Soho. Director Michael Winterbottom shows the passage of time by showing Nadia's walk in fast motion. At the same time he gradually fades out all diegetic sounds and replaces them with a non-diegetic, comforting musical score by Michael Nyman that serves as a counterpoint to the sights of traffic and night clubs. Winterbottom shifts attention away from the surrounding environment and towards Nadia, mirroring her mood.

Later in the film he repeats this strategy: a character named Eddie, who is about to become a father, suffers a panic attack and leaves his house to ride his motorcycle through London, all night. Winterbottom also shows Eddie's journey in fast motion, while filtering out all sounds except that of the motorcycle, which later in the scene is also replaced by Nyman's music. Again the director focuses the audience's attention on the character and his preoccupied state of mind. ${ }^{96}$ Barbara Flückiger has shown that the disappearance of sounds from the soundtrack is an effective strategy for filmmakers who want to signify the alienation of their characters from reality:

The disappearance of sounds marks or indicates loss of a sense of reality. The subject, the character, seems disconnected from the acoustic surroundings and, thereby, from the real world. (Flückiger 2001: 397) ${ }^{97}$

\footnotetext{
${ }^{96}$ Later in the film Eddie is involved in an accident because he does not pay attention to the other traffic.

97 "Das Verschwinden der Geräusche markiert oder stimuliert einen Realitätsverlust. Das Subjekt, die Figur, erscheint von der Lautsphäre und damit von der Realität abgekoppelt."
} 


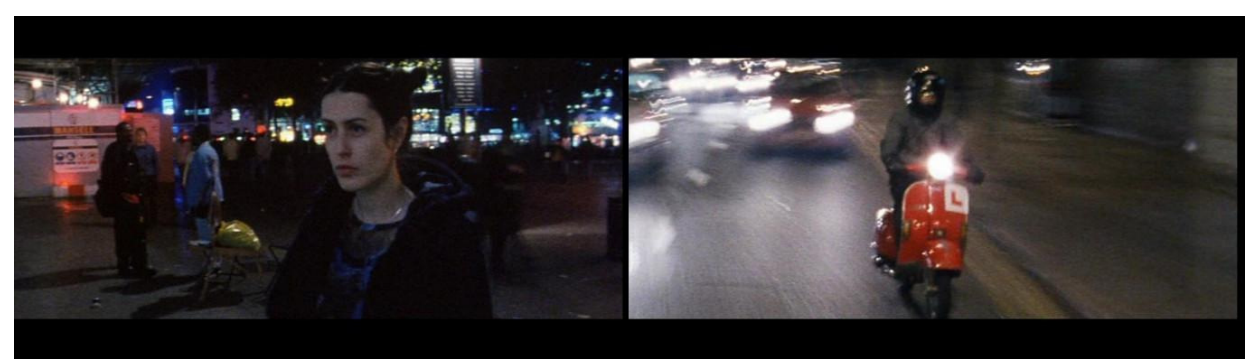

Illustrations 18: In two scenes in WONDERLAND (Winterbottom, 1999) the sequence of images is speeded up and music replaces background sounds in order to signify the lack of connection the characters have with their surroundings.

In the detective film BRANNIGAN, traffic sounds are also replaced by music. The lead character, an American detective who has come to London to organize an extradition, spends a lot of time in cars, going from one place to another. But apart from a spectacular chase sequence, nothing much happens during these car rides. The filmmakers have replaced the sound of the car with music, to fill the gap in the action and bridge the scenes before and after the car rides.

So, while characters do travel through London, the sounds of their travels, and that of the surrounding traffic is often masked by music. And although the exact narratological motivation for this masking differs from one film or scene to the next, the general effect is that the characters are shown to experience their journeys as "nonevents": unimportant moments in between other scenes that are more significant, or lengthy periods spent in contemplation, with little or no attention for the outside world.

There is one other issue to be mentioned about travel in London. As Ewa Mazierska and Laura Rascaroli have claimed, London is a city that is hostile to "strolling": "We rarely see people in films walking the streets of London, and when they do, it usually ends bad for them" (Mazierska \& Rascaroli 2003: 169). Although there are indeed plenty of examples of people walking around London and being killed, raped or mugged, there are also plenty of examples in which this is not the case. Perhaps the best example is NOTTING HILL. In this film the characters mainly move about afoot, whether it is crossing the street or taking long romantic walks.

Mazierska and Rascaroli's argument that cinematic London is a place hostile to strolling is based on a comparison of London with Paris, Dublin and Rome. However, based on my own quantitative analysis and in comparison to Berlin and Amsterdam, the amount of footsteps audible in London-in-film is very high: $9.8 \%$ in London versus $4.2 \%$ in Berlin and $0.8 \%$ in Amsterdam (As percentages of all USEs in all four decades.). These are numbers that strangely clash with Amsterdam's image of a villagelike city (see Chapter 3). According to my own analysis, Mazierska and Rascaroli's claim deserves some nuance. In contrast to Amsterdam-in-film and Berlin-in-film, we can hear many sonic traces of walking in London-in-film. Compared to Amsterdam and Berlin-in-film, London does not seem to be hostile to "strolling" at all. 
The changing stagings of the sound of travel in London-in-film can generally be compared to those in films set in Amsterdam and Berlin, marked by the dominance of car sounds, and the eventual replacement of discrete traffic sounds by indiscrete background sounds. But there are some differences as well. More than in Berlin or Amsterdam we see that in London particular locations related to specific types of transportation are used as settings for film narratives. So the sounds of trains and airplanes, merely popping up occasionally in the background in other films, play an important role in the narratives of THE LADYKILLERS and OUT OF THE CLOUDS, and in establishing the location of their setting. And although the Underground is hardly present in the soundscape of London-in-film, it is a preferred location for horror movies.

My attention to the relationship between genres and the representation of Londonin-film's soundscape shows that particular types of transport are more important to some genres than to others. Conventional car chases in thrillers and police films, for instance, mean that in such films more car sounds are heard than in (romantic) comedies. Furthermore, the social fragmentation of London and the isolation of working class characters are reflected in low numbers of traffic sounds in social drama, as well as a total absence of train and boat sounds in these films.

\subsection{Living in London}

You find that in London there is a continuous background sound wherever you are. There is always a "mush" of traffic. However, the quality of that "mush" changes according to geography, architecture, time of day, etc. The city has a certain "roar" that comes from millions of people, cars, buses and everything else that makes up a city in a large, contained space (Larry Sider, personal correspondence, 20-02-2011).

In Patrick Keiller's LONDON, a character named Robinson claims that London is becoming more and more uninhabitable, due to the conservative policies of the Thatcher and Major governments. ${ }^{98}$ As a result of John Major's 1992 election win "there would be more traffic and noise pollution." The gateposts of the park, to which Robinson had been listening (LONDON is a quite poetic film), had turned quiet after the election. Keiller paints a very bleak picture of London, although correspondence with his sound designer Larry Sider suggests that Robinson's opinions are an exaggeration of Keiller's thoughts on the subject. ${ }^{99}$ For Keiller, London is just not a nice city to live in. A number

\footnotetext{
${ }^{98}$ However, Larry Sider, the sound designer for the film, emphasized that Keiller did not attribute the condition of the city solely to conservative policies: "we are made aware of the transformation that London has gone through - culturally, politically, economically, etc. And, this has always happened. As Patrick lays out the history of the city you realize that there is a thread that runs through the history of London - the bad things didn't start in the 1980s" (Sider, personal correspondence, 20-02-2011).

${ }^{99}$ Keiller "rather jokingly used to say the film was about "why London is not like Paris"" (Sider, personal correspondence, 20-02-2011).
} 
of other films, especially from the 1990s, also represent London in this fashion. But other representations show London in a more favorable light.

In this section I will examine the film sounds that relate to "living in London" and that its residents can hear on an everyday basis. The Canadian composer and acoustic ecologist Raymond M. Schafer has called these the keynote sounds of the soundscape: the sounds that are always there in the background, and that you would only notice when they ceased to be there (Schafer 1994 [1977]: 10). In this section I will employ a somewhat wider definition of keynote sounds, one that also includes common sounds that are not necessarily heard every day, such as rain, so often associated with England and London.

In the following pages I will look into the keynote sounds of filmic London. I will discuss the various sounds that make up what sound designers call the "atmosphere." Apart from indistinct and non-discrete sounds, which I have labeled as "unspecified background sounds," keynote sounds include such sounds as rain, birdsong, and children playing. I will show how people experience these sounds and how their meanings and functions vary in different film genres.

If carrying around an umbrella at all times is quintessentially English, so is the bad weather, and chatting about it. As an American gangster says in SNATCH: "London. You know: fish, chips, cup "o tea, bad food, worse weather, Mary fucking Poppins... London." In many films, characters refer to the bad weather as part of the English experience. FOREIGN CORRESPONDENT's American journalist discusses it with a Dutch diplomat during a cab ride, and the two protagonists of A TOUCH OF CLASS meet for the first time when, in the rain, they compete for a taxi and then decide to share it. The similarity between the scenes in FOREIGN CORRESPONDENT and A TOUCH OF ClASS is remarkable: in both cases two characters who do not know each other share a taxi, and then, during the ride, discuss the weather. ${ }^{100}$

From a semiotic perspective, the weather is a cardinal function for action to take place, and for characters to talk and act. ${ }^{101}$ However, even though people respond to the weather, they do not respond to the sound of it. Nonetheless, those sounds are not without meaning: in NIL BY MOUTH and WONDERLAND the pouring rain punctuates the dreary state of mind of the characters, and the lack of prospect in their lives. But when the future of a character is looking good, not even a flood can bother them. This is evident, for instance, in the final romantic encounter in FoUR WEDDINGS AND A FUNERAL, in which a soaked Andy McDowell is finally reunited with her lover Hugh Grant. A scene that ends with McDowell saying:

\footnotetext{
${ }^{100}$ Remarkably, in FOREIGN CORRESPONDENT the bad weather is discussed by the characters in London on a perfectly sunny day, while the rain starts pouring as soon as the action relocates to Amsterdam. As Hitchcock commented: "We were in Holland and so we used windmills and rain" (quoted in Truffaut 1985: 135).

${ }^{101}$ Cardinal functions are elements of a narrative that initiate or conclude an uncertainty. Anything that characters react to or that makes other characters react to them. See also Chapter 1, section 4.
} 
Is it still raining? I hadn't noticed.

Another common keynote sound of London-in-film is the sound of birdsong. Wonderland, Four Weddings AND A FunERAL, SNATCH, FeVER PITCH (Evans, 1997) and especially LONDON are movies teeming with chirping and singing birds. Perhaps it is not a coincidence that these films are all from the 1990s, when traffic sounds reached their lowest share. In fact there is no sound of birds to be heard in films from the 1930s, and only in one film from the 1950s: SEVEN DAYS TO NOON. In the 1970s birds can be heard in Melody (Hussein, 1971), FrenZy (Hitchcock, 1972) and PerformanCE. So their presence went up in London-in-film (even if characters rarely seem to react to them), while traffic sounds and other background sounds showed a steady decrease. This gradual appearance of birds, accompanied by a decrease in traffic sounds, is indicative of the changing identity of the city: London-in-film, so it seems, has become a greener place.

Of course, birdsong is not exclusively a part of London-in-film's sonic atmosphere, and it is heard as often in Berlin and Amsterdam. But this does not seem to be the case for the sounds of children playing in the street. In London, $1.8 \%$ of all USEs are related to children playing, in comparison to $0.8 \%$ in Amsterdam and $0.6 \%$ in Berlin. Partly, this (fairly) high percentage can be explained with reference to individual films: MELODY is about school children, and accounts for 19 out of 30 USEs related to children in the 1970s. But in my sample for Berlin there are four films about children, and yet the overall percentage of children's sounds is lowest for Berlin-in-film. ${ }^{102}$

The sound of children playing, in London, is closely tied to particular locations in the city. In Keiller's LONDON, children play in the same park where the character called Robinson listens to the gateposts. As the gateposts "stop talking" after the 1992 election, the sound of children playing is muted as well. The filmmakers have sonically created a sinister connection between Robinson's disappointment with the election result, his pessimistic outlook on the future and the presence of children in the urban soundscape.

Children playing are also heard more often in less fancy or even poor districts of London. In STEPTOE \& SON, their sounds are constantly in the background whenever the action takes place in or near the house of the two lead characters, who run a scruffy scrap iron business. In WONDERLAND, they are heard near Nadia's cheap apartment, but not in the (more) upscale neighborhood where her parents live. And in NIL BY MOUTH children are heard playing in between the tall concrete apartment buildings. In contrast, children are conspicuously absent from the fancy streets in NOTTING HILL, Four WEDDINGS AND A FUNERAL and BRIDGET JONES' DIARY (Maguire, 2001). This is hardly incidental. The sociologist Colin Ward refers to a study of Nottingham children which

\footnotetext{
${ }^{102}$ The four films are the three versions of EMIL UND DIE DETEKTIVE $(1931,1954,2001)$ and IRGENDWO IN BERLIN (Lamprecht, 1946). In all these films children are treated as, or take on the role of adults. This may partly explain why we do not hear them play often, but it does not explain their relative absence from the soundscape.
} 
revealed that working class children play outside more often, with less parental supervision or participation (Ward 1978: 33). This may explain that their cries and screams are heard more often in poorer neighborhoods-in-film as well. It is a keynote sound of British lower class urban districts.

The keynote sounds of the city are always there, as Larry Sider states, but they can be used quite differently by filmmakers, in order to create different experiences for characters in the film and for the audience. The experience of "living in London" as described in this section, relates to one of Charlotte Brunsdon's tropes of cinematic London: Local London. Local London, as the opposite of Landmark London, is the city as experienced by its residents, rather than its tourists. It is the city of everyday life in which time is cyclical and repetitive, and most days follow the same pattern of getting up, going to work and going to the pub (Brunsdon 2007: 57-59).

Keynote sounds are part of this everyday life and its repetitive experience, which does not necessarily have a negative ring. Above I referred to the hostess of an East End pub in OUT OF THE CLOUDS, to whom the familiar sounds of church bells and of the ships going down the river sounded like a comforting concert. These sounds structured her experience of time and space: because it was a Friday, she knew which ship it was that she heard, or because she recognized the ship she knew it must be Friday. The church bells situated her in a particular place in London, imbuing her with a particular identity. After all, only people born within the reach of the bells of St. Mary-Le-Bow can be said to be real "cockneys" (Howse 2007). ${ }^{103}$

Scenes such as these allow us to categorize sounds as auditory topoi. Based on the distance of a listener to a sound source, the quantity of the source as well as the direction, the rhythm of a sound and its appreciation by the narrator, sounds can be perceived as comforting, sensational, intrusive or sinister (Bijsterveld 2008: 41-50). Comforting sounds are usually single sounds from sources far away with an indistinct direction and a regular rhythm, like the church bells from the example above. Intrusive sounds, on the contrary, are often irregular sounds, with multiple sources close to the listener who perceives these sounds as coming straight at him or her. Consider, for instance, the example of the incessantly barking dog in WONDERLAND, which drives Nadia's mother Eileen mad. The neighbor's dog barks day and night, affecting Eileen's mental wellbeing, but not that of her husband Bill, who has stopped hearing the noise:

"I didn't hear anything."

“That's because you don't want to hear anything."

\footnotetext{
103 "It is within the sound of St Mary-le-Bow, in Cheapside, that true Cockneys are said to be born. In which case, no Cockneys were born between 1856 and 1858, during which period a neighbour of the church, Mrs Elisabeth Bird, declaring that the noise of the bells would kill her, succeeded in having them silenced. When they resumed, she went on living" (Howse 2007).
} 
As this interaction underscores, people can get used to sounds and they can decide not to hear them. Two examples of the latter, from the same film, we already discussed above, when Nadia's and Eddy's state of mind was mirrored by the muted sound of the traffic around them. Our relation with the sounds in our environment is an important part of our identity. The urban soundscape does not only contribute to the identity of the city, but also to the identities of its inhabitants. As Joy Parr writes about the residents of a small Canadian town that was entirely displaced to make way for a large canal:

The villagers had made sense of themselves through their sensing bodies. After the flood, the fires and the clearing, there were no physical reference points for the selves they had been, no benchmarks for the spatial practices of daily life ... Internally, the disorder was a deafening clamour. (Parr 2010: 101)

Parr continues by quoting a villager who speaks about the sound of the new and the old town, and its perception:

"I guess the quietness, that's the only way I can explain it. It seemed to be so much quieter in the old town. I don't know, maybe it's just all in your emotions, your mind, that you were quieter." (Parr 2010: 101)

Parr's work shows how people give meaning to their environment through their senses, and how their sensed experience of their environment contributes to their personal identities. We have no direct access to film characters and their experience of the filmic city, but the wry comments of Eileen and Bill in WONDERLAND, and the explanation of the sounds of the city and the river by the hostess in OUT OF THE CLOUDS are telling enough.

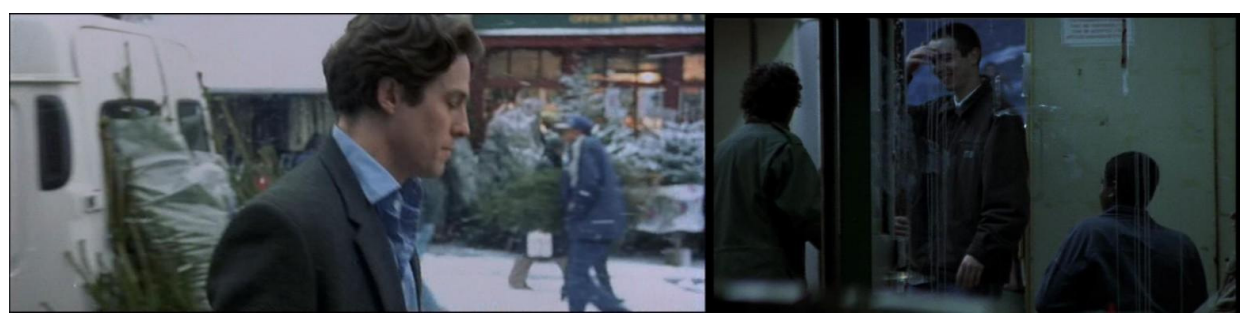

Illustrations 19: Background sounds are replaced by pop music in NOTTING HILL (Michell, 1999) but they drown out the junkies' dialogue in NIL BY MOUTH (Oldman, 1997)

Not only psychological character motivations, but also generic conventions can play a role in the representation of keynote sounds. In romantic comedies the volume of background sounds and surrounding traffic is much lower than in social critiques of urban life, such as Wonderland, NiL BY MOUTH and NAKED. And if they do not have a lower volume, these background and traffic sounds in romantic comedies are often replaced by popular songs. A characteristic scene in NotTING HILL sees Hugh Grant's 
protagonist William walking across a street market. The soundtrack of this scene does not feature market sounds, but a recording of Bill Withers' Ain't no Sunshine. As William ponders the absence of his lover, Anna (Julia Roberts), the seasons change from summer to autumn, winter and spring. As in WONDERLAND (see the previous section) the music in the soundtrack makes it possible for time to pass more quickly. In contrast, when junkies loiter on the dirty streets of London, both in NAKED and in NIL BY MOUTH, they have to shout to make themselves heard over the noise of passing cars. And as their confused and repetitive dialogue is often interrupted by traffic sounds, those scenes feel longer than they actually last.

Careful examination of the narratological functions of USEs in the three genres reveals, strikingly, that the use of catalysers, informants, cardinal functions and indices is almost similar in thrillers, comedies and social drama. The percentage of USEs that are cardinal functions ranges from $11.9 \%$ in social problem films to $12.5 \%$ in thrillers. Such a small spread also occurs for catalysers $(56.9 \%$ in social drama and $58.4 \%$ in comedies), informants $(26.7 \%$ in comedies and $29.3 \%$ in social drama) and indices $(6.2 \%$ in thrillers and $9.8 \%$ in comedies). In the second chapter on Berlin-in-film, we were able to establish the degree to which a city was an active agent in the narrative by considering the ratio between cardinal functions and catalysers, and the ratio between indices and informants. These results indicate that the cardinal function to catalyser ratio is basically the same for the three genres I identified in London-in-film. This means that the city is an equally active character in film narratives in all three examined genres, even though the actual nature of the city's role in the narrative can strongly vary. The indice proper to informant ratio shows a greater variation, with thrillers as the category with a lower use of urban sounds as indices proper, which may be the result of the genre's greater reliance a sinister silences — not counted as USE.

$$
\text { Cardinal function to catalyser ratio Indice proper to informant ratio }{ }^{104}
$$

$\begin{array}{lll}\text { Comedies } & 0.21 & 0.37 \\ \text { Thrillers } & 0.22 & 0.21 \\ \text { Social drama } & 0.21 & 0.28\end{array}$

Mazierska and Rascaroli place NOTTING HILL and WONDERLAND at opposite ends of the spectrum of possible representations of London (Mazierska \& Rascaroli 2003: 171). These films, and their generic siblings, are indeed opposites when it comes to their representation of the experience of the sound of the city. Characters in films live with noise as they do with bad weather: they accept it - although sometimes they can only do so by ignoring the sounds and retreating into their own world. In some cases, most notably in romantic comedies, this is perhaps not even a bad thing: characters don't mind getting soaked, don't notice that it is still raining or don't hear the noises of the

${ }^{104}$ In film set in London ain all four decades under study. 
street because they have their heads in the clouds. Or, as in OUT OF THE CLOUDS, a down-to-earth working-class woman simply enjoys the soundscape of the city, as if it were a musical concert.

\subsection{Leaving London and the end of the metropolis}

This chapter started with an investigation into the filmic conventions of "arriving in London": an analysis of the repertoires of sounds used to represent the activity of coming to town. Whether by ship, sounding its horns, or by train, pulling into the station while puffing out smoke, or underscored by music, entering the city has been represented in a wide variety of ways.

This makes it all the more remarkable that there are no conventional or generic sonic strategies to represent "leaving London." Quite a number of films actually show how difficult it is to leave the city in the first place: the protagonist of NIGHT AND THE CITY (Dassin, 1950) is stuck in his life of petty crime, although he dreams of a better future. And Chas (James Fox), the central character in PERFORMANCE, may plan to leave London, fleeing from his former criminal colleagues, but he ends up hiding in Notting Hill, the same place where almost thirty years later international film star Anna Scott settles down with her new British husband, William, after giving up her successful career. This last example reminds us that it is also possible for characters to choose to stay in London, having no desire to leave it.

If film plots contain departure scenes at all, the actual leaving of London is rarely shown. A case in point is SNATCH, a film in which the Irish gypsies simply vanish, leaving behind nothing but a barren field where once their caravans were parked, while the departure of American gangster boss Avi Denovitz (Dennis Farina) is accompanied by the same three sounds that announced his arrival: a cab door slammed, a Concorde taking off and the loud bang of a stamp in a passport. "Anything to declare?" the American customs officer asks him. "Yeah, don't go to England."

Another element in this respect is that even when characters are shown to leave the city, their departure does not prove to be final. Apparently, there is something special about London because most characters in my sample return to it again. In Hitchcock's THE 39 STEPS, STAGE FRIGHT and FRENZY, characters temporarily leave the city to avoid the police or to retrieve evidence. But they all must return to London to prove their (presumed) innocence. Finally, it is also Avi Denovitz' fate to get another stamp in his passport after all, when in the final moments of SNATCH he learns that the diamond he was after turned up in London again.

But not only in thrillers and crime films do characters leave and return to London: they do so as well in romances and romantic comedies. In A TOUCH OF CLASS the protagonist goes through great troubles to leave the city by airplane for a romantic holiday with his secret mistress in Spain. The characteristic sounds of the airport (echoing footsteps in a large hall, public announcements and the whining of airplane engines in the distance) and of the airplane's take-off serve as prominent elements of the 
soundtrack, so as to build up the excitement surrounding his secret mission. Curiously, perhaps, his return is not accompanied by these same sounds of travel. Instead, he returns in silence, as if through the backdoor, and the plot plunges us directly into the calm streets of Soho again - as if nothing happened.

Another interesting example can be found in SEVEN DaYs To NoON. In this film, a mad professor has threatened to set off a nuclear bomb in the inner city of London, and this prompts a large-scale evacuation, as everyone is supposed to leave the city immediately, either by train or in trucks. As viewers we witness an impressive, orderly operation: most people comply and queue neatly, and with a typical stiff upper lip the city's residents remain calm - quite a contrast with the hysterical crowds in American disaster films. Left to itself, and to the soldiers and policemen who try to find the bomb, the deserted city is remarkably quiet and peaceful. The silence is only broken by the soldiers' footsteps, their marching and the sounds of lions, monkeys and elephants in the London Zoo. Occasionally, especially as the supposed hour of the bomb's detonation approaches, we hear Big Ben. But this time its sound is hardly comforting, for it highlights that if the mad professor has his way, the city will soon be a totally deserted place forever. Big Ben's iconic sound has thus become a rather sinister, uncanny sound.

The only way to leave London and never return, it seems, is by leaving it as a dead person. The criminals in THE LADYKILLERS all (accidentally) end up as corpses on an outward bound train. Their untimely departure is underscored by the exaggerated thuds of lifeless bodies hitting the freight wagons that leave the city.

The scenes of empty London streets in SEVEN DAYS TO NOON predate similar scenes in New York in VANILLA SKY (Crowe, 2001) and I AM LEGEND (Lawrence, 2007), and in London in Danny Boyle's 28 DAYS LATER (2002). This last film does not even feature the sound of Big Ben or the sounds of zoo animals: after a devastating epidemic and chaotic street riots the city is entirely silent, apart from a single bird flapping its wings, and the sound of the protagonist walking through a pile of tourist souvenirs on Westminster Bridge. After he woke up from a coma, not knowing what happened in the last couple of weeks, the silence and emptiness of the city is even eerier than in SEVEN DAYS TO NOON. However, director Boyle does provide some counterweight by underscoring this scene with calm music from an electrical guitar.

The devastation of London as a metropolis is not just a major theme of science fiction films, however. The character Robinson, in Patrick Keiller's LONDON, in fact sees the city disappear before his eyes, as the city grows into a more and more uninhabitable place. Proper urban life is no longer possible there, as these quotes from the film show:

London, he says, is a city under siege from a suburban government which uses homelessness, pollution, crime, and the most expensive and run down public 
transport system of any city in Europe as weapons against Londoners' lingering desire for the freedoms of city life.

For Londoners, London is obscured. Too thinly spread, too private for anyone to know. Its social life invisible, its government abolished, its institutions at the discretion of either monarchy or state or the City, where at the historic centre there is nothing but a civic void, which fills and empties daily with armies of clerks and dealers, mostly citizens of other towns. The true identity of London, he said, is in its absence. As a city it no longer exists. In this alone it is truly modern. London was the first metropolis to disappear.

London-in-film, as other scholars have pointed out, has always been a collection of separate communities and disconnected places, such as the East End, the West End, Notting Hill and South London. These are all places in and onto themselves, rather than parts of a larger city. A group of suburbs without a center, as Robinson would put it. The sound design of LONDON contributes to this particular representation of London: the metropolis is no longer there. There is traffic, quite a lot actually, but cars, buses and distant trains pass by the two protagonists who try to walk through the city. Even when they are physically close to the traffic, they seem distanced from it; not in the least because the two characters are never on-screen: we only hear the voice of the narrator. The effect is comparable to that of the two traffic scenes in WONDERLAND, also because of the occasional presence of classical music on the soundtrack.

Finally, the soundscape of LONDON is marked by plenty of quiet and even silent scenes. The unspecified background sounds, which sound designer Larry Sider still refers to as the "roar" of the city, are just background sounds indeed, their sources being far away. Birdsong is omnipresent. And, strikingly, whenever the royal family features in the film, the soundtrack is muted. Robinson, not a fan of the monarchy, complains that the royal family takes up too much space in the city. No wonder, then, that when the Queen reopens Leicester Square or when the Queen Mother unveils a statue of a contested war hero we do not hear a single diegetic sound.

\subsection{Conclusion}

As argued in the previous chapters, the soundtracks of fiction films offer enhanced echoes of cities, of their soundscapes and of cultural sensibilities regarding sound, cities and modern life. The particular nature of these echoes is informed by filmmakers' efforts to create reality-effects, by the technologies at their disposal and the production practices of the day, but also in relation to political views and developments in film culture.

This chapter has shown, however, that the forms that the enhanced echoes can take are also linked to genre, to the type of films made and the sort of stories told. According to Rick Altman, genre films are films that share a topic and a structure. Moreover, topic and structure are closely intertwined as well. In other words, the sort of story told 
informs the way it is told. Genre films, especially popular and successful genre films, do not only draw upon our knowledge about the genre and our expectations of the film; they in turn inform future films, thus contributing to the evolution of the genre and the sensibilities of the audience. They echo our knowledge and our expectations about how particular stories are to be told. Genre films teach us how we tell a story about crime, about poverty or about love.

As my argument in this chapter has sought to establish, filmmakers, in order to achieve this goal, draw on more than good writing and direction and strong performances by actors. The design of the soundtrack is an integral part of telling a film's story. And, because genre informs how a story is told, it also influences sound design. A romantic comedy has a different sound than a thriller or social drama, not just at such "obvious" moments as gunfights and car chases, but throughout the film, also during everyday activities in the city. These films do not just tell a story about, for instance, crime; they also share with us an experience of the city as an urban thriller.

Ideally, a thriller opens with the shrieking sound of a steam locomotive's horn, as a train pulls in at a large and busy station. When people exit the train we hear the hustle and bustle on the platform. The camera lingers on the door of the train compartment until, somewhat overwhelmed by this new and exciting but also dangerous environment, the face of our protagonist appears. In a bar or café near the train station, he has a first ominous meeting with a shady figure. In this pleasant, informal atmosphere, with tinkling glasses and laughing patrons, the inexperienced protagonist does not recognize the ill intentions of his companion. Later in the film our protagonist has come to know the darker sides of city life, as he lives in a small room in a bad neighborhood. Barking dogs and police sirens keep him from his sleep. Penniless, he turns to his old friend from the café, who promises him a fortune in return for a simple and harmless job. Cue the car chases and gunfights. Our thriller ends with the protagonist on the run, trying in vain to get out of the city. Silence sets over the city as in the early morning a dead body is floating in the river.

In contrast, an urban romantic comedy opens with light non-diegetic music during its opening credits sequence, which can also help us figuring out where this story takes place. We are given a bird's eye view of the city, and then snapshots of a few landmarks, before the camera settles on a nice house in a fancy street. As the nondiegetic music fades out, we hear the bells of a famous church. Birds chirp, a bicycle passes by and an alarm clock beeps. Our protagonist gets up, gets dressed and heads out to her work as a columnist at a fancy newspaper. The office is a brightly colored place filled with the sounds of people typing and telephones ringing. When the protagonist's slimy boss invits her to diner to "discuss her career," a car alarm goes off in the distance. When she walks to the restaurant, our protagonist is not paying attention to her surroundings. The sounds of traffic and the background roar of the city are almost muted, or even entirely replaced by a well-known pop song. Clumsily the protagonist bumps into a dashing stranger. He appears to be a chef who just moved into town. He is late for his first day of work in the fancy restaurant where the protagonist meets with her boss. A silent, stuck up place without much laughter. Two or three mishaps and 
misunderstandings later, after a last-minute race to the airport and an emotional but heart-warming message on the public address system wedding bells finally ring. This is what the city sounds like as a romantic comedy.

And this is the bigger picture. Not only the identities of places are constructed through the stories people tell each other about them; also our own personal and group identities as city dwellers are formed by storytelling. The way we tell each other stories about family, work, crime or love is based on, and in turn informs, how we feel about these topics. Although it may not be the first element of a fiction film that we pay attention to, or even register consciously upon a first viewing (the verb we use already gives this away), sound significantly contributes to how we tell these stories. To counter this visual bias - and promote a truly audiovisual understanding of film - I only want to say: "Listen, this is how we tell a love story." 


\section{Chapter 7}

\section{Conclusions}

\subsection{Representing the city: variations on a theme?}

This book started with a reflection on the myth of the cinematic city: the idea that the experience of a modern city can be described as a "film-like" experience-negative or positive - and that film is therefore the most appropriate medium to stage the urban condition of life. As we have seen, the myth of the cinematic city has its origins in the silent era of early film, and found its most faithful expression in the genre of the "city films" of the 1920s. These avant-garde films, which used documentary footage and experimental editing to create visual symphonies, celebrated the nervous rhythm of modern life (Uricchio 1982: 1-3). The word "visual" is crucial here, as the paradigmatic films of this genre (RIEN QUE LES HEURES, CHEVOLEK S KINOAPPARATUM and BERLIN, DIE SINFONIE DER GROßSTADT) ${ }^{105}$ were produced before the transition to synchronized, recorded sound. ${ }^{106}$ After this introduction in 1927 in the United States and from 1929 onwards in Europe, filmmakers have provided sonic representations of urban spaces of urban soundscapes - in their films that challenged the myth of the cinematic city. As my analysis of the three cities-in-film has shown, Amsterdam has long been represented as a big village rather than as a modern metropolis; the soundscape of Berlin in the 1930s was staged as a cacophony, rather than as a symphony; and London has been depicted as a collection of different and distinctive neighborhoods and communities, instead of as one big city.

As regards all three cities under study in this dissertation, we have seen filmmakers negotiate thematic and narrative oppositions. A traditional opposition underlying the narrative construction and experience of the cinematic city is the one between attraction and danger. (Mennel 2008: 22-3) Classic fictional stories of the city, of which we encountered some in this study, derive their narrative tension from a balancing act between these attractions and dangers. Characters in films such as BERLIN AleXANDERPlatz (Jutzi, 1931), EMIL UND DIE DETEKTIVE (Lamprecht 1931), THE 39 STEPS (Hitchcock, 1935) and TRAINSPOTTING (Boyle, 1996) are attracted to the city's economic opportunities, romantic possibilities and cultural life, but many fall victim to its harsh realities, such as poverty, loneliness and crime.

One finding of this study is that this classical opposition at work in the representation of cities is only one of many. My long-term, comparative perspective has revealed an important number of additional contrasts and oppositions used to evoke the

\footnotetext{
${ }^{105}$ By Alberto Cavalcanti (1925), Dziga Vertov (1929) and Walter Ruttmannn (1926) respectively.

106 "Silent" films were never completely silent, but accompanied by lectures, music or sound effects (Abel \& Altman [eds.] 2001; Altman 2004).
} 
ambiguous character of the modern city. For instance, an examination of the soundscape of thirty-two films set in Amsterdam between 1934 and 2001 highlighted a tension between depictions of Amsterdam as either a small city or a big village. My analysis of Urban Sound Events (USEs) in these films show that the city's portrayal changed, going from a relatively silent place in the 1930s to a more crowded and noisy urban environment in the 1970s, and back to a more village-like city in the 1990s. In 1930s musicals such as DE JANTJES (Speyer, 1934) and BLEEKE Bet (Oswald \& Benno, 1934) Amsterdam is a calm village, where social life is structured around small talk and sentimental folk music. In the 1970s, the various soundmarks that evoke city life - such as folk songs, church bells and barrel organs - are drowned out by traffic sounds and modern life's background rumble. Soundmarks made up $11.9 \%$ of all USEs in the 1930 s, but only $2.7 \%$ in the $1970 \mathrm{~s}$. Background and traffic sounds combined, on the other hand, increased from $50.3 \%$ to $70.9 \%$ in these same decades. Interestingly, background and traffic sounds decreased to $60.3 \%$ in the 1990 s, while the soundmarks are heard again, albeit in a different context. Specifically I discussed the barrel organ in AMSTERDAMNED (Maas, 1988), the Westertoren bells in BABYLON (Terstall, 1988) and folk music in LEK (van de Velde, 2001).

Filmic representations of Berlin, an iconic city of the twentieth century (Fritsche 1996; Mennel 2008: 21-22), offer a great number of contrasts and oppositions that are characteristic of the modern city. Examples include the tension between different experiences of the urban environment; between left-wing and right-wing politics; between a clean, harmonious city and a city in ruins; between East and West, young people and adults, rich and poor, locals and immigrants and so on. ${ }^{107}$ My analysis of the Berlin corpus (thirty-three films) revealed sonic equivalents of these tensions: the oppositions between symphony and cacophony, sounds of construction and destruction, and political sounds and silences. In contrast to Amsterdam, the analysis of Urban Sound Events in Berlin-in-film does not show a "neat" circular development, but highlights the constant construction and reconstruction of the city and its identity.

Modern London has often been identified as a collection of disparate places, villages and communities, rather than as a unity. This notion of London, first described by Ford Madox Ford in 1905, has also informed the representation of this city in fiction film (Ford 1905: 8; Mazierska \& Rascaroli 2003: 171; Brunsdon 2007: 12-14). This has inspired me to examine various Londons-in-film. The great number of "genre" films in the corpus for London led me to study the soundscapes of various genres, rather than different periods in history. My analyses of Urban Sound Events in romantic comedies, thrillers and social dramas has revealed that thrillers, such as THE 39 STEPS and Night AND THE CITY, often highlight the classical opposition between attraction and danger in the city, especially to the visitor of London. Romantic comedies, on the other hand, use

\footnotetext{
${ }^{107}$ Berlin AleXANDerPlatz (Jutzi, 1931), Kuhle WAMPE Oder: Wem GeHÖRT DIE Welt? (Dudow, 1932), HitlerJunge QueX (Steinhoff, 1933), WUNSCHKONZERT (Von Borsody, 1940), Die MÖRDER SIND UNTER UNS (Staudte, 1946), IRGENDwo IN BERLIN (Lamprecht, 1946), Die HALBSTARKER (Tressler, 1956), BERLIN ECKe Schönhauser (Klein, 1957), Die Dritte Generation (Fassbinder, 1979) and ICH CheF, Du TURNSHUH (Kutlucan, 1998).
} 
the city and its soundscape as a pretty and relatively silent backdrop to the romantic adventures of local residents. By way of conclusion we can say that these genres have their own, very different, sonic conventions, resulting in specific representations of London's soundscape. London-in-thrillers seems to present a city that is radically different from the one in London-in-comedies or London-in-social-dramas. This highlights the importance of genres - and their narrative conventions - and legitimates our interest in film culture as an analytical category in its own right.

As my study has shown, the representation of cities in films is much more complex than the myth of the cinematic city suggests. The staging of the city-in-film involves more than a balancing act between evoking a sense of its attractions and of its dangers. Other oppositions are at work as well. By listening closely we have learned that the cities-in-film discussed reflect a wide range of variations on multiple themes: village and city, symphony and cacophony, deconstruction and reconstruction, political sound and silence, locals and visitors, and so on and so forth.

To study this more complex relationship between city and cinema, I have explored the staging and representation of urban soundscapes in fiction film by paying attention to four contextual levels, aimed at explaining the changes and con-tinuities observed in the sonic representation and staging of my three cities: film-makers' attempts at constructing reality-effects, changing technologies and produc-tion practices in the film industry, politics and film culture. This framing allowed me to address how filmmakers have staged the soundscapes of Amsterdam, Berlin and London, and how these stagings contributed to the changing identities of these cities.

\subsection{Representing cities in image and sound}

As mentioned in Chapter 1, the relationship between the city and cinema has been the subject of many publications in the fields of film and media studies. Most of these studies, however, zoomed in on the visual representation of the city. My dissertation instead focused on the sonic dimension of the city, recognizing not only that since 1927 film has been an audio-visual medium, but also that the importance of sound has historically been neglected in film studies. The study of film sound has won terrain albeit slowly - since the 1980s (Hilmes 2005: 250). At the same time, we must acknowledge that sound can only have an added value in relation to the image. If imagebased studies of film have made the mistake of being (selectively) deaf, studies primarily aimed at film sound must not be blind to the fact that film is an audio-visual medium.

But what has the analysis of film sound contributed to our understanding of the filmic city? And how have filmmakers used sounds to add meaning to their audio-visual representations of cities? Let us first have a look at the filmmaker's perspective. As shown in Chapter 2, the introduction of sound was at the very heart of theoretical debates about the status of film as art in the late 1920s and early 1930s. Already in their 1928 "Statement from the U.S.S.R.," the Soviet filmmakers Sergei Eisenstein, Vsevolod 
Pudovkin and Giorgi Alexandroff pointed out that sound can be used for two different purposes. Filmmakers can use sound to confirm what is shown in the image, thereby strengthening the cinematic illusion; and they can juxtapose seemingly unrelated sounds and images, thereby creating a new perception and meaning of the filmic representation. As the Soviet directors put it:

First of all there will be the commercial exploitation of the most saleable goods, i.e. of speaking films - of those in which the record of the sound will coincide in the most exact and realistic manner with the movement on the screen, and will convey the "illusion" of people speaking, of the sound of objects and so on....

The first experiments with sound must be directed towards its pronounced noncoincidence with the visual images. This method of attack will only produce the requisite sensations, which will lead in course of time to the creation of a new orchestral counterpoint of sight-images and sound-images. (Eisenstein, Pudovkin \& Alexandroff 1998 [1928]: 83-84; italics in the original)

The history of cinema since 1928 has taught us that commercial exploitation has persisted, and that experiments with sound have remained marginal. In fact, the coming of sound coincided with the end of a number of experimental forms of cinema worldwide (Williams 1992: 133, 135-37). At the same time, the views of these Soviet directors are still relevant. Their basic observation still holds: filmmakers can use sound to confirm or exaggerate what they show in the image, or they can create juxtapositions and new meanings.

At the time, film sound offered filmmakers a new set of tools to articulate in new ways the oppositions underlying their representation of a city. One of the films discussed above, KUHLE WAMPE ODER WEM GEHÖRT DIE WELT, develops the opposition between rich and poor by showing the life of the poor in Berlin and emphasizing the bicycle as their means of transportation. The "army of the unemployed" (according to the film) races from factory to factory in search of a day's work. But although the bicycle is staged as a visual icon of poverty, its sonic representation is completely absent. Throughout the film, we do not hear a single bicycle or bicycle bell. Instead, images of people cycling are underscored by non-diegetic music. This "mute" representation of bicycles is even more striking in comparison with the representation of cars. This mode of transportation of the well-to-do features much less prominently in the film, but when cars are seen, their sounds are heard as well. Director Slatan Dudow and his crew deployed sound here to do something they could not do with the image alone: not only have they shown the opposition between rich and poor, and their respective modes of transportation, they also commented on the (perceived) silencing or denial of poverty and the poor in Weimar Berlin and Weimar cinema. ${ }^{108}$

${ }^{108}$ For its depiction of Communist ideology, the film was initially forbidden by the German censor (Kracauer 2008[1932]: 51-6; Vogt 2001: 278-9). Contemporary critic Bernhard von Brentano remarked that the powers- 
Another example of the use of sound to add meaning to a city's representation regards Amsterdam. The preservation of its historical center has greatly contributed to the city's representation as a small city or big village. For one thing, the working class people who inhabit the Jordaan neighborhood in the 1930s musical films - with all their typical humor, musicality and communal spirit - live on the same streets and in the same buildings as the yuppies and college students of the 1990s films. They stroll past the same canals. But this stable visual representation of Amsterdam as a big village is disturbed in AMSTERDAMNED, in particular in the scene in which a police officer pursues a serial killer in a spectacular speedboat chase on those same canals. This creates a strong visual counterpoint, evoking the dangerous elements of a modern city. In subtle ways, however, sound is deployed by the film's director, Dick Maas, to complicate preconceived notions of the city. In the speedboat chase, he plays with two soundmarks of Amsterdam and Dutch cinema to show that his representation of the city as a place of danger and crime is not without irony and self-awareness. First, Maas does not shy away from destroying a barrel organ, one of the strongest sonic icons of Amsterdam-in-film, in a crash with a police car. The second famous sound in the scene is the well-known musical theme from the successful film FANFARE, by Bert Haanstra (1958). By recourse to an elaborate stunt that sends one speedboat flying over a bridge, a little barge, on which Haanstra himself conducts an orchestra that plays this theme, is miraculously saved from a crash and certain destruction. Within the space of two minutes Dick Maas plays with two soundmarks of Amsterdam and Dutch cinema and eases the tensions between the big village and the modern city.

The possibility of adding irony and self-awareness to this scene constitutes the added value of sound to the filmmakers in this example. To film scholars and sound historians, in turn, film sound analysis offers insights in the meanings and interpretations that filmmakers have given to sound and our cultural heritage of sound. Filmmaker Dick Maas for instance makes a clear statement in this scene regarding which sounds should be conserved and which can be done away with. Or didn't he? Actually, that whole stunt involving the speedboats, Haanstra and the theme of FANFARE was largely a joke. As sound recordist and editor Georges Bossaers has said, Maas' motivation was not to destroy the barrel organ and preserve FANFARE; the director simply needed an excuse to send a speedboat flying over a bridge. ${ }^{109}$ Nevertheless, it would be a mistake to say that it would be the scholar's fault to read too much into this scene. After all, Maas could have put any obstacle in front of the speedboat. He chose to use Haanstra and FANFARE, presuming his audience's familiarity with the two.

The representation and staging of urban soundscapes in fiction film can give us valuable insights - insights in how cities are considered to sound in the ears of filmmakers; in the meaning of particular sounds to particular people; and in the status of the sources of sounds. Let us, for instance, return to the car for a moment. As mentioned above, the car was still a mode of transportation for the rich in the 1930s film KUHLE

that-be made it impossible to make any film outside the state-controlled Neu-Babelsberg studio system (von Brentano [1932] quoted in Vogt 2001: 279).

${ }^{109}$ Personal interview with Georges Bossaers, 2011 
WAmpe oder Wem GehÖRt Die Welt. When, in the Dutch film Pygmalion (Berger, 1937) a car does appear in a working class area its presence elicits cheers from the neighborhood children. A similar staging of the car is found in BLEEKE BET (1934): an off-screen car horn signifies the arrival of a taxi and the subsequent start of a wedding. By the 1970s, however, sounding a car horn merely serves as a means of expressing displeasure with the congested traffic (GEEN PANIEK!). The different stagings of car sounds in these films inform us about the changed status of automobiles in Dutch society between the 1930s and the 1970s.

These examples from Dutch films are quite straightforward, but there are also more complex stagings of car sounds. In East Berlin in the 1970s the presence and meaning of car sounds involved a complicated matter. An examination of car-related Urban Sound Events from this period reveals a number of seemingly conflicting developments: car sounds made up $18.9 \%$ of all USEs, a decrease when compared to the $22 \%$ of the 1950s. But we also know that the actual number of cars in the GDR increased strongly in these same twenty years. Perhaps this increase is reflected in the increase of background sounds, from $9.4 \%$ to $27.4 \%$ ? In that case cars would be present in East Berlin-in-film, but not necessarily in the lives of the characters portrayed in films such as Die Legende Von Paul und Paula (Carow, 1973) and Solo SunNy (Wolf, 1980). This would make sense, considering that the relaxation of artistic policies, following a change in the East German government in 1973, made it possible for filmmakers to show a less idealistic picture of life in East Germany, showing that car ownership was beyond the means of ordinary citizens. The relatively high level of "on-screen" car sounds, compared to West Berlin in the same period, supports this interpretation (89\% in East Berlin compared to $78 \%$ in West Berlin). As Eisenstein, Pudovkin and Alexandroff claimed, the coincidence of sound and image produces an emphasis on the represented object (Eisenstein, Pudovkin \& Alexandroff 1998 [1928]: 83-84). In other words, the presence of cars in East Berlin is emphasized by the coincidence of sound and image. Their presence is something special, and it involves specific social-cultural behavior: in fact, to go to work, characters in East German films of the 1970s frequently carpool.

My point is that it is only possible to draw subtle and complex conclusions like the ones discussed above from an extensive, combined quantitative and qualitative analysis of many films from different periods and different places. We only recognise the barrel organ as a soundmark of Amsterdam as a result of its many appearances in various films (and other media) from different decades. And the curiosity of the presence and status of car sounds in East Berlin-in-film in the 1970s could only be noticed in comparison to that same presence in the 1950s, or in West Berlin. These conclusions indicate why it is important to listen to our mediated cultural heritage. They underline the added value of sound. 


\subsection{The sound of silence}

One thing that my quantitative analysis of film sounds does not reveal is the moments when there is no sound. And yet silence is a very important narrative tool in the dramatic staging of the city. In several films and scenes mentioned in this dissertation it is the silence that stands out; it is the silence that gives a specific meaning. Because sensorial overstimulation - whether enjoyed or not by characters in films - so often characterized the mythical cinematic city, moments of silence invite us to critically reflect upon that myth.

Silence can appear on the film soundtrack in various forms, and it can have various dramatic purposes. Let me give a few examples. The myth of the cinematic city relies on the image of an overwhelming city, a stereotypical place full of noises. Therefore the absence of sound in the city-in-film can produce an extremely uncanny, sinister experience. A good example of such a dramatic staging of silence in a city-in-film is the final part of SEVEN DAYS TO NOON (Boulting \& Boulting, 1950). In this science-fiction film London has been evacuated and we hear nothing but the cries of animals in the zoo, and the bells of Big Ben in the distance. A similar staging of London is presented in another science-fiction film, 28 DAYS LATER (Boyle, 2002), when the protagonist finds the city deserted after an apocalyptic event. However, silence as a narrative tool is not only sinister in science-fiction films. As my analysis of spy thrillers from the 1950s and 1970s in Chapter 5 has shown, the border zone between East and West Berlin was often staged as a place of sinister silence. In THE MAN BETWEEN (Reed, 1953) two characters try to escape back to West Berlin, hidden in a truck. When the truck is halted by the border police, they have to keep quiet. However, when they are discovered, the silence is disturbed by the sounds of gunshots and barking guard dogs.

But silence is not necessarily sinister. The same border zone, or to be specific, the empty field where the Alexanderplatz once was, is a place of melancholic silence in Wim Wenders' DER HIMMEL ÜBER BERLIN (1987). The old man who wanders across the deserted field experiences the silence as an absence of sounds that once filled this place, before the war and the division of Berlin. His listening represents a craving for a city that no longer exists, the exciting Berlin of the roaring twenties. Yet, there is no full silence at former Alexanderplatz, as we do hear the rumble of modern Berlin in the distance, as well as the sound of a helicopter passing over. So this scene is not just a nostalgic lament about a city that has disappeared; it is also a poetic portrait of a man who is trapped in the past while the city moves on without him.

Finally, silence does not necessarily need to refer to the absence of sounds in the diegetic world. A filmmaker can also decide to change the perspective of his narration from a (supposedly) objective outsider's view to a subjective character's point of view. The terminology used already implies that this can be done with visual strategies, but filmmakers can also use sound to achieve this effect. For instance, on two occasions during the film WONDERLAND (1999), director Michael Winterbottom fades out the sounds of London to share with the audience the state of mind of the characters Nadia and Eddie: they have withdrawn themselves from reality and have retreated into their 
own world of thoughts and worries, while walking or driving through the city. As Barbara Flückiger pointed out, the disappearance of sounds marks a loss of reality (Flückiger 2001: 397). London has not ceased being noisy in WONDERLAND, but these characters no longer hear the sounds of the city.

We learn from these various silences the persistence of the myth of the cinematic city. Cities are supposed to be noisy, busy places. When they are not, something seems wrong. However, silence can be quite attractive and comforting too. It is only when there is silence that we may hear the sounds that matter. When the city has come to rest, in the evening, the pub hostess in OUT OF THE CLOUDS (Dearden, 1955) takes time to listen to the familiar sounds of church bells ringing and boats passing that make up the rhythm of her everyday life. If we take time to listen carefully to the silences on the soundtrack, there is more for us to learn than we might think.

\subsection{Echoes, resistance and play}

This conclusion has so far aimed at demonstrating the importance of listening to the mediated city, by focusing on the importance of sound as well as silence. This work has inspired me to reflect critically, not only on the cinematic city, but also on the act of listening to film. I propose to use the metaphor of the "enhanced echo" as a conceptual tool for the mediated stagings of urban soundscapes, a move inspired by my dissatisfaction with the strictly constructivist definition of film sound prevailing in Film Studies (Williams 1980; Altman 1992b; Lastra 2000). In my opinion it is a mistake to think of the soundtrack purely as a construction, and to ignore the relationship between original and representation, as James Lastra does. This bypasses the fact that representations often do have an original. In addition to the constructivist perspective, I suggest that there is a relation between an existing location and its representation in fiction film. Accordingly, I propose to introduce some measure of realism in the concept of the staged soundscape. Rather than being a return to a classical notion of realism, which proposes that a recorded sound is an exact reproduction of its original, my intention is to stress that for a reality-effect to be successful a representation needs to resemble its original, or needs to meet the listening audience's horizon of expectation.

From Roland Barthes we learned that reality-effects are produced by those elements of a text that are not necessary for the development of the story. With regard to film, we can think of the little details that make up the background, or the sounds that just "happen to be there" while characters carry on with their business. When a film crew decides to film a scene on location in, for instance, Amsterdam, many of such details find their way into the audio-visual representation of the city. Often that is the intention, sometimes it happens unintentionally. Filming may be stopped when an airplane passes over, but other less intrusive and disturbing sounds do end up on the soundtrack. Film producers may be able to close a street; they cannot silence the background sound of a city. And they do not want to either. It is exactly those background sounds, those tiny auditory details, which produce the reality-effect. That is why sound recordists always 
record a few minutes of "room tone" on location; so that it can be used during the sound editing in post-production, if desired. ${ }^{110}$ Filmmakers intentionally create echoes of existing locations that can serve as a narrative resource to produce reality-effects.

Sometimes cities are not very cooperative in the process of being staged. They may resist representation. When writing about the construction of place identity, Cliff Hague acknowledges such resistance: "The vibrancy of everyday life necessarily sets the structures within which place identities are imagined, experienced and changed" (Hague 2005: 11). Quoting Michel de Certeau, Hague distinguishes between the "concept city" of "utopian and urbanistic discourse" and the more messy and experiential discourses of place (Hague 2005: 11). If we translate this to film, we may say that the representation of a city in the filmmaker's mind may not be the same as the one that he is able to produce. An airplane flying over and ruining a recording is perhaps the most obvious example of such resistance, but the production history of BERLIN ALEXANDERPLATZ is also illustrative: because of the difficulty of filming on location and the inadequacies of early sound technology, a large part of the Alexanderplatz area was recreated in the studio. But to make the scenes on the square appear realistic, original sound recordings were used on the soundtrack. The resistance to staging was circumvented by shooting in the studio, and a reality-effect was achieved by the use of an "enhanced echo."

I may have given the impression that filmmakers have few options at their disposal to stage or represent existing places. They have to stage the city in such a way that their representations correspond to the audience's real and filmic experiences. ${ }^{111}$ To add to their concerns, the city can actively resist representation, or the technology at hand can be inadequate. Although filmmakers do experience limitations and frustrations, these create opportunities as well. In fiction, more so than in documentary, filmmakers have the freedom to play with reality-effects, viewer expectations and aesthetic conventions. It is this creative freedom that makes that the identity of a city-in-film, and consequently the identity of a city itself, is continuously under construction and open to development. In fiction you can let a group of school kids scream their lungs out when the body of a murdered prostitute falls on top of their tour boat (AMSTERDAMNED). That would be difficult to achieve in a documentary. ${ }^{112}$ This "freedom to play," however, does not only exist in thrillers or action movies. The calm and silent village in the middle of the busy city in NOtTING HiLl (Michell, 1999) and the cacophony of traffic in BERLIN ALEXANDERPLATZ are also examples of this playful experimentation with city sounds. One thing we have learned from examining the soundscapes of Amsterdam-in-film, Berlin-in-film and London-in-film is that these soundscapes are not just "realisticenough" backdrops to the action. They are more than "realistic-enough": they echo existing ideas and concerns about urban identity and urban life. And they can do so because of the space for play created by fiction.

\footnotetext{
${ }^{110}$ Personal interview with Ben Zijlstra, 2011.

${ }^{11}$ As we have learned from Fritsche, a city's real existence and its existence in textual and audiovisual representations cannot easily be distinguished (Fritsche 1996: 4). See also Chapter 1, section 1.

${ }^{112}$ With which I do not by any means want to suggest that creativity, both in form and content, is not a part of the documentary tradition. Rather, I suggest that fictional genres display different means of creativity.
} 


\subsection{Creative encounters: Sound Studies and Film Studies}

One of the ambitions of this study has been to confront the scholarly perspectives of Film Studies with those of the field of Sound Studies. This is a challenging endeavor, surely, not in the least because the field of Sound Studies is not institutionally demarcated. Sound scholars come from various fields, such as Media Studies, Science and Technology Studies, History, Sociology, Cultural Anthropology and Musicology. Even film scholars working on sound are sometimes considered part of the field of Sound Studies (Hilmes 2008). So connections and crossovers are there already. However, two conclusions of this study that may seem obvious or natural to film scholars can be of particular interest to the field of Sound Studies. One is the crucial role played by the "space for play" described in the pages above, and the other is the recognition of a "double hearing" that takes place in (fiction) film. What do "space for play" and "double hearing" specifically amount to, and why could they be of interest for sound scholars?

The space for play opened up by the fictional quality of the films under study concerns the freedom of the filmmaker to insert into an at first sight familiar representation unfamiliar elements; or, for that matter, the freedom of the audience to understand representations on their own terms. William Whittington has connected the notion of play to sound design practices at the Pixar studio in the 1980s and 1990s. Sound, in Pixar's animated short films, is not only a dominant formal element with which the filmmakers play around; playing with sound is also an essential thematic element in these films (Whittington 2012: 368).

The "double hearing" that takes place in fiction film is also a direct result of the fictional nature of the sources and of the practice of producing fiction films with synchronized sound. What I mean by this is that there is a discrepancy, or a possibility of a discrepancy, between the sound heard and experienced by the audience, and the sound heard and experienced by the characters in the diegetic world of the film. It is the conventional position of the microphone that creates this possible discrepancy. Rather than being placed inside characters' heads, the microphone is placed on the outside, listening in on the action. ${ }^{113}$ There is no possibility for a film audience to know with absolute certainty which sound a character hears or pays attention to, and how he or she experiences it, except for the rare occasion in which a character describes a sound and its meaning to him or her. These moments are of particular interest to the sound scholar because "double hearing" becomes "shared hearing": the audience and the scholar become one with a fictional character and his or her experience of the soundscape. An example of this is the balcony scene in OUT OF THE CLOUDS, in which tourists and locals experience the sounds of nocturnal London in different ways.

The difference with silent cinema is striking indeed. In silent cinema the image was supposed to suggest the sound, including the experience of it by the characters. You could see someone hearing a sound, and at the same time you could see their reaction to

\footnotetext{
113 Although the sequences in WONDERLAND, in which city sounds are faded out in order to "place" the audience inside Nadia's or Eddie's head are rather successful attempts at achieving this.
} 
and experience of it. Silent films were actually abundant with staged sounds and voices - the audience just could not hear them. ${ }^{14}$ "Deaf cinema" therefore seems a much more apt label for this period in film history (Chion 2009: 3-7). With the transition to sound film, silent film's rich vocabulary of visually expressing sound, became obsolete. The explicit staging of characters' experiences of sounds became more implicit in sound film, and thereby less "visible" for the audience. The experience of sound only becomes explicit again when the characters in a film talk about it. For sound scholars aspiring to study the experience of sound by characters in film, the transition from silent film to sound film, from no hearing to double hearing, makes their job more complex and challenging. For filmmakers, meanwhile, this transition meant they had to invent new audiovisual and narrative means of conveying the experience of sound. "Playing" with sound is not just an artistic option for filmmakers - it is a necessity.

While Sound Studies could be inspired by a more playful approach to the analysis of sound as a narrative or dramatic element, film scholars could be challenged to adopt a more "analytic" mode of listening to film sound. By "analytic" I mean the diagnostic mode of listening that has been the object of numerous studies in the field of Sound Studies. Jonathan Sterne, for instance, has described the importance of listening in medical practices in a period before the arrival of scans and visualizations, thereby underlining the diagnostic potential of the ear (Sterne 2003). And Stefan Krebs pointed out the importance of proper listening to car engines, both to drivers and mechanics, in the first half of the twentieth century (Krebs 2012).

In Film Studies, sound's potential for carrying information is often underestimated. The emphasis is on mood and atmosphere, on emotion and ambience. Film scholars often equate the visual with the rational, and the aural with the emotional, causing sound to be considered a less important carrier of information in the cinematic space (Branigan 1989: 312, 318-9). As Rick Altman argued, film sound raises questions that are subsequently answered by the image:

Fundamental to the cinema experience, therefore, is a process - which we might call the sound hermeneutic - whereby the sound asks where? And the image responds here! (Altman 1980: 74, italics by original author)

Challenging Altman's thesis, my approach shows that it is worthwhile to ask what questions the image poses that the sound answers. Quite often the image leaves us with uncertainty about where we are, what just happened, or how a character feels. As demonstrated, it is often the film sound that answers these questions, that helps to orient the audience. Sound is an important carrier of information, for the spatial and the temporal framing of the narrative as well as the moods of the characters.

It would be silly, in my opinion, to argue that sound does not have an emotional function in film. It is quite obvious that it does. As does the image. What we need to

\footnotetext{
${ }^{114}$ Apart from the situations in which a cinema offered sound effects or voices from behind the screen; but these situations were exceptional and/or experimental (Altman 2004: 102-06, 166-73).
} 
underline is that sound has informational dimension too; it is the added value of sound, as discussed above, that is the key to understanding that informational dimension. What is it that the soundtrack does that the image does not or cannot do? What does sound tell us that we cannot see? Listening to film sound in this way, "analytically" if you will, does not happen enough in Film Studies yet.

However, the introduction of digital technologies may lead film scholars to adopt a more analytical mode of listening. In Chapter 2 I argued that film scholars have not yet responded to the introduction of digital technologies in film production, distribution and exhibition, whereas previously in the history of film sound theory paradigm changes were closely related to developments in technology and production practice. The work done by William Whittington (2007) and Mark Kerins (2010) forms an exception to the neglect of the digital by film sound scholars. It is possible to find an analytical mode of listening to film sound in their studies of sound in science fiction and digital surround sound (DSS), respectively. Kerins interviewed several American sound designers about their use of DSS and analyzed the use of this new technology in storytelling. An analytical mode of listening might thus be prompted by the introduction of digital technologies, but it also relies on the use of digital resources by the scholar. As Kerins has stressed, analyzing a DSS soundtrack requires the proper sound reproduction technologies (Kerins 2010: 210-11). Likewise, I could not have performed my own film analyses for this study without the availability of films on DVD. The analytical mode of listening is not only a mode of listening to film; it also urges us to reflect critically upon our methods of research and theories of film sound.

\subsection{New (sound) perspectives}

In this dissertation I have described the representation and staging of the soundscapes of Amsterdam, Berlin and London in fiction film. In addition to the knowledge acquired about these staged soundscapes, I hope my work contributes to the fields of Sound Studies and Film studies on a theoretical and methodological level as well.

On a methodological level, the conceptualization of the Urban Sound Event made it possible for me to make a quantitative analysis of the use of sound in film narratives. Quantitative analyses are still uncommon in Film Studies. The measurements of shot lengths by Bordwell, Staiger and Thompson (1984) and by Barry Salt (1985) are exceptions. Quantitative approaches are more common in reception oriented studies. But such studies measure audience perception and preferences (for instance Hoffman \& Schwender 2007) or the emotional effect of films on viewers (Till et al. 2011). Quantitative analyses of the audiovisual text remain scarce.

By combining a quantitative analysis of city sounds in film with a more traditional qualitative approach, I enabled myself to analyze a large body of films, thereby avoiding the pitfall of drawing my conclusions from a few canonically established classics only. Moreover, my quantitative analysis had a different focus than the few existing quantitative analyses of film sound, as these are solely aimed at the sonic 
properties of sound, rather than at the meaning of sounds. Barbara Flückiger, following Raymond M. Schafer, introduced the sound object (Klangobject) in Film Studies. The Klangobject is defined by Flückiger as "the tone itself, its acoustic nature, not the material object (an instrument or another type of source) that produces it" (Flückiger 2010: 21). ${ }^{115}$ The Urban Sound Event is quite the opposite of the sound object: by coining it I was not primarily interested in its actual sound or acoustic properties (although these do play a role in its evaluation) but foremost in its source. The USE is a semiotic concept; it signifies another "real world" sound. This leads me to the theoretical contribution this dissertation makes to the fields of Film and Sound Studies. The recognition that mediated soundscapes stage and represent soundscapes that have a life outside film as well has urged me to inject some notion of "realism" in my understanding of the film soundtrack.

My analyses, and their contextualization, have shown that there is a relation between urban soundscapes and their filmic representations, even if sound is transformed through the act of recording and the processes of sound design and sound editing and mixing. The representations of urban soundscapes in fiction film can be understood as "enhanced echoes" of these soundscapes. And if we follow Emily Thompson in defining "soundscape" as "both a world, and a culture constructed to make sense of that world" (Thompson 2002: 1), these representations echo not only the sounds of a city, and its acoustic properties, but also the understanding of those sounds by filmmakers, audiences, and city residents. We can even say that these representations become in turn part of the culture that makes sense of the world. They do not just echo urban soundscapes and identities; they contribute to them.

Film Studies can benefit from the combined quantitative and semiotic analysis of film texts. It is an approach that makes it possible to study a great number of films, in a comparative perspective that can be diachronic and synchronic. Many contributions to film studies, and film sound studies, are hampered by the fact that their conclusions are based on the examination of a limited number of films, usually films that belong to an already established canon of "classics." If anything, quantitative approaches can contribute to the critical assessment of the myths of Film Studies, of which the myth of the cinematic city is only one.

Both Film Studies and Sound Studies can benefit from the concept of the enhanced echo as a metaphor for the sonic representations. As we have seen in Chapter 2, the tension between the constructivist character of the soundtrack and its mimetic function has never been completely resolved. It has led to models of film sound that deny the existence of original sounds (Lastra 2000) or suggest that film sounds refer to nonexistent originals (Wurtzler 2007). My conviction is that the concept of the enhanced echo, which admits the transformational character of film sound but stresses the direct (if not indexical) relationship between the representation and its existing signified, does resolve part of that tension. Furthermore, the metaphor of the enhanced echo can benefit Sound Studies because it is not limited to filmic representations of sounds. It also

115 “... den Ton selbst, Seine akustische Beschaffenheit und nicht das materielle Objekt (ein Instrument oder eine anders geartete Quelle), von dem es stammt." 
applies to representations in radio, television, literature and other textual sources, whether of a fictional or documentary nature. Döblin's descriptions of Berlin's soundscape are also echoes: transformed and delayed repetitions of sound. The concept of the enhanced echo may therefore make it possible to make intermedial comparisons between representations of sound in different sources. And that is exactly a project to which this research has attempted to contribute. 


\section{Annex A: Filmography}

\section{Films situated in Amsterdam}

DE JANTJES (1934)

Dir. Jaap Speyer. Starring: Fien de la Mar, Johan Kaart, Heintje Davids \& Sylvain Poons.

Summary: Three sailors arrive home, in the Amsterdam neighborhood De Jordaan, only to find that their girlfriends have not all been equally patient for their homecoming. Their romantic adventures are interspersed with musical performances of typical Amsterdam folk songs.

BLEEKE BET (1934)

Dir. Alex Benno \& Richard Oswald. Starring: Aaf Bouber, Johannes Heesters, Sylvain Poons \& Fien de la Mar.

Summary: A green-grocer marries off her daughter to the sickly son of a shady business partner, against the wishes of the girl and her actual lover. Another "Jordaan musical," that combines an old-fashioned representation of Amsterdam with performances of folk music.

OP STAP (1935)

Dir. Ernst Winar. Starring: Louis Davids, Heintje Davids, Jopie Koopman \& Fien de la Mar.

Summary: An unfortunate piano tuner hopes that his daughter and her fiancé will do better in life. The arrival of a rich uncle from the Dutch Indies offers new possibilities, but the piano tuner's greedy wife may be an obstacle to happiness.

ORANJE HEIN (1936)

Dir. Max Nosseck. Starring: Harmen Bouber, Aaf Bouber, Johan Elsensohn \& Annie Verhulst.

Summary: The last of the "Jordaan musicals." The neighborhood rallies together to reunite the family of Thijs, a drunk with a good heart, when his wife finally decides to leave him.

KOMEDIE OM GELD (1936)

Dir. Max Ophüls. Starring: Herman Bouber, Rini Otte \& Matthieu van Eysden.

Summary: A simple bank clerk is first fired when he loses a suitcase filled with money, but subsequently becomes a pawn in a financial scandal that teaches him and his daughter important lessons about the value of money.

PYGMALION (1937) 
Dir. Ludwig Berger). Starring: Lily Bouwmeester, Johan de Meester \& Eduard Verkade.

Summary: Dr. Pickering takes charge of flower sales girl Liesje. He plans to turn her into an upper class lady to win a wager with his friend Higgins. Dutch adaptation of George Bernard Shaw's famous stage play.

FOREIGN CORRESPONDENT (1940)

Dir. Alfred Hitchcock. Starring: Joel McCrea, Laraine Day \& Herbert Marshall.

Summary: An American journalist travels to London and Amsterdam to cover a peace conference that has to prevent looming war. However, the peace is threatened when a major Dutch diplomat is murdered and the American journalist gets caught up in the plot.

\section{EEN KONINKRIJK VOOR EEN HUIS (1949)}

Dir. Jaap Speyer. Starring: Heintje Davids, Johan Kaart, Annie van Duyn \& Rob de Vries.

Summary: Because of the post-war housing shortage in Amsterdam, an upper class family is forced to provide living quarters to a family of market vendors in their posh villa. A comedic class war ensues, but the conflict is resolved through the love between the son and daughter of the two families.

\section{STERREN STRALEN OVERAL (1953)}

Dir. Gerard Rutten. Starring: Piet Muyselaar, Willy Walden, Johan Kaart \& Kitty Janssen.

Summary: An Amsterdam taxi driver plans to leave The Netherlands for Australia with his family, in search for a better future. However, his future son-in-law gets himself in trouble with the law when he tries to raise money to accompany them. The taxi driver's efforts to solve these troubles do not work out as planned.

\section{Het WonderliJKe LeVEN VAN WiLlem PAREL (1955)}

Dir. Gerard Rutten. Starring: Wim Sonneveld, Peronne Hosang, Femke Boersma \& Hans Kaart.

Summary: Radio comedian Wim Sonneveld gets into a lot of trouble when one of his types, barrel organ player Willem Parel, escapes form the realm of fiction to cause chaos on the streets and in the high society of Amsterdam. A highlight is a protest of barrel organ players staged by Willem Parel.

\section{KLEREN MAKEN DE MAN (1957)}

Dir. Georg Jacoby. Starring: Kees Brusse, Annet Nieuwenhuyzen, Johan Kaart \& Rijk de Gooyer.

Summary: A stolen costume containing an important document accidentally ends up in the possession of an innocent man ignorant of the document. He subsequently ends up in strange situations he cannot quite comprehend. 
JENNY (1958)

Dir. Willy van Hemert. Starring: Ellen van Hemert, Maxim Hamel, Kees Brusse \& Andrea Domburg.

Summary: In this first Dutch color film a young girl, member of a rowing crew, falls pregnant out of wedlock. However, her boyfriend does not want to get married. It takes the help of the girl's rowing coach and a friendly doctor to turn the boy around.

\section{MAKKERS STAAKT UW WILD GERAAS (1960)}

Dir. Fons Rademakers. Starring: Ellen Vogel, Guus Hermus, Ank van der Moer \& Jan Teulings.

Summary: Three Dutch families struggle with their troubles during the Saint Nicholas season: A cheating husband may or may not come home, a teenage son wants to hang out with his friends instead of at home and a couple that has already split up try to figure out their separate futures.

\section{RIFIFI IN AMSTERDAM (1962)}

Dir. Giovanni Korporaal. Starring: Maxim Hamel, Johan Kaart, Jan Blaser \& Rijk de Gooyer.

Summary: A criminal who is just released from prison has to elude the police, a rival gang and the victim of his last crime in order to secure the hidden loot of that crime. However, that briefcase full of jewels has a history of its own as well.

Blue Movie (1971)

Dir. Wim Verstappen. Starring: Hugo Metsers, Carry Tefsen \& Kees Brusse.

Summary: Michael, just out of prison, is on probation. He is set up in a little apartment in the Bijlmer, where he enjoys a number of erotic adventures before deciding to make his money in the sex business.

WAT ZIEN IK? (1971)

Dir. Paul Verhoeven. Starring: Ronnie Bierman, Sylvia de Leur, Piet Römer \& Jules Hamel.

Summary: Two prostitutes live and work together in the Amsterdam Red Light District. When one of them is beaten up by a pimp, and the other one falls in love with a married man, they try to leave their life behind and find real love. However, it proves to be quite difficult.

DIAMONDS ARE FOREVER (1971)

Dir. Guy Hamilton. Starring: Sean Connery, Jill St. John \& Charles Gray.

Summary: James Bond is briefly in Amsterdam when he tries to track down diamonds that are smuggled from South Africa to the United States.

GEEN PANIEK (1973) 
Dir. Ko Koedijk. Starring: Rijk de Gooyer, John Kraaykamp, Hetty Blok \& Trudy Labij.

Summary: Rijk picks up his mate Johnny when he is released from prison. It takes Rijk some time to get used to modern life, but soon they start up a successful handyman service together. Their new business is threatened when a real estate developer sets his eyes on the brothel from which the two run their service.

NAAKT OVER DE SCHUTTING (1973)

Dir. Frans Weisz. Starring: Rijk de Gooyer, Jennifer Willems, Jon Blumer \& Sylvia Kristel.

An arcade owner, a former Karate champion and a school teacher get involved in a murder mystery when the Karate champion backs out, last minute, from a pornographic photography shoot. A highlight is the climactic tram chase through Amsterdam.

\section{TURKS FRUIT (1973)}

Dir. Paul Verhoeven. Starring: Rutger Hauer \& Monique van de Ven.

Summary: A young sculptor remembers his brief love affair with and marriage to the sexy but unpredictable Olga. Jealousy and problems with his in-laws undermine the relationship. A few months after their break-up the two meet by coincidence, for the last time.

\section{HET JAAR VAN DE KREEFT (1975)}

Dir. Herbert Curiel. Starring: Willeke van Ammelrooy, Rutger Hauer \& F. van Bouwdijk Bastiaanse.

Summary: Alcoholic hair dresser Toni cannot decide whether she wants independence, a settled life with the father of her daughter or new love with businessman Pierre. A sad fate eventually brings Pierre and Toni together.

TWEe VROUWEN (1979)

Dir. George Sluizer. Starring: Anthony Perkins, Bibi Andersson \& Sandra Dumas.

Summary: A middle-aged woman strikes up an affair with a young girl, in this adaptation from the Harry Mulisch" novel. Things go awry, though, when the girl inexplicably runs off with the woman's obnoxious ex-husband.

\section{GRIJPSTRA EN DE GIER (1979)}

Dir. Wim Verstappen. Starring: Rijk de Gooyer, Rutger Hauer \& Willeke van Ammelrooy.

Summary: The investigation of a suicide that might have been a murder leads police detective Grijpstra and his younger colleague De Gier into the world of drugs trafficking. The suspects are all members of a mysterious religious cult.

\section{AMSTERDAMNED (1988)}

Dir. Dick Maas. Starring: Huub Stapel, Monique van de Ven \& Serge-Henri Valcke. 
Summary: A serial killer is stalking the canals of Amsterdam, randomly murdering people who come to close to the water. Police detective Eric Visser is charged with finding and arresting the killer. The highlight of the film is a spectacular speedboat chase through the canals.

\section{LOST IN AMSTERDAM (1989)}

Dir. Pim de la Parra. Starring: Kenneth Herdigein, Sabine van den Eynden \& Ira Goldwasser.

Summary: A private detective loses himself in Amsterdam's criminal underworld after he sets out to find the missing husband of a rich lady. Curiously, the film is entirely spoken in English.

\section{KRACHT (1990)}

Dir. Frouke Fokkema. Starring: Theu Boermans, Anneke Blok \& Dave van Dinther.

Summary: A widowed farmer from the southern region of Limburg travels to Amsterdam for a trade fair. There he meets a young woman. She travels to Limburg to live with him, but she has a difficult time adjusting to country life and filling the dead woman's shoes.

DE DRIE BESTE DINGEN VAN HET LEVEN (1992)

Dir. Ger Poppelaars. Starring: Loes Woutserson, Victor Löw \& Jack Wouterse.

Summary: Successful violinist Sacha returns to Amsterdam to visit her friend, but he is not at home. Wandering though the city, she meets the bohemians Caspar and Maarten, who teach her the three most important things in life.

ZUSJE (1995)

Dir. Robert Jan Westdijk. Starring: Kim van Kooten, Romijn Conen \& Hugo Metsers.

Summary: After years of absence Martijn returns in his sister Daantje's life, filming everything she does. Much to her chagrin and that of her boyfriend. However, Martijn has a plan: to disclose a family secret and right a terrible wrong.

\section{BABYLON (1998)}

Dir. Eddy Terstall. Starring: Nadja Hüpscher, Rifka Lodeizen \& Domenico La Ferrara.

Summary: Five stories about love, relationships and sex play out in the sun-drenched Jordaan neighborhood in Amsterdam, connected by the sound of the bells of the Westerkerk.

DE PIJNBANK (1998)

Dir. Theo van Gogh. Starring: Jack Woutserse, Paul de Leeuw, Roeland Fernhout \& Eric van Sauers.

Summary: After a hostile takeover, a cold war starts between successful bank employee Peter, and the new manager Bouke. Bouke tries to get rid of Peter, but Peter knows the key to company secrets that Bouke wants to know. 


\section{DE BOEKVERFILMING (1999)}

Dir. Eddy Terstall. Starring: Dirk Zeelenberg, Nadja Hüpscher, Najib Amhali \& Femke Lakerveld.

Summary: Promising young film director Lars is hired to adapt a successful novel for the screen. But he tallies in choosing his leading actress, playing three women against each other, and trying to get each of them to sleep with him.

JEZUS IS EEN PALESTIJN (1999)

Dir. Lodewijk Crijns. Starring: Hans Teeuwen, Kim van Kooten en Peer Mascini.

Summary: Ramses returns from the cult he has been living with to visit his dying father. Once back in Amsterdam, staying with his worldly sister, he is tempted by the (sexual) attractions of the big city. Meanwhile, religious nutjobs await the return of the Messiah on top of a Bijlmer apartment building.

LEK (2000)

Dir. Jean van de Velde. Starring: Cas Jansen, Thomas Acda, Victor Löw \& Ricky Koole.

Summary: Young police officer Eddy is approached by his childhood friend Jack, a criminal who wants to turn informant. As a result, Eddy is sucked into a web of corruption and betrayal in the Amsterdam police force.

\section{Films situated in Berlin}

M - EINE STAdT SUCHT EINEN MÖRDER (1931)

Dir. Fritz Lang. Starring: Peter Lorre, Otto Wernicke \& Theodor Loos.

Summary: A child murderer haunts the streets of Berlin. In their efforts to capture him, the police make life impossible for the criminal underworld. So the criminals, in turn, set up a manhunt of their own.

BERLIN ALEXANDERPLATZ (1931)

Dir. Phil Jutzi. Starring: Heinrich George, Maria Bard \& Margarete Schlegel.

Summary: Just released from prison, Franz Biberkopf has a hard time adjusting to life in Berlin. He tries to stay on the straight path, but is lured back into a life of crime and violence.

EMIL UND DIE DETEKTIVE (1931)

Dir. Gerhard Lamprecht. Starring: Rolf Wenkhaus, Fritz Rasp, Inge Landgut \& Hans Joachim Schaufuß.

Summary: While traveling to Berlin to stay with his grandmother, young Emil is money is stolen by a fellow traveler. In Berlin, Emil teams up with a gang of streetwise kids to 
capture the criminal and retrieve his money. The first of many adaptations of Erich Kästner's novel.

KUHLE WAMPE ODER: WEM GEHÖRT DIE WELT? (1932)

Dir. Slatan Dudow. Starring: Hertha Thiele, Ernst Busch \& Martha Wolter.

Summary: A working class family is evicted from their house and has to live in a slum of tents outside the city. While the older generations in the camp do nothing but complain and drink, the young people work hard to build a better future under Socialism.

\section{GRAND HOTEL (1932)}

Dir. Edmund Goulding. Starring: Greata Garbo, John Barrymore, Joan Crawford \& Lionel Barrymore.

Summary: A number of individual dramatic stories play out in a fancy Berlin hotel. A broke baron tries to steal a dancer's pearls, a terminally ill accountant confronts his employer and several people fall in and out of love.

DAs TeSTAMENT DES DR. MABUSE (1933)

Dir. Fritz Lang. Starring: Otto Wernicke, Rudolf Klein-Rogge \& Gustav Diesel.

Summary: A series of recent crimes all lead back to criminal mastermind Mabuse. The problem is; Mabuse has been locked away in an asylum for years. Police chief Lohmann has to find out who has taken up the legacy of Mabuse and is now trying to overthrow society.

\section{VIKTOR UND VIKTORIA (1933)}

Dir. Reinhold Schünzel. Starring: Renate Müller, Herman Thimig \& Hilde Hildebrand. Summary: In this comedy of mistaken identities, variety performer Viktor, who impersonates a female singer, loses his voice and is forced to hire aspiring Susanne actress to replace him. The cheat is too successful, though, as Susanne is "discovered" by an agent.

\section{HITLERJUNGE QUEX (1933)}

Dir. Hans Steinhoff. Starring: Jürgen Ohlsen, Heinrich George \& Berta Drews.

Summary: Young Heini is sent to a communist youth camp by his no-good father. However, he chooses to stay with the much cleaner and nicer Hitlerjugend. Working for the Hitlerjugend, Heini is killed by communists while distributing Nazi pamphlets.

\section{WUNSCHKONZERT (1940)}

Dir. Eduard von Borsody. Starring: Hedwig Bleibtreu, Joachim Brennecke \& Ilse Werner.

Summary: At the 1936 Olympic games, Inge falls in love with air force pilot Herbert. However, before they can get married Herbert is sent on a secret mission. Years later the "Wunschkonzert" radio broadcast unexpectedly brings them together again. 


\section{DIE MÖRDER SIND UNTER UNS (1946)}

Dir. Wolfgang Staudte. Starring: Hildegard Knef, Wilhelm Borchert \& Robert Forsch. After the war, a young woman returns to what is left of her house in Berlin, finding that a drunk doctor has taken over the place. They share the apartment, while the doctor tries to come to peace with his guilt over a war crime he was forced to commit.

IRGENDWO IN BERLIN (1946)

Dir. Gerhard Lamprecht. Starring: Charles Bauer, Hans Trinkhaus \& Siegfried Utecht. Summary: Young boys have a hard time growing up in the ruins of postwar Berlin, without fathers or father figures. When Gustav's father returns from a POW camp, he is everything but the man Gustav knew.

\section{UNSER TÄGLICH BROT (1949)}

Dir. Slatan Dudow. Starring: Viktoria von Balasko, Paul Bildt \&

Summary: A family struggles to make ends meet after the war. The passive father falls out with one of his sons, who tries to set up a communal factory, but brings no money home. The other son does provide for the family, but through shady dealings.

\section{THE MAN BETWEen (1953)}

Dir. Carol Reed. Starring: James Mason, Claire Bloom \& Hildegard Kneef.

Summary: An English woman visits her brother and sister-in-law in West-Berlin. There she falls in love with a mysterious man, and unwillingly becomes involved in a humantrafficking scandal.

\section{EMIL UND DIE DETEKTIVE (1954)}

Dir. Robert A. Stemmle. Starring: Peter Finkbeiner, Kurt Meisel, Claudia Schäfer \& Wolfgang Condrus.

Summary: This second German adaptation of Erich Kästner's popular children's novel has a peculiar scene in which Emil's capture of the criminal Grundeis is celebrated with a big parade in the Olympic stadium.

\section{DIE HALBSTARKER (1956)}

Dir. Georg Tressler. Starring: Horst Buchholz, Karin Baal \& Christian Doermer. Summary: In a swimming pool Jan meets his older brother Freddy, who no longer lives at home. When the two reconnect, Freddy draws Jan into his gang of teenage criminals and both boys fall for sixteen year old femme-fatale Sissy, with tragic consequences.

BERLIN - ECKE SCHÖNHAUSER (Gerhard Klein, 1957)

Dir. Gerhard Klein. Starring: Ekkehard Schall, Ilse Pagé \& Ernst-Georg Schwill. Summary: A group of teenagers hang about on the Schönhauser corner in East-Berlin. They listen and dance rock'n'roll, of which adults disapprove. But the corrupting lure of 
the West leads some of the kids into a life of crime and violence, and ultimately to a tragic death.

\section{A DANDY IN ASPIC (1968)}

Dir. Anthony Mann. Starring: Laurence Harvey, Tom Courtenay \& Mia Farrow.

Summary: In a strange twist of events, a Soviet double spy is ordered by his British superiors to find and kill himself. With his cover nearly blown, he travels to WestBerlin, in an attempt to flee back to Moscow. But he is accompanied by a violent and distrustful colleague, who makes matters more complicated.

\section{Die Legende Von Paul und Paula (1973)}

Dir. Heiner Carow. Starring: Angelica Domröse, Winfried Glatzeder \&Heidemarie Wenzel.

Summary: Single mother Paula and the unhappily married Paul begin a passionate love affair. However, Paul's family and career interfere time and again with couple's plans. This film stands out because of its simultaneously realistic and poetic portrayal of life in East Berlin.

\section{EINER VON UNS BEIDEN (1974)}

Dir. Wolfgang Petersen. Starring: Klaus Schwarzkopf, Jürgen Prochnow \& Elke Sommer.

Summary: A poor student finds out that his professor has committed plagiarism. He blackmails the professor, and ruins his life, even dating his daughter. The professor then turns to drastic measures to get rid of the student.

\section{DIE FLUCHT (1977)}

Dir. Roland Gräf. Starring: Armin Mueller-Stahl, Jenny Gröllman \& Erika Pelikowsky. Summary: When his proposed research program is rejected, Dr. Schmidt plans to follow the example of one of his colleagues, and defect to the West. However, when he reverses that decision, the Western agents blackmail him into defecting.

\section{DiE DRITTE GENERATION (1979)}

Dir. Werner Rainer Fassbinder. Starring: Eddie Constantine, Udo Kier \& Harry Baer. Summary: A shrewd businessman plans to boost the German sales of security computers by financing a terrorist group. This "third generation" of left wing terrorists consists of jealous and confused middle-class thirty-somethings, whose incompetence leads to much violence and death.

\section{SOLO SunNY (1980)}

Dir. Konrad Wolf. Starring: Renate Krößner, Alexander Lang \& Dieter Montag. Summary: Sunny is the singer in a mildly successful band from East Berlin, but she feels out of touch with her audience and her band. After a failed affair with a saxophone player she is kicked out of the band and has to get her life back on track. 
CHRISTIANE F. - WIR KINDER VOM BAHNHOF ZOO (1981)

Dir. Uli Edel. Starring: Natja Brunckhorst, Thomas Haustein \& Jens Kuphal.

Summary: Teenager Christiane lives with her sister and mother in a drab apartment in Berlin. At a David Bowie concert she uses heroin for the first time, and subsequently she drifts off into a life as a homeless drug addict and child prostitute, despite incidental efforts to kick off.

\section{DER HIMMEL ÜBER BERLIN (1987)}

Dir. Wim Wenders. Starring: Bruno Ganz, Solveig Dommartin \& Otto Sander.

Summary: Two angels, Cassiel and Damiel, guard the population of a divided Berlin. When Damiel falls in love with a circus performer, he starts to doubt his immortal existence and wants to become human.

IN WEITER FERNE SO NAH! (1993)

Dir. Wim Wenders. Starring: Otto Sander, Bruno Ganz \& Natassja Kinski.

Summary: Some years after his friend Damiel decided to become human, and after the fall of the Berlin Wall, the angel Cassiel decides it is time for him to make the same decision. Meanwhile, Berlin is visited by Michail Gorbachev, Lou Reed and Peter Falk.

MÄNNERPENSION (1996)

Dir. Detlev Buck. Starring: Til Schweiger, Heike Makatsch, Marie Bäumer \& Detlev Buck.

Summary: As part of a research program, two inmates are released from prison in the care of two women. They have to prove that they are reformed and ready to integrate in society. Romantic developments and comedic episodes follow.

OBSESSION (1997)

Dir. Peter Sehr. Starring: Daniel Craig, Charles Berling \& Heike Makatsch.

Summary: Zimbabwean national John travels illegally to Berlin to find out a secret about his past, but falls in love with Miriam, who has a longstanding relationship with Pierre. John's illegal stay in Germany and his troubled past complicate an already tragic love triangle.

\section{DAs LeBEN IST EINE BAUSTELLE (1997)}

Dir. Wolfgang Becker. Starring: Jürgen Vogel, Christiane Paul \& Ricky Tomlinson. Summary: When leaving his lover, Jan ends up in a demonstration, and he accidentally hits a police officer unconscious. The resulting fine leaves him jobless and penniless, his father dies and his lover tells him he might have AIDS. But at least he has a tentative romance going on with an extraordinary street musician.

ICH CHEF, DU TURNSCHUH (1997)

Dir. Hussi Kutlucan. Starring : Hussi Kutlucan, Wiebke Inn \& Senta Moira. 
Summary: Illegal immigrant Dudie escapes to Berlin in search for a new life. He is discriminated against and exploited, but he also finds love and a child to care for, until he is arrested and sent back to Afghanistan

LOLA RENNT (1998)

Dir. Tom Tykwer. Starring : Franka Potente, Moritz Bleibtreu \& Herbert Knaup.

Summary: Lola's boyfriend Manni accidentally loses 10.000 D-Mark that belong to a dangerous gangster. Lola now has twenty minutes to get the money and bring it to Manni before he will rob a supermarket. Seemingly small coincidences will decide whether or not Lola will be able to save Manni.

\section{NACHTGESTALTEN (1998)}

Dir. Andreas Dresen. Starring: Myriam Abbas, Dominique Horwitz \& Oliver Breite. Summary: The film follows several couples during a rainy Berlin night. A farmer comes to Berlin to visit a prostitute, a businessman takes care of a lost young boy at the airport and a homeless couple searches for a place to stay the night.

EMIL UND DIE DETEKTIVE (2001)

Dir. Franziska Buch. Starring: Tobias Retzlaff, Anja Sommavilla \& Jürgen Vogel.

Summary: This third German adaptaion of Erich Kästner's book is most remarkable because of some major changes in the story. For instance: Emil's remaining parent is now his father. Also: Emil's trip to Berlin is not voluntarily, but forced.

WASS TUN, WENN'S BRENNT? (2001)

Dir. Gregor Schnitzler. Starring: Til Schweiger, Sebastian Blomberg \& Nadja Uhl.

Summary: Of a group of six former squatters and anarchists, two still cling on to their old lifestyle, while the others have moved on after the fall of the Wall. The six are forced to come back together when an old bomb explodes, and the traces lead the police to them.

\section{Films situated in London}

BLACKMAIL (1929)

Dir. Alfred Hitchcock. Starring: Anny Ondra, John Longden \& Donald Calthrop.

Summary: Young Alice accidentally kills an artist who tries to rape her. When her police officer fiancée finds out, the two of them are blackmailed by a ruthless criminal, and forced to obstruct the police's inquiry.

VIKTOR UND VIKTORIA (1933)

Dir. Reinhold Schünzel. Starring: Renate Müller, Herman Thimig \& Hilde Hildebrand. 
Summary: In this comedy of mistaken identities, variety performer Viktor, who impersonates a female singer, loses his voice and is forced to hire aspiring Susanne actress to replace him. The cheat is too successful, though, as Susanne is "discovered" by an agent.

THE 39 STEPS (1935)

Dir. Alfred Hitchcock. Starring: Robert Donat, Madeleine Carroll \& Godfrey Tearle.

Summary: A Canadian staying in London is wrongfully accused of the murder of a mysterious woman. He has to travel all the way to Scotland, and back to London, to prove his innocence and unmask an espionage conspiracy. Mostly while handcuffed to a beautiful young woman.

\section{BulldOG DRUMMOND COMES BACK (1937)}

Dir. Louis King. Starring: John Barrymore, John Howard \& Reginald Denny.

Private investigator Hugh "Bulldog" Drummond is about to marry his fiancée as she is being kidnapped by evil criminals. They put Bulldog on a treasure hunt for clues, but with the help of his friends Algy and Colonel Neilson he is able to finally save the girl.

BULLDOG DRUMMOND's BRIDE (1939)

Dir. James P. Hogan. Starring: John Howard, Heather Angel \& H.B. Warner.

Summary: After an ingenious bank robbery the police ask the assistance of Hugh "Bulldog" Drummond. This forces him, again, to postpone his wedding to his beloved Phyllis Clavering.

\section{WATERLOO BRIDGE (1940)}

Dir. Mervyn LeRoy. Starring: Vivien Leigh, Robert Taylor \& Lucile Watson.

Summary: At the outbreak of World War Two a British general remembers meeting a beautiful dancer on Waterloo Bridge, during World War One. The two had a brief romance, which was interrupted when he was sent to France. After the, mistaken, report of his death, the girl becomes a prostitute, and too late she learns that he is still alive.

\section{FOREIGN CORRESPONDENT (1940)}

Dir. Alfred Hitchcock. Starring: Joel McCrea, Laraine Day \& Herbert Marshall.

Summary: An American journalist travels to London and Amsterdam to cover a peace conference that has to prevent looming war. However, the peace is threatened when a major Dutch diplomat is murdered and the American journalist gets caught up in the plot.

THE BLUE LAMP (1950)

Dir. Basil Dearden. Starring: Jack Warner, Dirk Bogarde \& Jimmy Hanley.

Summary: A young criminal shoots a veteran cop during a robbery. The young police officer who was the veteran's pupil is subsequently at the centre of the police's manhunt 
for the criminal and his associates. They become ever more trapped and start to distrust one another.

\section{StAGE Fright (1950)}

Dir. Alfred Hitchcock. Starring: Jane Wyman, Marlene Dietrich, Michael Wilding \& Richard Todd.

Summary: A young man is accused of having killed famous actress' husband. He asks the help of an old girlfriend who is secretly in love with him. But while she's trying to prove his innocence by going undercover as the actress' maid, she falls in love with the police detective working the case.

\section{SEVEN DAYS TO NOON (1950)}

Dir. John Boulting \& Roy Boulting. Starring: Barry jones, Olive Sloane \& André Morell.

Summary: To warn the world about the dangers of nuclear weapons, a crazy scientist steals an atom bomb and hides it somewhere in London. He gives the government seven days to fulfill his demands, or he will blow up London.

\section{NigHT AND THE CITY (1950)}

Dir. Jules Dassin. Starring: Richard Widmark, Gene Tierney \& Helen Nosseross.

Summary: A small-time crook and conman thinks he can make it big as a wrestling promoter, only to get caught up in affairs he cannot handle with people who are not afraid to use deadly violence.

\section{THE LAVENDER HILl MOB (1951)}

Dir. Charles Crichton. Starring: Alec Guinness, Stanley Holloway \& Sid James.

Summary: A mid-level clerk at the Bank of England has one brilliant plan to steal a carload of gold bullion. When he meets a souvenir trader he finally has the means of organizing the theft. However, unforeseen circumstances endanger the entire operation when the real gold gets mixed up with worthless imitations.

THE LADYKILLERS (1955)

Dir. Alexander Mackendrick. Starring: Alec Guinness, Peter Sellers \& Katie Johnson. Summary: A group of criminals rent a room in an old lady's house to plan a big heist. They even make her an unknowing part of their plan. However, they did not expect that getting away with the stolen money would be so difficult with old Mrs. Wilberforce around.

\section{OUT OF THE CLOUDS (1955)}

Dir. Basil Dearden. Starring: Anthony Steel, Robert Beattie \& David Knight.

Summary: The film portrays one day at Heathrow Airport, where various passengers and airline personnel struggle with important decisions. While bad weather prevents further air traffic romances bloom and end and careers are threatened. 


\section{A DANDY IN ASPIC (1968)}

Dir. Anthony Mann. Starring: Laurence Harvey, Tom Courtenay \& Mia Farrow.

Summary: In a strange twist of events, a Soviet double spy is ordered by his British superiors to find and kill himself. With his cover nearly blown, he travels to WestBerlin, in an attempt to flee back to Moscow. But he is accompanied by a violent and distrustful colleague, who makes matters more complicated.

PERFORMANCE (1970)

Dir. Donald Cammell \& Nicolas Roeg. Starring: James Fox, Mick Jagger \& Anita Pallenberg.

After killing the wrong man, a ruthless hitman has to leave London. But instead he stays with a former rock star and two groupies in the rock star's large house Notting Hill. There the four of them engage in drug induced games of identity changes and performances.

\section{MELODY (1971)}

Dir. Waris Hussein. Starring: Mark Lester, Tracy Hyde \& Jack Wilde.

Summary: Latimer and Ornshaw are friends at school, sharing everything despite the difference in their social class. However, their friendship is threatened when Latimer falls in love with Melody, and the two decide to get married. Ornshaw feels betrayed, but helps his friend when parents and teachers try to prevent the wedding from taking place.

Frenzy (1972)

Dir. Alfred Hitchcock. Starring: Jon Finch, Alec McCowen \& Barry Foster.

Summary: London is terrorized by a serial killer who strangles women with using neckties. The police have a suspect, but he is the wrong man. The question is whether they"ll find out before the real killer strikes again.

\section{STEPTOE AND SON (1973)}

Dir. Cliff Owen. Starring: Wilfrid Brambell, Harry H. Corbett \& Carolyn Seymour.

Summary: Father Albert and son Harold Steptoe run a disgusting junk dealership in London. Albert is none too pleased when Harold falls in love with a stripper and marries her. He tries to sabotage the marriage by joining the happy couple on their honeymoon to Spain.

\section{A TOUCH OF CLASS (1973)}

Dir. Melvin Frank. Starring: George Segal, Glenda Jackson \& Paul Sorvino.

Summary: A happily married American in London strikes up an affair with a divorced woman. They go on a disastrous holiday to Spain together, but when they come back the man realizes that he has fallen in love with the woman, even though he also still loves his wife. 
BRANNIGAN (1975)

Dir. Douglas Hickox. Starring: John Wayne, Richard Attenborough \& Judy Geeson.

Summary: Tough but honest American police officer Jim Brannigan is sent to London to arrange the extradition of an American mobster. However, when the criminal is kidnapped, the British police are not too happy with Brannigan's unconventional police work.

\section{NAKED (1993)}

Dir. Mike Leigh. Starring: David Thewlis, Lesley Sharp, Katrin Cartlidge.

Summary: Johnny flees from Manchester to London to avoid the revenge of the family of a girl he has raped. He first seeks out an old girlfriend, but soon ends up living on the streets, discussing life, philosophy and nonsense with whomever he finds on his way.

\section{LONDON (1994)}

Dir. Patrick Keiller. Starring: Paul Scofield.

Summary: After years abroad, The Narrator returns to London, invited by his former lover Robinson. Together they set out on a series of journeys through the city to uncover what Robinson calls "the problem of London."

Four WEDDINGS AND A FunERAL (1994)

Dir. Mike Newell. Starring: Hugh Grant, Andie McDowell, Kristin Scott Thomas \&John Hannah.

Summary: At the wedding of a mutual friend, the very British Charles falls in love with the American woman Carrie. She leaves him after spending one night together. It takes three more weddings and one funeral for Carrie and Charles to finally find each other again.

\section{TRAINSPOTTING (1996)}

Dir. Danny Boyle. Starring: Ewan McGregor, Robert Carlyle \& Kelly McDonald.

Summary: In Edinburgh, Renton is stuck in a life of petty crime and drug abuse. After an overdose and kicking off cold turkey, he sets out to London in search of a new life. However, this new life is threatened when is old friends come to join him and drag him back to the world of crime and drugs.

\section{FEVER PITCH (1997)}

Dir. David Evans. Starring: Colin Firth, Ruth Gemmell \& Mark Strong.

Summary: Paul is a high school English teacher with only one passion: The football team Arsenal. He has a tentative relationship with his colleague Sarah, but that relationship is threatened when Sarah falls pregnant and Arsenal have a chance to win the championship, for the first time in twenty years. 


\section{NIL BY MouTH (1997) \\ Dir. Gary Oldman. Starring: Ray Winstone, Kathy Burke \& Charlie Creed-Miles.}

Summary: Ray is a violent and alcohol-abusing husband to Valerie. After another fight she flees their house to live with her family. This confronts Ray with his own behavior and makes him decide to try and be a better person.

\section{LOCK, STOCK \& TwO SMOKING BARRELS (1998)}

Dir. Guy Ritchie. Starring: Jason Fleming, Dexter Fletcher, Nick Moran \& Jason Statham.

Summary: Four young friends buy into an illegal card game. Nothing can go wrong, but their opponent cheats and now they owe him a lot of money. They might steal it from their criminal neighbors who plan to rob some drug dealers. And there are also two antique guns in play that might be worth a decent sum.

\section{NOTTING HILl (1999)}

Dir. Roger Michell. Starring: Hugh Grant, Julia Roberts \& Rhys Ifans.

Summary: William sells travel books in a shop in Notting Hill. He accidentally bumps into movie star Anna Scott and the two strike up a brief romance. However, Anna's career and fame may stand in the way of this brief and fragile romance.

WONDERLAND (1999)

Dir. Michael Winterbottom. Starring: Shirley Henderson, Gina McKee \& Molly Parker. Summary: Three sisters living in London struggle with love, family and parenthood, while their parents' marriage falls apart over the neighbor's barking dog and their younger brother briefly returns to London, only to not visit his family.

\section{SNATCH (2000)}

Dir. Guy Ritchie. Starring: Jason Statham, Brad Pitt, Benecio Del Toro \& Vinnie Jones. Summary: Illegal boxing manager Turkish gets into trouble with a crooked fight promoter when one of his boxers is beaten up over a second hand caravan. Meanwhile various factions in the London underworld are after a precious diamond that was stolen in Antwerp recently.

\section{BRIDGET JONES'S DIARY (2001)}

Dir. Sharon Maguire. Starring: Renee Zellweger, Hugh Grant \& Colin Firth.

Summary: Bridget Jones is single, occasionally overweight and most of all: single. Her life changes dramatically when she is suddenly the object of affections of two attractive man: her boss Daniel and her childhood friend Mark. 


\section{Annex B: Films set in London, categorized by genre}

\section{(Romantic) comedies:}

VIKTOR UND VIKTORIA (Reinhold Schünzel, 1933)

THE LAVENDER HILl MoB (Charles Crichton, 1951)

THE LADYKILLERS (Alexander Mackendrick, 1955)

OUT OF THE CLOUDS (Basil Dearden, 1955)

MELODY (Waris Hussein, 1971)

STEPTOE AND SON (Cliff Owen, 1972)

A TOUCH OF CLASS (Melvin Frank, 1973)

Four Weddings and a Funeral (Mike Newell, 1994)

FEVER PITCH (David Evans, 1997)

NotTing HiLl (Roger Michell, 1999)

BRIDGET JONES's DiARY (Sharon Maguire, 2001)

\section{Thrillers:}

BLACKMAIL (Alfred Hitchcock, 1929)

THE 39 STEPS (Alfred Hitchcock, 1935)

Bulldog Drummond Comes Back (Louis King, 1937)

Bulldog Drummond' Bride (James P. Hogan, 1939)

FOREIGN CORRESPONDENT (Alfred Hitchcock, 1940)

The Blue LAMP (Basil Dearden, 1950)

STAGE FRIGHT (Alfred Hitchcock, 1950)

SEVEn Days to NoOn (John Boulting \& Roy Boulting, 1950)

Night AND THE City (Jules Dassin, 1950)

A DANDY IN ASPIC (Anthony Mann, 1968)

PERFORMANCE (Donald Cammell \& Nicolas Roeg, 1970)

FRENZY (Alfred Hitchcock, 1972)

BRANNIGAN (Douglas Hickox, 1975)

Lock, Stock \& Two Smoking Barrels (Guy Ritchie, 1998)

SNATCH (Guy Ritchie, 2000)

\section{Social problem films:}

NAKED (Mike Leigh, 1993)

NIL BY MouTH (Gary Oldman, 1997)

WONDERLAND (Michael Winterbottom, 1999) 


\section{Other:}

WATERLOO BRIDGE (Mervyn LeRoy, 1940)

LONDON (Patrick Keiller, 1994)

Trainspotting (Danny Boyle, 1996) 


\section{Annex C: Other films discussed}

MADAM DUBARRY (Ernst Lubitsch, 1919)

Das CABINET Des DR. CAligari (Robert Wiene, 1920)

DR. MABUSE, DER SPIELER (Fritz Lang, 1922)

DER LETZTE MANN (Friedrich Wilhelm Murnau, 1924)

DiE NiBELUNGEN (Fritz Lang, 1924)

RIEN QUE LES HUERES (Alberto Calvacanti, 1925)

BRONENOSETS POTYOMKIN (Sergei Eisenstein, 1925)

DAS MÄDCHEN MET DEN SCHWEFELHÖLZERN (Guido Bagier, 1925)

BERLIN, DIE SINFONIE DER GROßSTADT (Walter Ruttmannn, 1926)

METROPOLIS (Fritz Lang, 1927)

THE JAZZ Singer (Alan Crosland, 1927)

THE Singing FoOL (Lloyd Bacon, 1928)

CheVoleK s Kinoapparatum (Dziga Vertov, 1929)

MELODIE DER WeLT (Walter Ruttmannn, 1929)

MENSCHEN AM SonNTAG (Robert Siodmak, 1930)

WEEKEND (Walter Ruttmannn, 1930)

DREIGROSCHENOPER (Georg Wilhelm Pabst, 1931)

DAS Blaue Licht (Leni Riefenstahl, 1932)

THE PRIVATE LIFE OF HENRY VIII (Alexander Korda, 1933)

S.A.-MANN BRAND (Franz Seitz, 1933)

STUTTGART (Walter Ruttmannn, 1935)

DÜSSELDORF (Walter Ruttmannn, 1936)

ALEKSANDR NEVSKIY (Sergei Eisenstein, 1938)

ROMA, CITTA APERTA (Roberto Rosselini, 1945)

GERMANIA ANNO ZERO (Roberto Rosselini, 1947)

ZWISCHEN GESTERN UND MORGEN (Harald Braun, 1947)

IT ALWAYS RAINS ON SUNDAYS (Robert Hamer, 1947)

BERLINER BALLADE (Robert A. Stemmle, 1948)

LADRI DI BICICLETTE (Vittorio De Sica, 1948)

THE THIRD MAN (Carol Reed, 1949)

SYMPHONIE EINER WELTSTADT (Leo de Laforgue, 1950)

Rebel Without a CAuse (Nicholas Ray, 1955)

FANFARE (Bert Haanstra, 1958)

M*A*S*H (Robert Altman, 1970) 
POLYGOONJOURNAAL 72:05 (1972)

THE CONVERSATION (Francis Ford Coppola, 1974)

NASHVILLE (Robert Altman, 1975)

STAR WARS (George Lucas, 1977)

APOCALYPSE Now (Francis Ford Coppola, 1979)

ALIEN (Ridley Scott, 1979)

SPETTERS (Paul Verhoeven, 1980)

JURASSIC PARK (Steven Spielberg, 1993)

THE MAKING OF “JURASSIC PARK” (John Schultz, 1995)

SLIDING DOORS (Peter Howitt, 1998)

Beautiful People (Jasmin Dizdar, 1999)

VANILLA SKY (Cameron Crowe, 2001)

28 DAYs LATER (Danny Boyle, 2002)

LOST IN TRANSLATION (Sofia Coppola, 2003)

GOODBYE LENIN (Wolfgang Becker, 2003)

DAS LEBEN DER ANDEREN (Florian Henckel von Donnersmark, 2006)

I AM LEGEND (Francis Lawrence, 2007)

DER BAADER MEINHOFF KoMPLEX (Uli Edel, 2008) 


\section{Annex D: Tables}

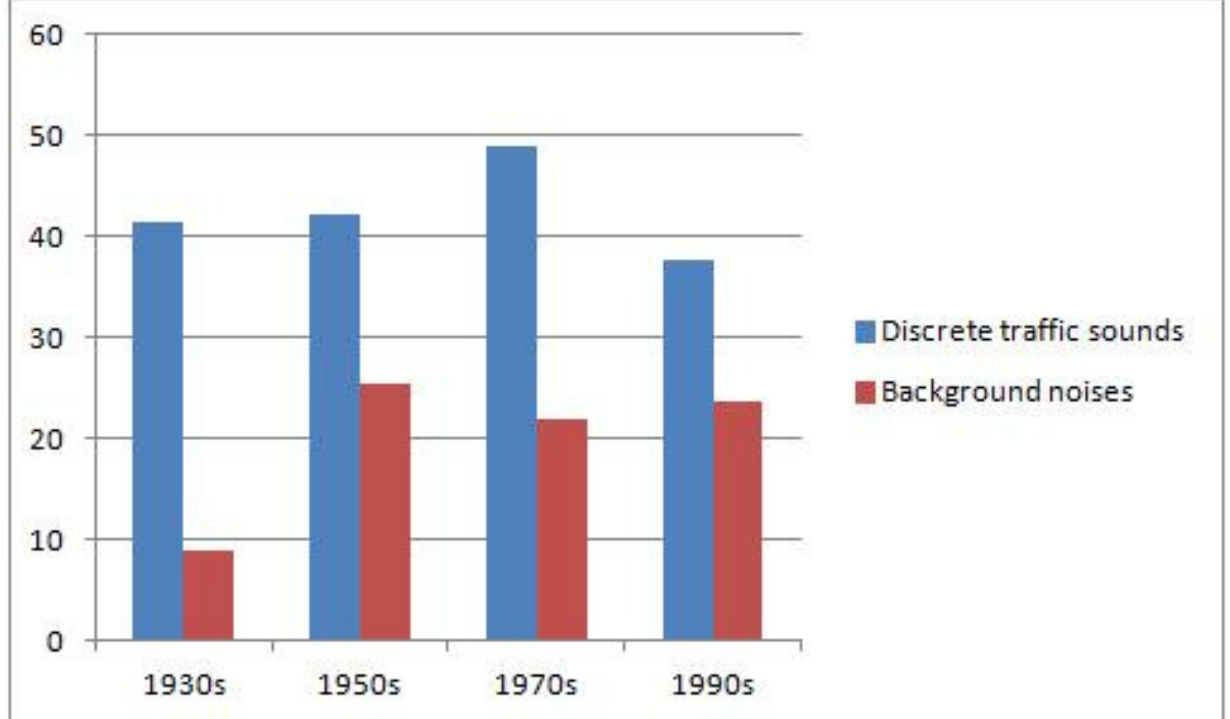

Table 1: Percentages of all Urban Sound Events categorized as discrete traffic sounds and nondiscrete background sounds in Amsterdam-in-film, specified per decade 


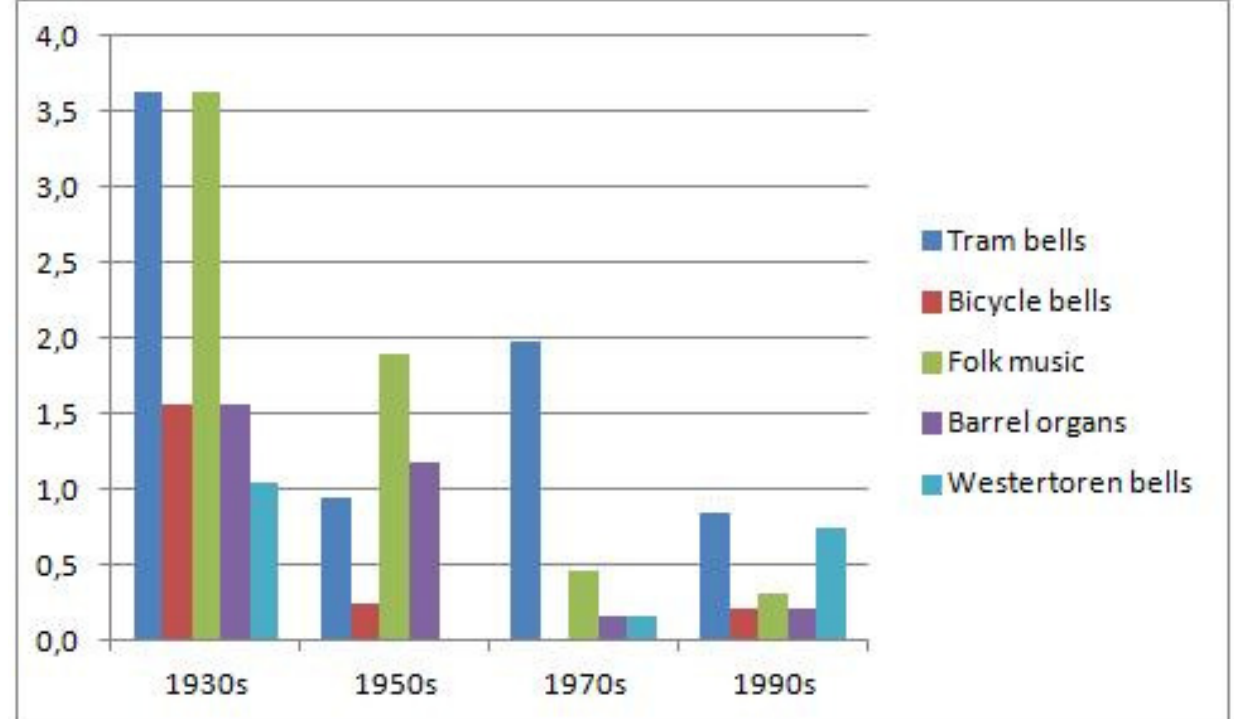

Table 2: Soundmarks of Amsterdam-in-film as percentages of all Urban Sound Events, specified per decade

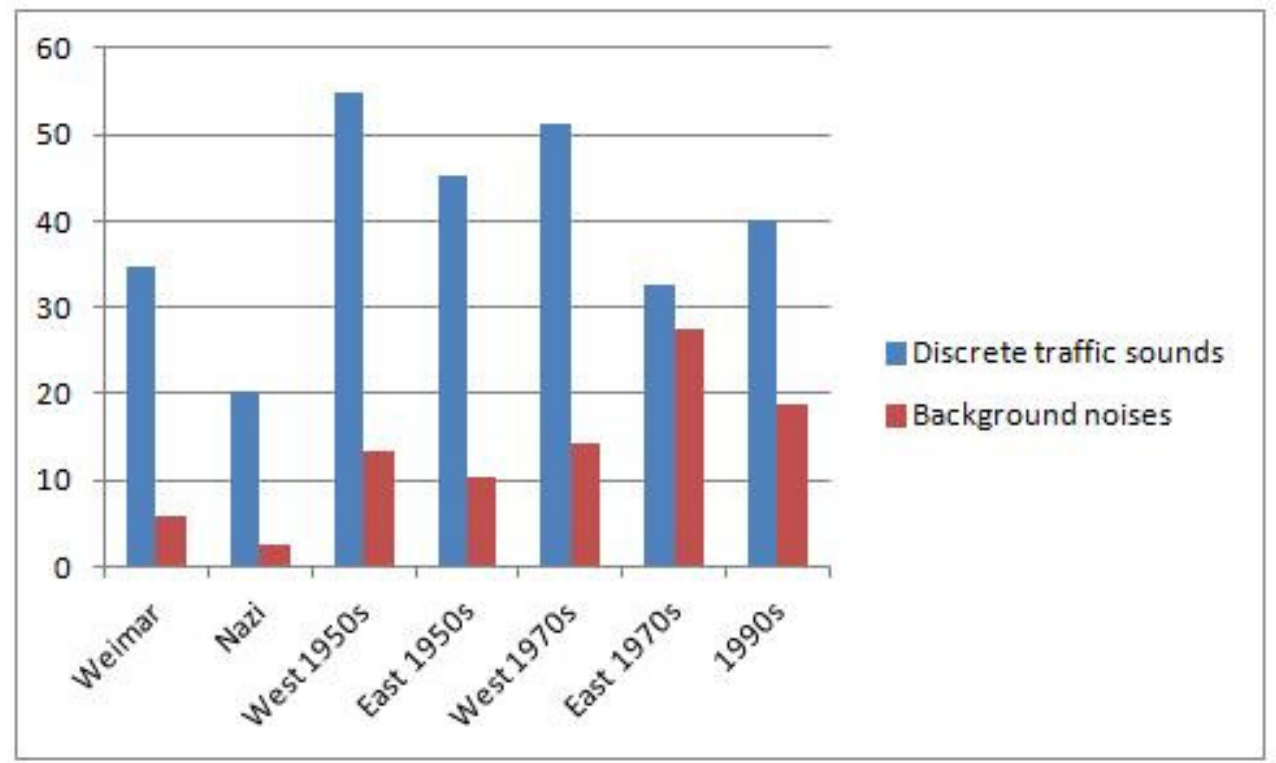

Table 3: Percentages of all Urban Sound Events categorized as discrete traffic sounds and non discrete background sounds in Berlin-in-film, specified per decade, and for East and West Berlin in the 1950s and 1970s 


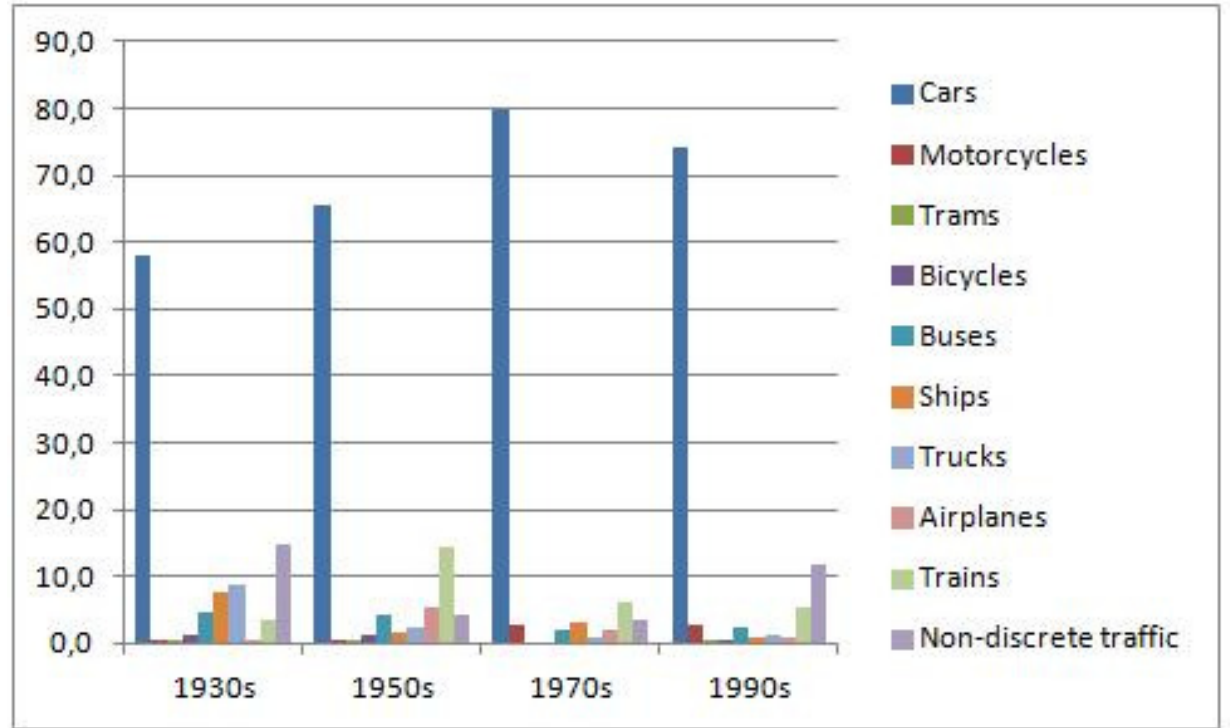

Table 4: Distribution of traffic-related Urban Sound Events over different modes of transportation in London-in-film, specified per decade

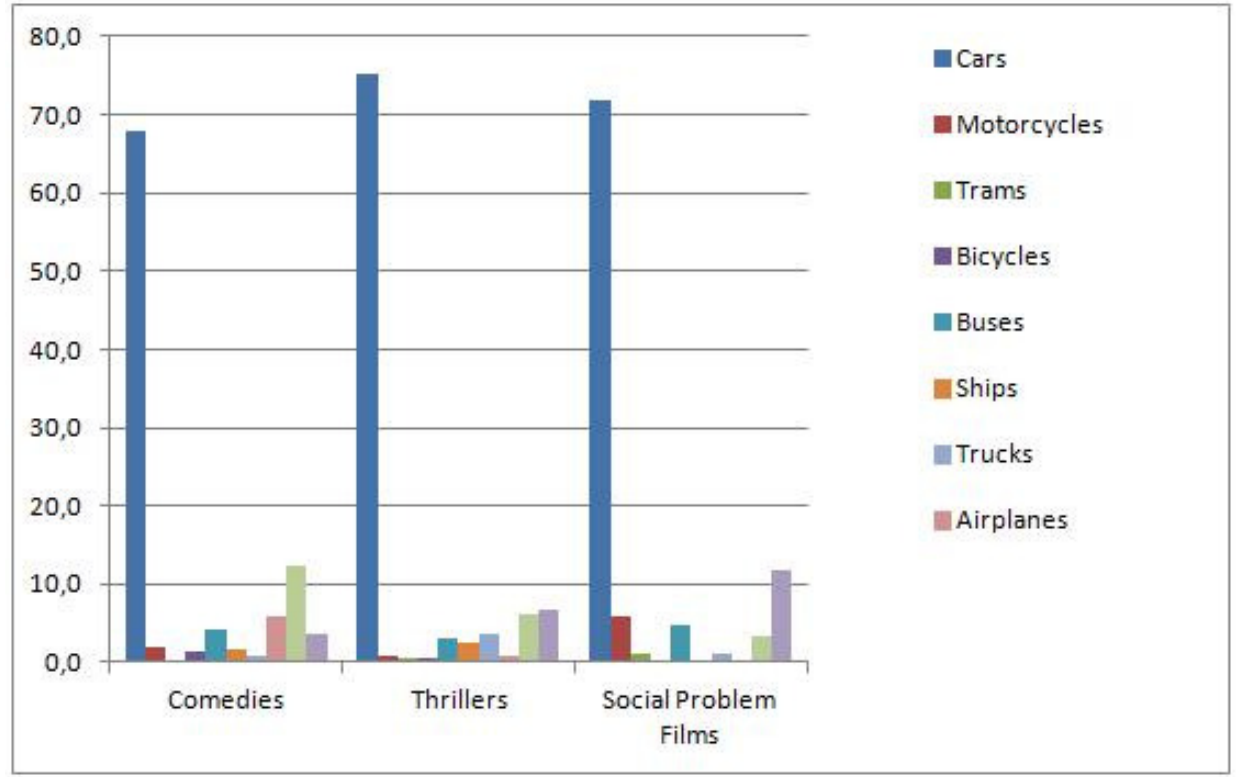

Table 5: Distribution of traffic-related Urban Sound Events over different modes of transportation in London-in-film, specified per genre. 


\section{Bibliography}

\section{Books, chapters \& articles}

Abel, Richard \& Rick Altman, eds. (2004), The Sounds of Early Cinema, Bloomington: Indiana University Press.

Altman, Rick (1980), Moving Lips: Cinema as Ventriloquism. Yale French Studies 60, 67-79.

- - - (1992a), General Introduction. In Sound Theory/Sound Practice, edited by Rick Altman. New York: Routledge, 1-14.

- - (1992b), The Material Heterogeneity of Recorded Sound. In Sound Theory/Sound Practice,edited by Rick Altman. New York: Routledge, 15-34.

- - (1992c), Sound Space. In Sound Theory/Sound Practice, edited by Rick Altman. New York: Routledge, 46-64.

- - (1999), Film/Genre. London: BFI.

- - - (2004), Silent Film Sound. New York: Columbia University Press.

Anderson, Benedict (1991 [1983]), Imagined Communities: Reflections on the Origin and Spread of Nationalism. London: Verso

Andrew, Dudley (1976), The Major Film Theories. An Introduction. London/Oxford/New York: Oxford University Press

Anonymous (1933), Phillywood. De Groene Amsterdammer July 29 1933, 1.

- - - (1934), Filmrubriek. "Hollywood" bij Amsterdam - Een bezoek aan "Bleeke Bet" - Hoe het achter de coulissen van filmland toegaat. Amersfoortsch Dagblad / De Eemlander May 26 1934, 14.

- - (1934), Bleeke Bet als film. Amersfoortsch Dagblad / De Eemlander May 8 1934, 7.

- - (1958), Jenny: niet écht goed toch een belofte. Dagblad voor Amersfoort February $211958,6$.

- - (1958), Jenny: niet flitsend, wel Nederlands en in kleuren. Leeuwarder Courant April $21 \quad 1958$.

- - - (2007), Berlin: Die Sinfonie der Großstadt. Ein Stummfilm von Walter Ruttman. Retrieved on February 222013 from http://www.arte.tv/de/berlin-die-sinfonie-dergrossstadt/1754610.html.

- - - (2008), Key scenes rediscovered. Key scenes from Fritz Lang's "Metropolis" have been rediscovered. Die Zeit July 2 2008. Retrieved on August 312012 from http://www.zeit.de/online/2008/27/metropolis-vorab-englisch/seite-1.

Appadurai, Arjun (1996), Modernity at Large: Cultural Dimensions of Globalization. Minneapolis: University of Minneapolis Press.

Arnheim, Rudolf (1974 [1932]) Film as Art. Fragments reprinted in Film Theory and Criticism. Introductory Readings, edited by Gerald Mast \& Marshall Cohen. New York: Oxford University Press, 27-31, 195-203. 
Augé, Marc (1995), Non-places. Introduction to an Anthropology of Supermodernity. Translation by John Howe. London: Verso.

Barr, Charles (1999), English Hitchcock. Moffat: Cameron and Hollis.

Barthes, Roland (2000 [1957]), Mythologies. London: Vintage

- - - (1977 [1966]), Introduction to the Structural Analysis of Narrative. In Image Music Text, edited by Stephen Heath. London: Fontana Press, 79-124.

- - (1986 [1968]), The Rustle of Language. Translated by Richard Howard. Berkeley / Los Angeles: University of California Press.

Baudry, Jean-Louis (1986 [1970]), Ideological Effects of the Basic Cinematographic Apparatus. In Narrative, Apparatus, Ideology. A Film Theory Reader, edited by Philip Rosen. New York: Columbia University Press, 286-298.

- - - (1986 [1975]), The Apparatus: Metapsychological Approaches to the Impression of Reality in Cinema. In Narrative, Apparatus, Ideology. A Film Theory Reader, edited by Philip Rosen. New York: Columbia University Press, 299-318.

Bazin, André (1974 [1958]), What is Cinema? Fragments reprinted in Film Theory and Criticism. Introductory Readings, edited by Gerald Mast \& Marshall Cohen. New York: Oxford University Press, 22-26, 90-102, 276-290.

- - - (2004 [1946-1957]), What Is Cinema? Vol. 1. Trans. Hugh Gray. Berkeley: University of California Press.

Beekhuis, Jacob Houdijn (1966) Geluidshinder door het Luchtverkeer. Amsterdam: Noord-Hollandsche Uitgevers Maatschappij.

Belton, John (1992), 1950s Magnetic Sound: The Frozen Revolution. In Sound Theory/Sound Practice, edited by Rick Altman. New York/London: Routledge, 154-170.

Bergfelder , Tim (2005), International Adventures. German Popular Cinema and European Co-Production in the 1960s. New York/Oxford: Berghahn Books.

Bianchi, Raoul V. (2002), Towards a New Political Economy of Global Tourism. In Tourism and Development. Concepts and Issues, edited by Richard Sharpley \& David J. Telfer. Clevedon: Channel View Publications, 265-299.

Bijsterveld, Karin (2001), The Diabolical Symphony of the Mechanic Age: Technology and Symbolism of Sound in the European and North-American Noise-Abatement Campaigns 1900-1940. Social Studies of Science 31(1), 37-70.

- - - (2003) "The City of Din": Decibels, Noise and Neighbours in The Netherlands, 1910-1980. Osiris 18, 173-193.

- - (2008) Mechanical Sound. Technology, Culture and the Public Problems of Noise in the Twentieth Century. Cambridge/London: The MIT Press.

- - (2013), Introduction: An Ears-on Experience. In Soundscapes of the Urban Past: Staged Sound as Mediated Cultural Heritage, edited by Karin Bijsterveld. Bielefeld: transcript, 11-30.

Bijsterveld, Karin, Annelies Jacobs, Jasper Aalbers \& Andreas Fickers (2013), Shifting Sounds:Textualization and Dramatization of Urban Soundscapes. In Soundscapes of the Urban Past:Staged Sound as Mediated Cultural Heritage, edited by Karin Bijsterveld. Bielefeld: transcript, 31-66. 
Birdsall, Carolyn (2012), Nazi Soundscapes. Sound, Technology and Urban Space in Germany, 1933-1945. Amsterdam, Amsterdam University Press.

Bloch, Ernst (1991 [1935]), Heritage of Our Times. Translated by Neville and Stephen Plaice London: Polity Press.

Blunk, Harry (1984), Die DDR in ihren Spielfilmen: Reproduktion und Konzeption der DDR-Gesellschaft im neueren DEFA-Gegenwartsspielfilm. München: Profil.

Bordwell, David, Janet Staiger \& Kristin Thompson (1985), The Classical Hollywood Cinema: Film Style \& Mode of Production to 1960. London: Routledge \& Kegan Paul.

Bordwell David \& Kristin Thompson (2001 [1979]), Film Art: An Introduction (6th edition). New York: McGraw-Hill.

Branigan, Edward (1989), Sound and Epistemology in Film. The Journal of Aesthetics and Art Criticism 47 (4), 312-320.

Braunger, Amely (2008) Intermedialitat und Urbanitat im Medienwandel - Eine Untersuchung zur Darstellung der urbanen Lebenswelt in Horspiel, Roman und Film am Beispiel van "Berlin Alexanderplatz.” Konstanz: Grin.

Brecht, Bertolt (2008 [1932]), Tonfilm "KUHLE WAMPE ODER: WEM GEHÖRT DIE WELT?" In Kuhle Wampe oder Wem Gehört die Welt. Kommentar und Materialen, edited by Heinrich Geiselberger. Frankfurt am Main: Suhrkamp Verlag, 44-47.

Brooker, Peter (2002), Modernity and Metropolis. Writing, Film and Urban Formations. New York: Palgrave.

Brunsdon, Charlotte (2007), London in Cinema: The Cinematic City Since 1945. London: BFI.

Burke, Peter (2009), Cultural Hybridity. Cambridge: Polity.

Campbell, Joseph (1949), The Hero With a Thousand Faces. New York: Pantheon Books.

Campan, Véronique (1999), L'écoute filmique: écho du son en image. Saint-Denis: Presses universitaires de Vincennes.

Charney, Leo \& Schwartz, Vanessa R. (1995), Introduction. In Cinema and the Invention of Modern Life, edited by Leo Charney and Vanessa R. Schwartz. Berkeley: University of California Press, 1-14.

Chion, Michel (1994 [1990]), Audio-Vision: Sound on Screen. New York: Columbia University Press. Trans. Claudia Gorbman.

- - - (1999 [1982]), The Voice in Cinema. New York: Columbia University Press. Trans. Claudia Gorbman.

- - (2000), Audio-Vision and Sound. In Sound, edited by Henry Stobarth \& Patricia Kruth. Cambridge: Cambridge University Press, 201-221

- - (2009), Film, a Sound Art. New York: Columbia University Press.

Corbin, Alain (1998 [1994]), Village Bells: Sound and Meaning in the 19th-century French Countryside. New York: Columbia University Press. 
- - - (2004), Identity, Bells and the Nineteenth-Century French Village. In Hearing History. A Reader, edited by Mark M. Smith. Athens/London: University of Georgia Press, 184-206.

Deutsche Demokratische Republik (1956), Statistisches Jahrbuch der Deutschen Demokratischen Republik 1955. Berlin: VEB Deutscher Zentralverlag.

- - - (1975) Statistisches Jahrbuch der Deutschen Demokratischen Republik 1974. Berlin: Staatlsverlag der Deutschen Demokratischen Republik.

Dibbets, Karel (1993), Sprekende Films. Amsterdam: Otto Cramwinckel Uitgever.

Dienst van Publieke Werken, Amsterdam (1934). Algemeen Uitbreidingsplan van Amsterdam. Amsterdam: Gemeente Amsterdam.

Dittrich, Katinka (1986), De Speelfilm in de Jaren Dertig. In Geschiedenis van de Nederlandse Film en Bioscoop tot 1940, edited by Karel Dibbets \& Frank van der Maden. Houten: Het Wereldvenster 105-144.

Doane, Mary Ann (1985 [1980]), The Voice in the Cinema: The Articulation of Body and Space. Reprinted in Film Sound: Theory and Practice, edited by Elizabeth Weis \& John Belton. New York: Columbia University Press 162-176.

Döblin, Alfred (2004 [1929]), Berlin Alexanderplatz. Translated by Eugene Jolas. London / New York: Continuum.

Doolaard, C.R. (1962), "Rififi in Amsterdam," snelle thriller van John Korporaal. Dagblad Voor Amersfoort May 10 1962, 4.

Dyson, Frances (2009), Sounding New Media: Immersion and Embodiment in the Arts and Culture. Berkeley: University of California Press.

Eisenstein, Sergei (1974 [1949], Film Form. Fragments reprinted in Film Theory and Criticism. Introductory Readings, edited by Gerald Mast \& Marshall Cohen New York: Oxford University Press, 75-89.

Eisenstein, S.M., W.I. Pudowkin \& G.V. Alexandroff (1998 [1928]), The Sound Film. A Statement from U.S.S.R. Reprinted in Close Up 1927-1933. Cinema and Modernism, edited by James Donald, Anne Friedberg \& Laura Marcus. London: Cassell.

Eisner, Lotte H. (1952), L'écran démoniaque: influence de Max Reinhardt et de l'expressionisme. Paris: André Bonne.

Elsaesser, Thomas (2000), Weimar Cinema and After: Germany's Historical Imaginary. London: Routledge.

- - - (2005) European Cinema: Face to Face with Hollywood. Amsterdam: Amsterdam University Press.

Eyman, Scott (1997), The Speed of Sound: Hollywood and the Talkie Revolution 19261930, New York: Simon \& Schuster.

Evans, Jennifer V. (2010), Life Among the Ruins. Sex, Space and Subculture in Zero Hour Berlin. In Berlin Divided City, 1945-1989, edited by Philip Broadbent \& Sabine Hake. New York/Oxford: Berghahn Books, 11-22. 
Fickers, Andreas, Jasper Aalbers, Annelies Jacobs and Karin Bijsterveld (2013), "Sounds Familiar": Intermediality and Remediation in the Written, Sonic and Audiovisual Narratives of Berlin Alexanderplatz. In Soundscapes of the Urban Past: Staged Sound as Mediated Cultural Heritage, edited by Karin Bijsterveld. Bielefeld: transcript, 77-116.

Fiske, John (2010 [1989]), Understanding Popular Culture. London/New York: Routledge.

Ford, Ford Madox (1905), The Soul of London. A Survey of a Modern City. London: Chiswick Press.

Flückiger, Barbara (2001), Sound Design. Die virtuelle Klangwelt des Films. Marburg: SchürenVerlag.

Fraenkel, Francis Frederik (1976), Het Plan Amsterdam-Zuid van H.P. Berlage: met een catalogus van uitgevoerde bouwwerken en een register van architecten. Universiteit Utrecht.

Fritzsche, Peter (1996), Reading Berlin. Cambridge: Harvard University Press.

Gaughan, Martin (2001) Ruttmannn's Berlin: Filming in a "Hollow Space?" In Screening the City, edited by Mark Shiel \& Tony Fitzmaurice. London, New York: Verso, 41-57.

Gelder, Henk van (1995), Hollands Hollywood. Amsterdam: Luitingh Sijthoff.

Gemeente Amsterdam (2009), De Auto en de Stad: Op weg naar een autoluw Amsterdam. Amsterdam: Gemeente Amsterdam.

Genette, Gérard (1980 [1970]), Narrative Discourse: An Essay in Method. Translated by Jane E. Lewin. Oxford: Blackwell.

Gibson, Pamela Church (2003), Imaginary Landscapes, Jumbled Topographies: Cinematic London. In London: From Punk to Blair, edited by Joe Kerr \& Andrew Gibson London: Reaktion Books, 363-370.

Gomery, Douglas (1976), Tri-Ergon, Tobis-Klangfilm and the Coming of Sound. Cinema Journal 16 (1), 51-61.

Grob, Norbert (2003), Phantasma Stadt / Phantasma Strasse: Zur großstädtischen Aura in Filmen der zwanziger und frühen dreißiger Jahre. In Diesseits der "Damonischen Leinwand": Neu Perspektiven auf das späte Weimarer Kino, edited by Thomas Koebner. München: Edition text + kritik, 57-84.

Grundmann, Uta (2001), The Intelligence of Vision: an interview with Rudolf Arnheim. Cabinet Magazine 2. Retrieved on November 12011 from http://www.cabinetmagazine.org/issues/2/rudolfarnheim.php.

Grywatz, Berthold (1988), Arbeit und Bevölkerung im der Weimar Zeit: eine historischstatistische Untersuchung. Berlin: Colloquium Verlag.

Gunning, Tom (2000), The Films of Fritz Lang: Allegories of Vision and Modernity. London: BFI.

- - - (2010 [2007], Moving Away from the Index: Cinema and the Impression of Reality. Reprinted in The Film Theory Reader: Debates and Arguments, edited by Marc Furstenau. London/New York: Routledge, 255-269. 
Hague, Cliff (2005), Planning and Place Identity. In Place Identity, Participation and Planning, edited by Cliff Hague \& Paul Jenkins London/New York: Routledge, 318.

Hake, Sabine (2008 [2002]), German National Cinema. 2nd Edition. London \& New York: Routledge.

Handzo, Stephen (1985), A Narrative Glossary of Film Sound Technology. In Film Sound: Theory and Practice, edited by Elizabeth Weis and John Belton. New York: Columbia University Press, 383-426.

Hård, Mikael \& Andrew Jamison (1998), Conceptual Framework: Technology Debates as Appropriation Processes. In The Intellectual Appropriation of Technology. Discourses On Modernity, 1900-1939, edited by Mikael Hård \& Andrew Jamison Cambridge / London: The MIT Press, 1-16.

Hilmes, Michele (2005), Is there a Field Calles Sound Culture Studies? And Does It Matter? American Quarterly 57 (1), 249-259.

Hobsbawm, E. \& T.O. Ranger (eds.) (1983), The Invention of Tradition. Cambridge: Cambridge University Press.

Hoffman, Dagmer \& Clemens Schwender (2007) Biographical functions of cinema and film preferences among older German adults: A representative quantitative survey. Communications 32 (4), 473-491.

Homer (2006 [approximately 700 B.C.], The Odyssey. Translated by Ian Johnston. Arlington: Richer Resources Publications.

Honig, Ronald (1996), Trein, Metro, Sneltram: Railinfrastructuur in Amsterdam. Amsterdam: Gemeente Amsterdam.

Howse, Christopher (2007), The Bells that make Cockneys. The Daily Telegraph, September 22 2007. Retrieved on 01-09-2011 from http://www.telegraph.co.uk/comment/personal-view/3642866/The-bells-thatmake-Cockneys.html.

Hughes, T.P. (1983), Networks of Power: Electrification of Western Society, 18801930. Baltimore: Johns Hopkins University Press.

Hutchins, Peter (2009), Beyond the New Wave: Realism in British Cinema, 1959-1963. In The British Cinema Book. 3rd Edition, edited by Robert Murphy. London: BFI, 304-312.

Jelavich, Peter (2001), The City Vanishes: Piel Jutzi's Berlin Alexanderplatz. In Screening the City, edited by Mark Shiel \& Tony Fitzmaurice London, New York: Verso, 58-79.

Kästner, Erich (2006 [1929]), Emil und die Detektive. Hamburg: Dressler.

Kellogg, E.W. (1983 [1955]), History of Sound Motion Pictures. Reprinted in A Technological History of Motion Pictures and Television, edited by Raymond Fielding. Berkeley, Los Angeles, London: University of California Press, 174-220.

Kelman, Ari Y. (2010), Rethinking the Soundscape. A Critical Genealogy of a Key Term in Sound Studies. Senses \& Society 5(2), 212-234.

Kerins, Mark (2010), Beyond Dolby (Stereo): Cinema in the Digital Sound Age. Bloomington: Indiana University Press. 
Kluyver, Alwin de (2000), Melodrama en keiharde actie in "Lek." Leeuwarder Courant April 282000.

Kooijman, Jaap (2008), Amsterdamned Global Village: A Cinematic Site of Karaoke Americanism. In Mind the Screen: Media Concepts According to Thomas Elsaesser, edited by Jaap Kooijman, Patricia Pisters \& Wanda Strauven Amsterdam: Amsterdam University Press, 188-197.

Kracauer, Siegfried (1984 [1947]), Von Caligari zu Hitler. Eine psychologische Geschichte des deutschen Films. Frankfurt am Main: Suhrkamp Verlag.

- - - (2008 [1932]), Kuhle Wampe verboten. In Kuhle Wampe oder Wem Gehört die Welt. Kommentar und Materialen, edited by Heinrich Geiselberger. Frankfurt am Main: Suhrkamp Verlag, 51-56.

Krebs, Stefan (2012), Automobilgerausche als Information. Ueber das geschulte Ohr des Kfz-Mechanikers. In Das geschulte Ohr. Eine Kulturgeschichte der Sonifikation, edited by Andi Schoon \& Axel Volmar. Bielefeld: transcript, 95-110.

Lachmund, Jens (2003), Exploring the City of Rubble: Botanical Fieldwork in Bombed Cities in Germany after World War II. In Science and the City, edited by Sven Dierig, Jens Lachmund \& J. Andrew Mendelsohn. Chicago: Chicago University Press, 234-254.

Lastra, James (2000), Sound Technology and the American Cinema. New York: Columbia University Press.

Lintorst, Gerdin (1988), De droomfabriek. Achter de schermen van de speelfilm. Houten: Het Wereldvenster.

Lister, Martin et al. (2003), New Media: A Critical Introduction. London: Routledge.

MacArthur, Colin (1997), Chinese Boxes and Russian Dolls: Tracking the Elusive Cinematic City. In The Cinematic City, edited by David B. Clarke. London/New York: Routledge, 19-45.

MacCabe, Colin (1974), Realism and the Cinema - Notes on Brechtian Theses. Screen 15(2), 7-27.

Manovich, Lev (2010 [2001]), The Language of New Media. Fragment reprinted in The Film Theory Reader: Debates and Arguments, edited by Marc Furstenau. London/New York: Routledge, 245-254.

Matzerath, Horst (1984), Berlin, 1890-1940. In Metropolis: 1890-1940, edited by Anthony Sutcliffe. London: Mansell, 289-318.

Mazierska, Ewa \& Laura Rascaroli (2003), From Moscow to Madrid: Postmodern Cities, European Cinema. London: IB Tauris.

McNeill, Isabelle (2010), Memory and the Moving Image. French Film in the Digital Era. Edinburgh: Edinburgh University Press.

Mennel, Barbara (2008), Cities and Cinema. New York: Routledge.

Minnis, Stuart (1998), Narration in the films of Andrei Tarkovsky. University of Kansas.

Müller, Eggo (2002), Unterhaltungsshows transkulturell: Fernsehformate zwischen Akkomodation und Assimilation. In Transkulturelle Kommunikation, edited by Andreas Hepp \& Martin Löffelholz Konstanz: UVK, 456-473. 
Murray, Bruce (1990), Film and the German Left in the Weimar Republic. From Caligari to Kuhle Wampe. Austin: University of Texas Press.

Natter, Wolfgang (1994), The City as Cinematic Space: Modernism and Place in Berlin, Symphony of a City. In Place, Power, Situation, and Spectacle. A Geography of Film, edited by Stuart C. Aitken \& Leo E. Zonn Lanham: Rowman \& Littlefield, 203-227.

Nederveen Pieterse, Jan (1995), Globalization as Hybridization. In Global Modernities, edited by Mike Featherstone, Scott Lash and Roland Robertson. London: Sage Publications, 45-68.

Nelissen, W.J.A. \& H. Schmall (1980), Van Railverbinding tot Ringweg. Honderd Jaar Verkeer in Amsterdam. In Wonen, Werken en Verkeer in Amsterdam, 1880-1980, edited by G.A. de Bruijne, J. Buit, M.W. Heslinga, G.A. Hoekveld and J. van Westrhenen. Amsterdam: Vrije Universiteit, 179-248.

Nijman, Jan (1999), Cultural Globalization and the Identity of Place: The Reconstruction of Amsterdam. Cultural Geographies 6, 146-64.

Nowell-Smith, Geoffrey \& Peter Thomas (2003). Editorial. Convergence: The International Journal of Research into New Media Technologies 9(5), 5-9.

Ovid (8 AD), Metamorphoses.

- - - (1922 [8 AD]), Metamorphoses. Translated by Brookes More. Boston: Cornhill Publishing.

Panofsky, Erwin (1974 [1934]), Style and Medium in the Motion Pictures. Reprinted in Film Theory and Criticism. Introductory Readings, edited by Gerald Mast \& Marshall Cohen. New York: Oxford University Press, 151-169.

Parr, Joy (2010), Sensing Changes. Technologies, Environments and the Everyday, 1953-2003. Vancouver: UBC Press.

Praag, B.M.S. van, B.E. Baarsma, J.G. Lambooy, A.P. Poot (1997), Vliegtuigen horen, geld zien. Economisch Statistische Berichten 4125, p 801.

Putter, Jos de (1991), Theorievorming rond de filmkritiek. In Filmkunde. Een Inleiding, edited by Peter Bosma. Nijmegen: SUN/Open Universiteit, 165-218.

Rehhahn, Yvonne (1996), Nur der veranderte Autor kann den Film verandern. In Berlin-Alexanderplatz. Drehbuch von Alfred Döblin und Hans Wilhelm zu Phil Jutzi's Film von 1931, edited by Helga Belach \& Hans-Michael Bock. München: Edition text + kritik, 210-223.

Rentschler, Eric (1984), West German Film in the Course of Time. Bedford Hills: Redgrave Publishing Company.

- - - (1996), The Ministry of Illusion. Nazi Cinema and Its Afterlife. Cambridge/London: Harvard University Press.

Robertson, Roland (1995), Glocalization: Time-Space and Homogeneity-Hetrogeneity. In Global Modernities, edited by Mike Featherstone, Scott Lash and Roland Robertson London: Sage Publications, 25-44.

Rodowick, David Norman (2007), The virtual life of film. Cambridge: Harvard University Press. 
Röhmer, Willy (1983), Leierkästen in Berlin, 1912-1932. Berlin: Dirk Nishen, Verlag in Kreuzberg.

Ryall, Tom (1993), Blackmail. London: BFI.

Salt, Barry (1985), Film Style and Technology in the Thirties. In Film Sound: Theory and Practice, edited by Elizabeth Weis and John Belton. New York: Columbia University Press, 37-43.

Sarris, Andrew (1974 [1962-1963]), Notes on the Auteur Theory in 1962. Reprinted in Film Theory and Criticism. Introductory Readings, edited by Gerald Mast \& Marshall Cohen New York: Oxford University Press, 500-515.

Schafer, Raymond M. (1994 [1977]), The Soundscape. Our Sonic Environment and the Tuning of the World. Rochester: Destiny Books.

Scheunemann, Dietrich (2003) "Dreigroschenoper und Kuhle Wampe. Über die künstlerischen Produktionsverhältnisse der Zeit" in Koebner, Thomas, Norbert Grob \& Bernd Kiefer (eds.) Diesseits der >Dämonischen Leinwand $<$. Neue Perpektiven auf das späte Weimarer Kino. München: Edition text + kritik, 411-432

Schoots, Hans (2004), Van Fanfare tot Spetters. Een cultuurgeschiedenis van de jaren zestig en zeventig. Amsterdam: Lubberhuizen \& Filmmuseum.

Segeberg, Harro (2003), Der Schriftsteller und der Tonfilm. Alfred Doblin und der Film Berlin Alexanderplatz. In Diesseits der >Dämonischen Leinwand $<$. Neue Perpektiven auf das späte Weimarer Kino, edited by Thomas Koebner, Norbert Grob \& Bernd Kiefer München: Edition text + kritik, 85-96.

Sergi, Gianluca (2004), The Dolby Era: Film Sound in Contemporary Hollywood. Manchester: Manchester University Press.

Shandley, Robert R. (2001), Rubble film: Germany in the shadow of the Third Reich. Philadelphia: Temple University Press.

Shiel, Mark (2001), Cinema and the City in History and Theory. In Cinema and the City. Film and Urban Societies in a Global Context. Oxford / Malden: Blackwell Publishing, 2-18.

Shiel, Mark \& Tony Fitzmaurice (2001), Cinema and the City. Film and Urban Societies in a Global Context. London: Blackwell Publishers.

Siewert, Senta (2009), Entrenzungsfilme: Jugend, Musik, Affekt, Gedächtnis : eine pragmatische Poetik zeitgenössischer europäischer Filme. Amsterdam.

Silverman, Kaja (1988) The Acoustic Mirror: The Female Voice in Psychoanalysis and Cinema, Bloomington: Indiana University Press.

Simmel, Georg (2002 [1903]), The Metropolis and Mental Life. In The Blackwell City Reader, edited by Gary Bridge \& Sophie Watson Oxford/Malden: WileyBlackwell, 11-19.

Singer, Ben (1995), Modernity, Hyperstimulus and the Rise of Popular Sensationalism. In Cinema and the Invention of Modern Life, edited by Leo Charney \& Vanessa R. Schwartz. Berkeley: University of California Press, 72-102

Smith, Mark M. (2001), Listening to Nineteenth-Century America. Chapel Hill: University of North Carolina Press. 
- - - (2013), Soundings: or, Why Historians of the Auditory Past Might Consider Getting Their Ears Wet. In Soundscapes of the Urban Past: Staged Sound as Mediated Cultural Heritage, edited by Karin Bijsterveld. Bielefeld: transcript, 6776.

Sonnenschein, David (2001), Sound Design. The Expressive Power of Music, Voice and Sound Effects in Cinema. Studio City: Michael Wiese Productions.

Sorlin, Pierre (1991), European Cinemas, European Societies 1939-1990. London: Routledge.

Spadoni, Robert (2007), Uncanny Bodies: The Coming of Sound Film and the Origins of the Horror Genre. Berkeley: University of California Press

Stahl, Heiner (2010), Mediascape and Soundscape. Two Landscapes of Modernity in Cold War Berlin. In Berlin Divided City, 1945-1989, edited by Philip Broadbent \& Sabine Hake. New York/Oxford: Berghahn Books, 56-68.

Sterne, Jonathan (2003), The Audible Past: Cultural Origins of Sound Reproduction. Durham: Duke University Press.

- - - (2013), Soundscape, Landscape, Escape. In Soundscapes of the Urban Past: Staged Sound a Mediated Cultural Heritage, edited by Karin Bijsterveld. Bielefeld: transcript, 181-194.

Stettner, Peter (1992) Vom Trümmerfilm zur Traumfabrik: die Junge-Film Union 19471952; eine Fallstudie zur westdeutschen Filmproduktion. Hindesheim: Olms.

Stilwell, Robynn J. (2007), The Fantastical Gap between the Diegetic and the Nondiegetic. In Beyond the Soundtrack. Representing Music in Cinema, edited by Daniel Goldmark, Lawrence Kramer \& Richard Leppert. Berkeley/Los Angeles/London: University of California Press, 184-204.

Stoffers, Manuel (2007), Het nerveuze tijdperk en zijn historici: De opkomst van de mentaliteits-geschiedenis in Duitsland 1889-1915. Maastricht: Maastricht University.

Street, Sarah (2009), British National Cinema. Second edition. London / New York: Routledge.

Szeman, Imre (2003), Culture and Globalization, or, The Humanities in Ruins. The New Centennial Review 3 (2), pp. 91-115.

Taylor, Greg (1999), Artists in the Audience. Cults, Camp, and American Film Criticism. Princeton, Oxford: Princeton University Press

Thompson, Emily (2002), The Soundscape of Modernity: Architectural Acoustics and the Culture of Listening in America, 1900-1933. Cambridge: MIT Press.

Thompson, John B. (1995), The Media and Modernity. Cambridge: Polity.

Thompson, Kristin \& David Bordwell (2003), Film History. An Introduction. 2nd Edition. New York: McGraw-Hill.

Till, Benedikt et al. (2011). A Study on the Impact of Film Dramas and the Mediating Effects of Emotional Modes of Film Reception and Coping Strategies. Journal of Media Psychology: Theories, Methods, and Applications 23 (3), 149-160

Truffaut, François (1985), Hitchcock. New York: Simon \& Schuster. 
Uricchio, William (1982), Ruttmannn's Berlin and the City Film to 1930. New York: New York University.

Verdaasdonk, Dorothee (1985), Nederland Filmland. De beroepspraktijk van regisseurs in de periode 1977-1983. Amsterdam: Uitgeverij Joost Nijsen.

Vogt, Guntram (2001), Die Stadt im Kino. Deutsche Spielfilme 1900-2000. Marburg: Schüren.

Waard, Romke de (1971), Het Draaiorgel. Alkmaar: De Alk.

Ward, Colin (1978), The Child in the City. London: The Architectural Press.

Weihsmann, Helmut (1997), The City in Twilight. Charting the Genre of the "City Film” 1900-1930. In Cinema \& Architecture. Meliès, Mallet-Stevens, Multimedia, edited by François Penz \& Maureen Thomas London: BFI, 8-27.

Weis, Elizabeth and John Belton (eds.) (1985), Film Sound: Theory and Practice. New York: Columbia University Press.

Welch, David (1983), Propaganda and the German Cinema, 1933-1945. Oxford: Clarendon Press.

White, Shane \& Graham White (2004), Listening to Southern Slavery. In Hearing History. A Reader, edited by Mark M. Smith. Athens/London: The University of Georgia Press, 247- 266.

Whittington, William (2007), Sound Design and Science Fiction. Austin: University of Texas Press.

- - - (2012), The Sonic Playpen: Sound Design and Technology in Pixar's Animated Shorts. In The Oxford Handbook of Sound Studies, edited by Trevor Pinch \& Karin Bijsterveld. New York / Oxford: Oxford University Press, 367-386.

Williams, Alan (1980), Is Sound Recording Like a Language? Yale French Studies 60, pp. 51-66.

- - - (1992) Historical and Theoretical Issues in the Coming of Recorded Sound to the Cinema. In Sound Theory/Sound Practice, edited by Rick Altman. New York: Routledge, 126-137.

Williams, Rosalind (1990), Notes on the Underground. An Essay on Technology, Society and the Imagination. Cambridge: The MIT Press.

Wurtzler, Steve J. (2007) Electric Sounds: Technological Change and the Rise of Corporate Mass Media. New York: Columbia University Press.

Zeeuw, A.J. De (1998), Hoe groot wordt Schiphol? In Economisch Statistische Berichten 4181, 940.

Zijlstra, Ben (2010), Leerstof Geluid Propedeuse 2010-2011. Amsterdam: Nederlandse Film en Televisie Academie.

\section{Websites}

The Internet Movie Database

http://www.imdb.com

Oxford English Dictionary 
http://www.oed.com

\section{Other sources}

Personal correspondence with Larry Sider, 20-02-2011

Personal interview with Ben Zijlstra, 26-01-2011

Personal interview with Georges Bossaers, 28-03-2011 


\section{Samenvatting}

In deze dissertatie onderzoek ik de rol van geluiden in de representatie van steden in fictiefilm. Daarbij gaat het onder meer om de representatie van de ervaring van het stedelijk leven, en de betekenis daarvan voor de constructie van stedelijke identiteit. De steden in kwestie zijn Amsterdam, Berlijn en Londen. De periodes waarop mijn onderzoek zich heeft geconcentreerd, zijn de jaren dertig, vijftig, zeventig en negentig van de twintigste eeuw.

Dit promotieonderzoek was deel van een groter onderzoeksproject aan de Faculteit Cultuur- en Maatschappijwetenschappen van de Universiteit Maastricht. In het project Soundscapes of the Urban Past werd de enscenering en dramatisering van stadsgeluiden in verschillende media onderzocht. Geluid is een belangrijk deel van het dagelijks leven in steden. Zo is het geluid dat hoort bij verkeer, transport en religie regelmatig het onderwerp van discussie en twist. Niet alleen tegenwoordig, in de vorm van debatten over kerkklokken, minaretten en overlast door vliegverkeer, maar ook in het verleden. $\mathrm{Al}$ aan het eind van de negentiende eeuw beklaagden intellectuelen in Londen zich over het lawaai dat geproduceerd werd door straatmusici. En in de jaren twintig en dertig van de twintigste eeuw ontstonden overal in de Westerse wereld "anti-lawaaigenootschappen" die stelling namen tegen de overlast veroorzaakt door verkeer, bouwwerkzaamheden en het uitgaansleven. Stadsgeluid, en de ervaring daarvan door stadsbewoners en -bezoekers, is overduidelijk een belangrijk element van het stedelijk leven.

Door filmwetenschappers is in de loop van de afgelopen honderd jaar ook een sterke verbinding gesignaleerd tussen het medium film en de moderne grote stad. We mogen zelfs stellen dat er een mythe van de filmische stad is ontstaan. Deze mythe wil ons doen geloven dat film het meest geschikte medium is om de moderne stad te representeren, en dat de ervaring van de stad op haar beurt sterke overeenkomsten heeft met de ervaring van film. De hectische, alledaagse ervaring van de moderne stad vertoonde immers grote gelijkenissen met het flikkerende en schokkerige beeld van de vroege films. En de fragmentatie die het moderne leven en de moderne mens karakteriseerden vond een weerspiegeling in de ruimtelijke en tijdelijke fragmentatie van een gemonteerd filmverhaal. De mythe van de filmische stad vond haar meest getrouwe expressie in de zogeheten "stads-symfonieën" van de jaren twintig. Deze films waren visuele odes aan de moderne stad, gecreëerd met documentaire beelden en met behulp van experimentele montages. De mythe van de filmische stad, zoals die haar uiting vond in de stads-symfonieën, geeft echter een zeer beperkt beeld van de mogelijke representaties van de moderne stad in het medium film. Ik leg hier de nadruk

op het woord "beeld," omdat juist het luisteren naar film, naast het kijken naar film, in mijn onderzoek duidelijk heeft gemaakt dat de moderne stad op een veelheid van manieren kan worden gerepresenteerd in film. 
Geluid is bij uitstek een vergankelijk fenomeen: Een geluid begint te verdwijnen op het moment dat het wordt gemaakt. Historische geluiden zijn er niet meer, tenzij die op een geluidsdrager zijn vastgelegd. Zoals de woorden "dramatisering" en "enscenering" echter aangeven, zijn stadsgeluiden in media geen directe kopieën van geluiden die daadwerkelijk in de stad te horen waren. Mensen die geluiden wilden beschrijven of vastleggen moesten keuzes maken, hun voorkeuren en meningen laten spreken en gebruik maken van media en materialen die geluiden transformeerden. Bovendien waren zij onderdeel en product van hun cultuur. Geënsceneerde en gedramatiseerde geluiden bieden dus een uniek inzicht: Niet alleen kunnen ze ons leren wat voor geluiden er ooit te horen waren in de stad, ze laten ons ook weten hoe men destijds over die geluiden dacht.

We kunnen de stadsgeluiden die we in films horen dan ook beschrijven als "versterkte echo's." Echo's zijn natuurlijk herhalingen van eerder gemaakte geluiden, die echter anders klinken omdat ze terugkaatsen van een materieel oppervlak. In deze dissertatie wordt de echo ingezet als metafoor. De stadsgeluiden die we horen in films zijn echo's van geluiden die daadwerkelijk ooit in steden geklonken hebben omdat filmmakers vaak een werkelijkheidseffect nastreven. Zij proberen een stad zodanig te representeren dat het publiek gelooft dat de film zich daadwerkelijk in die stad afspeelt. Dit streven naar een werkelijkheidseffect is de eerste mogelijke uitleg voor de bevindingen die mijn onderzoek heeft opgeleverd. Er zijn echter andere mogelijke verklaringen. Filmgeluiden zijn ook echo's van de door filmmakers gebruikte materialen en technologieën, en van hun dagelijkse praktijk van het film maken. Die technologieën en praktijken zijn in de loop van ruim zeventig jaar immers sterk veranderd. Tevens kunnen we filmgeluiden begrijpen als echo's van een politieke cultuur. Repressieve regimes functioneerden onder andere door een sterke censuur te hanteren, en juist in vrije samenlevingen hebben filmmakers hun medium gebruikt om hun visies uit te dragen. Bovendien kunnen we filmgeluiden begrijpen als echo's van de destijds heersende filmcultuur; het gehele discours van filmwetenschap en -kritiek. Ik spreek trouwens van "versterkte echo's" om te benadrukken dat geënsceneerde en gedramatiseerde geluiden geen inferieure aftreksels zijn van echte geluiden, maar eerder meer betekenis hebben, juist omdat we in filmgeluiden ook de echo's van cultuur, politiek en filmpraktijk horen.

Dit alles vindt $\mathrm{u}$ terug in hoofdstuk 1 , dat als een inleiding van deze dissertatie gelezen kan worden. In dit hoofdstuk leg ik uit wat ik heb onderzocht en waarom ik dat doe. In hoofdstuk 1 beschrijf ik ook hoe ik mijn onderzoek heb uitgevoerd. Een corpus van 95 films heb ik zowel kwalitatief en kwantitatief geanalyseerd. De kwalitatieve analyse betreft de uitvoerige bestudering van belangrijke scenes en momenten in films, en van het gebruik van stadsgeluiden daarin. De kwantitatieve analyse betrof het "tellen" van geluiden. Ik heb het concept van het "Urban Sound Event" gecreëerd om stadsgeluiden in films te identificeren en om ze telbaar en categoriseerbaar te maken. Een Urban Sound Event (USE) is een diëgetisch geluid (een geluid dat haar plaats heeft in de wereld van het verhaal) dat geproduceerd en gehoord wordt in de openbare ruimte, of dat hoorbaar is in privéruimtes maar wordt geproduceerd in openbare ruimtes of 
andermans privéruimtes. De USE's heb ik gecategoriseerd naar de bron van het geluid, en naar narratieve functie. Deze narratieve functies heb ik ontleend aan het werk van de Franse taal- en literatuurwetenschapper Roland Barthes.

De analyse van een groot aantal films, en niet alleen de klassieke "gerenommeerde" films, verdeeld over drie steden en vier decennia maakt het mogelijk om ontwikkelingen, verschillen en continuïteiten waar te nemen in het gebruik en de rol van stadsgeluiden in film, zowel diachroon als synchroon. Echter, die waarnemingen op zich zijn niet voldoende. Zij dienen ook geïnterpreteerd en verklaard te worden. Dat kan door een aantal contexten in beschouwing te nemen. Die contexten zijn het bovengenoemde streven naar het creëren van een werkelijkheidseffect, de filmtechnologie en -praktijk, politiek en filmcultuur. In hoofdstuk 2 bespreek ik de geschiedenis van twee van die contexten - filmcultuur en filmtechnologie - en toon ik aan hoe deze niveaus met betrekking tot het filmgeluid met elkaar verbonden zijn geweest gedurende het grootste deel van de twintigste eeuw. Ontwikkelingen in de technologie van filmgeluid zijn vaak direct gevolgd door nieuwe ontwikkelingen in de (academische) theorie van filmgeluid. De introductie van de geluidsfilm eind jaren twintig leidde tot een debat tussen voor- en tegenstanders van deze nieuwe kunstvorm. En het gebruik van nieuwe opname- en mixtechnologieën in de Amerikaanse mainstream cinema van de jaren zeventig werd gevolgd door een opleving van het debat over filmgeluid in de jaren tachtig. Opmerkelijk is dat de digitalisering van de filmproductie, -distributie en -vertoning in de jaren negentig niet of nauwelijks nog navolging heeft gehad in de theorie van filmgeluid. Ik concludeer in hoofdstuk 2 dat het verlies van de zogeheten "indexicale referentialiteit" (de directe materiële connectie tussen een gefotografeerd object en haar representatie) in digitale cinema ons er toe uitdaagt om de relatie tussen het originele geluid en zijn technologische reproductie te herdefiniëren. Dit is mogelijk niet eerder gedaan omdat de theorie van het filmgeluid grotendeels gebaseerd was op zogeheten "fantastische genres". Voor films die niet tot de genres van horror, science fiction en fantasy behoren, zoals de films die ik voor mijn onderzoek heb geanalyseerd, is het concept van de versterkte echo een goede metafoor voor het filmgeluid. Dit concept benadrukt immers het belang van het originele (historische) geluid voor haar representatie in film, maar het erkent ook dat de geluidsband van een fictiefilm in hoge mate een constructie is.

In de hoofdstukken 3 tot en met 6 heb ik de "soundscapes" van Amsterdam-in-film, Berlijn-in-film en Londen-in-film beschreven. "Soundscape" is een bijna onvertaalbaar woord dat in de jaren zeventig werd geïntroduceerd door de Canadese componist en akoestisch ecoloog Raymond Murray Schafer. Sindsdien is het concept op meerdere manieren gebruikt door wetenschappers in de cultuur- en sociale wetenschappen. In dit onderzoek heb ik gebruik gemaakt van de definitie die is gegeven door de techniekhistorica Emily Thompson. Zij beschouwt een soundscape als het geheel van geluiden die bij een bepaalde plek horen, alsook de cultuur waarin aan die geluiden een betekenis wordt gegeven. Wat dus bestudeerd wordt in de hoofdstukken 3 tot en met 6 zijn niet alleen de filmische echo's van geluiden van het verleden, maar ook de manier waarop 
die geluiden zijn gekozen, vastgelegd en gemixt, en de politieke context en de cultuur waarin die filmische echo's geproduceerd werden.

In hoofdstuk 3 beschrijf ik de soundscape van Amsterdam-in-film. Ik toon aan dat Amsterdam in de twintigste eeuw, door middel van filmgeluid, vooral gerepresenteerd als een groot dorp of een kleine stad. Het beeld en het geluid van Amsterdam-in-film komen niet overeen met de stereotypische of mythologische "filmische stad." Amsterdam-in-film is een relatief kleine, rustige en stille stad, met uitzondering van een korte periode in de jaren zeventig, waarin de representatie van de hoofdstad moderner en wereldser is. In de jaren negentig is Amsterdam weer een groot dorp, maar wel met een duidelijk internationale en multiculturele dimensie. Een "global village" zouden we kunnen zeggen.

Hoofdstuk 3 heb ik tevens gebruikt om de verschillende soorten geluiden te beschrijven waaruit de soundscape van een filmische stad is opgebouwd. Zeer belangrijk en alom aanwezig zijn verkeersgeluiden, en dan vooral de geluiden van personenauto's. Verkeersgeluiden zijn echter niet altijd goed te identificeren; regelmatig zijn zij onderdeel van het "achtergrondgeluid" van de stad. Veranderingen in de hoeveelheid waargenomen verkeersgeluiden en achtergrondgeluiden kunnen worden uitgelegd door te verwijzen naar veranderingen in de stad zelf, maar ook door veranderingen in de filmtechnologie en de dagelijkse praktijk van het film maken. Het achtergrondgeluid van een stad - dat geluid dat er eigenlijk altijd is en dat pas wordt gemist als het er niet is - wordt door Raymond Murray Schafer ook wel het "keynote" geluid van een stad genoemd. De "basso ostinato," in muzikale terminologie. Naast "keynote" geluiden onderscheidt Schafer de zogeheten "soundmarks": Geluiden die sterk verbonden zijn aan een locatie, en die belangrijk zijn voor de bewoners van die plek. Ik heb een vijftal soundmarks geïdentificeerd voor Amsterdam-in-film: Het geluid van trambellen en fietsbellen, straatorgels, Amsterdamse volksmuziek en de klokken van de Westerkerk. Deze geluiden zijn belangrijk in de representatie van Amsterdam als een groot dorp, maar ze komen relatief gezien steeds minder voor tot en met de jaren zeventig. In de jaren negentig, als Amsterdam-in-film opnieuw een groot dorp is, maken de soundmarks een kleine "comeback." Ze worden echter ingezet op nieuwe manieren, met ironie en zelfs sarcasme. Daardoor wordt duidelijk dat Amsterdam-in-film weliswaar weer een dorp is, maar niet meer met dezelfde onschuld en gezelligheid als in de jaren dertig en vijftig.

In hoofdstuk 4 bespreek ik de soundscape van Berlijn tussen 1926 en 1945. In de Weimar periode van de Duitse geschiedenis (1919-1933) was Berlijn de nieuwste metropool van Europa; een razend snel groeiende stad die tevens het fonkelende middelpunt was van de Europese culturele avant-garde. Berlijn werd echter ook het symbool van alles wat slecht was aan het moderne stedelijke leven: Moreel verval, verlies van traditie en armoede. Als jonge metropool in een nog jonger land dat in grote beroering verkeerde, was Berlijn een stad waarvan de identiteit nog niet vaststond. Deze was zogezegd nog "onder constructie." De identiteit van een stad is een symbolische en discursieve constructie; zij ontstaat in het culturele domein. En film, het nieuwe massamedium van de moderne tijd, was een belangrijke plaats voor het construeren en 
bediscussiëren van Berlijns identiteit. Mede dankzij één zeer beroemde, invloedrijke en "stille" film werd Berlijn het voorbeeld van de mythische filmische stad. In BERLIN, DIE SINFONIE DER GROBSTADT (Walter Ruttman, 1927) werd de Duitse hoofdstad neergezet als een symfonie, mede dankzij de muzikale begeleiding geschreven door Edmund Meisel. Na de introductie van de geluidsfilm begonnen Duitse filmmakers Berlijn echter anders te representeren: Als een overweldigende kakofonie. Een goed voorbeeld hiervan is de openingsscène van BERLIN ALEXANDERPLATZ (Phil Jutzi, 1931), een bewerking van het beroemde boek van Alfred Döblin. In deze openingsscène reist de zojuist uit de gevangenis ontslagen Franz Biberkopf per tram naar het centrum van de stad. Onderweg wordt hij bevangen door de beelden en de geluiden van de stad, die hem overweldigen en beangstigen. Door een inventieve combinatie van non-diëgetische muziek en diëgetische geluidseffecten weet regisseur Jutzi deze ervaring van de stad door Biberkopf te delen met zijn publiek.

Weimar Duitsland was een land met grote politieke spanningen en tegenstellingen, en die vertaalden zich in film. Zowel linkse als rechtse filmmakers produceerden propagandafilms. Nadat de nationaalsocialisten in 1933 aan de macht kwamen en de filmproductie centraliseerden, werd Berlijn weer afgebeeld als een harmonieus geheel, in een verwrongen echo van de stads-symfonieën van de jaren twintig. Na de Tweede Wereldoorlog lag de stad echter in puin, en bovendien was zij bezet, en verdeeld in vier sectoren (en later twee aparte steden). Niet alleen de stad moest opnieuw worden opgebouwd, ook de identiteit van Berlijn, en die van Duitsland. In hoofdstuk 5 toon ik aan hoe de identiteit van Berlijn-in-film in de tweede helft van de twintigste eeuw continu onderwerp van constructie en discussie blijft. Niet in het minst door de opsplitsing van de stad in het communistische Oost Berlijn en het democratische West Berlijn. In het midden, tussen die twee halve steden, lag een grenszone die in film als een plaats van stilte werd gerepresenteerd. Een stille en verlaten plek, waarvan het doorkruisen of oversteken bijzonder gevaarlijk was en begeleid werd door de incidentele geluiden van geweerschoten, sirenes en blaffende waakhonden. In de jaren negentig, na de hereniging van Duitsland en Berlijn, moet de identiteit van de stad nog eens opnieuw worden geconstrueerd. En weer valt de heropbouw van de identiteit van Berlijn-in-film samen met de wederopbouw van de stad, wanneer de Rijksdag en de Potsdamer Platz worden herbouwd met medewerking van (illegale) immigranten. De geluiden die geassocieerd worden met migratie, zoals exotische muziek, worden onderdeel van de soundscape van Berlijn.

De verschillende representaties van steden in film die ik in dit onderzoek tegenkwam, zowel diegenen die beantwoorden aan de mythe van de filmische stad als aan variaties op dat stereotype, zijn vaak gebaseerd op thematische of theoretische tegenstellingen: Stad en land, arm en rijk, communistisch en democratisch, lokaal en globaal, enzovoort. Maar juist de bestudering van één stad-in-film die in twee delen werd gesplitst door een muur - twee delen waarop men met gemak zulke tegenstellingen zou kunnen projecteren - maakt duidelijk dat het reduceren van stedelijke representaties tot simpele tegenstellingen niet altijd even productief of leerzaam is. De verschillen en overeenkomsten tussen steden-in-film zijn veel subtieler, 
en de bestudering van filmgeluid - dat het beeld kan weerspreken of nuanceren, er iets aan kan toevoegen of juist een afwezigheid kan aangeven - brengt zulke subtiele, genuanceerde representaties van steden aan het voetlicht.

In hoofdstuk 6 richt ik mijn blik op Londen-in-film. Ik heb verschillende alledaagse activiteiten in Londen-in-film bestudeerd om te onderzoeken hoe deze activiteiten worden gerepresenteerd door middel van geluid. Hierbij werd ik geïnspireerd door het werk van Charlotte Brunsdon, die "Cinematic London" benaderde als een "biographical city"; een stad begrepen vanuit het perspectief van het leven dat er in wordt geleid. Geluid is de auditieve perceptie van lucht die in beweging is gezet, en dus is er beweging - leven - nodig om geluid te hebben. Ik heb daarom geluisterd naar activiteiten als "aankomen in Londen-in-film," en heb geconstateerd dat er drie manieren zijn om als filmkijker in Londen te arriveren. De eerste manier is aankomen samen met een personage dat ook nieuw is in de stad. In dit geval maken filmmakers vaak gebruik van beroemde beelden en van beroemde geluiden, de soundmarks. Een tweede manier van aankomen dat de kijker midden in het leven valt van mensen die al in Londen wonen, in welk geval die plotselinge introductie vaak wordt verzacht met behulp van non-diëgetische muziek. De derde variant is dat men als kijker "arriveert" in een café, theater of nachtclub; een plek waar de Londenaren er zelf ook even "tussen uit" zijn. In navolging van enkele andere auteurs die over "meerdere Londens" schrijven, maak ik een onderscheid naar genres. Zo klinkt arriveren in Londen-in-film in een romantische komedie anders dan in een thriller, of in een sociaal drama.

Naast arriveren in Londen-in-film heb ik ook reizen in en wonen in Londen-in-film bestudeerd. Zo werd duidelijk dat reizen met de metro, hoewel een uiterst gewone en alledaagse activiteit in Londen, nauwelijks in Londen-in-film wordt gerepresenteerd. Althans: Het wordt nauwelijks in beeld gebracht, en de metro zelf, of de woorden "mind the gap" worden in fictiefilms niet gehoord. De meest voor de hand liggende verklaring daarvoor is dat de metro ondergronds is aangelegd, en dus minder vaak in het achtergrondgeluid "opduikt." Maar het verwijst ook naar de beperkte mogelijkheden tot geografische en sociale mobiliteit in Londen-in-film. Minder verrassend dan de relatieve afwezigheid van het geluid van de metro is de ontdekking dat er in thrillers meer auto's zijn te horen dan in komedies. Dit simpele feit kan worden geduid door op de grote hoeveelheid achtervolgingsscènes in thrillers te wijzen. Wonen in Londen-infilm is een kwestie van gewend raken en omgaan met het geluid van de stad. Sommige karakters slagen hier bijzonder goed in, en de regelmatig terugkerende geluiden van de stad en de rivier geven ritme aan hun bestaan. Andere karakters gaan minder goed om met het lawaai en worden gek van de blaffende hond van de buren. Genre speelt hierin opnieuw een belangrijke rol: Achtergrondgeluiden zijn minder aanwezig en zachter in romantische komedies dan in sociale drama's. De sterk verschillende soundscapes van Londen-in-film in verschillende genres hebben mij ertoe geleid te concluderen dat de stad-in-film meer is dan de neutrale locatie waarin een film zich afspeelt. Door te luisteren naar de geluiden van de filmische stad kan die stad zelf worden ervaren als een thriller, een drama of een romantische komedie. 
Hoofdstuk 7 dient als de conclusie van deze studie en hierin keer ik terug op enkele zaken die in mijn drie "case-studies" regelmatig voorkwamen. Ten eerste was daar de kwestie van de mythe van de filmische stad. Door alle verschillende manieren te laten zien waarop de stad in filmgeluid kan worden gerepresenteerd, en door de verschillende filmische identiteiten van drie moderne Europese hoofdsteden te onderzoeken heb ik aangetoond dat de mythe van de filmische stad een te simplistisch beeld schetst: De stad-in-film is veel meer dan een drukke en overweldigende locatie vol flitsende beelden en plotse, harde geluiden. De toegevoegde waarde van geluid is dat dit het beeld kan nuanceren of versterken, dat het een alternatieve interpretatie kan bieden of het publiek mee kan voeren in een anders ontoegankelijke ervaring van de stad door een karakter. Tevens moet het belang van stilte niet worden onderschat. Stilte kan comfortabel of sinister zijn. Zij kan iets zeggen over de plaats, over het genre, over de handeling of over de geestestoestand van een karakter in de film.

Door de geluidsband van een fictiefilm te benaderen als een echo kunnen we zowel het belang aangeven van het originele geluid als het constructieve karakter van die geluidsband. We kunnen zien dat de stad zich soms "verzet" tegen de representatie die een filmmaker van plan is te produceren, maar dat het stadsgeluid zich ook leent voor "spel"; voor experimenten en nieuwe interpretaties. In dat "verzet" en dat "spel" schuilen ook de lessen die we uit deze studie kunnen afleiden voor filmwetenschappers en onderzoekers die zich bezig houden met "Sound Studies"; de twee disciplines waarop deze studie gebaseerd is. Filmwetenschappers zouden ervan kunnen leren om de informatiewaarde van geluid evenzeer te waarderen als haar emotionele of narratieve waarde. En de geluidswetenschappers in de cultuurwetenschappen kunnen hun horizon verbreden door open te staan voor de beleving van stadsgeluid via het spel en de experimenten die filmmakers met geluid uitvoeren. Deze dissertatie biedt hiertoe, door de studie van de dramatisering en enscenering van stedelijke soundscapes in fictie films, een eerste aanzet. 


\section{Curriculum Vitae}

Jasper Aalbers (Hoogeveen, 1984) graduated Cum Laude in Theatre, Film and Television Studies at Utrecht University in 2006. He subsequently completed a research master in Media Studies at that same university. During his studies he worked as a research and teaching assistant at the Faculty of Humanities in Utrecht for almost two years, and spent one semester as an Erasmus student at the University College Dublin, where he followed courses in Film Studies. From 2008 until 2012 he was employed as a $\mathrm{PhD}$ student at the Faculty of Arts and Social Sciences (FASoS) of Maastricht University. He received training at the local Graduate School as well as at the Netherlands Graduate Research School for Science, Technology and Modern Culture (WTMC). He is currently a tutor and thesis supervisor at FASoS, and is preparing for future research in Film and Media Studies. 